


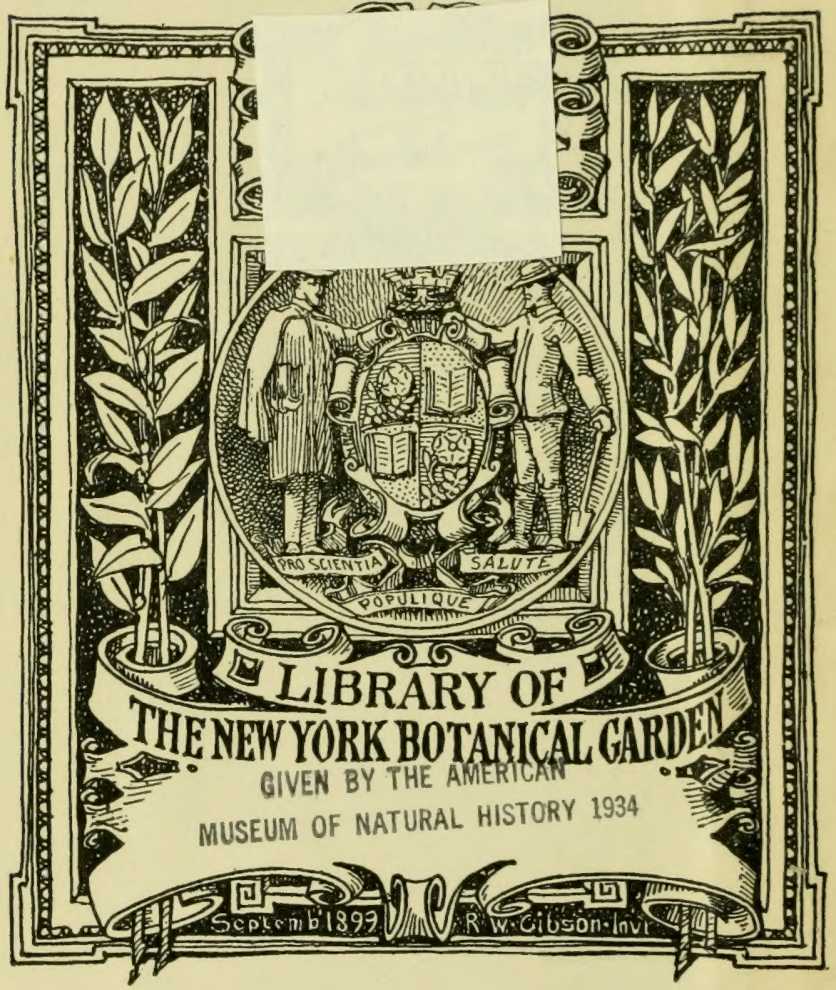




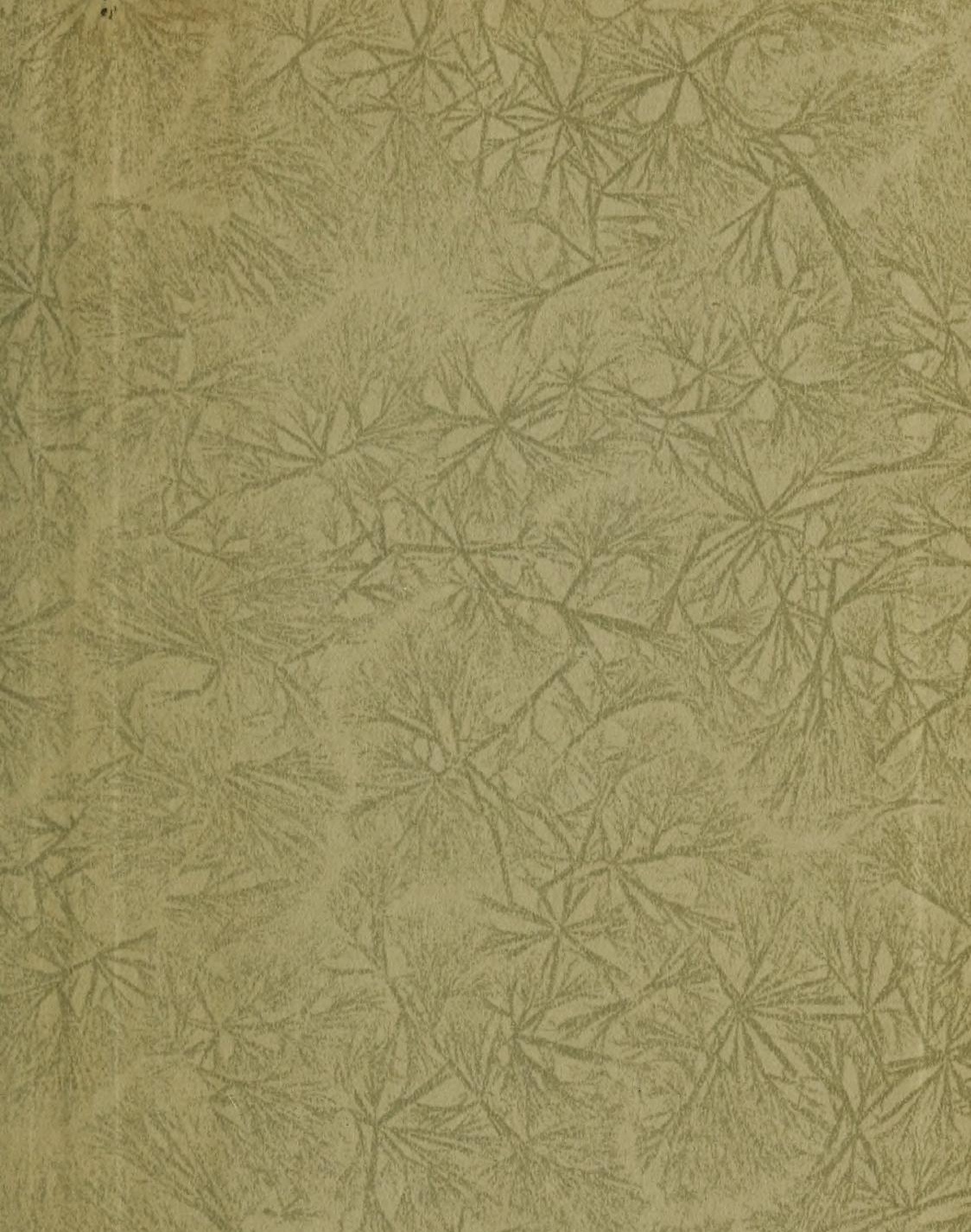

$-1820 \mathrm{xs}$

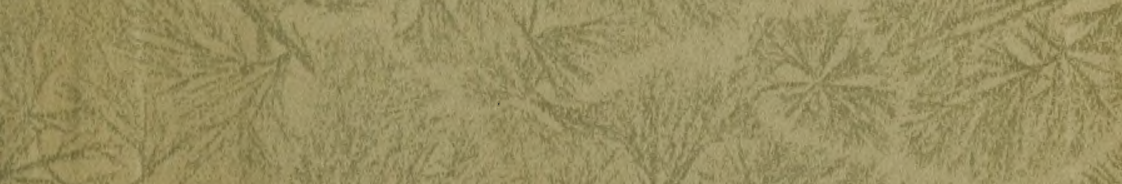

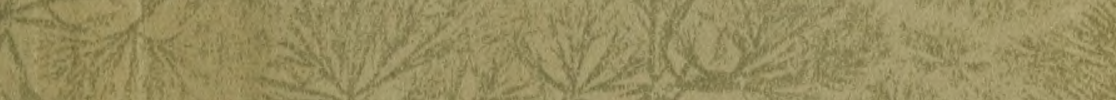
ind

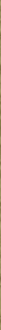

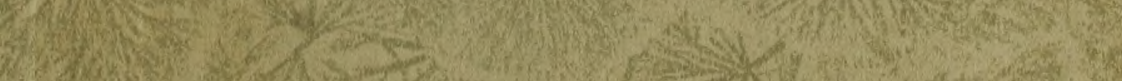







\section{MAJOR IONG'S}

\section{SECOND EXPEDITION.}






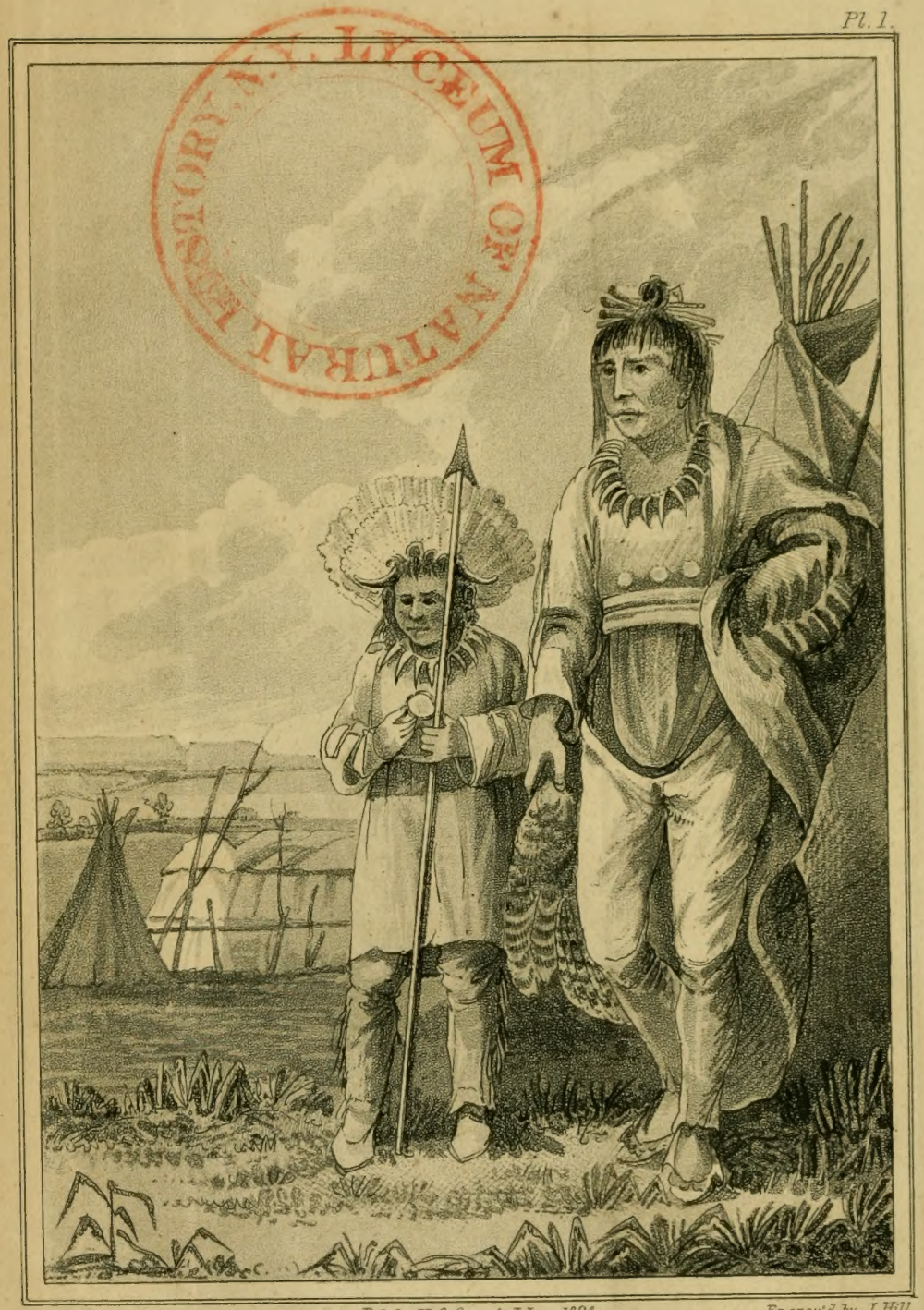

Design'd by S. Seymour.

Fub. by H. C. Carey \& I. Lea 1824.

Eingrav'a by J.Fill

WANOTAN AND TEIS SON . 


\section{NARRATIVE \\ or}

\section{AN FXPEDITION}

Tо THE

SOURCE OF ST. PE'TER'S RIVER,

LAKE WINNEPEEK, LAKE OF THE WOODS,

$$
\text { gec. } q \cdot c \text {. }
$$

PERFORMED IN THE YEAR 1823,

BX ORDER OF

THE HON. J. C. CALHOUN, SECRE'TARY OF WAR.

UNDER THE COMMAND OF

STEPHEN H. LONG, MaJoR U. S. T. E.

HIB: ARY

COMPILED FROM THE NOTES OF MAJOR LONG, MESSRS, SATORK

$$
\begin{aligned}
& \text { KEATING, AND COLHOUN, BUTANICAL } \\
& \text { GARDEN }
\end{aligned}
$$

BX

WILLIAM H. KEATING, A. M. \&c.

PROFESSOR OE MINERALOGY AND CHEMISTRY AS APPLIED TO THE ARTS, IN THE UNIVERSTT OF PENASYLVANIA; GEOLOGIST AND HISTORIOGRAPHER TO THE EXPEDITION.

IN TWO VOLUMES.

VOL. I.

\section{PHILADELPHIA :}

H. C. CAREY \& I. LEA-CHESNUT STREET.

1824. 


\section{EASTERN DISTRIC'T OF PENNSYLVANIA, to wit:}

BE IT REMEMBERED, That on the twenty-minth day of Norember, in the forty-ninth year of the independence of the inited States of America, A. D. 1824, H. C. Canex \& I. LeA of the said district, have deposited in this office the title of a book, the right whereof they claim as proprictors, in the sords following, to wit:

"Narrative of an Expedition to the Source of St. Peter's River, Lake "Winnepeek, Lake of the Woods, \&c. \&c. performed in the year 1823, "by order" of the Hon.J. C. Calhoun, Secretary of War, under the com"mand of Stephen H. Long, Major U. S. T. E. Compiled from the " notes of Major Long, Messrs. Say, Keating, and Colhoun, by Wil"liam II. Keating, A. M. \&c. Professor of Mineralogy and Chemistry "as applied to the Arts, in the University of Pennsylvania; Geologist "and Historiographer to the Expedition. In two volumes-Vol. 1."

In conformity to the act of the Congress of the United States, entitled "An act for the encouragement of learning, by securing the copies of maps, charts, and books, to the authors and proprietors of such copies, during the times therein mentioned."-And also to the act, entitled, "An act supplementary to an act, entitler, "An act for the encouragement of learning, by securing the copics of maps, charts, and books, to the authors and proprietors of such copies during the times therein mentioned," and extending the benefits there of to the Arts of designing, engraving, and etching historical and other prints."

D. CALDWELL,

Clerk of the Eastern District of Pennsylvania.

SEERHETT-LOCUST STREET, PHIXADELPHIA. 


\title{
HIS EXCELLENCY
}

\section{JA A}

\section{PRESIDENT OF THE UNITED STATES}

oF

\begin{abstract}
A M E RICA,
THIS WORK,

CONTAINING THE RESULT OF OBSERVATIONS

MADE DURING AN EXPEDITION

I'ERFORMED UNDER HIS ADMINISTRATION,
\end{abstract}

Is

VERY RESPECTFULLY INSCRIBED

J3 $\mathbf{Y}$

THE AUTHORS. 


\section{CORRECTIONS TO VOL. I.}

Page 19, line 18, for derangement, read disturbance.

25, 18, for compensates for a, read compensates the.

16, 15, for laid, read lay.

55, 4, for the Expedition, read we.

58 , 3d and 6 th from the bottom, for conjugate, read transverse.

58, 7th do. do. for transverse, read conjugate.

63, 9th from the top, for if it be not, read if it should not have been.

$66, \quad 12$, for objeet, rearl abjects.

$67, \quad 15$, for itself, read themselves.

74, 8, erase for

77, 17, for beach, read beech.

85,2 from bottom, for with, read to.

92, last line, for seems, read seent.

96 , 15, for counsels, read councils.

97, 18, for be, read is.

99 , 27, for decrepid, read decrepit.

99, last line, for as one of, read among.

100 and 106, line 11, for endowed, read endued.

115, 9, for are, read $i$.

115 , 22, for sowed, read sewed.

117, 14, for endowed, read endued.

124, 15, for be, read is.

140, 19, for dared, read durst.

144, 25, for lead, read led.

323, 25, for Iroquois, read Chippezuds.

CORRECTIONS TO VOL, II.

Page 8, line 17, for minister, read ministered.

8, 3 from bottom, for of, read on,

27, 19, for immense, read indefinite.

29, 6, for Superior, read Winnepeek.

36 , 28, for valleys, read vallies.

114, 16, for beach, read beech.

167, 13, for written, read composed.

$176, \quad 8$, for meal, read meat.

180, 9, for Desmarais, read Desmarest.

205, 8, for buffalo, read Buffalo.

210,27 , for west, read north-zuest.

213, 13, for Small Fox river, read Small Pox river.

$215, \quad 17$, for above, read about

219 , 29, for banks, read bars.

226, 13, after narrative, read and the accompanying Jap.

Note-Owing to the absence of Major Long, during the time of printing his report, Vol. II. Chap. V. the following discrepancies, between the spelling of words in that paper, and the accompanying map, have occurred, and are to be corrected as follows, viz. for Milwacke, Manitowacke, Pektanon, Little Pektanon, and Kakabikka, read Melwakee, Manitowakee, Peektano, Peektanos, and Kakabeka. 


\section{PREFACE.}

IN offering this work to the public, the compiler regrets that it has been delayed longer than was originally intended; the difficulties which he has encountered in the performance of a task for which he was quite unprepared, afford him his only apology. Inexperienced in the art of writing for the public, it is probable that he has fallen into many errors which, with more time, he might have avoided; but works of the nature of this admit of but little delay. Narratives of voyages of discoveries lose much of their interest, if the publication be long deferred.

The principal object which the compiler had in view, was to unite the documents confided to him, so as to present a faithful description of the country over which the - party travelled, and of the few adventures which interrupted the monotony of a journey through a wilderness.

It may be well to state that the historical part of the narrative, together with the topographical, and much of the descriptive matter, has been drawn from Major Long's notes. Mr. Colhoun's manuscripts, besides contributing to the same departments, and yielding the astronomical observations, have been very valuable in furnishing the greater part of the references to older writers. The comparisons between the observations made by our party and. the assertions of former travellers, are almost entirely due to that gentleman. From Mr. Say's notes, all that relates to the zoology and botany of the country traversed has been obtained, as well as much of the matter relating to the Indians. This last department has been completed from the compiler's nvu notes, which have likewise furnished the geological ob- 
servations. Besides which, the journals kept by each of the gentlemen, have frequently completed the remarke made by some other member of the party. It has been deemed unnecessary to state in all cases by whom the observations were made or recorded. This has, however, been done, whenever the facts appeared sufficiently interesting to require that the names of the observers should be annexed to them.

As Major Long's report to the war department presents a concise summary of the general features of the country visited by the party, it has been thought adviseable to introduce it as a conclusion to the narrative. Having been ordered to the Ohio to make an experiment to improve its navigation according to the provisions of a late act of Congress, Major Long was absent from Philadelphia during the preparation of that part of the manuscript which follows the three first chapters of volume first; this may account for some of the inaccuracies which the work will be found to contain; it is presumed that by his presence they would have been avoided.

The compiler has found it impossible in the description of the scenery of the Mississippi, \&c. to avoid the introduction of several words, which, although they are not sanctioned by the dictionaries, seem to be characteristic. and essential to such descriptions; of this nature are the words bluff, prairie, \&c. The term creek, being used in different acceptations in England and America, has been avoided in all cases, though with some inconvenience. The word mun will, it is believed, be found but once in the body of the work. Lest any false impression should be drawn from the introduction of the term estuary, it may be proper to state, that it has been inadvertently used in several cases, to designate the outlets of streams where the tides do not reciprocate. 
In compiling from notes written by many persons under the disadvantages of fatigues, hardships, and privations, it is not easy, however it may be desirable, to avoid the use of all objectionable terms; for these and other inaccuracies which the work may contain, the compiler must plead in excuse the difficulties to which he has previously alluded.

The greater part of the appendix will be found to have been prepared by Mr. Say. The loss which he experienced of the skins of many birds, quadrupeds, and fish, which he had collected, has prevented him from describing several new animals. It is believed that, if none of the shells collected had been lost, the amount of new species described would have been much greater. The plants preserved by Mr. Say, were placed in the hands of the Rev. Lewis D. de Schweinitz, who kindly undertook to describe them; the result of his valuable observations will be found in the appendix. With a view to give an idea of the climate of the country described, as well as to compare it with other places whose climate has been ascertained by older observations, the interesting tables prepared by Dr. Joseph Lovell, Surgeon General of the United States' Army, have been introduced, with his general observations upon the same. They are compiled from the records kept at the various military posts. The climate of Philadelphia has been established by the results of the observations made by Mr. Reuben Haines, at his residence in Germantown, six miles from Philadelphia; the great care which Mr. Haines bestows upon his observations makes them a fit term of comparison for all others. The introduction of these tables has superseded the necessity of recording the variations of temperature observed by our party; they were noted principally by Mr. Seymour.

It may be proper, however, to state, that, valuable as YoL. I. 
are the results contained in the meteorological tables, they can only be considered as approximations; because an uniform method of making observations has not yet been adopted. Those who are conversant with thermomctrical observations, know what influence the situation in which the instrument is exposed, and the materials of which it is constructed, exercise upon the results which it indicatesand how guarded we ought to be in adopting comparisons made with different instruments, and placed in different situations. Of the influence of the materials, the party had an opportunity of convincing themselves, by placing two of Mr. Keating's thermometers in the same situation with that of the surgeon at Fort St. Anthony. The latter instrument consisted of a glass tube attached to a brass plate. on which the graduation was marked; one of Mr. Keating's was known to be a good instrument; it had been made in Paris and had its division on a slip of paper enclosed in a glass tube: the other thermometer was a small pocket one, made by Mr. Fisher of Philadelphia, and was provided with an ivory scale. The usual exposure of the surgeon's thermometer was to the south-west. The two others were placed close to his. The results are indicated in the following table.

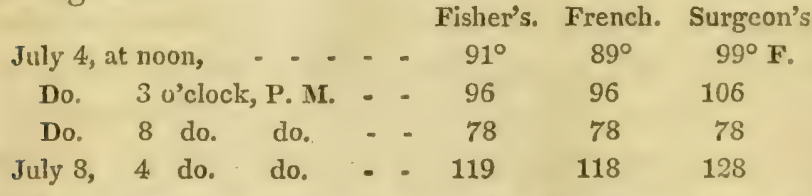

This proved, that when exposed to the direct rays of the sun, or to their reflection by the parade ground, the thermometer with the brass plate was uniformly ten degrees higher than that made entirely of glass, though at other times it stood at the same elevation. At the time these observations were made, the surgeon was absent. At Fort 
St. Anthony the thermometer was exposed to the southwest; at other posts, we have seen it facing the cast; sometimes the instruments were protected from, at other times they were exposed to, the rays of the sun: there can be no doubt that some variations must arise from these. causes; and we think it therefore desirable, in order to give the greatest value to the observations made at all the garrisons in the United States, that the surgeons should be provided, at the public expense, with instruments of uniform and approved construction; and that the observations should be made under circumstances as nearly similar as the great diversity in the situations of their posts will admit. Notwithstanding the variations produced by the causes to which we have alluded, we consider these tables as being very interesting, inasmuch as they afford the first comparative results upon the temperature of the United States in general, embracing an immense extent of country, and including great diversitios of climate.

We deem it but fair to state that the observations which Messrs. Say and Keating made, concerning the manners, \&c. of the Indian tribes which they met, were greatly facilitated by the valuable notes furnished to them by the American Philosophical Society, and which were chiefly prepared by Peter S. Duponceau, Esquire, one of the Vice Presidents of the Society, Professor Robert Walsh, jun. one of the Secretaries, and by Dr. Samuel Brown, " Professor of the Practice of Physic in the Transylvania University.

* The undersigned begs leave to state, that Dr. Brown's name was inadvertently omitted in the Preface to the "Account of an Expedition from Pittsburgh to the Rocky Mountains." 'The gentlemen of that party were provided with the same notes which were used on the se. cond expedition, and which were in boll cases found very valuable.

T. $S \Lambda Y$. 
In conclusion, the compiler has much pleasure in acknowledging the great obligations under which he lies to George Ord, Esquire, one of the Vice Presidents of the Academy of Natural Sciences, and one of the Sccretaries of the American Philosophical Society, for his assistance in the preparation of this work. Mr. Ord's perusal of the greater part of the manuscript previous to its being put to press, has preserved it from many inaccuracies which it. would otherwise have contained.

W. H. K. 


\section{CONTENTS OF VOL. I.}

\section{CHAP'TER I.}

$$
\text { Page. }
$$

Departure from Philadelphia. Geology of the Alleghanies. Cum-

berland Road. Wheeling - $\quad$ - $\quad$ - $\quad$ - 9

\section{CHAPTER II.}

Zanesville. Salt and Iron Works. Columbus. Piqua, Indian Antiquities. Ohio Canals, Fort Wayne - - - . 34.

\section{CHAPTER III.}

Description of Fort Wayne and its vicinity. Fur trade. Pota-

watomis

\section{CHAPTER IV.}

Carey mission-house. Lake Michigan. Chicago _ . $\quad$ - 139

\section{CHAPTER V.}

Rock river. Menomones. Geology of the country west of Lake Michigan. Prairie du Chien. Sauks and Foxes . _ - 172

\section{CHAPTER VI.}

Prairie du Chien. Indian remains. Division of the party. Missis. sippi. Dacota villages. Fort St. Anthony. Falls. River St. Peter 235

\section{CHAPTER VII.}

Geology of the Mississippi. The Expedition ascends the St. Peter. Character of the Country. Arrival at Lake Travers 302

\section{CHAPTER VII.}

Account of the Dacotas or Sioux Indians. Their divisions into tribes. Their numbers, language, manners and customs. Notice of Wanotan, principal chief of the Yanktoanan tribe. Description of the Columbia Fur Company's establishment on Lake Travers 


\section{LIST OF PLA'TES.}

Map of the Country traversed by the Expedition.

Plate 1. Wanotan and his son, to face the title page of Vol. $\mathrm{Y}$.

2. Plan of Indian fortifications at Piqua - - Page $56^{\circ}$

3. Heads of Metea, Wennebea, \&c. - - - - 90

4. View of the Maiden's Rock on Lake Pepin - - 284

5. Dacota and Chippewa songs - . . - - - 438

6. View of Lake Travers, to face the title page of Vol. II.

7. Killing of a buffalo near Red river - - - $\quad 22$

8. View of Indian lodges, \&c. at Camp Monroe - - 48

9. View of the Slave Falls on Winnepeek river - $\quad 99$

10. View of the Upper Falls of Wimepeek river $\quad 100$

11. View of the Lake of the Woods from Cosse's island 109

12. View of the Falls of Kakabikka on the Kamanatekwoya 138

13. View of the north shore of Lake Superior - - 185

14. Shells, \&c. - - - _ - - - - 254

15. Shells - - - - - - - - 264 
NARRATIVE OF AN EXPEDITIOE

TO THE

SOURCE OF ST. PETER'S RIVER. \&c. \& c.

\section{CHAPTER I.}

Departure from Philadelphia. Geology of the Allegha. nies. Cumberland Road. Wheeling.

THE success which attended the expedition to the Rocky Mountains, and the important information which it imparted concerning the nature of the valley drained by the Missouri and its tributaries, of which nothing was Innown but what had been observed by Lewis and Clarke, induced the government of the United States to continue its endeavours to explore the unknown wilds within its limits. The first object which appeared to it deserving of investigation was the district of country bounded by the Missouri, the Mississippi, and the Northern Boundary of the United States.

This triangular section includes about three hundred miles of longitude and seven hundred of latitude. Governor Cass had, on his late expedition, explored the southern shore of Lake Superior to the mouth of St. Louis river, and the water communication between Fond du Lac and the Mississippi, which river he ascended to the Upper Red Cedar or Cassina Lake, and then descended to the mouth of the Wisconsan. By this journey much light was Vor. I. 
thrown upon the history of the Upper Mississippi, whicin was previously known only through the fascinating, but imperfect, and in many instances, fabulous accounts of old travellers, and through the hasty observations of the late General, (then Lieut.) Pike, an officer whose zeal made him overlook difficulties which would have arrested a less hardy explorer, but who unfortunately was not provided with the means of making accurate observations.

All the later travellers who had visited the Upper Mississippi concurred in mentioning a river, discovered at the end of the seventeenth century, and known by the name of the St. Peter. This river, which discharges itself into the Mississippi at a short distance below the Falls of St. Anthony, had not been visited by any traveller but Carver, whose account of it, published about the year 1778, contains many circumstances which might induce us to question the accuracy of his report.

'The extent of the fur trade carried on by the British and American trading companies in that part of the country, the report of the easy communication between the head of the St. Peter and that of the Red River, whose waters running into Lake Winnepeck finally empty themselves into Hudson's Bay, and the various contradictory reports of the quality of the soil and the nature of the country on hed River, resulting from the conflicting interests of the two rival British companies, made it an object of interest to our government, to obtain correct information upon the country which lies on the St. Peter and the Red River to the 49 th parallel of north latitude, as well as to ascertain the nature of the country along our, as yet unsurveyed, northern boundary.

Accordingly, it was determined in the spring of 1823, " by the Executive, that an expedition be immediately 
fitted out for exploring the river St. Peter's and the country situated on the northern boundary of the United States between the Red River of Hudson's Bay and Lake Superior."

The command of the expedition was intrusted to Major S. H. Long, and he received orders from the War Department, dated April 25, 1823, of which the following is an extract:-

"The route of the expedition will be as follows:-commencing at Philadelphia, thence proceeding to Wheeling in Virginia, thence to Chicago via Fort Wayne, thence to Fort Armstrong or Dubuque's Lead Mines, thence up the Mississippi to Fort St. Anthony, thence to the source of the St. Peter's river, thence to the point of intersection between Red River and the forty-ninth degree of north latitude, thence along the northern boundary of the United States to Lake Superior, and thence homeward by the Lakes.

"The object of the expedition is to make a general survey of the country on the route pointed out, together with a topographical description of the same, to ascertain the latitude and longitude of all the remarkable points, to examine and describe its productions, animal, vegetable, and mineral; and to enquire into the character, customs, \&c. of the Indian tribes inhabiting the same." **

The advanced state of the season admitting of no delay, the necessary preparations for the expedition were hastily made, and the party left Philadelphia on the 30th of April -consisting of Stephen H. Long, Major United States?

* Reference was also made to the instructions which were issued by the War Department at the commencement of the Expedition to the Rocky Mountains, an extract of which is inserted in the Journal of that expedition. 
Topographical Enginecrs, commanding the ExpeditionTromas SAY, Zoologist and Antiquary-Willian $H$. Kenting, Mineralogist and Geologist-SAauel Serurour, Landscape Painter and Designer. Messrs. SAY and KEATING were likewise appointed joint literary journalists to the cxpedition, and charged with the collecting of the requisite information concerning the names, numbers, manners, customs, \&c. of the Indian tribes on the route.*

The party travelled in light carriages from Philadelphia to Wheeling, where they disposed of them and

* Lieut. Andrew Talcott of the United States' Topographical Enginecrs, had been appointed second in command of the expedition, and was to have assisted the commander in the astronomical and topographical department, but his services being required in another direction, James Edwand ColHour was appointed astronomer and assistant topographer, and leaving the City of Washington, proceeded to Columbus, (Ohio,) where he joined the party on the 20th of May.

Dr. Enwix James, Botanist, \&c. to the Expedition to the Rocky Mountains, and Surgeon in the United States' army, had been appointed botanist, geologist, and physician to the expedition. In pursuance of which, orders were sent to him at Albany, where he then was, to join the party at whecling or Columbus, and as it was apprehended that he might have alrcady left that place on his way to Bellefontaine on the Mississippi, (to which post he had been previously ordered,) letters were written with a view to intercept him, but which unfortunately did not reach him in season, and at the time when the party passed through Wheeling he was in Pittsburg, where he remained until it was too late for him to overtake them. By this unfortunate misunderstanding the expedition was deprived of the services of this active officer. An apprehension that some unforeseen event might prevent Dr. James from joining the expedition, induced the cummanding officer to obtain a division of the services allotted to lim, and the appointment of Mr. Keating to the geological department, while the botanical was reserved for Dr. James. It continued vacant during the expedition, a circumstance which was much to be regretted. Mr. Say undertook however to collect such plants as might appear to him interesting, but with that diffidence with which a man will attend to a task with which he does not profess to be conversant. 
jurchased horses in exchange. This part of the journey was performed in eleven days. The usual route through Lancaster, Columbia, York, and Gettysburg, was travelled. Here they left the Pittsburg turnpike road and reached Hagerstown in Maryland by a cross road; from Hagerstown they continued along the Maryland turnpike road to Cumberland, where it unites with the national road, upon which they travelled to Wheeling.

From Philadelphia to Wheeling, the Geologist has an opportunity of observing almost every formation, from the old primitive to the coal strata. On leaving Philadelphia, the primitive soon disappears, and is replaced by the transition limestone, which is of a blue colour, very much intermixed with quartz in veins running through the mass. There are also patches of white limestone which are observed in sundry places, and which being of a highly crystalline character, might almost induce us to rank this limestone as primitive.

We find occasionally breaking through the limestone, hills composed of amphibolic rocks; this accident is more frequent as we approach the Brandywine. These hills are very readily discernible from the undulations of the limestone country, by the difference in their outward form, which in the limestone hills is mammillary, constituting low and rounded swells; while the amphibolic hills are steep, and covered with a wilder vegetation. Beyond Lancaster the rocks assume a slaty appearance, which increased as we approached the Susquehanna. At Columbia we had an opportunity of observing the rock as it is laid bare in the bed of the river. It there appears to be the red sandstone, and is that mentioned by Mr. Maclure in his observations on the gcology of the United States. It constitutes part of a red sandstone formation, which crosses through the 
states of New Jersey, Pennsylvania, Maryland, and Virginia. This formation extends in a general north-easterly direction. The rock appears to be nearly horizontally stratified, but from the slight inclination which it presents to the north, the strata are presumed to extend in a northeast and south-west direction.

The limestone and red sandstone, with its accompanying red slate, alternately appear on the west side of the Susquehanna. The limestone is generally found in the valleys, and the sandstone upon the acclivities of the hills, which are generally crowned with small patches of trap. This rock occurs, however, only upon the higher hills, where it seems to have protected the sandstone from dccomposition.

On approaching Millerstown, the country assumes a more broken appearance; the limestone ceases, and indications of crystallization are visible in the rocks. Millerstown, (sometimes called Fairfield,) is situated on the eastern side, and at no great distance of that ridge which is generally called the South mountain, and which may be considered as the easternmost of the parallel ridges, which constitute the great chain of Alleghany mountains, at least in the southern part of Pennsylvania. In the vicinity of this place, there are masses of a calcareous breccia, in every respect similar to that found on the Potomac, and which has acquired of late a well-merited celebrity, on account of its having been used for the beautiful columns which adorn the interior of the Capitol, in the City of Washington. This breccia, which is too well known to require description, consists of fragments of limestone of very many kinds, differing in texture, colour, \&c. all imbedded in a calcareous cement. Some of these fragments have a fine saccaroidal or subsaccaroidal grain, while others are compact. 
There are also fragments of white quartz intermixed with those of limestone. The breccia appears to form partial deposits in the coves or valley basins of that vicinity.

In the neighbourhood of this town there are numerous indications of the existence of large deposits of copper. The ores of this metal have been found in many places, and excavations were commenced as far back as the year $179 \mathrm{~S}$. Some of the ore obtained at this place was sent to England, where it is said to have been worked to advantage. An attempt was made last year to resume the operations, but with no great success. The want of a person qualified to determine as to the best spots at which to commence the excavations, may be considered as the principal obstacle existing at present to the success of these works. The ore hitherto extracted is not sufficiently rich to warrant works to any great extent, but some specimens which were analysed last year in Mr. Keating's laboratory in the University of Pennsylvania, yielded as much as thirty per cent. That the smelting of this ore could be made profitable, if a sufficiency of it were obtained, appears from the circumstance, that a ton of the ore which was sent to Centre county, to be reduced at one of the iron works, yielded about three hundred weight of metal.

The ore discovered in this vicinity varies, but is for the most part a mixture of the oxidule, (red oxide,) with the green carbonate, the hydrate, the copper pyrites, the sulphuret of copper, and gray copper ore. The whole of it appears very much intermixed with siliceous matter. These masses of copper ore are in a talcose slate-they are to be observed every where. Doubts exist as to the manner in which they lie, the sides of the excavations had sunk in, so much, at the time the party passed through, that it was not in their power to determine that question; from the in- 
formation which was received, it would appear probable, that the ore has been worked, in one place at least, on a vcin rumning nearly east and west. The rock, as has been observed, is a talcose slate, which in some places appears to be penetrated with copper pyrites. These mines all lay in a hill known by the name of Jack's mountain; upon the top of which a porphyritic rock occurs. The crystals are of feldspar; the cement is of a red colour, and appears to be compact feldspar, (petrosilex palaiopetre of de Saussure;) besides the crystals of feldspar, there are some of quartz and probably of mica. This porphyry appears principally upon the east side of the mountain towards the top-no indications of stratification were observable. The porphyry constitutes probably a subordinate formation in the talcose slate which reappears on the crest of the hill, and is there very abundantly studded with small crystals, which are presumed to be epidote. In descending on the west side of Jack's mountain, the blue limestone reappears rery distinctly stratified, the strata running north-east and south-west, it dips in most places about $\mathrm{SO}^{\circ}$ to the southeast. The dip varies however, being only in some places about $30^{\circ}$, as may be very distinctly observed in the cxcavations made for cellars, \&c. at Hagerstown.

This town is pleasantly situated in Washington county; Maryland, on the great turnpike road which leads from Baltimore to Cumberland. We saw here specimens of the white marble which occurs at Boonsborough, about ten miles south-east of Hagerstown. It is said to exist there in considerable quantities on the west side of the South mountain not far from its foot. It was at first mistaken for gypsum by the people in the neighbourhood, and very abundantly applied to manure their lands, and it was only after its inefficacy had been demonstrated by experience, that 
its true nature was ascertained. This marble is of the finest white, with a subsaccaroidal grain, and may become of great use in buildings; it is however too fine-grained for statuary purposes. An analysis of it was made with a view to ascertain its purity; it was found to consist entirely of carbonate of lime, with little or no foreign admixture. It certainly belongs to the primitive formation, and corroborates the opinion we had formed at Millerstorvn, that the primitive rocks reappear to the west of the red sandstone formation; a circumstance not stated in the geological observations of Mr. Maclure. It is probable, however, that the appearance of the primitive there is but partial, and confined to certain localities, where it rises through the incumbent strata of transition rocks. There is an extensive cave or grotto in the blue limestone, about seven miles to the east of Hagerstown, which has not yet been fully explored.

From Hagerstorvn to Cumberland the mountains are numerous, and the works which have been executed for the road have in many places laid the rock bare, so as to make its structure apparent. We there see a great variety in the nature of the rocks, which however are observed uniformly to belong to the transition or secondary; the former being observed near to Hagerstown, and passing gradually into the latter, which occur very distinctly in the vicinity of Cumberland. At first, the blue limestone, with a considerable, though varying, dip to the south-east, is seen gradually passing into a slaty rock, which finally predominates, and is a transition clay-slate, probably the Grauwacken-shiefer of Grerman mineralogists. This however is found in parallel directions, alternating, as is believed, with this limestone, on a distance of several miles. After which, as we approach the North mountain, a sandstone of VOL. I. 
apparently very ancient formation, and which we feel inclined to refer to the red sandstone formation, occurs. It frequently acquires a reddish colour, and being in great measure composed of quartz, assumes in some places the appearance of an eisentiesel. Its stratification is very distinct, extending from north-east to south-west and dipping to the north-west. This stratification is not visible ora both sides of the mountain. The eastern slope being carried upon the crests of the strata, which are very brittle, a sort of soil is soon formed from the fragments of the rock, which entirely conceals it from view, but on the western slope it is very well marked. On the summit of the hill, numberless fragments of trap rock are strewed in erery direction. To the west of this ridge we again strike the clay-slate, which continues along the valley of the Potomac. being interrupted by the appearance of the blue limestone. in the traverse valleys of the Big and Little Conolaway Creeks. This slate differs very much from that described above as constituting the North mountain. The latter is a quartzose, the former an argillaceous slate; and the difference of dip is sufficient to distinguish them.

This clay-slate is formed of alternate layers of a very shistose mass and a more compact one. The layers rary in thickness, many of them however not exceeding a few inches. In the more compact layers there are indieations of a globular structure consisting of concentric shales.

The slate is soon succeeded by a sandstone, which constitutes several of the mountains known by the local appellations of the Sideling, Town-hill, \&c. It is not possible to determine with precision the spot at which the sandstone of coal formations commences, indeed we think it probable that no such limit exists in nature. The process may have continued without any marked interruption. 
from the time at which the transition formations were produced, until the coal and its accompanying strata had commenced to be formed. We observe, in most cases, that the slate and reddish sandstone occupy the base of the higher mountains, and constitute the whole of the lower ones; while the crest of the high hills is formed of a sandstone which in every respect resembles that of the coal formations. There seems likewise to be a difference in the organic remains contained in these rocks, for in the lower ones there are but vegetable impressions, (chiefly stems,) while in the superior strata, shells belonging to the genus Terebratula or Productus, are very frequently met with.

We had an opportunity of ascertaining that the slate which occupies the whole valley of the Potomac, in this district, varies in its dip; sometimes inclining to the southeast, and at other times to the north-west. In one spot we observed the change in the dip produced by a very gentle undulation, without any derangement or interruption in the stratification. Overlaying this slate, there is a limestone of a blueish colour, presenting signs of organic remains, and constituting Martin's Hill, which is one of the highest in the range. This limestone appears at first to be horizontally stratified, after which it assumes an inclined position, and on ascending becomes nearly vertical, while the top of the hill is crowned with large masses of limestone, quite free from stratification, and presenting only a very irregular division. Upon the summit of the mountain the limestone is cavernous, and contains many organic remains, among which the Terebratula and Productus are chiefly discernible. It is filled with veins of crystalline carbonate of lime, which in some places assumes regular forms.

From Cumberland to Wheeling the geology of the country is much simplified. The coal formation predomi- 
nates without any interruption. It consists merely of alternating strata of slate-clay, sandstone, limestone, and coal. Of these the sandstone is the most abundant; it is generally fine-grained, composed principally of fragments of quartz, connected by a siliceous cement. In some cases there is much mica, and at times a little feldspar, so as to constitute in local formations a regenerated granite not unlike that observable in the coal basin of St. Etienne in France, but these are rather mineralogical curiosities, and can scarcely be considered as forming a feature in the geology of this part of the route. The stratification is nearly horizontal, and is very distinct wherever the slate-clay is found, but whəre this rock is deficient, the sandstone loses its stratified character, or at least ceases to present it in a distinct manner.

The sandstone frequently alternates with the slate-clay, and it is not uncommon to observe a real passage of the one into the other; in some cases, as in the neighbourhood of Cumberland, the slate-clay is very rare.

The limestone is compact, of a grayish or brownish colour, very argillaccous, emitting a strong argillaceous odour when breathed upon; it occurs in parallel stratification with the above-mentioned rocks, and exists very abundantly all over the country, where it may be seen in many places alternating with the other strata; but we know of none where this can be so well observed as on the west bank of the Monongahela, in the neighbourhood of Brownsville, in those places where the road has been dug into the hill.

The coal has not yet been found to the eastward of Cumberland, but west of this town it occurs almost every where; it is found in beds which vary in thickness from an inch to several, sometimes ten, feet. It appears that 
these beds extend over the whole country, for the same may be traced for miles without any sensible alteration in its appearance. There are various beds at different levels and of different qualities, and it is from this circumstance, probably, that the coal of one neighbourhood is considered preferable to that of another, because they work upon beds at different levels; yet it may be also that in some cases they work upon one and the same bed, the quality of which may be improved or impaired from accidental circumstances. Small excavations are made in numberless places so as to answer the wants of the consumers. It is generally obtained at the mouth of the pit for five dollars per hundred bushels, and is sometimes sold as low as four cents per bushel. In the town of Cumberland it usually sells for about ten dollars per hundred bushels.

The abundance of timber in that district, and the thinness of the population, have not yet rendered coal the exclusive fuel used, and it was not until we approached the vicinity of Wheeling that we found coal exclusively used in lime and brick kilns.

The most common disposition of the strata presents the sandstone as the lowest member of the formation, above it is the coal, which is itself overlayed by the slate, and the limestone covers the whole, and becomes itself a substratum for a superior bed of sandstone, \&c.

The only substances of any importance which accompany these rocks, are iron pyrites, and probably the white pyrites. These minerals are so abundant throughout the rocks, that they in many places produce a very rapid decomposition and destruction, and unfit them for many uses of domestic economy; thus many of the beds of coal which would otherwise prove valuable, are so completely pervaded with pyrites that it is impossible to use them as fuel in 
private houses. This will probably ever prevent their being applied to metallurgical purposes. The pyrites not only penetrate the coal and its accompanying slate, but they extend even into the sandstone, to which they in many cases impart a tendency to decomposition, so great as to render it unfit for use as a building stone. To the universal diffusion of this mineral we must attribute the circumstance that the country about Wheeling abounds in mineral springs, strongly charged with sulphates of iron and alumine. Indeed it is a matter of considerable surprise, that with such an abundance of vitriolic matter at hand, and with an inexhaustible store of coal in immediate contact with it, no attempt has as yet been made to derive advantage from it, by converting it into green vitriol, alum, and sulphate of alumine. No doubt can be entertained of the facility with which this might be effected, and of the great advantage which would attend it. There is no place we think, where chemical manufactures of every kind could thrive to such advantage as at Wheeling. With coal mines even in the very heart of the town, with a constant and never-failing navigation, by means of which the products of its industry may be sent to a certain market, backed by a rich agricultural district to support the excess of its population, Wheeling seems destined to rise to great affluence, becoming in a manner the emporium through which all the commerce between the east and west must pass.

We were much disappointed at not finding in the rocks as many organic impressions as we had expected; we could discover no shells in the rocks, though we have reason to believe that the limestone must in some places abound in them.

In the sandstone there are many vegetable impressions, 
apparently of palms. The vegetable matter had completely disappeared, leaving only an impression, which, although very distinct, was not sufficiently well characterised to allow of a determination of its nature. This sandstone is of a grayish colour, middling-sized grain, and appears to be very micacious in some parts, while in others it consists of quartz nearly pure. The impressions are not very large, seldom more than ten or twelve inches long, and lay parallel to the stratification of the rock. At the hill over which the national road passes, in the immediate vicinity of Wheeling, the sandstone is about fifty or sixty feet in height, divided into layers of variable thickness: over this is a stratum of coal eight feet thick. In this coal, as well as in the accompanying slate, there are many remains of vegetables converted into pure charcoal, and entirely free from bitumen. These though numerous, are too im. perfect to allow of determining the species to which they belong. This bed, as well as the other parallel ones, when not too much intermixed with pyrites, is worked by galleries running into the hill. The works are very carelessly carried on and the waste of coal is great. The propping is very rough and unsafe, frequent accidents occur from this circumstance. The ventilation is not understood, and many works have been abandoned from the foulness of the air, no attempt being made to correct it. No inconvenience has as yet been experienced from inflammable gases; but the carbonic acid and the gaseous oxide of carbon are very abundant.

This bed of coal is separated from a superior one by a bed of slate-clay of about three feet in thickness, which from its unsoundness is always worked at the same time as the upper and lower beds of coal; although the upper coal be but six or eight inches thick and of a very inferior 
quality; but in this manner a safer roof is obtained for the excavation.

The limestone is considerably affected by the pyrites, and being in some places, as we were informed, magnesian, it gives rise to sulphate of magnesia, which might also probably be worked to advantage. The pyritous beds of limestone are only such as come into contact with the coal, the superior strata are said to be quite free from it.

The only circumstance worth mentioning concerning the coal mines is, that they have frequently been on fire, and that there are many indications of conflagrations at a more remote period, probably caused by the spreading of the fires lighted at the surface by the Indians to facilitate their hunting. From these conflagrations the slate is in many places observed to be quite altered in its appearance, so as to resemble porcelain jasper in its characters.

No iron ore has been found in this neighbourhood, and we looked in vain, for indications of the argillaceous carbonate of iron, so usually to be met with in coal fields. We were informed that at some distance from the town, large quantities of iron ore had been discovered, but which from the characters ascribed to it we were induced to believe were not the argillaceous carbonate, but the oxide and hydrate of iron.

Having thus presented in one connected view, the various geological observations which were made on this part of the route, we return to notice the other interesting circumstances which attracted the attention of our party.

The route which we travelled is far more interesting to the general observer than that to Pittsburg, the country along the Potomac offers many very fine views, among which none is more remarkable than that from Sideling-hill. The ranges of mountains as they then present themselves, strike 
the traveller in the most favourable manner. The freshness of the vegetation is peculiarly grateful to the eye in the commencement of May, and contrasts beautifully with the deep blue of the distant mountains. At times the road winds along the valley; and again, it crosses the ridges, offering the greatest variety of scenery and affording to the artist many views worthy of his pencil; for while the bottoms abound in rich and smiling prospects, the mountainous parts arrest the attention, by their bold and gigantic features, and by the antique forests which cover them.

The season in which we commenced our journey, was not very favourable to the proper display of vegetation. The frost had not yet subsided in the mountainous districts, and the very heavy rains which had fallen in great abundance this spring, had retarded all the products of the earth to an unusual degree, but the fine blossoms of the dogwood tree, (Cornus florida,) which every where met the eye, amply compensated for a want of other flowers.

Art has done little to add to the charms of the natural scenery, except in the construction of a road. The question of the propriety of opening, at the national expense, a communication between' the Ohio and Potomac, had been so much the subject of discussion, as to make us desirous of observing the mode in which it had been executed, and the too favourable idea, which we are, perhaps, always led to form, of what carries with it a national character, together with an account of the immense expenditure incurred in the making of this road, had prepared us for a magnificent work. We were therefore somewhat disappointed at the state in which we found it, as it is very inferior in execution to the Maryland road, which connects with it. There is in the whole of the national road but little to justify the high enlogiums which have been passed upon it. The immense VOL. I. 
expense, amounting to nearly Lwo millions of dollars, $(\$ 1,995,000$,$) which has attended its construction, can be ac-$ counted for but by a reference to the difficulty of making a road across high and steep ridges, which perhaps had not been sufficiently explored, to ascertain the lowest levels and the most accessible points; and, as we think, to the injudicious manner in which the original contracts were given out. We were credibly informed, that in most cases the original undertakers did nothing themselves, but portion out their contracts to a second set of contractors, and in some cases it happened that the third or fourth set alone performed the work, the other contractors sweeping away immense sums without any labour.* Had the route been properly divided into small lots, and these only given to such as were really qualified to execute the work, no doubt can exist that a considerable saving would have been obtained. The letting it out into large sections had the disadvantage of making it an object of speculation, and of alarming many who would otherwise have offered themselves as contractors.

Another cause of the great expense which attended it, was the location of its western end in the valley of Wheeling creek, instead of carrying it over the high land. Some difference of opinion exists in the country as to the propricty of this selection. We were informed by many, that this location had been made, rather with a view to benefit private interests, than with a careful regard for the public good. Certain it is, that the number of bridges which werc required in the route through the valley, added very considerably to the expense of the road. There are no less than seventeen bridges over the main creek, within thirteen miles of this valley road. It is but justice to observe,

* One of these is said to have accumulated in this manner a fortune of one luundred and twenty thousand dollars. 
that the bridges are, for the most part, substantial, well built, and even elegant in their construction.* A circumstance which enhanced much the expense of the valley road, was the necessity of propping it in many places by a stone wall or parapet, amounting in the aggregate to at least one-fourth or one-third of the distance. The road has, however, along this route, the advantage of being carried almost on a dead level, and in the other parts, where it crosses the mountains, it must be acknowledged that the ascents are better regulated than on any other road we have, ever travelled. But a great defect which prevails throughout the whole route, and which we had not expected to meet with, is that of using stones of too large a diameter on the road. After all the improvements which have been, of late years, made in this important branch of engineering, and after the very just celebrity which the M'Adams' roads have obtained in

- At the extremity of one of these bridges, a monument has been erected by a Mr. Shepherd, one of the principal contractors of this road. From an inscription on the monument, we learn that it was erected by "Moses and Lydia Shepherd, in honour of Mr. Speaker Clay, as a testimony of their gratitude to him, and of their high veneration for his public and private character." Mr. Clay is known to have advocated this undertaking, on the floor of congress, with much talent and zeal. There are, we believe, as yet, but few instances of monuments erected in our country by private individuals, to comme. morate the public services of our statesmen, and we must regret that the taste which designed, and the hands which executed this monument, were not equal to the liberality which provided for it. We have seldom seen a more clumsy attempt at allegory, or a more unfortunate introduction of emblematical figures. The inscriptions are also equally deficient in taste, in grammatical construction, and in orthography. In order to improve its appearance, the stone in itself a beautiful building material, has been covered with a wash or paint, which, having scaled off from some parts and remained upon others, contributes to give it a motley and uncouth appearance. 
England, we had hoped that the suggestions of this able engineer on this subject, would have been more closely adhered to. Whatever may have been the defects or the mistalies which attended the location or execution, no doubt can exist as to the importance of the work itself, or as to the soundness of the policy which led to it. By the opening of it, the nation has gained a great deal; it has ascertained the practicability and the expediency of entering largely upon a system of internal improvements, the necessary consequence of which must be, to unite by closer bonds, the distant parts of our vast country; and of all improvements, none can be more important, than such as tend to connect the waters of the Gulf of Mexico with those of the Atlantic. Immediately allied to this subject, is the possibility of making a water communication between the Ohio and Potomac. At a time when, by a broad and liberal policy, the executive of the United States has been authorized to apply to the consideration of this important object, the united talents of the civil and military engineers of our country, and when a full and able report upon the practicability of this comnexion may be expected from those most competent to decide upon it, we shall be excused from embodying here, the imperfect information which a transient visit through the country has allowed us to collect.

We found some interest in that part of the route which lies near Smithfield, as being the scene of some of General Washington's earliest military operations. The ruins of Fort Necessity, constructed at that distressing season, when the French troops with their savage allies extended along the banks of the Ohio, and oppressed our frontier settlements, are still to be seen in what are called the Big Meadows, about fifty miles west of Cumberland. This fort was crected in the year 1754, and after having been defended. 
with great valour, was surrendered in the campaign which preceded Braddock's defeat, (Marshall's Life of Washington, Vol. ii, p. 9,) and the remains of it still to be traced, show that the ditch was inside of the embankment, which comports better with Indian warfare.* The fort stands about a quarter of a mile to the south-west of the road, and it is difficult to trace its outline, but from the observations we made, it would appear as if it had been triangular and scarcely one hundred feet in length. It is said that when Washington first entered it, his force amounted to six hundred men, but that having advanced on his march towards

* We are led to notice this fact more particularly, from the imporrance which Bishop Madison has attached to the circumstance of the ditch being inside of the ramparts in most, or perhaps in all the Indian remains, which are considered as fortifications. His opinion that these works were not of a military nature, appears to us very far from being proved. He quotes Livy and Polybius to show us, that in Roman works, " the parapet or breastwork was formed of the earth dug out from the fosse and thrown up on the side of the camp"-and lie further asks, "whether the military art does not require that the ditch should be exterior." We do not consider this to be the question at issue. We have derived our notions of fortifications from the Romans, and we have continued to this day, probably with propriety, to place the ditch outside of the rampart; but this is no reason why works constructed by the Indians for military purposes, may not have had it otherwise. If we form our opinion of their notions of the military art, from the traces still visible among the Indians, who, if they be not their lineal descendants, have at least succeeded to them in the inhabitance of that country, (and it is more consistent to look to them than to the Romans in this case, we will find that their usual practice is, when apprehensive of an attack from an enemy, to make a small excavation, by digging up a little earth, which they uniformly throw out in the direction from which they apprehend an attack, and then to descend into this hollow where they find themselves sheltered from the missile weapons of their enemics. (Vide a letter on the supposed fortifications of the western country, from Bishop Madison of Virginia to Dr. Barton, Amer. phil. Trans. Vol. vi. i, p. 132.) 
Fort Duquesne he was abandoned by a considerable proportion of his men, and this circumstance, together with the information which he received, that the French were advancing against him with reinforcements, obliged him to abandon for the time his contemplated march, and to return to Fort Necessity, which he was engaged in repairing when the enemy made his appearance. The country in the vicinity was probably at that time destitute of timber, the growth upon it not being very large. A fine brook which flows near it, has retained the name of the unfortunate general who, in the ensuing campaign paid for his rashness by the loss of his life. Indeed, it is said, that the remains of General Braddock were interred within two miles of this fort, near the old road called Braddock's road, and at the spot where he died during the retreat which closed this disastrous campaign.

In this vicinity there is a blowing spring, which is situated in an excavation on the side of a hill. The stream of air which issues from a crack or crevice in the rock, is very considerable, and sufficiently powerful to extinguish a candle. By placing our ears near to the crevice we heard, very distinctly, the sound of water running under ground, probably upon a rocky and unequal bed; it runs out at a short distance lower down. This stream of air is doubtless produced by the same cause which is made to operate in the construction of the water blasts, used in metallurgy. We had no means of collecting and examining the gas which escapes, but we had no reason to believe it other than atmospheric air.

This section of our route does not offer to the zoologist much subject of observation. The wild animals which formerly roved over this part of our country have been driven further west, or completely cut off by the advance 
of civilization, and the domestic animals which now occupy their place, have nothing to characterize them. We cannot, however, omit noticing the extraordinary size and strength of the Pennsylvania waggon horse, which yields in these particulars to but ferv breeds. There are several appellations by which the different breeds of this useful animal are distinguished in Pennsylvania, such as the Conestoga, the Chester line, \&c. but these are principally of a local import. The usual height of farm and waggon horses is about sixteen hands or five feet four inches, measured according to the usual custom. We were credibly informed that horses seventeen, seventeen and a half, and even eighteen hands high, are by no means rare. A few have been known to exceed that size, and we have been told that one, the largest ever known in the country, had attained the gigantic size of nineteen hands or six feet four inches. As a proof of the great strength which they sometimes attain, it is said that an experiment was once tried in the city of Lancaster, which resulted in a single horse's dragging: around the court-house on the bare pavements, without the intervention of wheels or rollers, two tons of bar iron, which had been bundled together for this experiment.

The town of Wheeling appears to be in a very flourishing: condition, and the increase in its population has been very great, since the completion of the national road. Business has taken a new direction; instead of centering, as it formerly did in Pittsburg, it now goes principally to Wheeling, which has the advantage of a much more permanent navigation all the year round. The population amounts at present to upwards of two thousand inhabitants. The situation of the town is pleasant, the river here is about five hundred yards wide, and there is opposite to the town a large and beautiful island nearly three-quarters of a mile 
wide. The town is divided into the old and the new, the former is built upon a narrow bank, which extends between the river and the ridge of hills on the eastern shore; the new town is built a little below the old, on the river, and has a wider field to expand upon, owing to the junction of the lateral valley of Wheeling creek with that of the river. We regretted to find brick resorted to as a building material, not only in the construction of private houses, but even of churches and other public edifices, while a beautiful sandstone admirably adapted to the purposes of architecture, and which might be obtained at 2 very low price, remains unwrought.

The weather was so unfavourable during the three days which we remained here, as to preclude the possibility of ascertaining by astronomical observations the latitude and longitude of this town.

In our walks along the banks of the river, which are covered with a vast deposit of alluvium, and which present in this vicinity at least, no section of rocks, we were struck with the immense number of pebbles partaking of the nature of primitive rocks, which are strewed along the surface of the ground. They are not, it is true, of a large size, and their smooth and rounded surfaces attest that they have travelled far from their native sites. In examining our imperfect geological maps to endeavour to assign to them an origin, we feel at a loss to decide whence they may have been brought. We find no primitive formations nearer than those on the north side of our great lakes, which, from the aspect of the country, may be supposed to have given rise by their destruction to these extensive alluvia of primitive débris. Among these pebbles, chiefly of granite, gneiss, sienite, \&c. we observed a rock formed of feldspar, quartz, and handsome crystals of translucent garnets, 
which appear to be very abundantly disseminated throughout the rock."*

There is in Wheeling a glasshouse, which we visited ; the glass made there is very good; the sand which they use is brought down from the banks of the Alleghany, and appears to consist of silex nearly pure; the alkali added is principally unwashed ashes. We wore somewhat surprised at hearing, that the clay used in the manufacture of their crucibles was brought from Germany; indeed we consider this very improbable, as a clay very well adapted to this purpose is found in many parts of the country. The atmosphere in the glasshouse was extremely foul, orving to the sulphurous vapour disengaged from the coal.

The hills in the neighbourhood of the town are covered with masses of clay, sand, \&c. which, as soon as they become penetrated with moisture, slide along the upper surface of the rocks, even where their inclination is but small. This feature is observable only on the northern slopes, the southern are much more abrupt. We were at first induced to attribute it to the effect of the winter frosts, but Colonel M'Ree, who had examined its appearance with care, attributes it principally to the action of moisture.

* On the banks of the river there were but few shells, and these were referrible principally to the Unio praelongus, (Barnes,) and to the Unio crassus, and Unio purpureus of Say. Among the land univalves, Mr. Say observed the following shells, which had been previously described by him; viz. the Helix albolabris, Helix thyroidea, Helix alternata, Helix palliata, IIelix profunda, Ielix tridentata, Helix solitaria, Helix inornata. (Vide Nicholson's Cyclopoedia, Amer. Fid. anc? Journal of the Acad. Nat. Sci. of Philadelphia, Vols. 1 and 2.)

Vox. I. 


\section{CHAPTER II.}

Zanesville. Salt and Iron Works. Columbus. Piqua. Indian Antiquilies. Ohio Canals. Fort Wayne.

HAVING spent three days in Wheeling, and changed our mode of conveyance, in order to accommodate ourselves to the state of the roads, rendered almost impassable for carriages by the unusual quantity of rain which had fallen this spring, we crossed the Ohio in a team-boat, propolled by two horses. The river is there divided into two branches by the aforementioned island, which is about three quarters of a mile wide; over the first branch of the river a team-boat plies constantly, and corresponds with a common ferry boat on the other branch. The Ohio road is carried along the valley of a rivulet called Indian Wheeling, and is rendered extremely unpleasant to travel, by the frequent crossings of that brook. It was however so bad at that season of the year, that many preferred travelling up the bed of the creek to following the road. It has been observed by all travellers, that the Ohio runs in a valley, the average breadth of which does not exceed a mile and a half, the sides being lined by ranges of hills, which are generally termed the River Mountains; these vary considerably in height, generally ranging between three hundred and five hundred feet. After these are ascended, the country is rough, but the hills comparaively are small. These are, however, very steep, probably 
owing to the nature of the stratification, which is horizontal throughout the country; for it is a fact, which general observation confirms, that those hills, which are composed of rocks horizontally stratified, are generally steepest in their ascents, and present a tabular form at their summit. The coal formation of Wheeling is very extensive; the cxact limits of this coal basin have not yet been traced with accuracy, but as far as we are able to judge from the information obtained upon a country as yet but thinly settled, and in which natural science has been little attended to, it would appear that it probably reaches as far to the north-east as Lawrenceville, in Tioga County, Pennsylvania, and perhaps may be considered as connected with that lately discovered in Tioga County, (New York,) near' the head of Seneca Lake. The coal found at that place is, as we were informed, abundant, of an excellent quality, and well characterised as bituminous. The eastern limit may be taken to be formed by the main ridge of the Alleghany mountains. Upon its western and southern limits we are not prepared to decide, but it is probable that its breadth bears but a small proportion to its length.

At Zanesville we had an opportunity to observe the geological features of the country to advantage. The bed of the Muskingum is deeply incased, and the stratification is exposed for a considerable distance. It there presents the same features as in the vicinity of Wheeling, but the order of stratification and the character of the rocks are somewhat different.

A very fine break displays the following section: commencing at the lowest rocks, there is a sandstone of a tolep: ably coarse grain, filled with remains of vegetable substances converted into charcoal. in some cases partaking of 
a bituminous character, so that a gradual and invisible, but certain, transition from the charcoal to coul manifestly takes place. These remains are, however, as far as we saw thern, so much impaired as to make it impossible to assign to them any particular place in fossil botany, though of their vegretable origin no doubt can exist. In remarking upon their position, we ascertained, that they generally lay in the direction of the stratification, very seldom intersecting it. Besides fragments of charcoal and coal, we found impressions of plants, some of which were tolerably well characterised. In one instance a phyllolithos, (Martin,) was collected in a very good state of preservation.

The sandstone in a few cases assumes a somewhat micaceous appearance, consequently a more slaty structure, and then resembles that hereafter to be noticed. The rock immediately superincumbent is presumed to be a bed of slay-slate; though the junction being concealed and the relative positions of the rock being judged of only by the general level of the country, it was not in our power to decide in a positive manner whether or not there were any other strata interposed between the two.

This slate-clay is very brittle, and easily divisible; on cxposure to the atmosphere it readily crumbles, and lays open to vicw concentric globules of argillaceous carbonate of iron, in erery respect similar to those observed in other coal formations.

The iron ore is found in rounded or oval masses, somewhat flattened in the direction of the stratification; it appears to be quite abundant, and, we doubt not, if made the object of an exploration, would be found suficiently so to justify the erection of iron works on a large scale.

Resting upon the slate-clay, we observed a bed several feet in thickness, composed of a dark gray limestone 
very compact in texture, but presenting at the same time a slaty structure, and divisible in layers parallel to the stratification. This limestone is replete with organic remains, chiefly belonging to the Encrinite, Terebratula, Productus, \&c. among which we also found a shell belonging to the genus Trochus or Turbo. These shells are very abundant in the rock; they are found, as far as we could judge, irregularly disseminated, and adhering so closely that it is impossible to separate them, or to divide the mass into specimens which shall exhibit their characters uninjured; but being for the most part formed of calcspar, they resist decomposition better than the compact limestone in which they are imbedded, and from this circumstance the best specimens are found protruding from the exposed surfaces of the rock.

This bed offered great interest to the two naturalists of the expedition, the one as zoologist, the other as geologist. Mr. Say thought he beheld in it the confirmation of an opinion which he had long entertained, that, of all fossils, the Encrinus is that which resists decomposition best. Without pretending to dispute the correctness of the observation, as a general one, $\mathrm{Mr}$. Keating thought that the present instance did not confirm it, and that there were many spots where the bivalves, (Terebratula and Productus,) indicated a greater degree of hardness and solidity, by resisting the effects of the weather better than the Encrini. 'This we state as being perhaps the only time when the iwo naturalists differed in their observation of the same fact, when coming under the notice of both.

Upon this limestone lay a bed of coal, of about two feet: in thickness, and apparently of a very good quality; some works of no great amount were undertaken here not long sinee. which are unattended to at present. We wore told, 
however, that in other parts of the country this coal is tvorked to arlvantage. It is the usual fuel in the town, being worth from four to six cents per bushel.

It is corered by a bed of slaty rock, which in some cases assumes a decided appearance of slate-clay, and in other points runs into a micaceous sandstone, not unlike the micaceous parts of that described as the lowest stratum visible in this vicinity; like the former it is filled with vegetable impressions of a very undecided character.

Over this slaty rock another bed of limestone occurs, the sharacters of which, resembling in every respect those of the stratum under the coal, require no further description. The superior bed, as well as the inferior one, is rich in impressions of Encrinites, Terebratula, Productus, \&ic. which shells retain their pearly lustre, and even in some cases their animal matter.

The limestone is covered with a fine vegetable mould, and affords a rich soil, not inferior to any of the limestone bottoms of Pennsylvania. We had no means of ascertaining what rocks lay below the first bed of sandstone obsorved in this break, but from what we could discover in the bed of the canal then digging in the neighbourhood of the town, we believe it to rest upon a sandstone in every respect similar to that described in the first chapter as existing in the neighbourhood of Wheeling, and we have cvery reason to believe that the same alternation of strata which exists there, would be found in like manner here, and that if shafts were sunk, inferior strata of coal might. be reached.

Zanesville is a pleasant and flourishing town, situated at the junction of the Licking creek and Muskingum, about ninety miles above the confluence of the Muskingum and Ohio. As a manuficturing town it possesses great ad. 
vantages. A dam built across the two streans, a short distance above their junction, gives it a command of water power which is calculated to set in motion very extensive mills and manufactories. It was the observation of these, natural advantages, that induced the late $\mathrm{Mr}$. Zane* to fix upon it as a seat for a town; the rapid growth of the place has raised it to a rank among the most thriving towns in the state of Ohio. A number of manufactories have already been established there, which appear to be conducted with spirit and enterprize; among these a manufactory of cut nails belonging to Mr. Reeves deserves notice. The iron for the manufactory is prepared by him from the pigs by the process of puddling and rolling. Glasshouses, in which both green and white glass are made, exist there; it is said that the clay from which they make their crucibles, and which is found at a short distance from the town, is excellent. Within four miles of Zanesville, on "Licking creck," there is a furnace at which an hydrated oxide of iron is worked. The difference in the price between cast iron and pigs is so great as to enable them to convert the whole of their produce into hollow ware, which is readily disposed of at

* A few days before our arrival at Wheeling, Mr. Zane, the founder of Zanesville, died in that place. This man was extensively known as having been one of the first settlers in that state. He was one of those pionecrs of civilization, of which the bistory of our western states presents us so many instances, men equally distinguished by a dauntless courage, an unwearied perseverance, and by the success with which they resisted the aggressions of the aborigines, who frequently attempted, but in vain, to oppose those, whom they, perhaps very justly, considered as trespassers upon the soil which they had inherited from their fathers. Mr. Zane's character was highly respectable, and among the many aneclotes still current in Ohio, many of which attest his courage, there are none but such as are reputable to him as a man of feeling. 
seventy dollars, while the pigs command only thirty dollars a ton. Bar iron, and that not of the best quality, is sold for one hundred and twenty-five dollars. The little iron, refined in this vicinity, is generally of an inferior character. The experiment of manufacturing the iron by rolling, as is done at Reeves' establishment, has not been attended with sufficient success to lead to a more gencral introduction of this process. We conversed with several intelligent iron masters on the subject, with a view to obtain accurate information on the advantages of this method over that of hammering; the result of which was, that the product obtained from rollers was not so uniformly good as that obtained by hammering, which, in the opinion of our informants, was due rather to the defect of the workmen than of the process. The management of rollers is probably not well understood by them. We have taken occasion to record this information, because it appears to us that every thing that can throw light upon the manufacture of iron, is interesting. We consider the question of the propriety of using rollers, as a highly important one, and as one not yet settled; we know that a strong prejudice exists in this country against the rolled iron; and that the results of experiments made in Pennsylvania, are rather unfavourable; but we likewise know, that the process is very extensively carried on in England, where it has met with a decided preference in many instances; and the economy which attends it, must make it very desirable that it should prove successful. Experience shows that all innovations in the arts meet with objections; and that the failure of those, who attempt to repeat them without proper care or knowledge, is not unfrequently attributed to the imperfections of the process, instead of being charged to the inexperience of the operators. 
It is a remarkable fact, that with the admitted superiority of the British over American castings, no attempts have been made to work the same ore and by means of the same fuel which have proved so successful when used abroad. It is a truth with which every person who feels an interest on this subject, is conversant, that the clay iron stone is the principal ore used in England; that it is smelted by means of coak; that the products are extremely advantageous; that results equally favourable, if not more so, have been obtained in Silesia from the same ores; that experiments which have been made on the same subject in France, have been attended with the happiest results. We may therefore wonder, that so much of this valuahle ore is allowed to remain unwrought in the midst of the very fuel which ought to be used to smelt it; and that a preference should be given to the hydrates and oxides of iron, worked with charcoal, very frequently with great disadvantage.

The furnace which we visited near Zanesville, was built in 1809, and was, as we were told, the first erected in the state of Ohio; its inside is lined with fire-bricks made of the clay which is used for crucibles in the glasshouse, and the proprietors informed us that it was their intention to make large bricks of the same materials for their hearths, as all the stones they had heretofore used had proved defective, and had obliged them to suspend their operations under a year's blast, at a time when the rest of the furnace was in a very sound state. This experiment, if successful, will be attended with great advantages to the country. The clay has been analysed in Mr. Keating's laboratory in the University of Pennsylvania, and found to contain about seventy-two per cent. of silex, with alumine, little or no lime, and no metallic oxide.

The iron ore used here is an hydrated oxide, which

VoI. I. 
yiclds in castings about thirty-three per cent. It smelts very readily of itself, requiring but a slight addition of about three per cent. of limestone. Among the great improvements which have been made at this place, is the connexion, by means of a canal with locks, between the upper and lower level of the Muskingum. The company who erected the dam, were bound by their charter to keep a lock navigation in repair, and their improvements, which have removed all obstacles to the navigation, will doubtless prove very valuable, as they have afforded them a very extensive water-power. Salt was some time since obtained at Zanesville, and all along the Muskingum; but of late the works here have been abandonerl, the springs being ton weak. It appears that those below are very productive; it is calculated that one hundred gallons of water from these will generally yield about a bushel of salt weighing fifty pounds; hence the water must contain upwards of six per cent. of salt. The establishments, as they are generally made in this country, contain twenty kettles of the capacity of ninety gallons each, costing together about seven hundred dollars; of these kettles or pans, fourteen are used for evaporating and six for crystallizing the salt. During the evaporation, a sediment is formed, which is supposed by some to consist of loam and lime; no experiments have as yet been made upon it to ascertain its nature. No use has ever been made of it, but it would doubtless prove very valuable in agriculture. The depth to which they bore varies much, it is generally about two hundred feet. In some cases the auger holes, which are about three inches in diameter, have been sunk to seven hundred feet in depth. The expense of course varies according to the depth, but the work is generally undertaken at from one dollar and fifty cents to two dollars per foot. In one instance, where the boring extended to 
upwards of one hundred feet, it was performed for seventyfive cents per foot. The whole capital required to put up salt works in this neighbourhood, is estimated at four thousand five hundred dollars; and when the work is prudently conducted, the business is considered very good; though the price of salt is at present low.

It was in boring for coal, a few years since, that a deception was practised, which made considerable noise in the country, and produced much mischief in Zanesville and its vicinity. It appears well ascertained, at present, that the silver, said to have been found in one of the auger holes bored on the banks of the river, had been thrown in by some evil-minded persons. The pretended discovery induced many to speculate largely upon the mine, before the detection of the plot, whence they incurred great losses; this event occurred in the year 1819 .

The banks of the river are strewed with vast numbers of pebbles, much rolled, and evidently carried from a great distance. They consist principally of quartz, in some cases hyaline, in others partaking of the nature of jasper, agate, semiopal, \&c. fragments of granitic and amphibolic rocks are also to be met with here and there. Specimens of petrified Retipore and Favosites striata, Say, and of a new genus of the Polypiers lamelliferes of Lamarck, Chonemblema, Say, * were also observed on the shore. These petrifactions are siliceous and rolled, and bear the appearance of having been removed far from their original locality. Specimens of the Favosites striata are also common in this vicinity.

We observed near the bank of the river a considerable accumulation of common flint, (quartz silex, which consisted of irregularly shaped blocks of silex, apparently no-

* Appendis, I. A. 
dules, which had been imbedded in a rock, in the manner in which the same substance lies in the chalk of the neighbourhood of Paris; its colour is black. Upon inquiry we were informed, that these blocks are gathered from the fields, where they are found loose and scattered; they do not carry with them the appearance of much attrition. They are used in the glasshouses in the preparation of fine white glass.

Among the features which strike the traveller, as he contemplates the scencry of the Muskingum, none contributes more to give a character of originality to the landscape, than a rude bridge erected across the river, in which the architect has contrived to connect three forks or arms, one of which reaches to the cape formed by the junction of the Muskingum and Licking creek, while the other two establish a connexion between the opposite banks of the Muskingum, below the junction of the two streams. This presents an uncouth mass, contrasting well with the magnificence of the scenery. The bridge appears destitute of solidity, and will probably be soon replaced by a more elegant and permanent one. It is thus that the rule works of the first settlers in the west are disappearing gradually, and making way for the more improved structures of civilized life.

Having remained half a day in Zanesville, we continued our journey towards Columbus, which we reached on the 19th. The route between these two places offered us but little interest. To the mineralogist it presents none at all, being level, flat, and covered with an allurium. We were informed that coal had been obserred in many places, but in no instance of a quality to warrant its extraction; and that no where had it been worked beyond five miles west of the MIuskingum. Our road, which led us through 
the valley of Licking creek, was very even. The rocks were always concealed from view, execpt in one or two places, where alsrupt cliffs rose at too great a distance from the road, to permit us to decide upon their nature; but their general aspect appeared to connect them with those observed in the vicinity of Zanesville.

Our attention was, however, soon directed in another chamnel. The country about the Muskingum appears to have been at a former period the seat of a very extensive Aboriginal population. Every where do we observe in this valley, remains of works which attest, at the same time, the number, the genius, and the perseverance of those departed nations. Their works have survived the lapse of ages; but the spirit which prompted them has disappeared. We wander over the face of the country; wherever we go, we mark the monuments which they have crected; we would interrogate them as to the authors of these mighty works, but no voice replies to ours save that of the echo. The mind seeks in vain for some clew to assist it in unravelling the mystery. Was their industry stimulated by the desire of protecting themselves against the inroads of invaders, or were they themselves the trespassers? did they migrate to this spot, and if so, whence came they? who were they? where went they? and wherefore came they here? Their works have been torn open; they have been searched into, but all in vain. The mound is now levelled with the sod of the valley; the accumulated earth which was perhaps collected from a distance into one immense mass to erect a monument deemed indestructible, over the remains of some western Pharoah, is now seattered oves the ground so that its concealed treasure may be brought to light. Every bone is accurately examined, every piece of metal or fragment of broken pottery is curiously studied, 
still no light has as yet been thrown upon the name, and date, of the once populous nation which formerly flourished on the banks of the numerous tributary streams of the Ohio.

Such were the reflexions suggested to us by our visit to the numerous mounds and Indian works which abound in this part of the country, the first of which we observed in the small village of Irville, situated eleven miles west of Zanesville. It has been openerl, and as usual, it has yielded bones. This mound was about fifteen feet in diameter and four and a half in height; it appears to have had an elliptic basis. Our guide told us, that he was present at the opening of it, and that there were a number of human bones, and among others, a tolerably entire skeleton which laid with its head to the north-west; the arms were thrown back over the head. Besides the bones, there were numerous spear and arrow points, and of the latter, we picked up one on the spot. There was also a plate of copper of the length of the hand, and from five to six inches in width, it was rolled up at the sides, and had two holes near the centre; its weight, we were told, might have been about a quarter of a pound, but was probably heavier; for it must have been very thin, if, with those dimensions, it weighed so little. What could have been the use of it, except as an ornament, was not determined; indeed, the inhabitants of that part of the country are so much accustomed to dig up bones, and remains of the Aborigines, that they are very careless about observing or recording the objects found, and the circumstances under which they were discovered. We were told that pieces of copper, and even of brass, had been frequently collected. The copper may easily be accounted for, without a reference to a higher degree of civilization, or to an intercourse with nations more ad- 
vanced in the arts. The existence of native copper strewed upon the surface of the ground in many places, will easily account for the circumstance of its being used by the natives as an ornament, in the same manner that the Copper Indians of the north have been known, from the earliest days of their discovery by the whites, to adorn their persons with it, but we cannot account for the discovery of ornaments of brass, unless we admit an intercourse with nations that had advanced in civilization. The existence therefore of fragments of this alloy in mounds, appears to us doubtful; for if true, the Indians who constructed them must have been much more refined than we can suppose they were; or they must have had intercourse with civilized nations. The erection of these mounds, which appear to be in a great measure contemporary, was certainly much anterior to the discovery of this continent in the fifteenth century ; and therefore it is not from Europeans that these pieces of brass were obtained; if again, we repeat it, they have been found interred in these works.

Besides this mound, there are many others in the immediate vicinity of Irville, some of which have very great dimensions; we observed one, near the road, which had been but recently excavated at its summit; it was perhaps about thirty-five or forty feet high. These mounds were for the most part overgrown with bushes; we could discover no order or plan in their relative positions, and from the scattered and irregular manner in which they lie, it does not appear that they were intended to be connected svith any work of defence; it is more probable, that they were erected as mausoleums over the remains of the dead, and that the difference in their size was intended to convey an idea of difference in the relative importance of those, whose bones they covered. We were informed that this valley and the neighbouring hills abound in excava- 
tions resembling wells; we met with none of these; they are said to be very numerous, and are generally attributed to the first French adventurers, who being constantly intent upon the search of the precious metals, commenced digging wherever they observed a favourable indication; not having seen any of these, we could not pretend to express an opinion upon their origin, but from the number in which they are represented to be, as well as from their dimensions, they appear to us far exceeding the abilities of those to whom they are attributed; and to have required a much more numerous and permanent population than these adventurers are known to have brought orer with them; we would therefore prefer the opinion which ascribes them to the same nations that erected the mounds, and who may have sunk these wells, either for purposes of self-defence, according to the usual mode of Indian warfare, or as habitations, in the manner known to be practised by some Indian tribes, (vide Harmon's deseription of the Carriers, ${ }^{*}$ ) or finally, for some other cause as yet undiscovered. Their great depth, which is said at this time in many cases to exceed twenty feet, may be considered as an objection to the opinion which we have advanced. The supposition of Mr. Atwater, that these wells, which he states to be at least a thousand in number, were opened for the mere purpose of extracting rock crystal and hornstone, appears to us too refined; what ever may have been the advances of these nations in civilization, we have no reason to belicre that they had carried them so far as to be induced to undertalic immense mining operations, for the inere purpose of obtaining these articles. (Archrologia Americana, vol. i. p. 130.)

Newark is a pleasant little town, situated at the fork of

"Journal of a Voyage and Travels in the Interior of North America. by D. W. Harmon, Andover, 1820. 
Licking and Raccoon creeks, about twenty-five miles from Zanesville. Within a short distance of it are some very fine remains of Indian works, which we were deprived from seeing, having been misinformed as to their real position; but we had less cause to regret this, as an excellent description of them has been published by Mr. Caleb Atwater, whose zeal and activity in exploring those old Indian works, have acquired for him a distinguished rank among the antiquaries of America. From his account of them, it would appear that these works must have covered several miles of country, and that they were perhaps connected with other works, situated at a distance, by parallel walls extending over a space of thirty miles. Of the labour bestowed upon them, an idea can be formed from the circumstance, that among these works there " is a circular fort, containing about twenty-six acres, having a wall around it, formed by the ground which was thrown out of a deep ditch on the inner side of the wall; this wall is now from twenty-five to thirty feet in height." (Archæol. Am. i. 127.)

In the vicinity of Newark we observed an orchard, every tree of which was propped, having, as we were told, suffered much from a violent south-westerly gale on Easter Sunday of this year; the fact would not have appeared to us worthy of notice, but for the observation that this gale of wind, which was felt very extensively throughout the country, was observed to have a different direction in different places; at Philadelphia it is known to have been from the north-east. It may be a question, whether these two gales were in any manner connected, and if so, why they happened to proceed from different directions.

At Newark the party fell in with Captain John Cleves Symes, a man whose eccentric views on the nature of the VoL. I. 
globe, have acquired for him, not only in America, but also in England, a temporary reputation. The partial insanity of this man is of a singular nature. It has caused him to pervert, to the support of an evidently absurd doctrine, all the facts, which, by close study, he has been enabled to collect from a vast number of authorities. He appears conversant with every work of travels from Hearne's to Humboldt's, and there is not a fact to be found in these which he does not manage with considerable ingenuity, to bring to the support of his favourite doctrine. Upon other subjects he talks sensibly, and as a well-informed man. In listening to his expositions of his views of the concavity of our globe, we felt that interest which is inevitably awakened by the aberrations of an unregulated mind, possessed probably of a capacity too great for the narrow sphere in which it was doomed to live; and which has consumed itself with the fire, which if properly applied, would doubless have illunined some obscure point in the science which it so strongly affects. In another point of view, Captain Symes has a claim to our best sympathies for the galiantry with which he serץed his country during the war.

From Newark to Columbus the road passes through a moist and heavily-wooded country, well calculated for the growth of the beach tree, which was found here superior in size to any previously observed. This part of the route Jying remote from any navigable streams, is almost destitute of population; and it was only when we came to the immediate vicinity of Columbus, that we again found ouxselves in the midst of civilization.

The spot upon which the metropolis of Ohio now stands, presents a remarkable instance of those rapid changes which are so often to be met with in our western states. In 1512 a single $\log$ cabin only could be obserwed, where now a popu- 
lation of fifteen hundred inhabitants is seen enjoying all the comforts, and carrying on all the business of an old settlement. The situation of Columbus is, however, far from presenting advantages that can compete with those of many other western settlements. Much difficulty and division appears to have prevailed in Ohio previously to the location of the seat of government; and this spot was probably selected by a sort of compromise, rather with a view to its central situation than from any great local advantage. It stands on the left bank of the Scioto, at about half a mile from Franklinton, whose site on the right bank was thought too low and unhealthy.

The party were here joined by $\mathrm{Mr}$. Colhoun, who had travelled from Washington city by the national road to Wheeling, and thence proceeded to Columbus, where he waited for the arrival of the Expedition. Some further arrangements required to accommodate ourselves to the country through which we had to travel, occasioned in this town a delay of one day, during which we experienced a remarkably heavy thunderstorm, which was accompanied by a wind apparently like a hurricane, its direction shifting at every moment; this produced much damage in the town, and among other things carried off both the gable ends of a house, the wind forcing a way for itself under the roof.

The banks of the Scioto are covered with pebbles, apparently from primitive formations; no rocks were visible in place, but the limestone used in the town, and which is filled with organic remains, is said to be found in the vicinity; it appears to be similar to that observed at Zanesville.

The wealth of Ohio has been so often the subject of discussion, that we felt an interest in ascertaining how far the reports circulated were correct. We found that, in fact, 
the produce yielded by agriculture so far exceeds all dcmands for it, that it has become a sort of dead stock in the hands of its owners. The price of grain has fallen so low, that the only mode of disposing of it consists in distilling it into whiskey, of which the price is twelve and a half cents per gallon, and when retailed in small quantities it sells at the rate of twenty-five cents per gallon. Such prices must of course be a check upon all industry, and at the same time productive of much mischief by offering a temptation to intoxication, which too many find it impossible to resist.

The weather had already set in very warm, the thermometer standing usually at noon at upwards of eighty degrees. Observations for latitude and longitude were commenced here, but were interrupted by the storm.

Wednesday, May 21st, the expedition left Columbus on its way to Piqua, situated on the Miami, about seventy miles west of Columbus, and likewise in the state of Ohio. 'The intermediate country is but thinly settled; the soil is black, and not very deep, seldom more than eight inches; it is underlaid with sand and pebbles, which are evidently the detritus of granitic rocks, similar to the large boulders observed every where throughout the country. No rocks to be met with in place. Although the country is very high, being probably from the best measurements which have been made, at least three hundred and fifty feet above the surface of Lake Erie, and consequently upwards of nine hundred feet above the surface of the ocean, it is very wet, being swampy, with occasional open woods and soft marshy prairies, very unlike those that are described by travellers as existing to the westward, and which we afterwards met with on the St. Peter's, \&c. The whole of this part of our route led us irresistibly to the conclusion, that 
we were travelling upon the bottom of some lake, whose waters had, at a comparatively modern period, broken their bounds and found their way to the ocean. It is true, that in the present state of our geographical and geological knowledge of the valley drained by the Mississippi, it is impossible to assign any probable limits to this vast internal ocean; we know too little of the true direction of the different chains of mountains, which extend throughout this section of our country, or of their respective heights, to allow us to trace the limits of that powerful dam which formerly kept the whole of our western country under water; nor can we attempt to show in what places and from what causes the dam was forced, but the mere inspection of the high plains, which form the centre of the state of Ohio, must satisfy us that they doubtless owe the characters which they now present, to the recent sojourn of water. The country is covered with a very heavy growth of wood; many of the trees are upwards of five feet in diameter. These forests consist chiefly of oak, ash, elm, hickory, sugar-maple, black-walnut, beach, tulip, wildcherry, \&c. The cctton-wood tree, and the garden-coral honeysuckle were first observed here in great abundance; the tulip or Liriodendron, is the tree which attains the largest size. The soil, though good, is not of the first quality, and it is generally observed that the dark black soil, which predominates, is inferior in quality to a chocolate-coloured one which is occasionally met with. The average produce of the best crops of Indian corn amounts to about fifty bushels per acre; a good crop of wheat yields about thirty bushels. The increase of population in this district is far from being as rapid as it promised to be; the want of a market, the unhealthiness of all the marshy 
lands, and the constant impulse to an emigration further to the west, have prevented many settlements being made, remote from the streams. Wild and unimproved land may be had, in most places, at two dollars per acre, and there is still some public land, belonging to the United States, which may be purchased at one dollar and a quarter per acre. The surface of the country presents some slight undulations. The only stream of any consequence which we met between the Scioto and the Miami, was Mad river, a tributary of the latter. The name which it bears was given to it on account of the wildness of its scenery, and of the agitation of its waters, resulting from the roughness of its bed. This is one of the most romantic streams which the western country presents. Instead of the wide, and frequently bare bed, in which the other streams run with a slow and lazy pace, Mad river descends in many parts of its course through a narrow and contracted channel, with the rapidity of a torrent. Notwithstanding the uncultivated and uninhabited state of the country, we saw but little game; this consisted of a few deer and wild turkeys, which however kept so far from our course as to prevent our firing at any.

The town of Urbanna is small, but neatly laid out. We met here with a family of emigrants lately removed from New Jersey, for the purpose of raising the Palma Christi, and manufacturing from it Castor oil, which they propose sending to the eastern cities, by the way of New Or-

- Besides the ague and intermittent fevers, we were informed that a very fatal disease had prevailed during the last summer; it is well known to the west under the name of the sick stomach, or milk sickness, and is supposed to be produced by drinking milk, which has become unwholesome from some cause or other; many persons died of it last year. 
leans; they have already planted twelve acres of it, and from the experiments which have been made, anticipate much success in this culture.

The expedition stopped for a day at Piqua, a small incorporated town, situated on the west bank of the Miami river, and on a spot which appears to have been the site of a numerous Indian population. The river is navigable for keel boats, a few miles above the town, during half the year. The town is built in a semicircular bend of the river, so that its streets, which are rectilinear, and parallel to the chord of the arc, are terminated at both ends by the water. The spot is one of the most advantageous in the country for a large population; the situation is very fine for defence against aggressors; and we find that with their accustomed discrimination, the Indians had made this one of their principal seats. The remains of their works are very interesting, and being, we believe, as yet undescribed, we surveyed them with such means as were at our disposal. They consist for the most part of circular parapets, the elevation of which varies at present from three to five or six feet; but which bear evident marks of having been at one time much higher; many of them are found in the neighbourhood of the town, and several of them in the town itself. The plough passes every year over some parts of these works, and will probably continue to unite its levelling influence with that of time, to obliterate the last remains of a people, who, judging from the monuments which it has left behind, must have been far more advanced in civilization than the Indians who were found there a century or two ago; and of whom a few may still be seen occasionally roving about the spot, where their fathers met in council.

We observed one elliptic and five circular works, two of 
which are on the east bank of the river, the others are on the west. The ground appears, in all cases, to have beeu taken from the inside, which forms a ditch in the intcrior: its depth cannot of course be ascertained at present, as it is in great measure filled up, but it must have been considerable. The area, within the ditch, probably retained the level of the surrounding country. The parapet may have been from three to four feet wide, but from slow decay it appears much wider. The first which we visited, (A.) is situated at about a quarter of a mile to the south-west of the town, and half a mile westward of the river; it appears to have been the most important of all, and forms, as it were, the centre round which the others were disposed. Its form is circular; its diameter is about one hundred and fifty feet: it has a gateway from eight to ten feet wide, which faces the river. Immediately connected, and in close contact with it, to the south-south-east, there is a small circular work, (a.) the parapet of which is considerably higher; its diameter is about forty-three feet; it has no gateway or opening whatsoever. It has generally been considered as intended for a look-out post; but this opinion appears incorrect, from the circumstance that it is not raised high enough for this purpose; that its size is much greater than what would be required for a mere post of observation; and finally, that its construction essentially differs from that which is recorded by Mr. Atwater and other observers, as belonging to such posts of obserration. There is nothing to support this opinion but its situation, which is in the most elevated part of the plain. We however think it more probable, that it was considered as a strong hold which should be resorted to in the last extremity.

\footnotetext{
"Sce the annexed plan.
} 
This opinion accounts for all the characters which we observe about it. Its situation near the main fort at the centre of the works; its smaller dimensions, which, while they would admit a considerable force, would permit it to be defended more easily than the extensive works with which it is connected : the height and thickness of its parapet confirm this belief. The circumstance of there being no gateway, is an additional proof for us, that it was intended to be used like the citadel of a modern fortress, as the last spot in which the remnants of a defeated army might be concentrated in order to make a decisive stand against their aggressors.

Proceeding in a direction south sixty-five degrees east from the first work, at a distance of about seven hundred and sixty feet we find another fortification, (B.) which, like the former, is partly situated in a ploughed field, but which passes also over a bye-road. In this old work, the white man has built his barns, stables, \&c. and appears anxious to hurry on the destruction of what would, if uninjured by him, have resisted the assaults of time. The parapet of this fort is not quite so elevated as that of the former; its dimensions are larger, being about two hundred and twenty-five feet in diameter; it has a gateway fronting that in the first fort, and similar to it. If any covered way ever existed by which these two works were connected, it has disappeared, no trace of it being at present visible.

Taking again the first fort, (A.) as a centre, and proceeding from it in a course north eighty-five degrees east, we find another circular enclosure, (C.) distant seven hundred and fifty feet from the first, and about five hundred and forty feet in a northerly course from the second; its parapets are higher than those of the other two; its diameter

VoL. I. 
is about one hundred and fifty feet; it is provided with a grateway fronting that of the first fort. Between the second and third forts, (B. and $\mathrm{C}_{\text {. }}$ ) and near the bank of the river, there are remains of a water-way, (W.) formerly connected as we suppose with the third fort; these remains consist of a ditch dug down to the edge of the river; the earth from the same having been thrown up principally on the south side or that which fronts down the river, the breadth between the two parapets is much wider, near the water, than at a distance from it; so that it may have been used either for the purpose of offering a safe passage down to the river, or as a sort of harbour, in which canoes might be drawn up; or perhaps, as is most probable, it was intended to serve both purposes. This water-way resembles in some respects, that found near Marietta, but its dimensions are smaller. The remains of this work are at present very inconsiderable, and are fast wasting away, as the road which runs along the bank of the river intersects it, and in the making of it, the parapet has been levelled and the ditch filled up; this is much to be regretted, as this work, if it could be seen in its perfect state, would perhaps discover the motive which led to the erection of these fortifications, the attacks against which they were intended to provide, and the means with which the resistance was to be cffected. But the largest of the works on the western bank, still remains to be noticed. This is an elliptical construction, (D.) of great eccentricity; its transwerse and conjugate diameters measuring eighty-three and two hundred and ninety-five feet; it is situated six hundred feet in a direction north forty degrees cast from the first fort, its conjugate axis extends nearly east and west; we observed no gateways; this work is almost,effaced, its parapet does not rise quite one foot above the ground. 
We crossed the river in a canoe, and landed at the foot of a very steep hill, about one hundred feet high. On the top of this hill, remains of a fort (E.) in a very good state of preservation are to be seen; it lies in a direction north sixty degrees east from the first fort which we visited, and is one hundred and twenty-three feet in diameter; it is placed on a very commanding position, on the brow of the hill which has unfortunately been partiaily washed awsy. and has carried down with it about one-third part of the works. There is at present but one gatervay visible, which is on the east side, and is about six or eight feet wiclc. This part of the works is one of the most interesting, it having: as yet received no injury from the hands of man. It is covered with trees of a very large size. Upon the top of the parapet we found the trunk of a tree, which had cvidently grown long after the rampart had been constructed, and probably much after it had ceased to be the theatre of bloodshed and of assault. The interior part of the trunk was very much decayed; but we counted two hundred and fifty concentric layers in what appeared to be less than the outer half; whence we concluded that this tree was certainly upwards of five hundred years old at the time it was cut down. These works all bear the impress of a very remote antiquity; in some cases, trees of a very large size are seen growing upon the trunks of still larger trees. We have, as we conceive, no data to cnable us to refer to them any definite date; but we are well warranted from all their characters in assigning to them an antiquity of upwards of one thousand years.

At about fifty rods to the north-north-west of the last. mentioned work, there is another, which is circular, and of a much larger size. It has two gateways, one fronting east, and the other west. We did not sce this last, but we are 
indebted to some of the inhabitants of Piqua for a description of it.

About these forts there are, as might be expected, many Indian arrow-heads, and other remains to be found. Those which we saw present however nothing peculiar. We observed both the war and the peace arrow-head, or that which is used in hunting, and which is distinguished from the war arrow-head, by the absence of the acute shoulder, with which the war arrow is always provided, in order to cause it to remain in the wound, from which it cannot be extricated without much danger and pain to the patient: whereas, that used in hunting is such that it can be withdrawn without difficulty. For the same reason, while the latter is attached to the arrow very firmly, the war heard adheres to it but imperfectly, so that after it has entered into the body, if the arrow be withdrawn, the head remains buried in the flesh. Among other things found near these fortifications was a piece of broken pottery, which was considered as of Indian manufacture; but on examining it closely, we immediately recognised it to be a fragment of a small earthen crucible, and from its appearance we belicve it to be of French manufacture, as it resembles more the French than the German crucible. Taking this into consideration, and bearing in mind that the first French settlers in this country were constantly looking out for ores of gold, silver, \&c. we entertain no doubt that this, instcad of being of Indian manufacture, is a fragment of a crucible, probably imported from France, and used in some docimastic experiment.

We had an opportunity the ensuing day, on our road to Fort St. Mary, to see the remains of an old Indian work, which consists of stones apparently from the destruction of a stone wall which is supposed to have been erected by the same 
nation. It is situated about three miles west of Piqua, on a bluff elevated about thirty feet above the level of the valley of the river. The wall, which is considered by some as having been erected for purposes of defence, stood near the brink of the hill; facing to the south-east. It has been completely thrown down, but its limits may be very distinctly traced by the stones which lay on the ground, forming an ellipsis whose axes are respectively fifteen hundred and nine hundred feet.* This work is stated upon the authority of Col. Johnston, to enclose an area of seventeen acres. The longest axis extends in an east and west line; the distance of the nearest point of the ellipsis to the river was estimated to be about seven hundred yards. At its south-eastern part, it is supported by a circular earthen fort, similar to those previously described, and measuring about thirty-six yards in diameter. The stones, of which the wall was built, are all rolled, mostly granitic, few of them are calcareous; they are in every respect similar to those we find scattered over the country, and especially on the banks of the river. At present they form a loose pavement, about six feet wide round the ellipsis. The figure of the ellipsis deviates in some cases from a strict regularity, probably to accommodate itself to the surface of the country as it then was. In sundry parts, and more especially towards the west side, are many gateways or interruptions in the walls; which are generally from six to eight feet wide. Back of these, and within the area of the ellipsis, we find a number

* This as well as the measures given for the preceding works, must be taken as approximate. When the distance was small, it was determined by means of a measuring tape; when long, by pacing the ground; the measure of the pace having been first determined by experiment. The courses or directions are correct, having been taken with a compass. 
of stones heaped up in the form of mounds, which are suy.. posed to be the remains of small works, thrown up for the defence of the gateway, and so situated that one mound will protect two gateways. Although the general opinion seems to be favourable to the idea, that this stone wall was erected as a fortification, we by no means consider this as proved. All the stones which are found there, if arranged so as to form the highest possible wall, would probably not rise above four and a half to five feet; but in order to afford the wall any degree of solidity, it would be necessary to give it such a brealth as would probably reduce its dimensions to less than three fect. On the part of those who do not consider this as the remains of a military work, it may be argued that we have no proof of these stones having ever formed a wall; that they may have been gathered for the purpose of forming the elliptical pavement which they now present. That this may have been constructed for motives which we cannot at present conceive of, is no proof that such motives may not have existed; further, it may be said that, admitting these stones to be the remains of a wall, it is not probable that it was made for military purposes, as a work of this kind would certainly not have been erected for the protection of a small force, and as a large number of persons collected in it would harc been quite unprotected against arrows and other missile weapons. That the situation, though a commanding one, appears quite untenable for want of water, which can only be procured by descending the hill towards the river, in which case the party venturing out would be exposed to be cut off by the encmy. A spring was, it is true, obscrved within the elliptic cnclosure; but the small quantity of water which it affords at present, renders it improbable that it should have been at any time sufficient for the con- 
sumption of as large a force as would have been required in the defence of so extensive a work. The number of gateways it may be said, likewise excludes the possibility of its being intended as a work of defence; for they are very numerous and sometimes within four or five feet of each other. The unevenness of the ground, part of the wall being along the sides of the hill and much lower than the rest, may be urged as another strong objection to its being considered as a military work. If it be not intended for purposes of war, what was the intention of those who crected it? Its extent, the labour which it required in order to accomplish it, its form and situation, in fine, all its characters would then concur in leading to the belief that it must have been a religious monument; probably forming an arena where their sacred festivals, their games, their ceremonies could be conveniently carried on. The number of the gates, the heaps of stones which lay near them, all tend to prove that no other origin can be safely ascribed to it. It was suggested that this may perhaps be the remains of a pound, similar to those made by the Indians to this day, for the purpose of entrapping buffaloes and other wild game. But this opinion is likewise excluded by the little resistance which a wall of such small dimensions, formed by the union of uncemented stones but loosely piled together, would have presented to the powerful efforts of the wild animals which it would have been intended to enclose. Its situation on an uneven ground, likewise excludes this hypothesis from any claim to plausibility.

The stones used vary much in size, from that of a walnut to the largest which a man may carry; doubts may exist whether this wall was raised upon an earthen parapet; if there was one of this kind, it has certainly disappeared almost entirely, yet in a few places the elevation 
formed by the stones, appeared greater than might have been expected from the quantity of materials which were observed. It is, therefore, not impossible that, in some places at least, the wall may have been supported by an earthen parapet. The motive for which these stones were collected will probably ever remain a secret; and we must be contented with surmises, all of which are unsatisfactory, because all are founded upon hypothetical manners, which we ascribe to the authors of these works. When we observe a circular rampart with a fosse, a gatervay and a traverse inside of the gateway, we discover a similarity to our modern fortifications, and we immediately consider that this may have been erected for the same purpose; rvithout enquiring into the foundation which we have for assigning to them the same system of fortification which we have adopted. In examining into the character of man, whether civilized or savage, we are, it is true, struck with the powerful influence which two of the most opposite passions, a warlike and religious spirit will exercise over him; and to one or both of these we may attribute his most astonishing actions, whether good or bad. 'The experience of every nation prores, that almost all religious faiths have led to the undertaking of vast constructions. Without recurring to the Egyptian and Indian antiquities, we find in the splendid remains of Greece and Rome, in the colossal and magnificent Gothic cathedrals of the middle ages, and even in the more recent edifices of modern times, that religion has at all periods been the principal motive. which induced men to exert their genius and expend their labour in constructions. Judging, by the same test, of the nations long since extinct, which at one time covered the banks of our western streams, we will not be surprised if the remains of their finest works bear the sharacter 
of having been undertaken, partly at least, with religious views.

On the road from Piqua to this stone wall, we passed a very large mound, which had been partially cut down in order to make room for the road. This mound has, as we believe, never been opened. In this vicinity and near the bank of the river, is the residence of Colonel John Johnston the Indian agent, a man whom we should judge to be of estimable feelings as, unlike most of the settlers in this new country, he has respected the remains of these Indian works, and has not suffered the ploughshare to pass through them. Colonel Johnston observes, that he does not know that any Indian works have been found due north of Miami county, (Ohio,) though they occur to the south and south-west as far as the Floridas. (Western Gazetteer, p. 290.) About half a mile to the south of the town of Piqua, there is an old Indian cemetery, it is situated upon a level piece of ground, elevated about twenty feet above high water mark, and in a romantic spot intersected by a small run. The surface of this place is formed by limestone rocks, laying bare and deposited in horizontal strata. Upon these rocks it appears that the corpses were deposited, and that they were covered over with slabs of stone, some of which were tolerably large; over these a thin soil has been formed, in the lapse of ages, and this supports a scanty herbage. Upon reaching the spot, we found that most of these mounds had been broken open for the purpose of burning into lime the fragments of stone which composed them, and of avoiding thereby the trouble of working into the solid rock. We opened several, but in all cases we found the bones very much injured; indeed, all of them were more or less broken except one, which was evidently a toe bone. They had become very much altered, and were yellow and VOL. I. 
cellular. We took specimens with us to examine them chemically, with a view to ascertain what changes they had undergone; but they were lost with part of our collections. The objects which seemed to resist decomposition most effectually, were tecth. Of these we found, however, but few, not more than half a dozen; two of them were milk teeth, the rest had belonged to adults; they were rather of a small size, and worn out almost to the root. The bones all lay scattered and without order; they were fragments of the cranium, the arms, shoulders, \&c. which almost crumbled under the pressure of the fingers. The only object that we noticed with them, were the two incisor teeth of a ground squirrel, which were probably of fortuitous deposition.

The rocks in the neighbourhood of Piqua are uniformly composed of a white limestone, of a compact texture, but containing many cavities filled by crystallized carbonate of lime. It is filled with organic impressions, among which Mr. Say determined the Flustra, (expanded and branched,) the Terebratula, the Caryophillæa, and probably several others. A rolled specimen, which is supposed not to belong to this formation, contained a tolerably good impression of Favosites striata, $\mathrm{S}$.

We also found here a specimen of primitive limestone with mica; but it was evidently rolled, and bore no resemblance to the rocks which occur in place in this vicinity. At Piqua the rocks are all very well stratified, the strata being nearly horizontal. This limestone is found to yield by burning, a lime of a tolerably good quality. It is stated that salt springs have been discovered in various places near Piqua, but we met with none.

There is a very considerable rapid in the Miami at this place, which has induced a company to cut a canal for the 
accommodation of the ascending navigation. This improvement is now completed, and affords them a fine water-power, with a fall of nine feet. This, together with the fertility of the adjoining country, which is represented as formed of a very rich prime soil, of a chocolate colour: will doubtless soon lead to the erection of extensive grist mills at this place; the capital of the company not being adequate to the undertaking, the mills which they have established are by no means suitable to the power of which they can dispose. The Miami is fordable here at almost all seasons of the year, but there is a very good bridge over the river. The name of the town is derived from that of one of the principal tribes of the Shawanese Indians, who formerly roved through this part of the country, spreading. itself as far as the Pickarva plains, situated about seventy-five miles to the south-east. This tribe is now nearly extinct, the few remaining descendants of it have united themselves with the Miamis, and are settled in the vicinity of Fort Wayne.

After spending a very interesting day in Piqua, in the examination of its antiquities, we left this place with a feeling of gratitude for the kind attentions shown to our party by the inhabitants of the town, and particularly by the Register of the Land-office, Major Oliver, late of the Army, whose acquaintance with the country made him a very interesting companion in our investigation of the antiquities of the vicinity.

The country through which we travelled lies near the head waters of Loramie's creck, one of the tributaries of the Miami. We entered this day upon what may be termed the table land, that divides the waters of the Lakes from those of the Gulf of Mexico, and continued on it or in its immediate vicinity, until we reached Prairie du Chien on 
the Mississippi. As we shall have frequent opportunity of recurring to the singular feature, which this country presents in the interlockage, almost every where apparent, between the head streams of two mighty rivers, whose waters fall into the occan at a distance of upwards of two thousand miles, we need not enter at present into many particulars. It will suffice to state, that after leaving the tributaries of the Miami, we came, in less than two hours' ride, to the rivers which send their waters to the Gulf of St. Lawrence. The intermediate country is wet and marshy, there is no appearance of a ridge, properly speaking; it is an elevated flat plateau, the nature of which is marshy.

This remarkable feature in the topography of the state of Ohio, has not escaped the attention of its inhabitants. We find that the possibility of establishing a connexion between the rivers that empty into the lakes, and the tributaries of the Ohio, has long since been asserted by the statesmen of the west. 'The only point which remained unsettled was, what direction should be given to the proposed works, and which of the many routes suggested, was preferable? On this point it cannot be doubted that the prerequisite information had not been obtained, and consequently that no decisive answer could be given; in the absence of authentic calculations, prepossessions founded on local interest were, perhaps, allowed to exercise too great a sway. To avoid these evils, and with a view of doing justice to the whole state, the legislature of Ohio by a very liberal policy appointed a board of commissioners to examine the whole country, make accurate surveys of the various routes which had been suggested, ascertain by gaging or otherwise, the quantity of water on each route; and finally locate lines of canals upon such routes as appeared to them practicable. 
They were directed to submit the result of their operations to the legislature, who would then be enabled to decide upon the merits of the respective routes.

These duties were too extensive and too arduous to admit of their being executed in one season; and the commissioners have been arrested in many of their surveys by the unhealthiness of the country, through which they were obliged to carry on their operations. We have taken pains to acquire information on this interesting subject, and we are inclined to consider that which we have received as correct, because it was obtained from persons conversant with it, and particularly from M. T. Williams, Esq. of Cincinnati, one of the acting commissioners, with whom we had the pleasure of travelling for a few days; and who, in the many conversations which we had with him, has shown himself master of the subject. We have likewise drawn part of our information from the able report made on the 21st January, 1824, by the canal commissioners to the general assembly of Ohio, for copies of which we are indebted to Mr. Williams.

From this report it appears that the routes proposed may be reduced to four, viz. :-

The first route would be to connect the waters of the Grand river of Lake Erie with the Ohio, at the mouth of the Big Beaver creek. This route, being very near to the Pennsylvania line, and in some parts east of it, cannot be eligible by the state of Ohio, if any other practicable route may be found. From the surveys made by Judge Geddes, or under his direction, it would appear that this summit, which is known by the name of the Mahoning summit level, is elevated three hundred and forty-two fect above Lake Erie, and two hundred and fourteen feet above the 
Ohio at the mouth of Big Beaver creek.* This canal would therefore require upwards of five hundred and fifty feet of lockage. The question whether or not a sufficiency of water can be obtained on this ronte is still undecided.

The second route contemplates connecting the Muskingum with the lake, which may be done either by the Tuscarawas and the Cuyahoga creeks, or by the Killbuck and Black rivers; a third division of this route purposes ascending the Killbuck, continuing along the summit level in an easterly direction to the Cuyahoga, and descending that stream to the lake. These three plans may be considered as parts of one general route, the preference to either being a question, which it will only be important to decide, after the propriety of adopting the Muskingum route shall have been decided in the affirmative. The summit level between the Killbuck and Black river, is elevated three hundred and thirty-seven feet above Lake Eric and three hundred and sixty-one above the Ohio at Marietta. It would therefore require near seven hundred fect of lockage. The level between the Cuyahoga and Tuscarawas has been found to be four hurdred and four feet above Lake Erie and four hundred and twenty-eight above Marietta. The locks would therefore exceed eight hundred and thirty

* We have here adopted the measurements given by the canal cora. missioners in their report, though we are afraid that a mistake may have escaped their notice; the height of this summit level was stated by a gentleman whom we met at Columbus to be three hundred and twenty-four fect, which appears more correct, for by a comparison of the difference of level between Lake Erie and the mouth of the Muskingum, the fall of the Ohio from the town of Beaver in Pennsylvania to Marietta would be one hundred and fifty-two feet, if we adopt the calculations of the commissioners; whereas, upon the other data it would be but thirty-sis feet, which is much more probable. 
feet; this section of the Muskingum route, though longer, and crossing a higher summit than that up the Killbuck, would probably be preferred, as being more easily supplied ivith water.

The third route for the canal is that which would connect the Scioto and Sandusky rivers. These streams, passing nearly in a north and south line through the centre of the state, seem at first sight to be the most eligible for the canal if it be practicable to execute it in this direction. Doubts had been entertained concerning the quantity of water which might be obtained on this summit, but as Judge Geddes and Mr. Forrer had ascertained that most of the head waters of the Great Miami river might be brought upon the summit level of this route, generally designated in Ohio as the Tyamochte level, hopes were entertained that it would prove practicable. This level is elevated about three hundred and fifty-four feet above the lake, and four hundred and fifty-five above the mouth of the Scioto, whence it will require about eight hundred and ten feet of lockage. Upon a further survey of the country, and gaging the streams. the commissioners have however come to the final conclusion, that the supply of water on this route would probably be insufficient to overcome the losses by leakage; evaporation, \&c. ; and that it would leave no supply of water for the expenditure in the passage of boats through the locks. In their calculations they have assumed as a basis the loss of water by leakage, evaporation, \&c. on the New York canals, which has there proved much greater than had been anticipated, as it amounts to an arerage of one hundred cubic feet per minute, for every mile of canal route. This amount was reduced by proper allowances for the difference in the nature of the country through which it was contemplated that the canal would pass; but, even 
with these allowances, they have been led in believe, that "the upper levels on the Sandusky and Scioto route, could not be supplied with the necessary quantity of water in dry seasons, by either of the methods proposed and considered; and the board after deliberating on the subject, from the facts and views laid before them by the acting commissioners, came to the conclusion that a further expenditure of time or money in locating a canal line on the Sandusky or Scioto route would be inexpedient, unless some other method should be devised, or some other source of supply discovered." It has therefore become, to say the least, "extremely doubtful whether a canal on the Sandusky and Scioto route can ever be made."

The fourth route which has been suggested, and which is termed the western route, has for object to unite the waters of the Great Niami and Maumee rivers, by means of Loramie ereek and the Auglaize river. The summit level in this case will be elevated three hundred and eighty-nine feet above Lake Erie, and five hundred and forty above the Ohio near Cincinnati; occasioning therefore a lockage of about nine hundred and thirty feet. This route appear's 10 be the best supplied with water; it would pass through a section of country inferior to none in America, in the fertility of its soil, or the amount of surplus productions which it is capable of sending to market; it would become a source of immediate and extensive profit, by the quantity of water which it would bring to the termination of the canal at Cincinnati, affording power for extensive and valuable hydraulic works, which are there much needed. The commissioners appear to be of opinion that the bed of the river ought not to be pursued, but that a thorough-cut ought to be made. The summit level would be in the vicinity of Fort Loramie. This canal would probably be about two 
hundred and fifty miles long. The supply of water would be amply sufficient even for locks of the size of those on the New York canal. Allowing the expense to be the same as in New York, this canal would probably cost about three millions of dollars; but the experience which has been acquired in the construction of that work, warrants us in believing that a similar undertaking may hereafter be performed at a more economical rate. However this may be, no doubt can exist as to the benefits which Ohio would reap from this canal.

From all that has been stated, it appears that the last of these routes is that which offers at present the most decided advantages, but the plan which the commissioners have in contemplation, and which, if practicable, will we doubt not, at their suggestion, be undertaken by the state of Ohio, is one that would prove as beneficial to that state as it will be honourable to it. This plan would be to construct a canal which would unite with the lake as near the north-east corner of the state as nature will permit, and passing through the great vallies of the Muskingum, the Scioto, and the Miami, in a south-ivestwardly direction, enter the Ohio near the south-ivest corner of the state. The commissioners appear to be aware of the difficulties they will have to encounter; but the data they have already collected on this subject, are favourable to the execution of the scheme, and if they should be equally successful during the summer of 1824, in establishing the complete connexion, they will have the honour of having suggested a course, which, if it be not adopted at present, will be so at a future time; for, after the undisputed benefits which canals have afforded wherever they have been made, it is impossible to doubt that, with the great natural advantages which she possesses, Ohio will be among the first to enlist herself VoL. I. 
among the patrons of an extensive system of internal im. provement.

After crossing Loramie's creek two or three times, we reached St. Mary's river, which unites at Fort Wayne with the St. Joseph to form the Maumee. The historical recollections which connect themselves with the section of country through which we travelled, compensate for the little interest which it offers to the naturalist. To him nothing can be more annoying than to pass over a marshy, swampy country, where no rocks appear in situ, and where but few boulders are met with; where the animals are few in number, and apparently afraid to risk themselves in spots in which their speed would avail them but little. It is true, that the pursuits of the botanist might have been carried on successfully, in a situation where an abundant growth of plants would probably have offered him objects worthy of his notice; and this would have compensated the rest of the party for the apparently uninteresting character of the country; for, in an expedition of the nature of ours, the success of each individual in his peculiar pursuit, becomes a source of gratification to all. Being, however, unaccompanied by a botanist, we found in this part of Ohio nothing to interest us but the recollection of the busy scenes of war which had at a former time been enacted in this district. As the principal field upon which all the military operations of Generals St. Clair, Wayne, and Harrison, were conducted, there is much cause to dwell with pleasure upon the spot. A vast difference exists, however, between the theatre of an Indian warfare and that of the military undertakings of civilized nations. The descriptions of the spots, upon which the latter occur, are so much more accurate that they never ran be mistaken; while of the former we seldom know the 
exact site. Even the history of the defensive works which were erected, soon loses part of its interest by the destruction of the works themselves. We read of the deeds done in the neighbourhood of Fort Loramie by the French, or of the Miami villages by St. Clair, but if we travel over the ground, we find but few traces of these deeds. At Fort St. Mary, which was one of General Harrison's principal depots in 1813 and 1814 , we sce but the remains of a half-ruined blockhouse, and of a very miserable hut surrounded by pickets, which are fast falling to decay. A few years more and the remains of these works will be sought for by the traveller as unsuccessfully as we now search for the spots upon which St. Clair fought, and Wayne conquered. A young growth of trees is rising, which, if not levelled by the axe of the forester, will soon conceal the last traces of the clearing, made by Wayne for the advance of his army, which was pointed out to us as Wayne's road. The party arrived in the afternoon of the 24th of May at Fort St. Mary, just in time to avoid a heavy rain. A solitary log-house marks the spot where a little village formerly thrived, under the protection of the French fort, erected at this place. It stands on St. Mary's river, at a distance of fifty-eight miles by land from Fort Wayne; the distance by water is probably about one hundred and thirty-cight miles. The river is navigable, during half the year, for large boats, carrying from one to two hundred barrels; during the rest of the year, in dry seasons, there is scarcely water enough in it to float a canoe, and its course is very much impeded by driftwood. A little limestone of a very inferior quality has been found on the river bank, below the fort. From Piqua to St. Mary the soil is only of second quality, being in many places too wet and swampy for grain. The weather hart 
become very hot; at noon, Fahrenheit's thermometer stood in the shade at eighty-eight degrees. Our party began to suffer much from the inconvenience of mosquitoes and other insects. The entertainment which we received along the road was observed to become more and more rough, and to denote our speedy approach to the last limits of civilization. The cotton-rvood tree became much larger as we advanced. Mr. Say noticed the Papilio thoas and ajax in great number.

On leaving, on the 25th May, the miserable hut which had afforded us a shelter during the storm, our route led us along the banks of the St. Mary, which we followed down to its confluence with the St. Joseph, occasionally coming in sight of the river and keeping off from it, at times, according as its course was a straight or devious one; we travelled for twelve miles over the swampy country through which this river flows, after which we struck a beautiful dry prairie, known by the name of Shane's prairie, and at eighteen miles from Fort St. Mary we crossed the river at a settlement called Shanesville; both the prairie and settlement, (which consists of but one family,) owe their appellation to an interpreter, who is a half-breed Indian, his father was a Canadian, his mother an $\hat{o}^{\prime} t-t^{\prime} \mathfrak{a}^{3}-w_{a}^{\prime}{ }^{\prime}$.* He was employed as an interpreter and spy by General Harrison, during his western campaigns, and is considered as having acquitted himself of his duties faithfully; on the conclusion of the war he was rewarcled by the grant of a section, (six hundred and forty acres,) of land, which he has divided into town lots; he resides

* Whenever an Indian word occurs for the first time, its orthography and pronunciation will be indicated by using Walker's key. The sign (') prefixed to a vowel indicates that it is short, while the sign (') shows it to be long, the unaccented rowels have the usual quantity. 
within a short distance of Shanesville on part of his grant. 'The soil being considered of the best quality, and the situation on the river an advantageous one, he has already sold out some parts of it. No man is better known in this part of the country than Shane; his influence among the Indians is great, and he enjoys a high degree of popularity with the whites, founded upon the uniformly good character which he maintained during the war, and upon the unbounded confidence reposed in him by General Harrison. He was absent from home at the time we passed there, but we afterwards met with him at Fort Wayne.

The late heavy rains had so much swelled the St. Mary that it was impossible to ford it. We passed it in a canoe -our horses swam across. Fourteen miles of bad roads, leading however through a country remarkable for the excellence of its soil, and for its fine luxuriant growth of white and black oak, beach, hickory, shellbark, \&c. brought us to a new settlement, where, notwithstanding the badness of the accommodations, we were happy to find a hospitable reception. Near to this house we passed the state line, which divides Ohio from Indiana. In the state of Ohio we met with no Indians. Their numbers appear to be diminishing very rapidly. We were informed that they do not exceed two thousand, consisting principally of Ottawas, Miamis, Senccas, Wyandots, \&c. This neighbourhood abounds, as we were informed, in wolves, deer, and raccoons; bears are few, and the panther is seldom seen; we met with no wild animal whatever, on this part of our route. The distance from this to Fort Wayne is twentyfour miles, without a settlement; the country is so wet that we scarcely saw an acre of land upon which a settlement could be made. We travelled for a couple of miles with our horses wading through water, sometimes to the 
girth. Having found a small pateh of tame grass, (which from its colour, is known here by the name of blue-grass, ) we attempted to stop and pasture our horses, but this we found impossible on account of the immense swarms of mosquitoes, (Culex,) and horseflies, ('Trbanus,) which tormented both horses and riders in a manner that excluded all possibility of rest.

At a distance of about nine miles from Fort Wayne, we observed a large ash which had been blown down, the tree had been divided in two, in part of its length; a small trough had been excavated in it, in which an Indian child had been deposited, the upper segment of the tree had been replaced to cover the corpse, and the whole secured by a neat little frame. This rude grave had been torn open, doubtless by some white man, to rob it of the trifles with which the tenderness of an Indian parent supplies its offspring when about to travel to the land of spirits; the deceased must have been an infant, for the trough was not more than twelve inches long. We were informed that among the Potawatomis, this is a frequent, though not an universal mode of disposing of their dead. These solid coffins or rude sarcophages are often suspended in trees.

We arrived at Fort Wayne at an early hour in the afternoon of the 26th of May. The distance from Wheeling to Columbus is one hundred and forty miles, which we travelled in six days, that from Columbus to Fort Wayne amounts to one hundred and fifty-eight miles, which were performed in the same time, making an average of twentyfive miles per day. 


\section{CHAPTER III.}

Description of Fort Wayne and its vicinity. Fur trade. Potarvatomis.

AT Fort Wayne we made a stay of three days, during which our time was usefully and agreeably employed in acquiring some information concerning the manners and institutions of the Indian tribes which inhabit its vicinity. To a person visiting the Indian country for the first time, this place offered many characteristic and singular features. 'The town or village is small; it has grown under the shelter of the fort, and contains a mixed and apparently very worthless population. The inhabitants are chiefly of Canadian origin, all more or less imbued with Indian blood. Not being previously aware of the diversity in the character of the inhabitants, the sudden change from an American to a French population, has a surprising, and to say the least, an unpleasant effect; for the first twenty-four hours, the traveller fancies himself in a real Babel. The confusion of languages, owing to the diversity of Indian tribes which generally collect near a fort, is not removed by an intercourse with their half-savage interpreters. The business of a town of this kind differs so materially from that earried on in our cities, that it is almost impossible to fancy ourselves still within the same territorial limits; but the disgust which we entertain at the degraded condition in which the white man, the descendant of the European, appears, is perhaps the strongest sensation which we expe- 
rience, it absorbs all other's. To see a being in whom, from his complexion and features, we should expect to find the same feelings which swell in the bosom of every refined man, throwing off his civilized habits to assume the garb of a savage, has something which partakes of the ridiculous. as well as of the disgusting. The awkward and constrained appearance of those Frenchmen who had exchanged their usual dress for the breech-cloth and blanket, was as risible as that of the Indian who assumes the tight-bodied coat of white men. The feclings which we experienced while beholding a little Canadian stooping down to pack up and weigh the hides which an Indian had brought for sale, while the latter stood in an erect and commanding posture, were of a mixed and certainly not of a favourable nature. At each unusual motion of the white man's, his dress, which he had not properly secured, was disturbed, and while engaged in restoring it to its proper place, he was the butt of the jokes and gibes of a number of squaws and Indian boys, who seemed already to be aware of the vast difference which exists between them and the Canadian Fur-dealer. The village is exclusively supported by the fur trade, and will probably continue to thrive as long as the Indians remain in any number in this vicinity. It has, however, declined from year to year, owing to the gradual diminution of the Indian population. The traders seldom leave the town, but they have a number of Canadians in their service, known by the appellation of $E n-$ gagés, who accompany the Indians during their summer hunts, supply them with goods in small quantities, and keep an eye upon them, so that they should not defraud their employers by selling to others the produce of their hunts. The furs brought here consist principally of deer and raccoon skins; bear, otter, and beaver, have become very rare. The. 
skins, when brought by the Indians, are loosely tied or rolled; they are separated, folded, and made into packs three feet long and eighteen inches wide, which are exposed to a heavy pressure under a wedge press. These packs generally contain from forty to fifty deer skins, and about two hundred raccoon skins. Bear skins being rare, are not put up in packs, but are used to cover the other furs. The prices of skins vary every season, according to their quality and abundance. In 1823, the skins were worth at Fort Wayne-

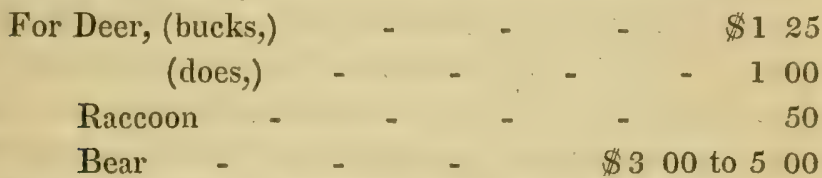

The amount of furs annually made up at this post is, as we were informed by a competent and disinterested judge, ahout two hundred packs, the average value of which may be fifty dollars each, making an aggregate of ten thousand dollars. But this value is rather a nominal than a real one, as the furs are paid for to the Indians at the prices just quoted, in goods which are passed off to them at a value at least double the amount of prime cost and expense of transportation. So that to the dealer the real expense attending the purchase of the furs does not amount to onehalf of their nominal value. They are usually sent down the Maumee to Lake Erie, and thence to Detroit, where they are for the most part purchased by the American Fur Company. At the time when we visited Fort Wayne, the number of Indians there was considerable. This is one of the stations at which the Potawatomis, Miamis, \&c. receive their annuities. The late Indian agent, Mr. Hays, was on the point of leaving the post, previously to which he was desirous of paying them an annuity, but this being VoL. I. 
the time of the year when they attend to their farming arocations, the chiefs had used their influence to keep their people from going to the fort. This delay prevented the immediate distribution of the annuity, and offered to the most idle and worthless of the tribes an inducement and an excuse for frequenting the town.

Fort Wayne, as it now stands, was erected in 1814, on the site of the old fort, the situation of which had been selected by General Wayne after his victory over the Indians. It is a square palisade, protected at two of its angles by block houses, calculated to be defended with artillery. The fort is considered as a good specimen of stockade fortification, which answers very well as a defence in Indian warfare. An improvement which it possesses, and which these works do not all present, is that of giving to the roofs of the barracks and other buildings enclosed by the palisade an inclination in one direction only, and this towards the area of the work; the advantage of which is to afford to the besieged a protection against their assailants, when forced to ascend the roofs, in order to put out fires occasioned by arrows conveying combustibles to the tops of houses, as is frequently practised by the Indians. The fort lies on the east side of St. Mary river, immediately opposite to its junction with the St. Joseph. On the other side of the Maumee we were shown the spot rendered conspicuous by the defeat of General Harmer's army in 1791. This might, we think, more correctly be called Harden's defeat, as by the account of it furnished both by Marshall and Ramsay, it appears that the detachment that was cut up was commanded by Coloncl IFarden.* Indeed, the whole of the country about the upper part of the Grand Miami and Maumee, (generally

* Marshall's life of Washington, Vol. 3. p. 302. 
called in the history of that war the Miami and Miami of the lake,) is interesting, as being the theatre of the war which raged from 1791 to 1794 , when a stop was put to it by the great victory achieved by General Wayne over the confederated Indian nations, on the 20th of $\Lambda$ ugust of that year. This may be consiclered as one of the most memorable events in our history, since the close of the revolutionary war, as it was obtained in front of a British fort which had been erected at the Maumee rapids evidently for the protection of the Indians.

General Wayne's victory was soon followed by the treaty of Greenville, concluded by him in the succeeding year; a treaty "by which the expensive and destructive war which had long desolated that frontier, was ended in a manner perfectly agreeable to the United States."

The situation of Fort Wayne was considered at the time of that treaty, as a favourable one to keep the Indians in check, and prevent the recurrence of the hostile measures which terminated in that treaty. It was one of the most advanced posts of the cordon which was drawn along the western limits of Ohio for the protection of the frontiers. It must be admitted that its position is a very judicious one for a work of this kind, although it would be very improper in a war with an enemy possessed of artillery, as it is commanded by several eminences in the vicinity. During: the late war, it was besieged for some time by the Indians, and a few men were killed on both sides. The garrison having made resistance, the Indians cut a $\log$ into the form of a field-piece, painted it black, and placed it on one of the heights within gunshot of the fort; they then summoned the garrison to surrender. Although aware that all resistance against artillery would be vain, the officer in command refused to comply with the summons. When the 
Indians finding their ruse de guerre to be unsuccessful. raised the siege.

No garrison is at present kept up at this place, and it is probable that even in the case of a future war, this post like many others, formerly considered of great importance, will be so surrounded with a white population, as to render any military force in its vicinity unnecessary. The works offer now a comfortable and suitable residence to the gentlemen attached to the Indian department. The removal of the garrison, and the decrease of the fur trade, will probably affect for a while the growth of the settlement. But it will eventually resume the importance to which it is entitled from its advantageous situation; as a central point at which three respectable streams connect, it must become the seat of an extensive trade. The St. Mary being navigable during part of the year for one hundred and thirty miles, the St. Joseph for fifty miles, and the Maumee offering during the spring, to boats carrying three hundred barrels, a free navigation along the whole of its course to Lake Erie, (one hundred and sixty miles,) a considerable quantity of produce will necessarily pass at Wayne. The prosperity of the town will be increased by the arrangements made by the government of the United States for the sale of the public land in the vicinity. At the time we passed through, we were informed that all the land about the village, and even that upon which it stands, was public property, but that orders had been issued to sell the whole, with the exception of about thirty acres near the fort, which were reserved for the use of the Indian agency. This accounted for the mean appearance of the houses, which are of $\log$, rudely put up, the roofs being made of clap boards kept down by logs. No person felt inclined to lay out money in building on property which could not be sold. The point 
of land upon which the town stands appears to be sandy, and of an inferior quality, but we were told that a very excellent soil prevailed in the vicinity. It was expected that the property would sell well, and it was thought that the quarter section, (160 acres,) upon which the town is situated, would yicld at public sale ten thousand dollars. We were somewhat surprised to find that the inhabitants of the Lown expressed no dissatisfaction at the prospect of the sale of a property upon which they had been residing, free of rent, for so many years, and that not the least question was raised as to the justice or propriety of a measure, by which they were about to be dispossessed of the small improvements which had been made by their fathers and themselves. But the population of Wayne partakes in this respect of the indifference and carelessness that characterize the two races from the admixture of which they have sprung. A circumstance which will add considerably to the future prosperity of Wayne, is its being at the commencement of the short portage of eight miles which sepasates the Maumce from the Wabash. An extensive trade has already been carried on through this route, and as it offers the most direct communication between the head of Lake Erie and the northern parts of Indiana, it will doubtless daily increase in importance.

In the vicinity of Fort Wayne, on the west bank of the river, we were shown a small tree growing on the spot where "Little Turtle" was buried. This was one of the most celebrated Indian chiefs ever known to white men. His character is well remembered by the old residents among the Indians, and from the accounts which have been given of him, we find but few names on record in the history of Indian chiefs that can be compared with his. His character will contrast advantageously with those of King 
Philip, Pontiac, and Tecumsch. The influence which he: appears to have possessed over the Indians was unbounded. Under these circumstances, it is to be regretted that all the facts connected with his life and character, have not been collected with care. Ife is the same whom Volney describes as having met with in Philadelphia in the year 1798. From the abstract furnished us by this able traveller of the conversations which he had with Little 'Turtle and with his interpreter, captain Wells, we are led to form a. very high opinion of the sound philosophy, and excellent judgment possessed by this chief. Of his military talents we can cntertain no doulbt, since it is well asecrtained that to him is chiefly to be ascribed the success which the Indians met with during the years 1791 and 1792. Like King Philip, Tecumseh, \&c. he is said to have entertained at one time the hope of forming an extensive coalition among the Indians, with a view to retrieve the soil of which they had been so unjustly deprived; but meeting with difficulties which he probably foresarv would be invincible, he, with more foresight than either of those chicfs, soon cliscovered that the day for such measures had long since passed away, and that the only advisable course, which remained for his nation to adopt, would be to make peace with the invaders, and endeavour to improve by their superior information. In this manner he succeeded in rescuing them from that destruction, to which King Philip and Tecumsch were hurrying on their brethren, at the time that they themselves became victims to the wars which they had been instrumental in producing. Doubtless his great spirit flattered itself with the hope, that by an advancement in the arts of civilized life, his brethren would regain that importance which they seemed to be on the point of losing for ever. His mind had predicted the awful consequences of the ay. 
jroach of white men. "No wonder," said he, "the whites drive us every year further and further before them, from the sea to the Mississippi. They spread like oil on a blankct; and we melt like snow before the sun. If things do not greatly change, the red men will disappear very shortly." How well-founded this apprehension has proved, and how rapidly the prediction has been verified, let the experience of every traveller to the west attest.

Little Turtle died in the ycar 1504 or 1805 , and his death at that time is very much to be regretted, as the attachment which he had contracted for the American nation had become so great, that it is presumed he would have used his influence, which was very great, to prevent the Indians of that vicinity from joining the British during the late war; and no doubt can be entertained that a peaceful policy, if supported by a man of his weight, would have prevailed.

The naturalists to the expedition being aware that few or no skulls of Indians exist in the collections of our Atlantic cities, were desirous of procuring some, and among others they would have been pleased to obtain that of this celebrated chicf. It would, in their opinion, have been interesting to observe, whether the examination of this head would have afforded any support to the new, and as yet uncertain, science of Phrenology. The principal traits which have been collected of the character of Little Tur1le, might have been compared with the developements of the brain, and this comparison would perhaps have led to some interesting results. They were likewise in hopes, that by disintering it they might have rescued, (for a while at least,) from final decay, the head of one of the greatest men who, to our knowledge, have adorned the character of the American aborigines. But upon consulting with the 
gentlemen of the Indian department, they found that the memory of Little Turtle was so much revered by his nation, and the visits of Indians to the grave of departed friends were so frequent, that such an attempt could not pass unnoticed, and that this apparent sacrilege would doubtless irritate them, and might lead to unpleasant conscquences. The hope of obtaining this head was therefore abandoned.

The expedition was as kindly treated as they could have wished, by the gentlemen attached to the Indian department at this place. General Tipton, (the present Indian agent,) and Mr. Hays, (the late agent,) afforded them all the facilities in their power; and to Mr. Kercheval, the sub-agent, they are under great obligations for the information which his long experience of the Indians, and his acquaintance with their language enabled him to communicate. In order to afford to the party an opportunity of obtaining the best information, General Tipton sent for one of the principal chiefs in that vicinity, with whom they conversed for two days.

The name of this man is $\mathbf{M}^{\prime} \mathrm{e}^{-}-\mathrm{t}^{\prime} \mathrm{e}-\hat{a}^{\prime}$, (which signifies in the Potawatomi language, Kiss me.) He was represented to us as being the greatest chicf of the nation; we had, however, an opportunity of ascertaining afterwards, that he is not the principal chief, but that he has, by his talents as a warrior, and his eloquence as an orator, obtained considerable influence in the councils of his nation. He may be considered as a partisan, who, by his military achievements, has secured to himself the command of an independent tribe. He resides on the St. Joseph, about nine milcs above Fort Wayne, at an Indian village called Mis-kwaw'â-s'è-p'è-ò'-t'ann, (town of the old red wood creek.) Bcing a chief of distinction, he came accompanied by his brother; as his rank required that he should be assisted by 
some one to light his pipe, and perform such other duties as always devolve upon attendants. Metea appears to be a man of about forty or forty-five years of age; he is a fullblooded Potawatomi; his stature is about six feet; he has a forbidding aspect, by no means deficient in dignity; his features are strongly marked, and expressive of a haughty and tyrannical disposition; his complexion is dark; like most of the Potawatomis whom we met with, he is charactcrized by a low, aquiline, and well-shaped nose; his eyes are small, elongated, and black; they are not set widely apart; his forchead is low and receding; the facial angle amounts to about $80^{\circ}$. His hair is black, and indicates a slight tendency to curl; his cheek bones are remarkably high and prominent, even for those of an Indian; they are not, however, angular, but present very distinctly the rounded appearance which distinguishes the aboriginal American from the Asiatic. His mouth is large, the upper lip prominent; there is something unpleasant in his looks, owing to his opening one of his eyes wider than the other, and to a scar which he has upon the wing of his nostril. On first inspection, his countenance would be considered as expressive of defiance and impetuous daring, but upon closer scrutiny, it is found rather to announce obstinate constancy of purpose, and sullen fortitude. We behold in him all the characteristics of the Indian warrior to perfection. If ever an expression of pity or of the kinder affections belonged to his countenance, it has been driven away by the scenes of bloodshed and cruelty through which he has passed. His dress was old and somervhat dirty, but appeared to have been arranged upon his person with no small degree of care; it consisted of leather leggings buttoned on the outside, a breech-cloth of blue broadcloth, and a short checkered shirt over it; the whole was covered with a Vor.. I. 
blanket, which was secured round his waist by a belt, and hung not ungracefully from his shoulders; generally concealing his right arm, which is rendered useless and somewhat withered, from a wound received during the late war, when he attacked with a small party of Indians, the force that was advancing to the relief of Fort Wayne. His face was carefully painted with vermillion round his left eye. Four feathers, coloured without taste, hung behind him secured to a string, which was tied to a lock of his hair. In our second interview with him, he wore a red and white feather in his head, that was covered with other orraments equally deficient in taste. Mir. Seymour took a likeness of him, which was considered a very striking one, by all who knew Metea. (Plate III.)

The chief was accompanied by his brother, who is much younger and resembles him, but whose features indicate a morc amiable and interesting disposition. We observed, that during the interview, the latter treated Metea with much respect, always preparing and lighting his pipe, and never interfering in the conversation, unless when addressed by the chief. On entering the room where the gentlemen of the party were, Metea shook hands with the agent, but took no notice of the rest of the company, until General Tipton had explained to him, through his interpreter, the nature of the expedition; the objects of his great father, the President, in sending it among the Indians; and the information which would be expected from him; he informed him likewise that his time and trouble would be suitably rewarded. The chief then arose from his seat, shook hands with all who were present, told them that he would very willingly reply to all their questions, but that according to usage, he was bound to repeat to his nation all the questions that would be asked, and the replies which he would make; 


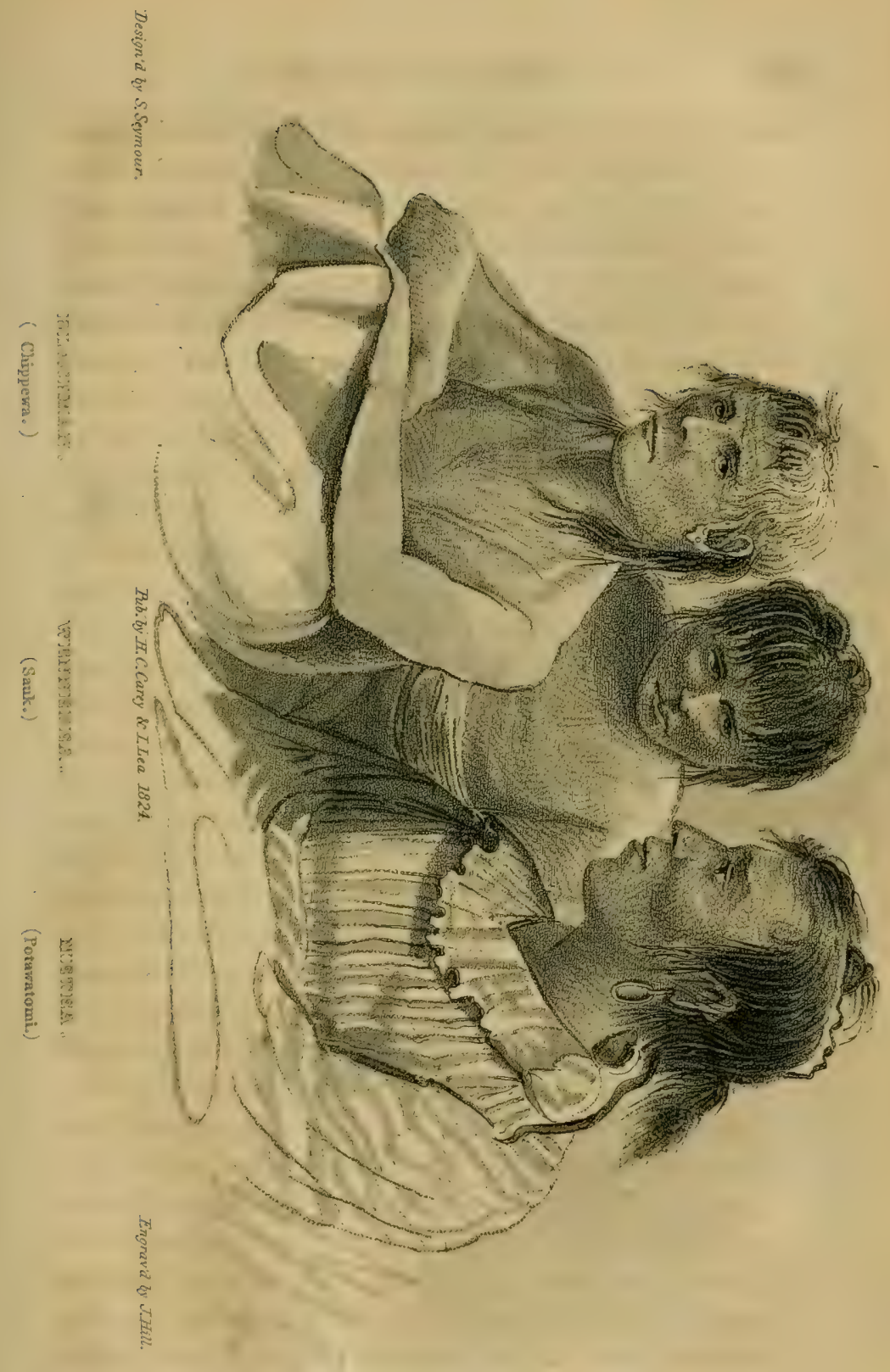




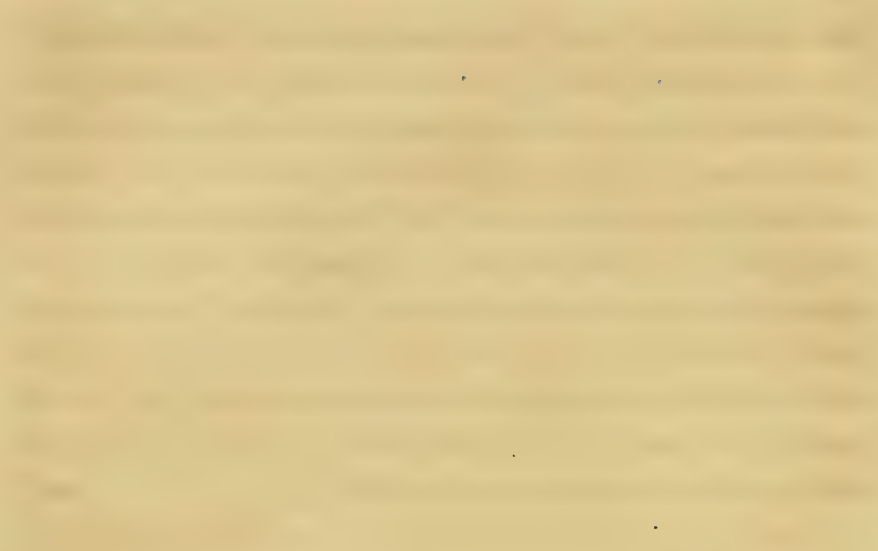

. 
that there were certain points, however, on which he could give no information, without having first obtained the formal consent of his community; that on those subjects he would remain silent, while to all others he would reply with cheerfulness, and that after they should have concluded their inquiries, he would likewise ask them some questions, upon points which he thought concerned his nation, and to which he trusted they would in like manner reply. He then resumed his seat, and answered with much. intelligence, and with a remarkable degree of patience, all the questions which were asked of him.

The Potawatomis, whose name as sounded by them-

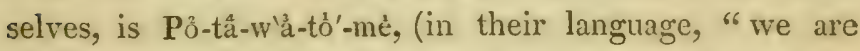
making fire,") appear to be connected not only by language but also by their manners, customs and opinions, with the numerous nations of Algonquin origin. The languages of all these nations bear evident marks of a common origin, and in some cases appear only to be dialects of the same tongue; and although diversities of dress and of dialect distinguish them, their customs and usages are evidently, for the most part, the same. Their traditions as to their origin are very uncertain. They believe that the first meeting between them and the Miamis occurred at a time not very remote.

The Potawatomis resided on the banks of Lake Michigan. Of their first meeting with the Miamis, the following: kradition appears to be fresh in the recollection of all. It is said that a Miami, having wandered out from his cabin, met three Indians whose language was unintelligible to him; by signs and motions he invited them to follow him to his cabin, where they were hospitably entertained, and where they remained until dark. During the night, two of the strange Indians stole from the hut, while their comrade and host were asleep; they took a few embers from 
the cabin, and placing these near the door of the hut, they made a fire which, being afterwardsseen by the Mia$\mathrm{mi}$ and his remaining guest, was understood to imply a council fire in token of peace between the two nations. From this circumstance the Miami called them in his language, W'à-h'ó-nâ-hâ, or the fire-makers, which being translated into the other language, produced the term by which this nation has ever since been distinguished.* All the Indians of this part of the country recognise their alliance with the Delaware Indians, whom they seem to consider as their forefathers, applying to them in councils the appellation of "Grand Fathers," and recognising their right of interfering and of deciding in last resort in all their national concerns. This right extends, however, only so far as to make their approbation necessary to the adoption of any important measure. Should it be withheld, the matter is again referred to the nations for consideration, in their separate councils, and should they persevere in the measure, it would bring on a separation of the alliance, and the nation refusing to submit to the decision of their grandfathers would be considered as strangers. No such instance is, however, recorded, and it is a remarkable trait in the character of all Indian institutions, as far as we have observed, that the principle of the binding influence of the will of the majority is unknown. In all their decisions, unanimity must be obtained, and very seldom fails to be procured. Firmness of purpose and an invincible perseverance in all plans against national enemies, seems with them to be

* This tradition, together with a considerable part of the circumstances which we shall embody in the following pages, was obtained from the Agent's Interpreter, Mr. Joseph Barron, a man whose long residence among the Indians, extensive acquaintance with their character, together with his unimpeachable veracity, confer much ralue upon all the information obtained from him. 
united to a great spirit of conciliation among themselves, and to an indifference as to the final result of any measure which they advocate in their councils. The success of a measure depends altogether upon the personal influence of the man who brings it forward. If he be one whom they deem wise in their generation, or if he be supposed to be gifted with supernatural talents, they will yield to his. suggestions without opposition, if on the contrary he be possessed of but little weight, he meets with no support, and his good sense probably induces him to relinquish his scheme.

When the Miamis first met with the Potawatomis, they applied to them the title of younger brothers; but this was afterwards changed, and their seniority acknowledged, from the circumstance that they resided further to the west; as those nations which reside to the west of others are deemed more ancient. This was settled in a council of the two nations, held some time after their first meeting; the Potawatomis being at present acknowledged and styled elder brothers, and the Miamis younger brothers: but the council fire is always held with the Miamis. By some it is mentioned, that they have no recollection of the Potawatomis having ever assisted at any coun cil fire but one, which was held on the St. Joseph, (of Lake Michigan?) and at which the Chippervas, Potawatomis, and Ottowas were present.*

* This statement is taken from a valuable manuscript of observations concerning the Indians, communicated to the party by Dr. Thomas P. Hall, Surgeon U. S. A. Dr. Hall was stationed at Chicago at the time we visited that post. Iis opportunities of obtaining information were such, as to render his notes valuable, and they are particularly so in the medical parts, from which we have made many extracts. As the observations, which he made, relate principally to the Potawatomis, it has been thought proper to connect them with those made at Fort Wayne. 
'Their notions of religion appear to be of the most simple kind; they believe in the existence of an only God,

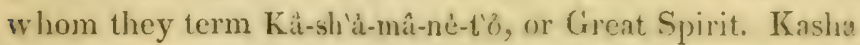
means great, and Maneto an irresistible almighty being. The epithet of Kasha is never applied to any other word, but as connected with the Supreme Being. It would be highly indecorous to apply it to a house, a horse, or any other visible object. Yet it is, in a few instances, applied to a good man, in order to give more force to the expression, by connecting his good qualities with those which they ascribe to the Great Spirit. They recognise also an Evil Spirit, whom they call MAatt-ch'à-mâ-né-t’ỏ, (from matcha, which signifies bad.) This unfavourable epithet is not restricted in its application, but is extended to all unpleasant or disagreeable objects. They consider themselves as indebted to the Good Spirit for the warm winds from the south, while the evil one sends the cold winds and storms of the north. The Matchamaneto resides in the cold regions of the north, where the sun never shines. The Kashamaneto, on the contrary, dwells at the "midday-sun's place." Their worship appears to be principally addressed to the Evil Spirit, whom they think it expedient to propitiate; the good one needing no prayers, for his natural goodness will always induce him to assist. and protect man without being reminded of it by his petitions; neither do they believe that their prayers to the Evi! Spirit can in any manner displease the Good. In certain cases, however, as when afflicted with disease, or whelı impelled to it in a dream, they will offer a sacrifice of living animals to the Kashamaneto. This is generally done at the suggestion of one of the chiefs or leaders, who calls all the warriors together, explains to them his riews, and ap. points one of them to go in search of a buck, to another 
he commits the killing of a raccoon, to a third he allots some other animal to be killed; and when they have been successful in their respective hunts, they meet and fasten the first buck which they kill, upon a high pole, and leave it in this situation, so that it may serve as a sacrifice to the Great Spirit. Any other animal would answer as well as a buck. Upon the remainder of the chase they feast. After having boiled the animal, they partake of it in the name of the Great Spirit. The object of these sacrifices is to obtain luck in their pursuits, whether of hunting or fighting; these feasts are generally accompanied with prayers, dancing, singing, \&c. The only period when they have regular sacrifices is during the winter and spring of the year; at which time, many of the warriors give feasts; each selects the time that suits him best, and invites such guests as he thinks proper. Having assembled them all, he rises, takes a sort of tambourine, formed by fastening a piece of skin or parchment upon a frame, he beats upon this and addresses himself to the divinity, accompanying his invocation by many violent gestures. They have no set form of prayer; when he has concluded, he resumes his seat, hands over the tambourine to another, who proceeds in the same manner. They have regular songs, which they sing together on such occasions. No other music is ever used but that of the tambourine.*

* Among the Shawanese there is a solemn festival called the green corn dance, which resembles the offering of the first fruits as enjoined to the Israelites. This practice is said to exist among the Creeks, Cherokecs, and other southern tribes, but is unknown to the Potawatomis and other nations, which live in the neighbourhood of the Shawanese. It is said, that among the latter, however ripe an individual's corn may be, he will not pluck it until after the celebration of the festival. 
Among the Potawatomis polygamy is not only allowed, but even encouraged; a man has two or more wives, sometimes four, according to his skill and success as a hunter. The number of wives which an Indian keeps, is equal to that which he can support and maintain; he, therefore, that has many, is respected as being a better or a more favoured hunter than he that has but one wife. Dr. IIall observes that polygamy exists in the proportion of twenty-five per cent. that some men have three, four, or five wives, and one man was known to have eight. They appear to be very attentive to the proper education to be given to children, in order to impart to them those qualities both of the mind and body, which shall enable them to endure fatigue and privation, and to obtain an influence, either in the counsels of the nation, or during their military operations. When questioned on this subject, Metea replied, that while he was yet very young, his father began to instruct him, and incessantly, day after day, and night after night, taught him the traditions, the laws and ceremonies of his nation. "This he did," said Metea, "that I might one day benefit my country with my counsel." The education of boys generally commences at ten or twolve years of age; they accustom them early to the endurance of cold, by making: them bathe every morning in winter. They likewise encourage them to habituate themselves to the privation of food. In this manner, children are observed to acquire, more readily, the qualifications which it is desirable for an Indian to possess. Parents use no compulsory means to reduce their children to obedience, but they generally succeed in obtaining a powerful infiuence over them, by acting upon their fears; they tell them that if they do not behave themselves as they are bid, that they will irritate the Great Spirit, who will deprive them of all luck as hunters, and as war- 
riors. This, together with the constant and never ccasing importance, which the children observe, that their parents attribute to luck in all their pursuits, is found to have the desired effect upon the minds of young persons, fired with the ambition of becoming distinguished, at some future day, by their skill and success. Their fasts are marked by the ceremony of smearing their faces, hands, \&c. with charcoal. To effect this, they take a piece of wood of the length of the finger, and suspend it to their necks, they char one end of it, and rub themselves with the coal every morning, keeping it on until after sunset. No person, whose face is blackened, dare eat or drink any thing during that time; whatever may be the cravings of his appetite, he must restrict them until the evening arrives, when he may wash off his black paint, and indulge, moderately, in the use of food. The next morning he repeats the ceremony of blackening his face, and continues it from day to day, until the whole of his piece of woud be cunsumed, which generally takes place in the course of from ten to twelve days.

After this term, they either suspend their mortifications, or continue them according as the exigencies of the case seem to require. From the information which was communicated by the interpreter and others, it does not appear that, in any one instance, have the Indians ever been known to break their fasts, whatever may have been the temptation to which they were exposed; so powerful, indeed, is their superstitious dread of that ill luck, which would attach to a transgression of their rules, that even children have been, in vain, tempted to take food when at the houses of traders, and beyond the control of their parents; in all cases they have declined it; neither does it appear that, during. those seasons of mortification, they indulge after sunset, in any unreasonable gratification of the i: Vor. I. 
appetite; in this respect, therefore, they prove themselves more consistent than the Mahometans, who are said while their Ramadan or lent lasts, to make up by the debaucheries in which they indulge in the night time, for the painful restrictions imposed upon them during the day, by the precepts of their prophet. The same apprehensions which will prevent an Indian, whether man or boy, from tasting food, while covered with his coating of charcoal, ivill not allow him to shorten the term of his penance by consuming the piece of wood too hastily. If he does not use it sparingly, he is certain that the charm or virtue with which he invests it, will be dispelled. In addition to these mortifications, the Indian attempts to impress upon his offspring a permanent and unshaken belief in the existence of a Great Spirit, ruler of the universe, whose attributes are kindness to men, and a desire of relieving them from all their afflictions: the necessity of doing all that may be grateful to him is often recurred to, in those exhortations by which every Indian parent instructs his sons, both morning and evening. It does not appear that the same care is extended to the religious principles of females. We never heard of their joining in fasts or mortifications; they are not allowed to take a part in the public sacrifices, and as they have no concern in the noble occupations of war or the chase, it probably matters but little whether or not they are agreeable in the sight of the Great Spirit. The only inducement which they have to pray is, that they may continue to hold a place in the affections of their husbands; but, as upon this point the men are quite indifferent, it would appear to them unworthy of their superior rank in creation, if they were to bestow a thought upon the subject.

Among the men of their own tribe, these Indians are refresented as indulging in many of the rirtues which have 
long been considered as peculiar to man in a state of eivilization. Children incapacitated from labour, or exertion. by accident or deformity, are carefully attended to, and seldom allowed to suffer, from a privation of any of the comforts which the rest of the tribe enjoy. It is considered disgraceful in a man, to inflict any injury upon a helpless or unprotected person. In a few instances, it is said, that children born deformed have been clestroyed by their mothers, but these instances are rare, and whenever discovered, uniformly bring them into disrepute, and are not unfrequently punished by some of the near relations. Independent of these cases, which are but rare, a few instances of infanticide, by single women, in order to conceal intrigue, have been heard of; but they are always treated with abhorrence. In like manner when going out on hunting excursions, elderly parents have been known to be abandoned, or exposed to a certain death, but these were likewise rare cases, which may be considered as always carrying with them a severe punishment by the utter contempt and detestation in which those who committed them were held. When questioned upon this point, Metea denied that it had ever happened; "as they have taken pains to raise us when we were young," said he, "it is but fair that we should return this care to them in their old age." Instances have however occurred even among the Potawatomis; one of which took place on the Milwacke, when a decrepid old woman, who had no horse to remove her from that place, was burned by them. In painful and violent diseases, Indians are sometimes killed at their own request, and afterwards burned to prevent contagion or the disease falling upon another. Their attentions to old persons, and their respect towards them, may be considered as one of the virtues in which they pride themselves most. 
and one of those which they exercise most frequently. To ideots they likewise generally extend a kind and humane treatment. By their relations, ideots are always treated with tenderness; but the idle and foolish, who are not connected with them, though they nerer abuse, will somefimes ridicule them; in this respect imitating the treatment to which they are so inhumanly, yet so frequently exposed, from the unthinking, even among civilized nations. There are some persons among them who think that ideots are possessed of more intellect than they make show of, and who believe them to be endowed with much intelligence, but by none are they held in the light of sorcerers. The same opinion is likewise entertained of insane persons, who are supposed by some to hold converse with the Deity; this opinion is not, however, universally adopted. Care is taken in the physical education of the Potawatomi from his earliest age, that his body should be straight and wellformed, no attempt is however made to change the shape of the head; the observations which have been made on this subject by various travellers, apply only to certain nations, one of which is designated by the term of Flat-heads, and it is highly incorrect to consider them as general. The shape of the head is one of the features which assists most in the discrimination of the various tribes. It is at least as easy for a person well acquainted with the Indians, to distinguish between the different nations, as it is among white men to observe differences between the various races that inhabit Europe; to an Indian this is even easier, as his long habits of scrutiny have made him quick at noticing differences which would escape the attention of less practised observers. "We know every tribe at first sight," said Little Turtle, "the shape, colour, legs, knees, and feet, are all to us certain marks of distinction." 
If in the intercourse of the Potawatomi with men of his own tribe, we observe many of the virtues and finer feelings which adorn mankind in all situations, we have, unfortunately, cause to regret that in his conduct towards other nations he appears under very disadvantageous colours. To a stranger, if he be not an enemy, it is true that he will extend the most unrestricted hospitality; his principles as well as his habits of life prevent his greeting him, or joining him in conversation; but all that the most liberal spirit can do, to secure to him a friendly and fraternal reception, is cordially done. In all his actions, words, and motions, the stranger must however take heed lest he reveal himself to be an enemy; for in that case, not the bread that they have been breaking together, nor the tobacco of which they have both smoked, nor the sacred laws of hospitality, could protect the guest from the sacrifice which the Potawatomi considers as enjoined upon him by the paramount obligation of destroying his enemy, or that of his nation, wherever he may meet with him. Their feeling of hatred and resentment against all nations with which. they are at war, has led them to deeds, from the recital of which we shrink in disgust. Among these there is none more horrible, and on the subject of which so much difference of opinion has existed, as that of cannibalism, ascribed to them by numerous travellers. We find it asserted, in plain terms, by some of the oldest writers upon America; * but it has been brought into question by many,

* The fact which we advance here of the cannibalism of the Pota. watomis, is not new as regards the North American Indians, though some travellers may have asserted it not to exist among them.

"I think," says Hennepin, "that the Neros and Maximians of old never invented greater cruelties to test the patience of martyrs, than the torments to which the Iroquois expose their cnemies. And 
who, having never visited the Indians, have been infuenced by a laudable incredulity, springing doubtless from a justifiable wish to close their eyes and ears against evidence which bears so hardly upon human nature. With these feelings the gentlemen of the expedition first heard the reports of the anthropophagy of the Potawatomi, and yiclded but an unwilling ear to every thing that could induce a belief in the existence of this disgusting trait in the character of the north-ivest Indians. Truth compels them however to assert, that the reports which they have received on this subject were so frequent, so circumstantial,

when we saw that their children were cutting slices of fiesh from the slave whom their parents had murdered with the most unheard of cruelties, and that these young anthropophagi were enting the flesh of this man in our own presence, we withdrew from the hut of the chief, and we would eat with them no longer, and we retraced our steps through forests to Niagara river." (page 40,) and again, in page 304.

"In this confusion it was not difficult for the Iroquois, united with the Miamis, to carry away about eight hundred slares, both women and young men. These anthropophagi eat immediately sereral old men of the lllinois nation, and burned a few others who had not strength enough to follow them to the country of the Iroquois, more than four hundred leagues distant." He however makes an exception in favour of the Nadiousioux, (Sioux?) whom he asserts, "not to be su inhuman, and not to partake of human flesh." (Page 68. Description de la Louisianne, \&c. \&c. par le R. P. Louis Hennepin, \&c. Paris. 1683. 12mo.)

Fven Adair, who may be considered as the great skeptic on this subject, in the same page in which he rejects the charge as a false one, states that he could not learn "that they had eaten liuman flesh, only the heart of the enemy, which they all do sympathetically, (blood for blood, in order to inspire them with courage." *** "To eat the heart of an enemy will, in their opinion, like eating other things before mentioned, communicate and give greater heart against the cnemy," \&c. Page 135. Ilistory of the American Indians, by James Adair, Esq. London, 1774. 4to. 
and derived from such respectable sources, that any conccalment of it, or any apparent incredulity on their part, would be a dereliction of duty. Even the most incredulous of the party, or those disposed to entertain the most favourable opinion of the Indians, were at last compelled to acknowledge that all doubt on the subject had been removed from their minds. They have been asked, whether they had ever been present at such a feast, and they have heard it asserted by respectable persons, that nothing but the autoptical observation of the travellers could induce them to place any credit in this imputed cannibalism; to this it may be replied that, travelling as they did, at a time when the Indians were comparatively in a state of peace, when few and but accidental hostilities had occurred between them, and these always at a distance from the route which they pursued; it could not be expected that they should have been themselves eye witnesses to these infamous orgies. But if it can be adduced in support. of their assertion, that the fact has been acknowledged by the Indians themselves, by those that had perpetrated the deed, that it has been uniformly admitted by the interpreters and traders who have long resided among them, who are connected to them by intermixtures, who are themselves partly Indians, and who declare having been present at the time it took place; if the names of the individuals who became victims to it, can be mentioned, if the additional circumstance of its having been observed at several thousands of miles distance, but among those Indians who are known to be of the same nation, and who speak dialects of the same language be taken into consideration, if these facts should be corroborated by names expressive of this custom, given to certain localitics by the Indians them- 
selves, and if all these should be found to concur with the observations recorded in the histories of the first travellers in America, (who, whatever may have been their errors, must be considered as having adhered more closely to truth than is generally supposed,) then with all this circumstantial evidence, strongly and uniformly bearing on one side of the question, is it possible for the most skeptical to refuse his belief to this fact, whatever may be the horrour which attends it. We are far however from asserting, that this practice has prevailed universally among the Indians; the evidences on the subject of the cannibalism of the Dacota or Sioux Indians, (Naudowessies of Carver,) are too few and too suspicious; they are refuted by too many contradictory facts to permit us to place any confidence in them; but the case is otherwise with the Chippewas, the Miamis, the Potawatomis, and all the other Indian nations which are known to be of Algonquin origin.

The motives which impel them to cannibalism are various: in some cases it is produced by a famine over the country, and of this we shall be able to cite a number of well attested instances, some of which carry with them very horrible features, when we treat of the Chippewa tribes west of Lake Superior. Another, and a more frequent cause, is the desire of venting their rage upon a defeated enemy, or a belief that by so doing, they acquire a charm that will make them irresistible. It is a common superstition with them, that he that tastes of the body of a brave man acquires a part of his valour, and that if he can eat of his heart, which by them is considered as the seat of all courage, the share of bravery which he derives from it is still greater. It matters not whether the foe be a white man or an Indian, provided he be an enemy, it is all that is re- 
quired. Mr. Barron has seen the Potawatomis, with the hands and limbs, both of white men and Cherokees, which they were about to devour.

It is well attested, that one of the officers, attached to Greneral Harmer's eommand, was taken prisoner by the Miamis, previously to the defeat of the whole army, and tortured by them in the most cruel and unrelenting manner for three days, on the west bank of the Maumee. The Indians declared that he had behaved with a remarkable degree of fortitude. Pieces of flesh were cut from his body, roasted and eaten by them in the presence of the agonized victim. No exclamation or groan could be drawn from the intrepid prisoner, until a squaw thrust a burning brand into his privates, when he was heard to exclaim, "Oh my God!" A young Indian warrior then declared, that the prisoner having proved himself a brave man, should no longer be kept in agony, and put a period to his sufferings by despatching him with his tomahawk.

One of the best attested instances, is that of Captain Wells, who was killed after the capture of Chicago in 1812. This man, who had been a long time among the Indians, having been taken prisoner by them at the age of thirteen, had acquired a great reputation for courage; and his name is still mentioned as the bravest white man with whom they ever met. He had almost become one of their number, and had united himself to a descendant of Little Turtle. At the commencement of hostilities between Britain and the United States he sided with his own countrymen, while the Indians of this vicinity all passed into the British service. When the fort was afterwards besieged by the united Indians, Captain Wells was there, having arrived two days prior with the orders from General Hull for the evacuation of the post. Wells was killed after the action, his body VoL. I. 
was divided, and his heart was shared, as being the most: certain spell for courage, and part of it was sent to the various tribes in alliance with the Potawatomis, while they themselves feasted upon the rest.

Among some tribes, cannibalism is universal, but it appears that among the Potawatomis it is generally restricted to a society or fraternity, whose privilege and duty it is on all occasions to eat of the enemy's flesh; at least one individual must be eaten. The flesh is sometimes dried and taken to the village. Not only are the members of this fraternity endowed with great virtues, but they can impart them by means of spells to any individual whom they wish to favour. No warrior can be elected into the association, except by the unanimous consent of all its members. In such a case, the candidate for this distinction, which is held in great esteem, makes a fine present to the society. We shall have an opportunity of recurring on some future occasion to this subject, and we shall be enabled to prove the participation in this nefarious practice, of many Indian tribes collected together on a memorable occasion, at the siege of Fort Meigs, in 1813. We do not wish to be considered as advancing the doctrine that human flesh is usually, or as a matter of preference, eaten by these Indians, or by any others with whom we may have met, but that it has been eaten on many occasions under the most aggravating circumstances, and without the least shadow of necessity, we consider as fully established.

Of their first origin, their ideas appear to be very confused. 'They all consider the earth as their mother, and some of them are impressed with the belief that they formerly resided under ground, and that they rose out from it. On this subject Mr. Keating held a conversation of better than an hour with Richarville, one of the principal chiefs of the Miamis, who 
gave him a long but confused account of the division which exists among the Miamis, into two tribes, one of which considers itself as having risen from the waters, and the other from the centre of the earth. Those of Neptunian origin, made their vay as is believed, to the surface, by climbing up trees, \&c. The man who gave this account is a half-breed Miami, his father being a Frenchman; he speaks very good French. At the time we saw him, he: was dressed like a trader, and from his appearance, manners and language, we should never have suspected him to be any other than a Canadian fur-dealer. He is said, howcver, to possess considerable influence with his tribe. He sometimes assumes the Indian costume, with the exception of the blanket, for which he always substitutes a capote. In the conversation which we had with him, we had reason to consider him as well entitled to the reputation which he has acquired, of being one of the most artful and deceitful of his nation. He declined meeting the party in conference, stating that the other chiefs of his tribe were absent, and that the circumstance of his holding a conference with white men might expose him to suspicion, which would the more readily attach to him on account of his being himself but a half-breed. This reason was too plausible to allow of our objecting to it; and we regretted that we could not test the sincerity of his offer, to answer all our questions, in a few days, when the other men of his nation would have arrived. The gentleman of the party who conversed with him, noticed that he had never met with a man whose manners evinced so much cunning and subtilty as those of this chief. Affecting not to understand questions to which he did not choose to reply, and involving all his answers in obscurity, he imparted no information concerning the points upon which he was questioned, except in the instance 
already alluded to, of the division of the Miamis into two tribes, whose origins are supposed to be so different. This might be considered as very interesting, if any confidence could be placed in such a man as Richarville. Of his craft and worthlessness, an idea can be formed from the circumstance that, when negotiating on the part of the Miamis a treaty with the commissioners at Chicago, he made it an indispensable condition that a tract of nine sections of land should be secured to him in fee simple, while the rest of his nation are merely joint tenants on their lands, and destitute of the privilege of disposing of the same, except with the consent of the Government of the United States. It must be regretted, that this mode of obtaining the assent of chiefs, to a treaty by private presents, grants, \&c. should have crer been allowed. It was, we believe, first introduced by the French, whose object was, by these pretended treaties, to which the chicfs of the nations were bribed to give their consent, to obtain a colour of right which the French government could afterwards maintain against European nations. This practice has existed so long, and is so universal, that it would perhaps be difficult to make a treaty with the Indians, if presents or grants were withheld from the chiefs; but in order to test the correctness of the principle, we need but look to the feelings which would be excited if an European power, while discussing the terms of a treaty with our government, were to offer or to consent to give any private presents to the negotiators on the part of our country. Richarville retains his attachment to the British government, and although residing upon our territory, and sharing in the annuity paid by the United States to the Miamis, he still holds a commission in the British service, and his name still appears on the half-pay or pension list of Great Britain.

Metea told us that the Potawatomis thought that they 
had always existed in the neighbourhood of Lake Michigan. That the first man and woman had been made by the Great Spirit. God sowed the seed and the men sprung up. When called upon to explain what he meant by this, he gave to understand that he had used the language in a figurative point of view, and as a parable. Their tradition at first mentioned but one original couple, the parents of the red people, from whom they believed themselves to have descended. But when they became acquainted with the different races of men, they supposed a couple of white, and another of black, had likewise been created by the Great Spirit, and that these had given rise to the white and black people whom they had since secn, but he had not troubled himself much with thinking on this subject. Soon after the white men came among them, they were told that, far to the setting sun, there was a race of people whose features and complexion resembled theirs. This had led them to thiink upon and discuss this matter frequently among themselves; they had often enquired from other nations whence they came, but they found strong reasons to adhere to their old traditions, that the land on which they now resided was that upon which the Great Spirit had first placed them. Metea has always been of the opinion that there is but one Grod, who is a Supreme Being, but that he has made a Spirit or God to be under him, whose special duty it is to take charge of the Indians. This he thought to be the common opinion of all Indians whom he knew. This inferior Deity stood to the Supreme Being in the same relation that the red man stands to the white. The existence of a Bad Spirit is considered as proved by the circumstance of there being lad men, for a Good Spirit could not have made any thing that was evil.

When questioned as to his opinion of a future life, and 
the immortality of the soul, he unhesitatingly replied that he had heard the white men talk of those things, but hact no belief whatever in them. He thought that after death both body and spirit decayed and disappeared; nor would he at all acknowledge a belief in the doctrine which we had heard asserted by the interpreter; as generally entertained by the Indians, that the spirits of the departed refurned after death to the Master of Life. In replying to this question he made use of a strong expression, " as a dog dies, so man dies-the dog rots after death, so does man decay after he has ceased to live." Being asked if it was true that they placed provisions near the dead, both at the time of death and afterwards, and if true, wherefore this was done, if both spirit and body decayed together? He replied, that this custom really prevailed, but he knew of no other foundation for it, than a dream of one of their ancestors, that a departed friend had appeared to him, and told him he was hungry, which induced him to take provisions to the grave of that man-he knew of no other cause for it. We felt some anxiety to obtain a more satisfactory answer from Metea on this point, as we knew that at the funeral of a nephew of his, he had once expressed himself thus in the presence of Mrs. Hackley, who repeated it to Major Long. "His spirit has ficd upon a long journey, and you must give him provisions that he may feed upon during his journey." Although all our attempts at obtaining a different answer from Metea proved abortive, we incline to the opinion that the doctrine of the immortality of

"Mrs. Hackley is the danghter of the late Captain Wells, by a Miami squaw, who was either the daughter or adopted child of Little Turtle. Ilaving received her education among white men, she unites to the manners of civilized life, many of the interesting peculiarities whicli distinguish makind in its primitive state. 
the soul, and of a future state of reward and punishment, is generally entertained by them, and that it probably preexisted to their intercourse with white men. Our opinion does not merely rest upon the general prevalence of this belief among all those who have made the least advance above the lowest state of barbarism, but upon the uniform opinion on this subject, expressed to us by those who were most conversant with Indian manners, and who had enjoyed the best opportunities of becoming acquainted with them. From Mr. Barron we heard that they generally admitted the existence of a future life, of which, however, they entertained very confused ideas, believing for the most part that the spirits of those who had lived a good life, went to a country where they could pursue without fatigue their favourite occupation of hunting, where animals would be plenty and fat. Not so with the spirits of the bad; theirs would be a country barren and nearly destitute of animals, where the chase would become a painful and unprofitable occupation. At any rate, they hold that their cxistence is at the disposal of the Great Master of Life. Many, however, when asked where their spirits went after death, carelessly replied that they knew not what became of them, they saw them not leaving the body. One of the strongest facts in corroboration of their entertaining a belief in futurity, and the immortality of the soul or spirit, is, that they all believe in ghosts or phantoms. "Once," said Mr. Barron, "on approaching in the night a village of Ottawas, I found all the inhabitants in confusion; they were all busily engaged in raising noises of the loudest and most inharmonious kind. Upon inquiry, I found that a battle had been lately fought between the Ottawas and the Kickapoos, and that the object of all this noise was to prevent the ghosts of the departed combatants from entering the village." 
It is impossible in secing them at present, not to fecl convinced that the time for correct information has passed away; they have imbibed from the missionaries so many notions which certainly did not belong to them originally, and the crafty policy of their chicfs to counteract the effect of their intercourse with white men, has raised so many idle and false traditions, that it is difficult to distinguish the genuine from the false doctrines attributcd to these nations in their original state. Of the many interesting customs, which, according to their traditions, were formerly prevalent among them, the derelietion of none is more to be regretted than of that which accompanied their marriage ceremony. This has now nearly disappeared from the face of the country. Their intermarriages with other nations have become so frequent, and the demoralizing tendency of their intercourse with the traders has been so great, that it has led them to neglect practices which were recommended to them by a venerable antiquity.

The form of courtship which existed formerly, is stated to have been as follows; when a young man had conceived an attachment for a female, or that he wished to make her his wife, he gave the first intimation of his design, by throwing a cleer into the lodge belonging to the girl's parent. This he would repeat for several days, from ten to fifteen, after which the father usually asked him what object he had in doing so, and whether it was to obtain his daughter. The young man having replied in the affirmative, the relations of the girl would, if they approved of the connexion, prepare a dress for the youth, which they would take to his house, and there the damsel's father would invest him with it. He would then take him home with him and introduce him to the bride; there the lover remained for the space of ten or twelve days, until his 
friends had prepared the presents they intended for his wife's family, and had taken them to their house. It was usual for the young couple to dwell with the wife's parents for the term of a year, during which time the hushand was, as it were, a servant in the family, giving to his father-in-law all the produce of his hunt. At the expiration of this term, he was at liberty to remove his wife to his own house, and treat her as he pleased. The opinion which is entertained by the Missouri Indians, and by all those who reside along the banks of the Mississippi, that it would be the height of indecorum in a man to speak, or even to look upon his son-in-law, does not exist at present, and is believed never to have prevailed among the Potawatomis. The power of the husband over his wife was unlimited, he might even put her to death if he chose, and she had lost all claim to the sympathy and protection of her own relations. They never would resent any treatment which she had been made to endure. There was no fixed time for marrying; girls were sometimes betrothed at a very early age, long before maturity. The presents which it was customary to make, were of the most valuable kind, and consisted of horses, venison, guns, \&c. In some instances it happened that the partics were mutually attached, and that they contracted a secret engagement, marrying without the consent of their parents. But these breaches of ceremony were usually made up, by the interchange of presents between the parents on both sides, who then confirmed the marriage.

It was usual for them, when an Indian married one of several sisters, to consider him as wedded to all; and it became incumbent upon him to take them all as wives. The marrying of a brother's widow was not interdicted, kut was always looked upon as a very improper connexion.

Vor. I. 
'l'he union of persons related by blood was likewise dis. liked, and discouraged. An incestuous connexion was at all times considered as highly criminal, but no punishment was attached to it. Instances of it are not, however, as rare as might be expected. Among the Potawatomis wc: heard of several. We were told at Chicago of two cases, which were accompanied by circumstances of an aggravating nature. A Potawatomi of the name of W'al-git-kétnâ-gứn, died a short time since, aged about fifty; he had married his mother-in-law, previous to which he had been connected with two of his daughters. He denied the connexion with his elder daughter, who, however, acknowledged that he had seduced her, by promising to teach her a spell by which she would be enablerl to destroy her enemies, by writing their names on sand. A fetw months afterwards, he was detected in an intercourse with his second daughter, whom he had likewise seduced. Both the women openly confessed their guilt, but with very little appearance of shame. This did not prevent their marrying subsequent1y. After these abominable transactions, he married their grandmother, who was the mother of his first wife. Another man belonging to the same nation, and who had become a chicf by the death of his brother, is known to have had intercourse with a woman that was the mother of his first wife. He afterwards deserted both, and took a third wife. The two other women, both mother and daughter, were subsequently married; this man's name was Ö-zàn-o̊'-t’âp, ( Yellow-head.) Butall these connexions are held in utter abhorrence by the nation at large, and those who contract them are considered as base and worthless members of the community.

The circumstances which attend funerals are likewise worthy of notice. They have, it is true, but few ceremo- 
nies at the time of the removal of the corpse ; but the manner in which this duty is performed deserves mention. The greatest pains are taken that all should be transacted in the most decorous manner; the spot selected is always as dry as the circumstances of the place will admit of. The body of the deceased is clothed in his best garments, and, if the relations can afford it, new clothes are obtained for this purpose. His moceassins, rifle, knife, money, silver ornaments, in fine, the whole of his property are placed near him: the corpse is laid with its face turned to the east. A small quantity of food is placed near the head. The funeral is generally attended by all the relations, who express their grief by weeping; but yells, dances, \&c. are not customary on such occasions. The deceased is buried in an erect, seated, or inclined posture, according to the wishes and directions which he may have given previously to his death, for these are always most implicitly obeyed. The graves in which they are buried are generally from four to five feet in deptl. If the deccased had previously to his death expressed a wish to be deposited in a tree, this is attended to; otherwise the corpse is always interred. When the corpse is to be deposited in a tree, it is first sowed up in a blanket, and this is suspended to the branches. The friends of the deceased visit it frequently, until they observe that the body is decaying; they then shake hands with it, and bid it a last farewell; but even after this they return yearly to visit the spot where it is deposited, and they uniformly leave some food near it. At the time of the funeral, they frequently light a fire near the head of the grave, and upon this they prepare their feast, throwing a part of the food on the grave for the use of their friend. If they have whiskey, they likewise scatter some gn the ground, but of this they are sparing, doubtless from 
the belief that the living require it much more than the dead. An inrocation is then made to the deceased, who is entreated to speed his course direct to the Great Prairic, without easting his eyes back; for they hold, that if on his way to the land of Spirits, he were to look behind him, it would bring ill luck upon some one of his relations, to whom it would be a signal, that his company was required by his departed friend. It is usual to mark the grave with a post, on which are inscribed in hieroglyphics the deeds of the deceased, whether in the way of hunting or of fighting. It is not uncommon for the survivors to adopt a male or female child as a substiute for their lost relative. When they bury a corpse in a trough hollowed out of a tree, they prefer one of ash wood, as they observe that it is less casily penetrated by water.

We are informed, that they profess to have been well acquainted with the art of making maple sugar previous to their intercourse with the whites. Our interpreter states, that having once expressed his doubts on the subject in the presence of José Renard, a Kickapoo chief, the latter answered him immediately, with a smile, "can it be that thou art so simple as to ask me such a question, seeing that the Master of Life has imparted to us an instinct which enables us to substitute stone hatchets and knives for those made of steel by the whites; wherefore should we not have linown as well as they how to manufacture sugar? He has made us all, that we should enjoy life; he has placed before us all the requisites for the support of existence, food, water, firc, trees \&c.; wherefore then should he have withheld from us the art of excarating the trees in order to make troughs of them, of placing the sap in these, of heating the stones and throwing them into the sap so as to cause it to boil, and by this means reducing it into 
sugar." In this short reply of the Kiclsapoo, we have a brief sketch of the rude process practised by the Indians in the preparation of the maple sugar. Previously to this they had learned the art of making and using pottery, but had abandoned it for the purpose, as Metea told us, of using wooden troughs, and hot stones, perhaps because their pottery did not stand fire well. The evaporation resulting from the action of the hot stones, produced a crystallization of sugar in the trough. Their process was a tedious and imperfect one, which probably required much time before it could be improved; to use the language of Nacoma, a Delaware, "Brother, there is a great difference between the white man and the Indian; we believe that we are not endowed with the same natural advantages which you possess, since we discover those things alone which nature places before us; we derive advantage of such tools and implements as she has provided for us, only so far as they appear to us useful, but without any attempt to inquire into their nature; you, on the contrary, have reeeived from the Master of Life, the disposition to erect to yourselves a system of education that enables you to treasure up the knowledge which you may have acquired, to endeavour to prosecute your discoveries, to make new applications of them, and to dive into those things with which you are unacquainted." We shall have an opportunity of comparing these ideas of the Delaware chief with the reflexions made by a Sauk Indian, who attended the expedition as a guide, and we shall be confirmed in the belief that, with all their apparent contempt for the whites, the Indians are frequently obliged to acknowledge the superiority of the civilized man, which however they improperly consider as the cause, and not as the effect of civilization.

The use of salt previously to the arrival of Europeans is 
likewise claimed by the Indians. They trace the origin of their acquaintance with this valuable condiment, to the observation of the preference given by elks to the water from salt licks; having tasted it, they liked it, and took some to boil their vegetables with, and having found it palatable, they boiled down the water in the manner that they had done the sap, and thus obtained salt. It is not improbable, that the sediments of white salt, which are frequently observed during dry seasons, in the vicinity of salt springs, may have taught them that it was by evaporation that the substance could be separated from the water which holds it in solution; for although the Indians were totally ignorant of the nature and causes of evaporation, they had noticed the process, and were aware, that it could result as well from the action of fire as from that of the sun.

Prior to their intercourse with white men, it appears that these Indians were not acquainted with any intoxicating liquors; if we except a decoction of a plant resembling the whortleberry, which was used by the Chippewas in cases of sickness only; it produced rertigo. As this fact was ascertained by Dr. Hall at Chicago, where the Chippewas and Potarvatomis frequently meet, it is not improbable that the latter were also acquainted with it, but it was never used except in cases of sickness. To the Europeans they are therefore indebted for all the evils which have attended too free a use of spirituous liquors.

The Potawatomis are not divided into tribes, designated by the name of animals, as is reported to be the case with the Missouri Indians, but they are distinguished merely from their local habitations. Those that live on the St. Joseph form a small tribe, in every respect similar to those residing near Chicago, or near Lake Michigan. Although not divided into regular tribes, they hare a sort $n !$ 
family distinction, kept up by means of signs resembling those of heraldry. These signs are by them called 'I'ó-te's' $\mathbf{m}$; they are taken from an animal or from some part of it, but by no means imply a supposed relationship with that animal, as has been incorrectly stated. It is merely a distinguishing mark or badge, which appears to belong to every member of a family, whether male or female. The latter retain it even after matrimony, and do not assume that of their husbands. It does not appear that this implies the least obligation of the Indian, to the animal from which it is taken. He may kill it or eat it. The totem appears to answer no other purpose than that of distinguishing families; it does not imply any degree of nobility or inequality of rank among: them. It is the same custom, which is improperly attributed by Carver to the Dacota or Sioux Indians, (Naudowessie.)

Independently of the name which he bears, and of the totem or badge of family to which he lays claim, an Indian has frequently a kind spirit to watch over him and 2ssist him. This tutelar saint is of course held in high veneration, and nothing is done that could in the least offend him. The mode in which each Indian becomes acquainted with the name or nature of this ministering spirit, is by dreams, in which he fancies that the Master of Life reveals himself to him in his sleep, under the form of some tangible object in creation, generally of an animal; under this shape the Great Spirit holds converse with him, and the Indian ever after supposes that this is the form in which he may expect to see the Great Spirit appear to him. To this animal, whom he considers as a medium of communication between him and the Master of Life, he addresses his prayers and states his wants; he consults it in all his difficulties, and not unfrequently ennecives that 
the has derived relief from it. Of course, he alstains from eating of the animal, and would rather starve than sacrilegriously feed upon his idol. But he holds the animal as a friend to himself alone. He knows that others have differcut spirits, and hence does not think himself bound to protect that animal against his companions, because he knows that there is no virtue in the animal for any one but himsclf. Sometimes, instead of the whole animal, it is only in some part of it that the charm resides, and in this case he will feel no hesitation in eating of all the other parts of the beast.

In their conversation, the Indians frequently display ronsiderable humour. Their attempts at wit are numerous, and often successful; but their wit as well as the general tenour of their conversation, is obscene; in proof of this, we might, if it were necessary, mention several instances; but they have been so frequently noticed by the travellers that have preceded us, that we feel ourselves excused from doing it. As an instance of an attempt at what they consider as wit, the following was related to us; an Indian called for milk; when they were about to give him some, he pointed to a whiskey bottle, and observed that it was the milk of that black cow, that he wanted. Such an observation is sure to draw peals of laughter from all about them, which encourages them to proceed. But perhaps, the most remarkable trait in their conversation is, that they feel none of that delicacy or restraint, which among civilized nations has proscribed many words from general use. With them every idea which enters into their head, or every word which they think of, is uttered without any respect for the company present. With this apparent obscenity in their conversation, the Indians are very guarded in their actions, and their manners indicate 
a considerable degree of native modesty. In this they generally excel the white men who live with them; and it is a fact, well attested by the experience of all who have spent any time among them, that they are seldom or never observed in an obscene or indecorous attitude.

Metea was asked, whether he had ever heard of any tradition accounting for the formation of those artificial mounds, which are found scattered over the whole country; when he immediately replied, that they had been constructed by the Indians as fortifications, before white men had come among them. "After men had been made," said he, " they scattered themselves over the surface of the earth, and lost all knowledge of each other. When they afterwards met, it was with fear and caution; they were engaged in wars, during which they erected these works, which served for defence, until treaties and alliances were made between them." He has always heard this origin ascribed to them, and has linown three of those constructions which are supposed to have been made by his nation. One is at the fork of the Kankakee and the Des Plaines rivers, a sccond on the Ohio, which, from his description, was supposed to be at the mouth of the Muskingum; he visited it, but could not describe the spot very accurately; and a third, which he had also seen, he states to be on the head waters of the St. Joseph of Lake Michigan. This latter is at about forty miles north-west of Fort Wayne, and five or six. miles distant from an Indian village called Mangokiva, on a small stream which empties into the St. Joseph; it is a round hill about as large as Fort Wayne. Major Long, who has seen those on the St. Joseph and at the mouth of the Kankakee, on a former visit to this country, considers them as natural, and not artificial elevations. One of the Miami chiefs whom the traders have named Legros, once told Barron that he had heard that his father had fought Vor. I. 
with his tribe in one of the forts at Piqua; that the fort had been erected by the Indians against the French, and that his father had been killed during one of the assaults made upon it by the French.

The chiefdom is hereditary among the Potawatomis. If a chief should be destitute of male heirs, sons or nephews, he assembles the warriors of his tribe, and appoints one of them as his successor. Should he die without leaving any male heir, and without having adopted any, then the warriors convene and appoint one of their number to succeed to the vacant dignity; "for a nation cannot exist" says Metea "without a leader." In their councils no regular debate takes place. The first man who is nominated as chief, generally unites all votes; it is evident that much must depend upon the influence of him who nominates a candidate. It is, however, usual to ascertain the wish of the people beforehand, and for this reason they are always consulted.

In like manner, if a man be desirous of leading a warparty, he mentions it to others, secures their assistance, and then publicly announces his intention in the village, when such as please follow him. Previous to his departure, he performs his religious ceremonies, and prepares what is termed his "medicine" or spell, by which he hopes to insure success. If the chief of the village be opposed to the scheme, he undertakes to prevent it, by influencing their superstitious fears. To this effect, he counteracts, as they suppose, the spells prepared by the warrior, by walking round him in a circle, and then resuming his place. This they so firmly believe to vitiate the medicine, that it immediately puts a stop to the expelition. The power of the chief appears to rest exclusively upon his personal influence. He can use no cocrcive measures to obtain what he wishes, or prevent what he dis- 
likes. Although the Indians have notions of right and wrong, they have no means of rewarding the former and redressing the latter; the chief cannot punish a man for any offence whatsoever. If the crime committed be flagrant, the party that deems itself injured may seek for redress in a forcible manner, but there is no mode of obtaining it by fair and legal means. In some cases, however, a breach of faith may be punished; if, for instance, a chief wishes to undertake a military operation, he convenes his warriors, and states his views; should they agree to it, they declare their assent by presenting him with a string of wampum, which is kept as an evidence of their acquiescence. Should any one of those who have agreed to go, afterwards break his promise, he is liable to be punished by forfeiture of part of his property, or by expulsion from the village. A string of wampum is sometimes sent from one village to another, with a piece of tobacco attached to it as a proof of the faith of the messenger. It has often been stated, that the Indians in no instance whatever punished their children. This is not correct as a general rule. Mr. Colhoun was informed, that the Potawatomis sometimes enjoin upon their children, as a punishment, the use of the charcoal and its accompanying fast. He also observes, that the circumstance of chastisement being inflicted by some Indians, is confirmed by Joutel's statement, that the Illinois and Cadoquias punished their children by throwing water in their faces; and by Jones's observations, that the Shawanese had the same practice, and likewise threw them into brooks.* The power of the chief is only exercised as

* Vide "Journal Historique du dernier Voyage de M. de la Salle, par Joutel." Paris, 1713, p. 284 and 342, and "Journal of two visits to some nations of Indians west of Ohio river, in 1772 and 1773 , by Rev. $\mathbf{D}$. Jones," 
long as he behaves himself in a manner agreeable to the wishes of his warriors, for though the dignity be a hereditary one, it is not uncommon for them to depose their chiefs. The principal prerogative of the chief is to conduct all military operations; when once war is declared, he cannot conclude peace without the consent of his warriors. 'The duty of dividing the annuity paid to them by the United States' Government, likewise devolves upon the chief. Formerly the partition was made by him in the manner that he thought best, but some cases of malversation have led to a different method. The money is paid to the principal chief of the nation, who calls his people round him, places them in a circle, and then throws a dollar to each, all round, continuing this operation until the whole of the money be disposed of. In this division the father of a family receives an equal share for every individual in his household, whether male or female, child or adult. The annuities paid to the Miamis amount to eighteen thousand dollars. The last census, taken a few years since, made their numbers eleven hundred and seventy-two, of whom three hundred were warriors. An accurate amount of the Potawatomi population could not be obtained here; it has been variously stated; we heard it rated at ten thousand, which is probably far beyond the true number. Those who receive their annuities at Fort Wayne, are not numerous, and the census of Indians in the state of Illinois does not admit of more than trvelve hundred Potawatomis. The payment of their annuities on the United States' territory, is $_{\text {is }}$ very much to be regretted; they ought to be paid to them on the Indian reservations, where by a humane law no spirituous liquors can be sold; if some means were taken of holding a sort of fair for cattle, and implements of agriculiure, at the time that the annuity is paid, they might, per- 
haps, be induced to apply to the purchase of useful objects, the money which is at present wasted in procuring spirits. Under the present system, the moment an Indian receives his annuity, he immediately converts it into whiskey; the deplorable effects of which upon their system are too well known to require that we should divell upon them; but we may be permitted to add the testimony of what came under our own inspection, to the great mass of information which has already transpired on this subject. During the three days that we stayed at Fort Wayne, we saw two Indians tomahawked. The first case happened the night of our arrival; this man was very severely cut in the head by some unknown person. It was supposed that it was by one of the French engagés. At the time this occurred, they were all concerned in a drunken frolic. The next day, on visiting the Fort, we met at the gate a few Indians, one of whom was in a state of intoxication; and we were informed by a boy, that he had threatened to shoot his wife. A few moments after, while we were engaged in conversation with the Indian Agent, word was brought to him, that the Indian had drawn his knife and severely wounded her in the forehead. It appeared the only provocation she had given him, was in attempting to draw him away from the town, and induce him to return to his village. In both these cases the loss of blood was very considerable, and such that it was believed none but Indians could have survived it; but they are so inured to pain and privations of every kind, that it cannot be doubted that they recover from wounds which to other men would prove fatal. The excellent surgical assistance which they reccive in all cases of wounds and bruises, may also be considered as one of the causes which tend to restore them to health. These assaults are, however, so common 
here, that no one appears surprised at them; they are considered as an every day occurrence. Generally an Indian will, after he has recovered from his drunken frolic, express great regret for the fatal effects which have attended it. This is peculiarly the case where he is at a distance from the white population, and where intoxication has not become with him an habitual or daily vice; otherwise the frequent repetition of these bloody frays renders him callous to their consequences. As an instance, we were told, that some time since, when the Baptist Missionary Society were allowed to occupy Fort Wayne as one of their stations, an Indian brought to the fort the corpse of his brother, and asked the Rev. Mr. M'Coy, who superintended the establishment, to provide for the funeral. On inquiry, Mr. M'Coy found that the deceased had been murdered a short time before, by the very Indian who had brought him in. When questioned as to the cause of his brother's death, the murderer carelessly raised the clothing from the breast of the deceased, and exhibited five or six wounds which he had inflicted with a knife, nor could any emotion of compunction be observed in his unyielding countenance. These evils may all be traced to the unfortunate circumstance, that the prohibition to sell spirituous liquors to the Indians only extends to their territory. If congress were to include in this prohibition all lands belonging to the United States, the evil could be partly, if not wholly, remedied. The inducement to smuggle liquor and sell it clandestinely, might be sufficiently great to prevent the mischief from being completely removed, but it would certainly render it rare. Perhaps, also, if the agents were required to pay them their annuities on the Indian reservation, and at a time when an opportunity would be given them of laying out their money in the purchase 
of cattle, implements of agriculture, and other useful or innocent articles, while the introduction of spirituous liquors would be closely guarded against, the great evil of intoxication would be rendered still more rare. Whatever mensures congress may choose to adopt to civilize the Indians, it is not difficult to foresee that they will ever prove unsuccessful, unless a check be immediately put to the sale of ardent liquors among them. The law that prohibits the sale of it upon their territory having proved insufficient, a more general system of restriction must be adopted.

Experience has likewise proved, that the term sale was not sufficiently comprehensive. The giving of spirits ought to be subjected to the same regulation; for it has been observed on the Missouri, as well as on the Mississippi, and probably every where throughout the Indian country, that if prohibited from selling it, the traders will give it to the Indians as an inducement to trade with them, taking care that the price of the liquor be included in that of the tobacco or other article sold to them at the time.

All Indians concur in considering intoxication as improper, and as the source of every evil. Among crimes, those that are held to be most atrocious, are murder, theft, and the violation of the advice and directions of their parents. Many, however, are said to be "foolish," and not sensible of crime. Rape is considered as visited by the anger of the Great Spirit, and is never practised but upon females in a state of intoxication. In the treatment of their wires, they are often severe and brutal; if they should prove lazy, or be deemed so by their unrelenting husbands, or if careless of their children, they are not unfrequently beaten with clubs. Among women no crime is considered so flagrant as infidelity to their husbands; this is punished with blows, and sometimes by cutting off the nose, or other mutilations. 
Scldom do the Potawatomis punish it by death, and it is very rare that they vent their resentment against the paramour. The barbarous punishment noticed by Mr. Say in the account of the manners of the Otos, Omawhaws, and other Missouri Indians, which he described under the name of the Round in the Prairie, (tour de la prairic of the Canadians,) is not known among the Potawatomis.

The Indians are liable to more distempers than might at first be expected from their mode of living. Croup is one of their most common diseases; in some seasons, most of the cases are fatal, while in others all the patients recover. No medicine is applied in this disease, except the maple sap, or sugar dissolred in hot water. Adults find relief from vomiting. Sore throat appears, also, to be one of their most frequent complaints; especially in the morning, but it soon passes off. They are often bitten by rattlesnakes; the wound is cured among the Potawatomis by poultices of the Seneca snake-root, draughts of violet tea, and Eupatorium perfoliatum; they have other remedies, which they lieep secret; the venom of the snake is considered greater at some periods of the moon than at others; in the month of August it is most so. These Indians entertain a high degree of veneration for the rattlesnake, not that they consider it in the light of a spirit, as has frequently but incorrectly been asserted, but because they are grateful to it for the timely warning which it has often given them, of the approach of an enemy. They therefore seldom kill it, unless when a young man fancies that he requircs a rattle, in which case he will have no hesitation in killing a snake; which act he, however, always accompanies by certain forms. He introduces it by many apologies to the animal, informing it that he wants the rattle as an ornament for his person, and by no means to make fun of it, and in testi- 
mony of his amity to the species, leaves a piece of tobacco near the carcase. The fang of the snake is held to be a charm against rheumatism and other internal pains; the mode of applying it consists in scratching the affected part until it bleeds. In their rude midwifery, they use the rattle to assist in parturition; it is then administered internally; it is not, however, used as an emmenagogue. Leprosy is known among them, and has been observed under some of its most horrible features. In a case, known to Dr. Hall, the patient required some one to be constantly scraping his body and limbs with a knife. A double handful of furfuraceous matter was daily discharged; he died in the course of six months; his feet had turned as black as gunpowder.

Fevers are common among the Potawatomis, and are either bilious, intermittent, remittent or continued; they affict most those who follow the game to the interior of the country; while those who reside along the shores of the lake enjoy much better health. The Indians observe that the easterly winds are the most wholesome, the southerly produce dullness and laziness, the north wind is too cold, and that from the west is very uncomfortable. Hæpatitis is not common; when it occurs, it is relieved by repeated vomiting until the bile is completely evacuated; if the bile be not discharged, the white of the eye turns yellow, and continues so until death ensues. Hydrocephalus and dropsy are, itseems, unknown to them. Small Pox is frequent, but is always introduced by white men; it does not, however, commit any great depredation; at one time it raged among them, and proved disastrous and incurable. Its evil effects were suspended by the introduction of the practice of inoculation and vaccination, which Little Turtle made known to them. Having never known the small

Vox. I. 
pox to be violent but once, they have not entertained that opinion, of its return at periodical times, which is said to be held by other nations. Dr. Hall's offer to vaccinate them was accepted by many and declined by others. Metea told us that vaccination had only been abandoned for want of the virus, he expressed a great wish to obtain some, and said if he had it, he would use his influence to disseminate it.

Syphilis was, according to Metea, known to the Indiars: in its mildest form prior to the arrival of white men among them. It is considered as having increased in rirulence and frequency, since the promiscuous intercourse of white men and squaws which is not interrupted, according to the uniform practice of Indians, during the period of the catamenia. When the disease is in its mild state, they cure it very readily by timely application to their medicine men; the principal remedies are decoctions of the red root and the prairie willow root, as also of sassafras. In such cases they drink very plentifully. These remedies are notapplied to the disease in its worst forms: we heard that they had remedies which, even in these cases, were considered as certain, but of which we could not ascertain the nature. In all such diseases, they apply to their regular doctors, who are said to charge very extravagant fees. These men combine the use of spells with that of herbs, and are held in very great esteem. Their materia medica consists of astringents, cathartics, emetics. mucilages, and sudorifics. Among the emetics most in use, we heard of pills made from the product of the evaporation of a decoction of the horse-chestnut boiled down to a viscous state. One of their sudorifics is said to consist in the application of a poultice of maize, boiled as for food, which is spread over the body of the sick person, who is first extended on a board or skin. The maize used in 
this application is afterwards used as food. The berry of the prickly ash is used by them as a varming medicine for inward complaints. They have no vesicatories but fire and hot water, which are applied for sore joints and rheumatism. Phlebotomy is performed with a small knife or with a thin lamina of flint attached to a stick in the manner of a fleam, and stuck in the flesh in the same way. For a pain in the head they bleed in the bend of the arm, or above it; for one in the side below the bend; and if the pain be in the back they bleed on the right or left ankle according as it inclines to the right or left side. Bleeding is never resorted to in fevers.

Calculous symptoms are accurately described, but the disease and its causes are unknown to them. The process of parturition is generally easy, the woman being on her Inees; it is sometimes assisted by bending the body over a cord, the ends of which are attached to the top of the cabin; the funis is regularly tied and cut. The operation of turning is unknown; no manual assistance is resorted to, even in cases of wrong presentation; and many instances have occurred in which the fœtus became putrid before it was expelled. They have professed midwives, who are paid for their attendance; these are principally old women. Men are never allowed to assist at the delivery of a woman. A general opinion has prevailed that all Indian women bathed in cold water immediately after parturition. This is however extremely incorrect; the practice exists among the Sioux or Dacotas, and among many other nations, but we very much question whether any nation of Algonquin origin practises it. The Potawatomi women are very careful not to expose themselves to cold after child-birth, and do not bathe for ten days unless the weather be very warm. The placenta not being always expelled naturally, they 
have recourse to a strong medicinal draught; it is stated, that if it should remain for several days, the husband takes his wife upon his shoulders, and carries her about for some time; the motion is said to assist in its expulsion. Mothers always nurse their children, and continue to suckle them for a great length of time, in some instances for three, four, or more years, if no subsequent pregnancy occur; in one case a mother was observed suckling a child twelve years of age. When the mother's milk fails, the child is fed with an extract of sweet maize in boiling water, and medicines are administered to renew the secretion. Metea had never heard of a total failure of a woman's milk while nursing her child; during a temporary interruption of it they sometimes commit children to the care of a friend, who acts as a nurse; but this practice is disapproved of. Parturition is seldom fatal: when it proves so, it is attributed to ignorance or carelessness on the part of the midwife; in women of indolent habit it is said to be painful, in the active it is much less laborious. Sterility is very common, but does not expose women to contempt, though it is frequently the cause of their being cast off by their husbands. The period of gestation varies from eight to nine months, and is seldom attended with sickness or nausea. Menstruation commonly commences at the age of fourteen, and continues until fifty, and in some cases sixty years; it is not uncommon to see a woman with gray hair, whose catamenia has not ceased. Many women become disabled from child-bearing by accidents during their first gestation, although still very young. Menstruation is often irregular with them; when too abundant, they have remedies which are represented as very successful, but which Metea declined indicating, as it was not usual for them to talk of these things except when 
called upon professionally, and with a fee. In a suppression of menses they seldom apply any remedy; as they are apprehensive that this might be productive of sterility, which is by all Indian women considered as the greatest curse that can be entailed upon them. During the period of the catamenia, women are not allowed to associate with the rest of the nation; they are completely laid aside, and are not permitted to touch any article of furniture or food which men have occasion to use. If the Indians be stationary at the time, the women are placed outside of the camp; if on a march, they are not allowed to follow the trail, but must take a different path and keep at a distance from the main body. This practice, which appears to prevail wherever man retains his primitive simplicity and purity of manners, has been very unphilosophically considered by Adair and other theoretic writers as a strong confirmation of the descent of the aborigines of America from the ten lost tribes of Israel. But as Charlevoix observes, "one must have good eyes, or rather a very lively imagination to perceive in them all that some travellers have pretended to discover."* The late Mr. Samuel Prince, of Boston, who resided three or four years in Owhyhee, assured Mr. Colhoun that the natives of that island are equally scrupulous with regard to the catamenia, and during its continuance; the women being secluded in houses without the villages. This custom of Owhyhee has not, we think, been noticed by any traveller that we have met with.

It has been often asserted that it was a common practice with Indian women to destroy the fotus. This may be correct as respects certain nations, but it oughí

- Charlevoix's Journal Historique, Letter 23 d. 
by no means to be considered as applicable to all; and we know it to be incorrect as respects the Potawatomis. All travellers concur in representing them as very proud of the number of their children. Where the mild and humane provisions of the Christian faith do not prevail, children form almost the only link which binds man to woman for life. It is the only obstacle to that constant repudiation of wives which occurred previous to the Christian dispensation; hence, independent of the moral turpitude of the deed, it would be the height of impolicy in a woman to impair the strongest claim which she has upon her husband's affections; besides these considerations, the Potawatomi woman is prevented from attempting infanticide from the fear which she entertains that abortion would be followed by the death of the parent.

Askabunkese, one of the most celebrated physicians among the Potawatomis, being asked whether chlorosis was known to them, said that he did not know it; the women were too modest to inform the men, and would knock him down with a stick if he were to inquire of them.

Among the Potawatomi, the practice of medicine is considered quite distinct from that of jugglery. Both are in great repute, but it appears that there is no interference. The man of medicine has, it is true, recourse to spells and incantations to add to the virtue of the plants which he uses; but this is totally unconnected with the avocations of the sorcerer and juggler, whose object is amusement, and who are resorted to for the recovery of lost articles, or to answer questions about persons and things at a distance, for which they sometimes get pay from the more ignorant, but they are soon detected in their clumsy arts. The sorcerers are treated with much respect, being held in great awc; they generally perform their tricks in the twilight, or during 
the night. Prophets formerly existed in great number, and were much revered; but the failure which attended the predictions made by the great prophet of the Shawanese, the brother of Tecumseh, has opened their eyes on this subject, and satisfied them that he, as well perhaps as the others who had enjoyed reputation among them, was merely a tool in the hands of a designing chief, to deceive the Indians into measures which he wished to effect.

The Potawatomis have a number of war songs, formed for the most part of one or two ideas, expressed in short and forcible sentences, which they repeat over and over, in a low humming kind of tune, which to our ears appeared very monotonous; they have no love songs, the business of singing being always connected with warlike avocations. We took down the words of one of their songs as follows :-

Yỏ-wâ-kwầ tâ-mầ-nở mẻ-chè-mỏ-kô-mản.

\section{What do I hear behind me? the Americans}

nẻ-tò-tât-wầ-nê-kà pè-tè-kả-wả, are entering our village. Prepare yourselves to fight.

Kà-nâ-mề-tâ-sể wể-tấ-sể nẻ-pỏ-wăn.

\section{We must die. Victory or death.}

The translation of two others is annexed, with a view to give an idea of the purport of their songs. "When I march against mine enemies, the earth trembles under my feet;" this is sung with considerable force by a warrior; the others joining in chorus, to the words yà, wå, often repeated, and concluded with a general whoop.

Another, which is very short, consists merely in the repetition of the words, "The head of the enemy is cut off, and falls at my fect;" with the exclamation ha-ha-ha, freqquently repeated.

Singing is always attended by the dance, and if pos- 
sible, by intoxication, in which ease it becomes incolerent and unintelligible. The only musical instruments which they use, are the drum, rattle, and a kind of flagelet. They have rarious kinds of dances known by the name of the war dance, medicine dance, Manito or spirit dance, wabano, metawee, mewicine, and beggar's dance. Their games are numerous and diversified; they resemble many of those known to civilized men; such as gymnastic exercises, battledore, pitching the bar, ball, \&ic. tennis and cup-ball, for which they use the spur of the deer with a string attached to it. They are fond of games of chance, particularly cards, which they have received from traders, \&c.

The Potawatomis are for the most part well proportioned, about five feet eight inches in height, possessed of much muscular strength in the arm, but rather weak in the back, with a strong neck, endowed with considerable agility. Their voice is feeble and low, but when excited very shrill; their teeth are sound and clean, but not remarkable for regularity. In persons of feeble habits, or of a scrophulous tendeney, the teeth are found to decay much faster than in others. Dentition is said to be a painful process among Indian children, a circumstance which we had not expected. Their complexion is very much darkened by exposure to the sun and wind, while those parts which are kept corcred, are observed to retain their native brightness. Children are red when new-born, after a few years they assume the yellow colour. Their sight is quick and penetrating, but blindness is frequent from the intense application of the eye in still hunting, and from exposure to the alternate, and, in some cases, united action of the sun and snow; doubtless also on account of the constant smoke in their huts. Their hearing is usually good when young; 
but is often affected in old age, probably by the effect of cold, or the usually disordered state of their stomach. Their olfactory nerves are said to be inferior in acuteness to those of the white man; which is singular, considering the extent of the sense of smelling among wild animals. We should have believed that man in his primitive state would be possessed of a more acute sense of smelling than when civilized; the facts stated on this subject of the Caraibs being able to trace men through the woods by the scent, like hounds, and of their distinguishing " the track of an Englishman or a negro, from that of a Frenchman or a Spaniard, by the sense of smelling," if true, would be strong confirmation of this doctrine.* It is said that the Arabs cannot bear the smell of a city.

Their endurance of cold is great. Their powers of digestion are strong, but exposed to severe trials. The quantity of food which an Indian will take when he has it in abundance is surprising, and if considered in connection with what is related by Captain Parry of the appetite of the Esquimaux, would lead us to believe that this is not peculiar to any nation of Indians, but that it belongs to man in general in his wild state. We find that it extends also to the half-breeds who live among them. The observations made at a later period of the expedition, upon the quantity of buffaloe meat consumed by every man of the party, confirm this. The usual allowance of fresh buffaloe meat to the guides and boatmen of the fur trading companies is not less than eight pounds per day; it is probable, that during the short time the party were among the buffaloe, the ration of each of the gentlemen averaged about four pounds. This is not to be attributed to any want of nutritive power in the flesh

* Archæologia Americana, vol. I. p. 426.

VoL. I.

18 
of the buffaloe, but to the great facility that attends the digestion of this food, and to the irregular habits which even the most civilized men readily acquire as soon as they find themselves beyond the pale of society. Certain it is, that if well provided with food, and not engaged in hunting, the Potawatomi will eat from ten to twenty times a day. Frequent exposure to privation of food has, however, accustomed him to endure the want of it with more fortitude, and perhaps with less real inconvenience, than the white man. There is also probably a moral support which the red man receives from the recollection, that however frequent, and however long have been the intervals during which he was deprived of all subsistence, they have always terminated in time to secure him from absolute famine; he therefore always retains the hope of being soon restored to abundance. The white man, less accustomed to these privations, considers himself as lost the very first time that he misses his usual allowance, and is deprived of the great accession of physical strength which proceeds from moral courage. Notwithstanding their great fortitude, the men of this nation are sometimes liable to unaccountable depression of spirits, which seldom, however, leads them to commit suicide; we heard of two instances only, one of which was in a fit of intoxication, and the other to get rid of a scolding wife.

This account of the Potawatomis might have been lengthened out by adding many circumstances which were related to us concerning their manners and opinions; but having given the most important, we shall withhold noticing the remainder, except in a few instances, when treating of other Indian tribes; in which case they may assist in a comparison between the different nations. 


\section{CHAPTER IV.}

\section{Carey mission-house. Lake Michigan. Chicago.}

THE only person worthy of note, whom the party met at Fort Wayne, besides those already alluded to, was Captain Riley, the same gentleman who has amused the world by an account of his sufferings in Africa. He has formed a settlement on St. Mary river, fourteen miles above Fort Wayne, which he has called Willshire, in honour of the British consul who redeemed him from captivity. The spot which he has selected is said to be the only one that affords a water-power within fifty miles of Fort Wayne; from which circumstance it will probably increase in importance. The party made arrangements to cross the wilderness, of upwards of two hundred miles, which separates this place from Chicago; they fortunately met here the express sent from the latter place for letters, and detained him as a guide. His name was Bemis, and we have great pleasure in stating, that of all the United States' soldiers who, at various times, accompanied the expedition in the capacity of escort or guide, none behaved himself so much to their satisfaction as this man. On the 29th of May, the party left Fort Wayne, the cavalcade consisted of seven persons, including the soldier, and a black servant, called Andrew Allison; there were in addition two horses loaded with provisions. The first day the party travelled but iwenty miles, and encamped on the bank of a small stream known by the name of Blue-grass; this is the last of the tributaries to the Mississippi which are met with in Indiana; all the streams which we crossed during the ensuing five or. 
six days empty their waters into Lake Michigan. The country to the west of Fort Wayne is much more promising than that which lies east of it. Though wet, and in some. places swampy, it is much less so than that through which we had previously travelled. The soil is thin, but of good quality; prairies are occasionally met with; the forests consist of white oak, shellbark, aspen, \&c. The weather, which was cloudy in the morning and showery in the afternoon, cleared off towards sunset, and our first night's exposure was attended with no evil consequences. The meadow on which we halted, was covered with a fine tame grass, which afforded us a soft couch, while it secured to our horses plentiful and palatable food. The streams we crossed this day were inconsiderable; the first known by the name of Eel river, is one of the head branches of the Wabash: it was considerably swollen at that time; we forded it with some difficulty, and met on the west bank a party of traders, who had been encamped there sometime with a large quantity of furs, which they dared not trust across the stream in its present state of elevation. They were nearly destitute of provisions, and we supplied them with one day's rations. A ride of thirty miles took us the next day to a fine river called the Elkheart, which it had been our intention to have forded before night; upon reaching its banks we found it so much swollen as 10 preclude the possibility of crossing it, unless a raft could be made; but as this would have detained us too long, we prefered attempting to make our way down the left bank of the stream. We were led to take this course from the circumstance, that the usual path crosses back to the left or southern bank, about twenty miles below the first crossing. The country travelled over this day, consisted of low flat ridges, the summits of which presented extensive levels 
interspersed with many small lakes and lagoons. These ridges are not more than ten or fifteen feet in height, their sides are so steep as to make them sometimes difficult of ascent for horses. The country is almost destitute of timber until within a few miles of the Elkheart, when we entered the river bottom, in which we found a noble forest of oak, black and white walnut, wild cherry, beech, poplar, ash, bass or linden, white and sugar maple, \&c. the soil upon which it grows appearing to be of the very best quality, but somewhat wet. Among the plants observed upon the prairie land, Mr. Say noticed a lupin with blue flowers, in full bloom and in great abundance; a fine cypripedium, and the wild flax, which grew in great plenty. Some of the small lakes or ponds are surrounded exclusively with a thick growth of white cedars, none of which are seen elsewhere, or intermixed with any of the forest trees on the more elevated ground. One of the most curious characters of the prairie, was the number of conical depressions in the earth, resembling the sink holes in the neighbourhood of St. Louis; they are from eight to ten or more feet in depth, and from twenty to thirty in diameter. They remind the geologist of the numerous funnel-formed holes which are observable in gypsum formations, and particularly in the muriatiferous gypsum of the vicinity of Bex in Switzerland, Moutiers in Savoy, \&c. No rocks appear in situ any where along these prairies, but they are covered with granitic boulders, bearing evident marks of attrition. The soil is likewise thickly studded with water-worn pebbles, and is therefore far inferior in quality to that over which. we passed the preceding day. The grass of these prairies is generally short and dry.

One of the greatest inconveniences we encountered at. this stage of our journey, and which was felt still more 
sensibly when travelling on the prairies west of the Mississippi, was the great range of the thermometer. We noticed this day, that at sumrise it stood at $38^{\circ}$, (of Fahrenheit's scale,) while at noon it had risen to $72^{\circ}$. So great a variation of temperature is productive of very heavy dews, to which we were frequently exposed, as we often neglected pitching our tents at night. In rising in the morning we found our clothes as wet as if they had been drenched in water. Whether the usual elevation of these prairies prevents the dew from being attended with the sickliness which generally prevails in the vicinity of rivers, or whether the life, to which men are exposed in crossing the prairies, protects them against the noxious influence of the dew, we know not; but it is remarkable that none of the party suffered from it. In no instance were any of us affected with either cold or rheumatismal pains; and if in one or two cases symptoms of fever prevailed, it was at a time when we had left the prairies.

A few Potawatomi Indians were met this day on their way to Fort Wayne. The trail which we followed was struck by that which leads to one of their villages about fifteen miles distant. The weather was hazy throughout the day; in the evening light clouds were observed. A genlle breeze from the north-west prevailed during the day. Our horses had been fastened, to prevent their rambling in the woods; meeting with but a scanty supply of grass in the neighbourhood of the river which was overgrown witl: bushes, and which offered them no other food but the barls. of trees, many of them broke the bark ligaments with which they were secured, and strayed to a considerable distance from the camp; these ligaments are called in the language of the travellers to the west " hobbles." The pursuit after the horses in the morning occasioned a great loss of time, 
which was however increased on discovering that the black boy (Andrew) had not returned with them; he having unfortunately lost his way in the woods. Our search after him having proved vain, we wrote directions for him to pursue our track, affixed them to a tree, and were on the point of leaving the camp, when fortunately he made his appearance. It is probable, as we afterwards found out, that he would have perished in the woods had he not come in just at that moment; for it would have been impossible for him to have traced the party in the thick forest through which our course led us: neither would it have been prudent for us to have remained any longer there, as our horses gave evident signs of their having been on short allowance since noon of the preceding day. Andrew's return to the camp enabled us then to attend to what appeared to be the most important object, which was to seek for a place where the horses might pasture to advantage. We therefore resolved upon following as short a course as we could to the prairic land, endeavouring at the same time to keep near enough to the river to reach the second crossing before night. In this attempt we met with great difficulties, from the closeness of the forest and the swampy nature of the ground. The horses laboured much to get through, and when we stopped at noon to pasture them on a small patch of grass, we found that our progress during four hours had been but about six miles. We had met with a bold and hitherto undescribed stream, about twenty yards wide, which empties into the Elkheart about three miles below the usual crossing, and which we have designated in our map as the south-west branch of that river. From the rapidity and depth of this branch we anticipated the same difficulties which we had encountered the evening before, but on continuing along the bank, for some 
time, we observed a large tree that had fallen across, and that afforded a safe and commodious bridge for ourselves and baggage, while our horses swam over. The afternoon of that day was consumed in passing through swamps, in which our horses were frequently in danger of being lost. At one place three of the horses with their riders, were near being severely hurt, by the fruitless efforts of the former to get over a bad hole. We were happy to get through without any more serious injury than that of being smeared with dirt from head to foot, and with the loss merely of a few spurs that stuck to the bottom of the pool. After one of the most trying days that any of us ever recollected having undergone, we encamped, at sunset, in a place so low that we could scarcely get a spot dry enough to spread our blankets; and before we had partaken of our evening meal, the mosquitoes arose in such numbers around us, that we were deprived of all rest for the night. We had likewise the mortification of finding that our horses were almost as badly off for grass this evening as the last; the distance travelled this day did not exceed twenty miles. Our course had been entirely directed by the compass, and was nearly west. An Indian trail which we observed in a direction north $40^{\circ}$ west, was followed for a while, with the hope that it would take us to an Indian village, but it only lead us back to the Ellkheart, which we found as deep and as rapid as at our last encampment. We observed here the remains of a frail canoe which, for a moment, we thought might assist us in crossing the river; but the weakness of this little vessel, soon convinced us of the impossibility of trusting to it; it was made of the bark of the linden or elm, procured by cutting through to the wood transversely, first at the foot of the tree, and then again about twelve feet above this. A 
longitudinal cut, uniting these two, allowed the bark to be shelled off in a single piece. It had then been reversed, so that the inner surface, while on the tree, formed the outside of the boat; the whole was finished by causing the middle part to bulge out, by means of sticks placed athwart, while cach end was pressed in, and rendered water-tight. This path having misled us, we retraced our steps until we ascended a bank, about twenty-five feet high, which runs parallel with the river, and we continued along the edge of this through thick woods of elm, prickly ash, red haw, spice ivood, papaw in flower, \&c. Our situation during the night was a very uncomfortable one, and little calculated to please those of the party, who were, for the first time, engaged on an exploring expedition. To be placed in the midst of a dense forest, surrounded by bogs, from which our horses had been extricated with great difficulty, uncertain as to the possibility of reaching by this route the spot at which we wished to arrive, tormented by insects, our horses faint for want of food, and all this at the commencement of our journey through the woods, was rather a discouraging situation. Anxious to escape from these difficulties, we resumed our journey on Sunday, the Ist of June, at as early an hour as we could, and were engaged for about five hours, in difficulties still greater than those of the preceding day. The thickness of the forest having obliged us to clismount and lead our horses, we waded knee deep in the mire, and met with a new obstacle in the necessity of making frequent halts, to replace on the horses the baggage which was thrown off, during the many leaps which they had to take over the fallen trees. After a while we reached a high and dry prairie, partly covered with young aspen bushes, rising to the height of from eight to ten feet, and so thick that it was almost impossible to kecp the wholen?

Vor.. I. 
the party in sight; this reminded Major Long of some of the difficulties he had experienced in travelling through the cane brakes of Arkansarv. On halting at noon, we discovered the Elkheart at no great distance, and from the account of our guides, concluded that we had got through our diffculties. To the younger travellers it was a source of much gratification, to find that the fatigues of that morning had exceeded all that their more experienced companions had ever met with, as it was to thein a sure warrant that they had not overrated their forces in undertaking the journey. At our noontime's encampment, we found the angelica plant, and the wild pea-vine. We soon struck a trail, and about three miles below, came to the lower crossing of the river; it was still so high that it would have been impossible to pass, but we experienced great pleasure in ascertaining that we had again fallen into the usual track from Wayne to Chicago; we observed here, for the first time, the equisetum growing in abundance. In the afternoon we travelled with ease and comfort over a prairie country interspersed with occasional spots of woodland. One of these prairies which was about five miles wide and one and a half long, was as level as possible, and as far as the eye could observe, it resembled a smooth unruffled sheet of water. The scene was enlivened, and the solitude interrupted by the quick flight of the deer which we disturbed while feeding, and which darted across our path with a rapidity that bafflesdescription. About sunset we arrived at a romantic stream called Devil's river, and here we encamped upon as beautiful a spot as the most fastidious could have wished for; we pitched our tent for the first time, and while partaking of a comfortable meal, in the open air, spent a more pleasant evening than perhaps we could ever have expected to enjoy in such a solitude. There was a still sublimity in the secne, 
which we have in vain looked for on many an occasion. The dreariness of our last encampment contrasted so strongly with the calmness of the present, that it powerfully reminded us of that constant mutability in the situation of man, which perhaps finds its parallel only in the unceasing changes which his ideas and his feelings undergo.

The next day we proceeded along the southern bank of the Elkheartand observed its junction with the St. Joseph. This last mentioned stream is known by the appellation of St. Joseph of Lake Michigan, in contradistinction to the river of the same name which empties into Lake Erie, and which we saw at Fort Wayne. The St. Joseph of Michigan is a fine stream, deeply incased; it is about one hundred yards wide, and being at that time very full, was both deep and rapid; it is the finest stream we have met with since we left the Muskingum, and perhaps even the Ohio. A beautiful prairie with a fine rich soil, offered to the party an easy mode of travelling, and the occasional glimpses which they caught of the St. Joseph and its adjoining forests, afforded them a series of varied but ever beautiful prospects, which were rendered more picturesque by the ruins of Strawberry, Rum, and St. Joseph's villages, formerly the residence of Indians or of the first French settlers. It was curious to trace the difference in the remains of the habitations of the red and white man in the midst of this distant solitude. While the untenanted cabin of the Indian presented in its neighbourhood but the remains of an old cornfield overgrown with weeds, the rude hut of the Frenchman was surrounded with vines, and with the remains of his former gardening exertions. The asparagus, the pea-vine, and the woodbine, still grow about it, as though in defiance of the revolutions which have dispersed those who planted them here. The very names of the vil. 
lages mark the difference between their former tenants; those of the Indians were designated by the name of the fruit which grew abundantly on the spot, or of the object which they coveted most; while the French missionary has placed his village under the patronage of the tutelar saint in whom he reposed his utmost confidence. Near to these we found two traders settled in the vicinity of Indian lands, or as is believed by many, upon the reservation itself; where they probably carry on a lucrative trade, if, as we were informed by one of them, a skin valued at one dollar was obtained for five gunflints, which had cost him a cent a piece. This is, however, the least evil; our objections to this trade would be much lighter, if the Indians were liable only to be defrauded of their dues; but great as is this injustice, it bears no comparison to the evils growing out of the constant temptation of liquor to which they are exposed, and which as is too well known it is impossible for them to resist. It is really shocking to observe the manner in which, notwithstanding the laws of the land, the dictates of sound reason, and morality, and the active efforts of the United States' agents, the traders persist in their practice of offering liquor to the Indians, the effect of which is to demoralize and to destroy them.

There is in this neighbourhood an establishment which, by the philanthopic views that have led to its establishment and by the boundless charity with which it is administered, compensates in a manner for the insult offered to the laws of God and man by the traders. The reports which we had received of the flattering success which had attended the efforts of the Baptist missionaries on the St. Joseph, induced us to deviate a little from our route to visit their interesting establishment. The Carey missionhouse, so designated in honour of the late Mr. Carey, the 
indefatigable apostle of India, is situated within about a mile of the river, and twenty-five miles, (by land,) above its mouth. The ground upon which it is erected is the site of an ancient and extensive Potawatomi village, now no longer in existence. The establishment was created by the Baptist Missionary Society in Washington, and is under the superintendance of the Rev. Mr. M'Coy, a man whom from all the reports we heard of him we should consider as very eminently qualified for the important trust committed to him. We regretted that at the time we passed at the Carey mission-house, this gentleman was absent on business connected with the establishment of another missionary settlement on the grand river of Michigan; but we saw his wife, who received us in a very hospitable manner, and gave us every opportunity of becoming acquainted with the circumstances of the school. The spot upon which the houses are built and the agricultural pursuits carried on, was covered with a very dense forest seven months before the time when we visited it, but by the great activity of the superintendant, he has succeeded in the course of this short time in building six good log houses, four of which are connected and afford a comfortable residence to the inmates of the establishment, a fifth is used as a schoolroom, and the sixth forms a commodious blacksmith's shop. In addition to this, they have cleared about fifty acres of land, which are nearly all enclosed by a substantial fence; forty acres have already been ploughed and planted with maize, and every step has been taken to place the establishment upon an independant footing. The school consists of from forty to sixty children, of which fifteen are females. They are either children of Indians, or half-breed descendants of French and Indian parents; there being about an equal number of each. It is contemplated that the 
school will soon be increased to one hundred. The plan adopted appears to be a very judicious one; to instruct them in the arts of civilized life, to teach them the benefits which they may derive from them, without attempting to confuse their heads by ideas of religion, the value of which it is in their present state, impossible for them to appreciate. It is only after they shall have been fomiliarized with the blessings attendant upon civilization, that they may be incluced to turn, with effect, their attention to the sublime principles of that dispensation to which we are indebted for all those comforts. To attempt to christianize them before they have been civilized, would be to expect of them a maturity of reasoning far beyond that of which experience teaches us that they are possessed. In his present state of wildness and ignorance, it is impossible for the Indian to appreciate the vast difference which exists between his heathen superstitions and the pure morality of the gospel. Could we entertain a doubt of what must strike every reflecting man as true, we need but open the books of the Catholic missionaries whose zeal first induced them to visit the trackless wastes of America, to ascend her as yet unknown rivers, and to risk every hazard and surmount erery obstacle, conveying the glad tidings of the gospel and baplising in the name of the Lord. What say they of their success, they were heard with patient attention, for such is the practice of the Indian, but what root did their words strike in the minds of their pupils? Father Hennepin, one of the most celebrated of these missionaries, has accounted for their ill success in the true way. "There are," says he, "several obstacles to the conversion of the Indians, but in most cases the chief difficulty arises from the indifference which they manifest for every thing. If we instruct them in the creation of the world, and in the mysteries of the 
christian religion, they say that we are right, and they generally applaud what we tell them. They would hold it to be a great breach of manners to intimate the least doubt as to the truth of all that we teach them, but having heard and praised all that we had to say, they pretend that we ought to show the same deference for the tales which they relate to us, and when we tell them that all they have advanced is false, their reply is, that as they have acquiesced in all that we have stated, it is foolish on our part to interrupt them and deny the truth of what they assert." "All that thou hast taught us, say they, respecting the belief of thy country is doubtless true as respects thy people, but it is otherwise with us who belong to a different nation, and who dwell upon lands which are on this side of the great lake." It is this indifference in all matters of faith, this belief that their doctrines were as good as those of the missionaries, that may $b^{2}$ considered as the true source of the failure of all attempts to christianize them. But after their ideas will have been expanded by a proper acquaintance with the arts of civilized life, then they cannot fail fully to appreciate the superiority of our faith over theirs.

The plan adopted in the school, purposes to unite a practical with an intellectual education; the boys are instructed in the English language, in reading, writing and arithmetic, they are made to attend to the usual occupations of a farm, and to perform every operation connected with it, such as ploughing, planting, harrowing, \&c.; in these pursuits they appear to take great delight; the system being well regulated, they find time for every thing. not only for study and labour, but also for innocent recreation, in which they are encouraged to indulge; and the kours allotted to recreation may perhaps be viewed as pro. 
ductive of results fully as important as those accruing from: more serious pursuits. In visiting Indian villages, we observed, that the children seldom played together in the manner in which those of white men unite for recreation. The pursuits of the Indian boy are of a solitary nature, he imitates the chace, practises shooting at a mark in order to acquire a sure aim, prepares his arrows, \&c. but seldom appears to enjoy that community of pleasures, from which a taste for society would necessarily spring. By inducing the boys of the Mission-house to play together, they will soon discover how many of the comforts and pleasures of life arise from the communion of souls; and they will be led to form attachments which will attend them through life, and which may induce them, after they have left the peaceful abode of the missionary, to continue in the course which has already been to them the fruitful source of so much delight. The females receive in the school the same instruction which is given to the boys, and are in addition to this, taught spinning, weaving, and sewing, both plain and ornamental; they were just beginning to embroider, an occupation which may, by some, be considered as unsuitable to the situation which they are destined to hold in life, but which appears to us very judiciously used as a reward and stimulus; it encourages their taste and natural talent for imitation, which is very great; and by teaching them that occupation may be connected with amusement, it may prevent their relapsing into that idleness, which has been justly termed the source of all evils. They are likewise made to attend to the pursuits of the dairy, such as the milking of cows, churning of milk, \&c. The establishw ment is intended to be opened for children from seven to fourteen years old, but they very properly receive them at a much earlier age, and even where a great desire of 
learning was manifęsted, older persons have been admitted. All appear to be very happy, and to make as rapid a progress as white children of the same age would make; their principal excellence rests in works of imitation; they write astonishingly well, and many display great natural talent for drawing. The institution receives the countenance of the most respectable among the Indians; there are in the school two of the grandchildren of Tò-pà-né-bà, the great hereditary chief of the Potawatomis, who has his residence upon this river. The Indians visit the establishment occasionally, appear pleased with it, and show their favour to it by presents of sugar, venison, \&c. which they often make to the family of the missionary. Some of the parents of the half-breed scholars pay for their children's board, and contribute in this manner to the support of the establishment; which, being sanctioned by the War Department, receives annually one thousand dollars from the United States, for the support of a teacher and blacksmith, according to the conditions of the treaty concluded at Chicago in 1821, by Governor Cass and Mr. Sibley, commissioners on the part of the United States. By this treaty about four or five millions of acres of land were relinquished by the Potawatomis. It was one of the conditions of the purchase, that a small tract of the Indian reservation should be conveyed in fee simple to the Baptist missionaries, for the purpose of forming a school and agricultural establishment. It is said that the Indians themselves selected this spot as being the site of their old village; this must have been very populous, as the remains of corn-hills, which are very distinctly visible at this time, are said to extend over a thousand acres. The village was finally abandoned about fifty years ago, but there are a few of the oldest of the nation who still recollect the site of their respective huts; they

Vou. I. 
are said frequently to visit the establishment, and to trace with deep feeling a spot which is endeared to them by "the memory of past joys, pleasing and mournful to the soul."

'The Carey Mission-house has been very liberally supported by the charitable contributions raised throughout the western states. The family have a flock of one hundred sheep, collected in Tennessee, Kentucky, and Ohio, and are daily expecting two hundred head of cattle from the same states. These contributions, together with the produce of their farm, will, it is thought, prevent them from being exposed to suffer as much from scarcity of provisions as they have already done. When we visited them, they were on short allowance, owing to the loss of a load of wheat which had been sent from Fort Wayne in a wagon a short time before we left that place, and which had been embarked in pirogues at the upper crossing of the Elkheart; by the accidental upsetting of the pirogues the whole of the cargo was lost.

We were told that the family had been deprived of the use of milk, during the whole winter, from the circumstance of their cows feeding upon a kind of wild onion which grows in the prairies. It may be well to state that, notwithstanding the great objection which the Indians: generally have to the use of milk, the children in the sehool have become quite fond of it. In order to give a greater extension to their establishment, they contemplate engaging Shane as an interpreter and assistant; from what we saw of this man while at Fort Wayne, we were not led to form so high an opinion of him as we had entertained from reports received on St. Mary's river.

No rock appears in place near the establishment; and we met with none on our way from Devil's river, except in one place where we observed, in a ravine, a calcareous for- 
mation evidently of the latest date, and which probably still continues to increase; it was filled with vegetables, some of which were unaltered, while others appeared to have undergone a partial decomposition.

Having engaged an Indian to lead us back from Mr. M'Coy's to the Chicago trace, we resumed our journey on the 3d of June. Our guide's hoary head would have satisfied even Humboldt himself, that his assertion " that the hair of Indians never becomes gray," was too general.* We have met with many instances, and the circumstance is so natural that we should not have mentioned it, but for the importance attached to the slightest observation of a traveller so accurate as Humboldt generally is. After travelling about ten miles through a prairie we parted from our guide, who considered himself amply rewarded with about half a pound of gunpowder. We then entered upon what is termed the fourteen mile prairie, which for the first seven miles presented an extensive plain uninterrupted by the least elevation, and undiversified by the prospect of a single tree. We had occasion to observe, on a former occasion, that the route which we travelled carried us along the height of land that separates the waters tributary to the Mississippi from those which empty into the lakes; and we had an opportunity of seeing this confirmed, in this place, by the fact that a communication between those waters has been effected, during wet seasons, through the fourteen mile prairic. It appears that a very leep swamp, which we avoided by our visit to the mission station, establishes a connection between two streams one of which empties its waters into the Kankakee, while those of the other run to the St. Joseph. This has. afforded, and still continues to afford every year an easy communication

* Polit. Ess, on the Kingd. of New Spain, (Lond. 1811, ) vol. i. p. 150. 
for canoes and small boats. $\Lambda$ intercourse has likewise existed, in wet seasons, across the prairie east of the trader's establishment which we passed on the previous day. At noon we rested our horses in the vicinity of the remains of an Indian village, named the Grand Quoit, and we observed a few Indian lodges scattered along the elge of the forest which encloses this prairie. On discovering our party on the prairie, the tenants of the lodges immediately rode out of the woods, advanced towards us, and opened a conversation with our guides. Their intercourse with white men, and the consequent departure from their original customs, were observable in the circumstance of their commencing the conversation, and in their minute inquries respecting our object and intentions in visiting the country. They are said to experience a great scarcity of food, which we can readily believe from the total absence of any kind of game which we have observed upon the route. An Indian who rode up near us, while we were partaking of our dinner, stopped and appeared to long after food; but called for none. We offered him some, which he very thanlifully accepted, and seemed to eat with great voraciousness.

Our party was this day overtaken by an express from Wayne, who brought letters to Major Long, one of which was from Dr. James, stating that he had been waiting in Pittsburg for the party. From the contents of his letter, we concluded that the hopes, which had been hitherto entertained, of his being able to effect a junction with us, were vain. These were the last letters, received from our friends, until we found some on our return at the Sault de St. Marie.

$\Lambda t$ about forty-three miles from the Carey station the trail which we followed struck the shores of Lake Michigan; this was a source of great gratification to us; as the 
last twelve miles of our road had been very dangerous on account of the numerous deep holes formed in it; to these may be added the many superficial roots that projected from the beech trees, in every direction, and that exposed the horses to frequent stumbling. The forest was almost exclusively composed of the finest growth of beech ; on some of the higher grounds we found, in great plenty, the partridge or fox-berry, (Gaultheria procumbens,) with its aromatic red fruit, in a state of perfect maturity; it was accompanied by the whortleberry in full blossom. We saw this day the first white pine, and in some places this tree was very abundant. We had been following for some time the valley of a small stream, called by the French, Riviere du Chemin, (Trail river,) but on approaching near to its mouth, our path winded to the south, and we found ourselves at the base of a sand-hill of about twenty feet in height; the fog which arose behind it, and the coolness of the air warned us of our approach to the lake, and on turning along the base of the hill we discovered ourselves to be on the beach of Lake Michigan. The scenery changes here most suddenly; instead of the low, level and uniformly green prairies, through which we had been travelling for some time past, or of the beech swamp which had offered us such difficulties during the last four hours of our ride, we found ourselves transported, as it were, to the shores of an ocean. We were near to the southern extremity of the lake; the view, towards the north, was boundless; the eye meeting nothing but the vast expanse of water which spread like an ocean, its surface at that time as calm and unruffled as though it were a sheet of ice. Towards the south, the prospect was limited to a few hundred yards, being suddenly cut off by a range of low sand-hills, which arose to a height varying from twenty to forty feet, in some instances rising perhaps to upwards of one 
hundred feet. When we first approached the lake, it was covered with a mist, which soon vanished and the bright sun, reflected upon the sand and water, produced a glare of light quite fatiguing to the eye. Our progress was in a southwestwardly direction, along the beach, which reminded us of that of the Atlantic on the coast of New Jersey. The sand-hills are undulating and crowned at their summits with a scrubby growth of white pine and furze; while the brow, which faces the lake, is quite bare. In the rear of the hills, but invisible from the beach, spreads a level country supporting a scattering growth of white pine, oak, beech, hophorn-beam, (Ostrya virginica, \&cc. East and west of us, a continuous narrow beach curved gradually towards the north and, bounded by the lake and the hills, was all that the eye could observe. At our evening's encampment of the 4th of June, we were at the southernmost extremity of the lake, and could distinctly observe that its south-castern corner is the arc of a greater circle than the south-western. The beach is strewed with fragments of rocks, evidently primitive, and probably derived from the decomposition of the same masses which, by their destruction, have given rise to the immense deposite of sand and pebbles that forms the bottom of the lake. These fragments, which are all rolled, vary much in size; the largest we observed weighed perhaps twenty or thirty tons. They consist of granite, mica and clay-slates, hornblende, \&c. The hills appear to have been produced by the constant accumulation of sand, blown from the beach, by the strong north-westerly winds which prevail during the winter scason; the sand is loose and uncemented. In a few places traces of lignite and peat are to be met with; doubtless resulting from the decomposition of the partial vegetation which grew upon these hills, and which was successively destroyed and buried under 
the sand; perhaps also from some of the drift-wood which is often carried ashore by the waves.

The lake appears to abound in fish, judging from the quantity that we saw gliding along the surface of the water; upon the beach there were many that lay dead, and that in some places rendered the air quite fetid. These belonged chiefly to the pike, the salmon-trout, \&c. We cannot learn that there is any great variety in the fish found in this lake. The streams passed this day, during our ride along the beach, were inconsiderable; the first is termed the Riviere des Bois, probably from the quantity of drift-wood observed near it; the English appellation for it is Stick river; the second, which we met, was the Big Calamick, (Ké-nố-mố-kônk of the Indians,) where the party dispersed. lluring the evening, each to attend to his own avocations. Major Long and Mr. Colhoun commenced observations for latitude, which they found difficult to complete on account of the fog which spread over the lake. Hunting and fishing parties were sent out, but which returned without having met with any success.

The colour of the streams which we passed indicates their origin in a swamp; and the great excess of water in this fen during some seasons, together with the loose nature of the sandy bar which divides it from the lake, causes it frequently to force the dam, and open to itself a new passage into the lake; there are near to this place two streams, one of which, named Pine river was opened last year; the other, termed New river, was formed a short time before. We crossed both these streams as well as the little Calamick, and funding that the travelling on the beach had become very uncomfortable, owing to a heavy fog, and a strong lake wind which announced an approaching storm, we crossed the sand hills, and travelled on the prairie; in this 
manner we were well sheltered from the wind. Our path led us over the scene of the bloody massacre perpetrated in 1812, when the garrison of Chicago was entirely destroyed by the Indians, (principally Potawatomis, after they had abandoned the fort and in violation of the pledge given to them by the Indians. No traces are now to be seen of the massacre; the bones, which are said to have remained for a long while bleaching upon the prairie, were at last gathered up and buried by order of Captain Bradley, who had the command of the new fort built on the ruins of the old one; but no one could point out to us the spot where they had been deposited. While resting at noon, on the bank of New river, we observed how difficult it is to judge correctly of objects on the prairie and, at the same time, how great is the similarity between the prairie wolf and the dogs owned by the Indians. While seated at dinner, we were told that one of the soldiers had discovered a wolf and was about to fire upon it. The whole party saw the animal and remained convinced that it was a wolf, until one of the men observed an Indian hut in the distance, and suggested that it might be a dog belonging to the tenant of the hut, which information induced the soldier to desist from shooting; a few moments afterwards an Indian made his appearance on the prairie and called the animal to him. This Indian was remarkable for the length of his beard, which, contrary to their usual custom, he had allowed to grow to the length of one inch and a half; his dress was indicative of the same slovenly disposition. We were obliged to commit to his charge one of the horses; this was the only one that had travelled the whole distance from Philadelphia; but he had become unable to proceed, having been affected for some time past with the distemper; and, notwithstanding all the care that was taken of him. he had 
become so faint that, even without any load, we found it impossible to make him keep up with the rest of the horses. The Indian undertook to take care of him for a few days, and then lead him to the fort, which promise he faithfully discharged.

In the afternoon of the fifth of June, we reached Fort Dearborn, (Chicago,) having been engaged eight days in travelling a distance of two hundred and sixteen miles, making an average of twenty-seven miles per day. Our estimate of the distance exceeds the usual allowance by sixteen miles, on account of the circuitous route which we took to avoid crossing the Elkheart. At Fort Dearborn we stopped for a few days, with a view to examine the country and make further preparations for the journey to the Mississippi.

In taking a retrospective view of the nature of the country travelled over, we find that from Fort Wayne to twenty miles west of Devil river, it presents as it were two distinct surfaces. 'The first, or lower one, is a level moist prairic covered with luxuriant herbage; the second, or upper one, is abruptly elevated twenty-five or thirty fect above the prairie land, and consists of a succession of flat ridges, uniform in height, but of unequal breadth, that are frequently disconnected by narrow straits of prairie land; from this circumstance the lower level presents a continuous surface, while the upper one is broken into distinct ridges insulated in the midst of the prairie. 'The soil of the ridges is poor and gravelly, covered with a thin growth of scrubby oaks; it appears to have been occasioned by what has been termed an ancient alluvial formation, (probably similar to those extensive deposites which are said to constitute the great plains that are observed in South America;) this formation having been afterwards divided by valleys

Vor. J. 
of a still later origin, has produced a lower level that is filled with a newer alluvion probably resulting from the action of causes which still continue to operate to this day; as we had an opportunity of remarking in the prairic east of the trading house which we visited previously to our arrival at the Carcy station. To these ridges succeeds a broken country consisting of insulated hills of a soil still inferior, but having more trees; among the oaks, that grow here, we observed for the first time the hickory interspersed.

Fort Dearborn is situated in the State of Illinois, on the south bank, and near to the mouth of Chicago river; the boundary line between this state and that of Indiana strikes the western shore of Lake Michigan ten miles north of its southernmost extremity, and then continues along the shore of the lake until it reaches the forty-second and a half degrec of north latitude, along which it extends to the Mississippi. The post at Chicago was abandoned a few months after the party visited it. Its establishment had been found necessary to intimidate the hostile and still very powerful tribes of Indians that inhabit this part of the country; but the rapid extension of the white population to the west, the establishment along the Mississippi of a chain of military posts which encloses them, and at the same time convinces them of the vigilance of the government, and of the inevitable destruction which they would bring upon themselves by the most trifling act of hostility on their part, have, it is thought, rendered the continuance of a military force at this place unnecessary. An Indian agent remains there, in order to keep up amicable relations with them, and to attend to their wants, which are daily becoming greater, owing to the increasing scarcity of game in the country.

We were much disappointed at the appearance of Chi- 
cago and its vicinity. We found in it nothing to justify the great eulogium lavished upon this place by a late traveller, who observes that "it is the most fertile and beautiful that can be imagined." "As a farming country," says he, "it unites the fertile soil of the finest lowland prairies with an elevation which exempts it from the influence of stagnant waters, and a summer climate of delightful serenity." "* The best comment upon this description of the climate and soil is the fact that, with the most active vigilance on the part of the officers, it was impossible for the garrison, consisting of from seventy to ninety men, to subsist themselves upon the grain raised in the country, although much of their time was devoted to agricultural pursuits. The difficulties which the agriculturist meets with here are numerous; they arise from the shallowness of the soil, from its humidity, and from its exposure to the cold and damp winds which blow from the lake with great force during most part of the year; the grain is frequently destroyed by swarms of insects; there are also a number of destructive birds of which it was impossible for the garrison to avoid the baneful influence, except by keeping, as was practised at Fort Dearborn, a party of soldiers constantly engaged at shooting at the crows and blackbirds that depredated upon the corn planted by them. But, even with all these exertions, the maize seldom has time to ripen, owing to the shortness and coldness of the season. The provisions for the garrison were for the most part conveyed from Mackinaw in a schooner, and sometimes they were brought from St. Louis, a distance of three hundred and cighty-six miles up the Illinois and Des Plaines rivers.

The appearance of the country near Chicago offers but few features upon which the eye of the traveller can dwell

* Schoolcraft's Narrative Journal of 'Travels, (Albany, 1820,) page 384. 
with pleasure. There is too much uniformity in the scenery; the extensive water prospect is a waste uncheckered by islands, unenlivened by the spreading canvass, and the fatiguing monotony of which is increased by the equally undiversified prospect of the land scenery, which affords no relief to the sight, as it consists merely of a plain in which but few patches of thin and scrubby woods are observed scattered here and there.

The village presents no cheering prospect, as, notwithstanding its antiquity, it consists of but few huts, inhabited by a miserable race of men, scarcely equal to the Indians from whom they are descended. Their log or bark houses are low, filthy and disgusting, displaying not the least trace of comfort. Chicago is perhaps one of the oldest settlements in the Indian country; its name, derived from the Potawatomi language, signifies either a skunk, or a wild onion; and either of these significations has been occasionally given for it. A fort is said to have formerly existed there. Mention is made of the place as having been visited in 1671 by Perot, who found "Chicagou" to be the residence of a powerful chief of the Miamis. The number of trails centring all at this spot, and their apparent antiquity; indicate that this was probably for a long while the site of a large Indian village. As a place of business, it offers no inducement to the settler; for the whole annual amount of the trade on the lake did not exceed the cargo of five or six schooners even at the time when the garrison received its supplies from Mackinaw. It is not impossible that at some distant day, when the banks of the Illinois shall have been covered with a dense population, and when the low prairies which extend between that river and Fort Wayne, shall have acquired a population proportionate to the produce which they can yield, that Chicago may become one of the points in 
the direct line of communication between the northern lakes and the Mississippi; but even the intercourse which will be carried on through this communication, will we think at all times be a limited one; the dangers attending the navigation of the lake, and the scarcity of harbours along the shore, must ever prove a serious obstacle to the increase of the commercial importance of Chicago. The extent of the sand banks which are formed on the eastern and southern shore, by the prevailing north and northwesterly winds, will likewise prevent any important works from being undertaken to improve the post of Chicago.

The south fork of Chicago river takes its rise, about six miles from the fort, in a swamp which communicates also with the Des Plaines, one of the head branches of the Illinois. Having been informed that this route was frequently travelled by traders, and that it had been used by one of the officers of the garrison, who returned with provisions from St. Louis a few days before our arrival at the fort, we determined to ascend the Chicago river in order to observe this interesting division of waters. We accordingly left the fort on the 7th of June, in a boat which, after having ascended the river about four miles, we exchanged for a narrow pirogue that drew less water; the stream we were ascending was very narrow, rapid, and crooked, presenting a great fall; it continued so for about three miles, when we reached a sort of swamp designated by the Canadian voyagers under the name of le petit lac. Our course through this swamp, which extended for three miles, was very much impeded by the high grass, weeds, \&c. through which our pirogue passed with difficulty. Observing that our progress through the fen was very slow, and the day being considerably advanced, we landed on the north bank, and continued our course along thr: 
edge of the swamp for about three miles, until we reached the place where the old portage road meets the current, which was here very distinct towards the south. We were clelighted at beholding for the first time, a feature so interesting in itself, but which we had afterwards an opportunity of observing frequently on the route; viz. the division of waters starting from the same source, and running in two different directions, so as to become the feeders of streams that discharge themselves into the ocean at immense distances apart. Although at the time we visited it, there was scarcely water enough to permit our pirogue to pass, we could not doubt, that in the spring of the year the route must be a very eligible one. Lieut. Hopson, who accompanied us to the Des Plaines, told us that he had travelled it with ease, in a boat loaded with lead and flour. The distance from the fort to the intersection of the Portage road and Des Plaines, is supposed to be about twelve or thirteen miles; the elevation of the feeding lake above Chicago river was estimated at five or six feet; and, it is probable that the descent to the Des Plaines is less considerable. The Portage road is about eleven miles long; the usual distance travelled by land seldom however exceeds from four to nine miles; in very dry seasons it has been said to amount to thirty miles, as the portage then extends to Mount Juliet, near the confluence of the Kankakee. When we consider the facts above stated, we are irresistably led to the conclusion, that an elevation of the lakes of a few feet, (not exceeding ten or twelve,) above their present level, would cause them to discharge their waters, partly at least, into the Gulf of Mexico; that such a discharge has at one time existed, every one conversant with the nature of the country must admit; and it is equally apparent that an expenditure, trifling in comparison to the importance of the 
object, would again render Lake Michigan a tributary of the Mexican gulf. Impressed with the importance of this object, the legislature of Illinois has already caused some observations to be made upon the possibility of establishing this communication; the commissioners appointed to that effect, visited Chicago after we left it, and we know not what results they obtained, as their report has not reached us; but we have been informed that they had considered the elevation of the petit lac above Chicago to be somewhat greater than we had estimated it. It is the opinion of those best acquainted with the nature of the country, that the easiest communication would be between the Little Calamick and some point of the Des Plaines, probably below the Portage road; between these two points there is in wet seasons, we understand, a water communication of ten or twelve miles. Of the practicability of the work, and of the sufficiency of a supply of water no doubt can exist. The only difficulty will, we apprehend, be in keeping the communication open after it is once made, as the soil is swampy, and probably will require particular care to oppose the return of the soft mud into the excavations.

In the immediate vicinity of Chicago, a secondary limestone is found, disposed in horizontal strata; it contains many organic remains. This limestone appears to us to be very similar in its geological as well as mineralogical aspect, to that observed above the coal formation on the Miami; but no superposition being visible, it is impossible for us to determine at present its relative age; we however incline to the opinion, that it is one of the late secondary limestones. We have to regret that the specimens which were obtained of the same have been lost, and that we are deprived of the opportunity of comparing them with those collected in other parts of our routc. This limestone, which 
lies exposed to view in some places, is for the most part covered with an alluvial deposite consisting of the detritus of primitive rocks. Upon the shore of Lake Michigan, specimens of native copper have likewise been orcasionally pickel up. We have in our possession, owing to the liberality of Dr. Hall, a specimen which is part of a mas:weighing two pounds, found by the express from Chicagn to Greenbay; it was picked up, on the lake shore, about five miles south of the Milwacke, a stream which empties, into the lake about eighty-five miles north of Chicago; the spot at which it was found is known by the name of the Soapbanks, and is stated by Mr. Schooleraft to consist of a bed of white clay; Dr. Hall was led to visit the spot in hopes of finding more copper, but met with none. We have dwelt upon this fact merely from the great importance which has been attached to every locality of native copper, by those who are induced to believe that, where a specimen exists, a mine ought to be looked for. In reading the relations of travellers on the subject we become satisfied of the incorrectness of this conclusion; wherever the copper has been found, it has always been in detached masses, generally of a small weight, and appearing evidently out of place. We must not therefore expect to find veins in their vicinity; if the existence of copper in the west deserves all that importance which it has received, a circumstance which we very much question in the present state of the country, it is not upon the study of the localities of these fragments of native copper that we are to waste our time and means. The main object must be to ascertain whence they came; and this can only be determined by an examination of the nature of the valleys, of the extent and abundance of the alluvial deposite in which they are found, and of the original primitive form:- 
lions, from the partial destruction of which these extensive deposites of alluvion, and the large boulders which accompany them, have received their origin. But these are considerations which we shall not broach at present, as they will find their place, more naturally, at a later period of this work.

Although the quantity of game in this part of the country is diminishing very rapidly, and although it is barely sufficient for the support of the Indians, still there is enough, and particularly of the smaller kind, to offer occupation to the amateur sportsman. There are many different kinds of aquatic birds, which feed upon the wild rice, (Zizania aquatica,) and other plants that thrive in the swamps which cover the country. Mr. Say observed, among others, the mallard, (Anas boschas,) shoveller-duck, (A. clypeata,) blue-winged teal, (A. discors, common merganser, (Mergus serrator,) common coot, (Fulica americana,) stellate heron or Indian hen, (Ardea minor,) \&c. \&c. In the lake there is also a great quantity of fish, but none appears to be of a very superior quality; the white fish, (Coregonus albus, Lesueur,) which is the greatest delicacy found in the lakes, is not caught at Chicago, but sometimes twenty or thirty miles north of it.

Observations, for latitude and longitude, were made here, by Mr. Colhoun, from which the situation of this place was found to be in latitude $41^{\circ} 59^{\prime} 53^{\prime \prime} \mathrm{N}$.-longitude $86^{\circ} 47^{\prime}$ 15" W.-Magnetic variation $6^{\circ} 12^{\prime}$ Fast.*

During our short residence at Chicago, we were, by the favour of Dr. Wolcott, the Indian agent, furnished with much information concerning the Indians of this vicinity, through his interpreter, Alexander Robinson, a half-breed

* See Appendix II. The longitude cannot be depended upon with certainty, as there was some doubt as to the error of the watch.

VOL. I. 
Chipperva, who informed us that the Indians who frequent this part of the country are very much intermixed, belonging principally to the Potawatomis, Ottawas, and Chippervas, (ơ'-ch'ê-pế'-w'àg, $\left.{ }^{*}\right)$ from which circumstance a great admixture of the three languages prevails here. The vicinity of the Miamis has also, in his opinion, tended to adulterate the language of the Potawatomis in the neighbourhood of Fort Wayne; and it is believed that this language is spoken in the greatest purity, only along the banks of the St. Joseph of Lake Michigan. Robinson did not suppose the Potawatomis to exceed two thousand five hundred souls; but it is probable that their number must be greater; especially as they are united with the Kickapoos, whose population amounts to six hundred in the State of Illinois. According to his observations, the Potawatomis believe that they came from the vicinity of the Sault de St. Marie, where they presume that they were created. A singular belief, which they entertain, is, that the souls of the departed have, on their way to the great prairie, to cross a large stream, over which a $\log$ is placed as a bridge; but that this is in such constant agitation, that none but the spirits of good men can pass over it in safety, while those of the bad slip from the $\log$ into the water and are never after heard of. This information they pretend to have had revealed to them by one of their ancestors who, being dead, travelled to the edge of the stream, but not liking

* We have in the course of this work conformed with the general usage in the spelling of this word, dropping the final $y$ used by many authors; but from the above method of spelling it, according to its pronunciation, it will be readily observed that the usual orthography can give no idea of the true Indian pronunciation of this word. The final letter ought to be pronounced in a manner intermediate between the $g$ and $k$. 
to venture on the $\log$, determined to return to the land of the living, which purpose he effected, having been seen once more among his friends, two days after his reputed death. He informed them of what he had observed, and further told them that while on the verge of the stream, he had heard the sounds of the drum, at the beat of which the blessed were dancing on the opposite prairie. This story they firmly believe.

With a view to collect as much information as possible on the subject of Indian antiquities, we inquired of Robinson whether any traditions, on this subject, were current among the Indians. He observed, that their ancient fortifications were a frequent subject of conversation; and especially those in the nature of excavations made in the ground. He had heard of one, made by the Kickapoos and Fox Indians, on the Sangamo river, a stream running into the Illinois. This fortification is distinguished by the name of E'tu'at'a $\mathbf{E}^{\prime} k$. It is known to have served as an intrenchment to the Kickapoos and Foxes, who were met there and defeated by the Potawatomis, the Ottowas, and the Chippewas. No date was assigned to this transaction. We understood that the Etnataek was near the Kickapoo village on the Sangamo.

The hunting grounds of the Potawatomis appear to be bounded on the north by the St. Joseph, (which on the east side of Lake Michigan separates them from the Ottowas,) and the Milwacke, which, on the west side of the lake, divides them from the Menomones. They spread to the south along the Illinois river about two hundred miles; to the west their grounds extend as far as Rock river, and the Mequin or Spoon river of the Illinois; to the east they probably seldom pass beyond the Wabash. 


\section{CHAPTER V.}

Rock river. Mennmones. Geology of the country west of Lake Michigan. Prairie du Chien. Saukis and Foxes.

IA VING spent a ferv days in Chicago, the party left that post on Wednesday, June 11th. By the instructions received from the War Department, Major Long had the option of striking the Mississippi at Fort Armstrong, or at Dubuque's lead mines, and then ascending that river to Prairie du Chien. It appeared to him, however, that if the direct rnute to Prairie du Chien, across the prairies, was practicable, it would save several days; but upon inquiry no person could be found who had ever travelled through, in that direction; and although from the description of the country, the route was supposed to be very practicable, yet from the impossibility of procuring a guide, it would have been relinquished, had not an old French engagé, by the name of Le Sellier, undertaken to direct the party. This man, who had lived for upwards of thirty years with the Indians, had taken a wife among the Winnebagoes. and settled on the head waters of Rock river; knowing the country as far as that stream, he presumed that he could find his way thence to Fort Crawford, situated on the Mississippi near the junction of the Wisconsan. Under his guidance the party proceeded on the first day of their journey, in a general direction nearly west, for about seventeen miles. The first stream passed, on that day, was the Chicago river, which we crossed about half a mile above the fort, and immediately above the first fork, (or Gary's river); the 
party next came to the River les Plaines, which is one of the head branches of the Illinois; it receives its name from a variety of maple, which by the Canadians is named Plaine. In Potawatomi the river is termed Shé-shìk-mâ-ô-shî-kẻ Sẻ-pé, (which signifies flumen arboris quæmingit.) This appellation is derived from the great quantity of sap which flows from this tree in the spring. We crossed the Des Plaines about four miles above the Portage road; it was forty yards wide, and so deep that part of our baggage was wet while fording it, but fortunatcly none materially injured. The length of the Des Plaines from this ford to its source is about fifteen miles, that to its confluence with the Kankakee about forty miles.

We encamped on the east bank of a small stream, about eight yards wide, designated by the Indians under the name of 'o-tò-kâ-kể'-nôgg, which means the uncovered breast. The voyagers call it De Page's river, from a Frenchman of that name, who died and was buried on the banks of this stream. The De Page enters the Des Plaines about half a mile above its junction with the Kankakee. From Chicago to the place where we forded the Des Plaines, the country presents a low, flat, and swampy prairie, very thickly covered with high grass, aquatic plants, and among: others with the wild rice. The latter occurs principally in the places which are still under water; its blades floating on the surface of the fluid like those of the young domestic plant. The whole of this tract of country is overflowed during the spring, and canoes pass in every direction across the prairic. Near the fording of the Des Plaines there is a Potawatomi village, some of the inhabitants of which came to converse with us, while we were encamped at noon, during a thunder storm. The birds we saw to-day consisted of prairie hens or grous, (Tetrao cupido) reed- 
birds, (Emberiza oryzivora, Wilson,) sand-hill eranes, (Grus canadensis,) curlews, \&c. Many badger holeswere observed; we saw at the garrison one of these animals, that had been raised in the fort, and whose playful, inoffensive manners, had made him a general favourite.

$\Lambda$ ride of about eighteen miles brought us to the banks of Fox river, which is a fine stream about one hundred and thirty yards wide, the scenery of which is varied by several islands scattered through its channel. The country; which consisted of prairie land, became handsomely wooded in the neighbourhood of the river; a couple of Indian lodges, seen in the distance, gave an appearance of inhabitance to the spot. These we found to belong to the M'é-nơ-m 'ó-n'é, or wild rice eaters, a nation that appears to be fast decreasing in numbers. The reports concerning the Menomone nation are so various, and we observed so few of them on the route, that we had not an opportunity of forming an opinion upon the disputed point of their Algonquin origin. It is said that few if any white men have ever been able to learn their language; and we have been assured by the late Indian Agent at Greenbay, (Major John Biddle, that he had found it difficult to obtain an interpreter capable of conversing with them in their own language. A considerable intercourse has, however, existed between them and white men; but it is said to be principally in the Algonquin languages, the prevailing medium of intercourse being the Chippewa, Ottawa, and Potawatomi languages, or as in most cases a mixture of these three dialects. The few Menomones whom we met with were of a light colour; resembling much that of the light mulattoes in our Atlantic states, probably nearer the colour of individuals resulting: from an admixture of fivc-eighths European with threeeighths of African blood. It is said that this light colour 
which distinguishes the Menomones from other Indians, results from a general admixture of European blood. But we have been assured, that eren when of pure Indian extraction, they are of a lighter colour than their neighbours, and are therefore often called the White Indians. Whether they be descendants of the Algonquins, or of a different race of men, is a question of much importance, and which perhaps may yet be resolved by those, whose opportunities of obtaining information, on that subject, are greater than ours were. If they be sprung from a different race of men, it may still be questioned whether they settled here, previously or subsequently to the Algonquin tribes. Charlevoix says that they were not populous in his time. "This is to be regretted," he adds, "for they are very fine men, and the best shaped of all Canada; they are even taller than the Pouteouatamis. I am assured that they have the same origin and nearly the same language as the Noquets and Saulteurs, (Leapers;)* but they add, that they have also a particular language, which they keep to themselves." $\dagger$ The Menomones at present reside principally on the west shore of Lake Michigan north of the Milwacke, in the vicinity of Greenbay, and on the head waters of Fox river, (of Greenbay,) of Menomone river, \&c. Their personal appearance is very favourable, and indicative of more neatness, and of a greater taste for ornament, than that of any other of our north-western Indians. Their mode of preparing belts, garters, sheaths for knives, moccasins, \&c. and of ornamenting them with beads, and with the coloured quills of porcupines, evinces much taste, and this of the best kind. It does not appear that with them the mere combination of many gaudy colours constitutes beauty; but this is made to

- Chippewas.

† Journal Historique, Letter 19th. 
depend more upon the proper union of the three colours, white, red, and blue united, to form symmetric and varied designs.

The Fox river, which we crossed, must not be mistaken for the same which runs north-eastwardly into Greenbay of Lake Michigan. Its course is in a different direction, being nearly south-west; it falls into the Illinois about fiftcen or twenty miles below the confluence of the Des Plaines and Kankakee.

The Fox river of the Illinois is called by the Indians Pish-t'ả-kó. It is the same which is mentioned by Charlevoix under the name of Pisticoui, and which flows, as he says, through the country of the Mascoutins. At present it is claimed, at least in this part, by the Potawatomis and Kickapoos, who are incorporated together; the Menomones are allowed to remain there, on account of their being connected by intermarriages. The river has a fine gravelly bottom, and was very easily forded. On the west side we reached a beautiful but small prairie, situated on a high bank, which approaches within two hundred and fifty yards of the edge of the water; and upon this prairie we discovered a number of mounds, which appeared to have been arranged with a certain degree of regularity. Of these mounds we counted twenty-seven; they vary from one to four feet and a half in height, and from fifteen to twenty-five in length; their breadth is not proportional to their length, as it seldom exceeds from six to eight feet. They are placed at uncqual distances, which average about twenty yards; they are chiefly upon the brow of the hill, but some of them stand at a greater distance back. Their form appears to have been originally oval; and the slight depression in the ground, observed sometimes on both sides of a mound, secms to indieate, that it has been raised by 
means of the earth collected in its immediate vicinity. We remained ignorant of the causes which may have given rise to their construction, or of the circumstances under which they were executed. Of their artificial nature, no doubt could be entertained. They may probably have been ancient dirt lodges, similar to the ruins observed by Mr. Say, during the expedition to the Rocky mountains, and which were known to be the remains of lodges that had existed within the memory of some of the Indians then living. It does not appear that the Indians, who reside near the Fox river, have any recollection or tradition on this subject. Our guide informed us, that they believed, upon the authority of the missionaries, that these mounds were of antediluvian origin, and probably erected as places of retreat for their families in time of war.

Proceeding two miles further, through a thinly wooded country, we crossed a brook four yards wide; and six miles further of fine, rolling prairie, interspersed with light woods, brought us to our encampment of the 12th of June. As we stopped upon the encamping ground, a night-hawk flew away and abandoned two eggs, which she appeared to have deposited on the ground, without preparing any kind of nest; they were of a dull white colour, thickly spotted over with dirty brown blotches. A heavy shower, accompanied by thunder and lightning, made the weather very comfortable. But a high wind, which arose during the night, rendered travelling very unpleasant in the morning. At about twenty-eight miles in a general westerly course from the Pishtako, we came to a beautiful winding stream, called the Kỉsh-wà-kè, (Cottonwood.) It is about twelve yards wide, and is a tributary of Rock river. About one and a half mile below the place where we forded this stream, we saw a small Indian vil-

VOL. I. 
lage, designated by the name of Wi-ke'sa, (little bend,) from its situation at one of the bends of the Kishwake. It consisted of four lodges, the population of which was computed to amount to at least sixty persons, as there were many crowded into one lodge; the village is chiefly inlabited by Menomones, with a few Potarvatomis who have intermarried with them. We stopped at the lodge of the chief, whose name is $K^{\prime}{ }^{\prime} a-k ' a-k e^{\prime}-\operatorname{sh}^{\prime} \mathfrak{a}$, (Crow.) He, together with many of his people, was engaged in his cornfields; on seeing the strangers, they gave the dog-whoop, and collected at the house at which we had stopped. They were all tall and muscular men, well built, and better looking than the Potawatomis generally are; their countenance was agreeable, and denoted none of that severity about the mouth which Volney ascribes to those whom he saw. The chief is a very old man and quite bald; at the time he approached us he had a child-board on his back, in which he carried his little grandson. Although advanced in years, Kakakesha had none of the decrepitude of old age; there was much dignity in his manner. The women were all very ugly, and the children looked like little imps, in whose countenance, and apparently deformed bodies, we could scarcely discover the embryo of men as tall and elegant as those who stood before us. Most of their youth had gone out on a hunting excursion. The men whom we saw were almost naked, having no other garment than the breech-cloth, but as we drew near them they gathered up thcir blankets; the women had a sort of short-gown and a blanket; the children ran about naked, with no other appendage than a belt round their loins. It is curious to observe that all Indians, whether old or young, wear a belt, even when they have nothing to attach to it; and the children, who seldom assume the breech-cloth until they at- 
kain the age of puberty, have all a belt tied round them, as soon as they can run about. The house, which we visited, was about twenty fect long by fifteen wide, and full twelve feet high at its centre. Seen from a distance, it resembled a log-house; but on approaching we discovered it to be formed of bark, secured to a frame made of poles, and covered with the same material. It had the appearance of being very comfortable. The fire was made in the middle of the house; two sides of the interior were occupied with a frame, three feet high and four or five feet wide, which was covered with blankets, skins, \&c. and on these the inmates sleep and eat; upon these we were invited to sit down. There is no sign of partition, or of any thing that can serve as a skreen to separate or divide one part of the family from another. A woman who was sick, lay in the lodge exposed to view, until the child, which was taken from the chief's back, and which was her's, was handed over naked to her. Whether from this circumstance, or to avoid the curious glances of some of our party, who appeared to be watching the sick woman's motions, we know not, but a blanket was soon suspended in order to conceal the patient from view.

The disposition of these Indians was friendly. The object of the expedition was explained to them, to which they made no reply, but the chief directed his squaw, who was a very fieshy woman, to give us some maple sugar in return for the tobacco we had presented him ; he expressed his regret at having no fresh meat to give us; but added, that if his hunters returned that evening with meat, he would send some to our camp. We were a little shocked at their familiar disposition, which we at first mistook for intentional impudence; they all collected round us, took our guns, and began to examine them with care, appeared 
to be highrly pleased with the double-barrelled guns of some of the gentlemen of our party; one of them even drew Mr. Say's hunting knife from the sheath, and after having examined it, returned it; he then took Mr. Say's hat, which was a white beaver one, and after having also examined this with care, tried it on his own head. All this, however, appeared to proceed rather from childish curiosity than from any intention to give offence. After some timc, they began to beg for bacon, which soon compeiled us to leave them.

In order to avoid all further importunity, we travelled ten miles before night, and encamped on a fine piece of level ground, which was watered by a small stream that discharged itself three miles below into the Kishwake. The thermometer was observed, at six o'clock, P. M. to be at eightytwo degrees in the shade, but no inconvenience was felt from the heat, owing to a fine westerly breeze which prevailed during the day.

On the 14th of July, the party reached Rock river, which is the most important tributary of the Mississippi, between the Illinois and the Wisconsan. Rock river is termed, in the languages derived from the Algonquin, Sin-sè-pè, and in the Winnebago, Wè-rò-shâ-nầ-grå, both which names have the same signification as the English term. It forms the division between the hunting grounds claimed by the Potawatomis, on the eastern side, and those of the Sauks, Foxes, and Winnebagoes on the west. At the place where we crossed the river, it was about one hundred and twenty yards wide; and its depth was such that it could not be forded at that time, though we were informed that it is customary for horses loaded with furs, to cross it without difficulty. We were ferried over in a small canoe, sent for us from an Indian 
village in the vicinity. We crossed Rock river just above the mouth of the Kishwake, the same stream which we had passed the day previous, but which, from its great increase, we scarcely recognised, when we saw it three miles above its mouth, where we were again obliged to cross it. Opposite to the mouth of the Kishwake there is a large island in Rock river. At the lower crossing of the Kishwake, we passed through an Indian village, designated by the name of the river, and which is inhabited by a mixed race of Potawatomis, Chippewas, Ottawas, Menomones, \&c. The chief, who belongs to the first of these nations, was away at the time we were there, and in his absence we sav no person who could converse with us. A lad, who was in the village, and who, as we were told, was the son of the late chief, when spoken to, made no answer, but seemed to be very stupid; although the other Indians did not appear destitute of intelligence, yet not one of them could converse with us. This indeed is one of the characteristics of Indians. The business of receiving and replying to speeches belongs to the chief, it is one of his proudest prerogatives, and it is one in which he chiefly endeavours to excel; while the other Indians, seeming to consider it as no concern of theirs, pay no attention to it, and are always at a loss, when spoken to by those whom they are accustomed to treat with respect or with regard; but with the traders, whom they ridicule, and for whom they openly profess the most manifest contempt, they will join in conversation very freely and familiarly. After having crossed Rock river, we stopped to dine on the high bank which confines it on the west side, and were not a little amused at the apparent delight with which the little Indian boy, who had brought the canoe to us from Kishwake village up Rock river, partook of the bread and bacon which we gave him; it really seemed as 
though it were the most delicate food that he had ever tasted.

The valley of Rock river is about half a mile wide at this place; it is utterly destitute of rocks, differing, in this respect, very much from the characters observed higher up, and which have entitled it to the name that it now bears. We could not, however, ascertain whether the rocks were there in place, or merely boulders. We had, in the course of the morning, observed a spot where the limestone appeared in situ; this was in every respect similar to that found near Chicago. The boulders and pebbles which, from Chicago to Fox river, had not appeared to be as numerous as in some other parts of the route, were, after we had seen the limestone in the morning, found to increase rapidly in number, though not perhaps in size. From his former observations upon the country, Major Long thought we were approaching what has been considered the lead formation of the west, and this was confirmed by the assertion of our guide, that much lead had been found on some of the tributaries of Rock river, where it is worked, by the Indians, in small quantities for their own use. This induced us to make a careful examination of the country, with a view to ascertain whether any lead ore occurred upon our route, and if it did, under what circumstances. We met with none; but from all the characters observed in the country, we hesitate not in considering its surface as covered by an ancient alluvion, the alluvion of mountains of the Wernerian school; and in which, of course, if any lead should be found, it must be out of its original site. This alluvion consists principally of a bed of loose and uncemented pebbles, varying in size from the smallest grain to the dimensions of an apple, and interspersed with boulders, which frequently aequire very large dimensions; but 
these do not appear to be so frequent here, whether it be because they are buried in, and concealed by the pebbles, or because they were not deposited here, we had no means of determining. The alluvion appears to consist chiefly of the detritus of primitive rocks, such as fragments of quartz, granite, sienite, \&c. but, as far as we could observe, without any trace of a metalliferous mineral. There are also many fragments of limestone, interspersed throughout the mass. Under the alluvion, the limestone observed in the morning probably extends to a great distance. From the observations which we have been able to make, we believe it to be the same limestone formation, which extends from Piqua to Fort St. Mary, and which is seen near Fort Wayne, Chicago, and Rock river. Whether it be the same as that observed further east, or in what relation it stands to it, we are not desirous of deciding positively, but we believe it to be at least as modern as that found above the coal formations of Wheeling and Zanesville, and perhaps more so. We have spoken of the supposed lead formations of Rock river; not having visited Dubuque's lead mines, or those in the state of Missouri, it would be impossible for us to express a decided opinion upon their nature; but from all that we have heard on the subject, as well as from what has been written upon these lead mines, we can scarcely hesitate in considering the ore as being equally out of place there. Whether the original sites, from which it has been detached, are still to be found in the vicinity, is a point which those alone who have seen the country are competent to decide, if indeed the question can in the present state of science be resolved; the authors who have written upon this subject have, as it appears to us, left the question open; for while they assert that the lead is found in clay, they appear to us desirous to convey, at all times, 
the impression that it is in place, as we are informed that it " is found in detached pieces and solid masses, in veins and beds in red clay, and accompanied by sulphurate (sulphate?) of barytes, calcareous spar, blende, iron pyrites, and quartz." Now, that all the indications mentioned by those who have seen these mines, justify a belief that the lead is not in its original site, we consider as satisfactorily proved. That the lead ore as well as the accompanying minerals, must be out of place, is equally apparent, from the circumstance, that while the clay is said to repose upon the limestone, the ore is not stated to have ever been worked in this rock. We are told, that "the greatest proportion of lead ore is, however, found imbedded in, and accompanied by, the sulphate of barytes resting in a thick stratum of marly clay, bottomed on limestone rock. The rock is invariably struck at a depth of from fifteen to twenty feet, and puts a stop to the progress of the miner in a common way. To go further, it is necessary to drill or blast, and this creates an expense which the generality of diggers are unwilling to incur, if not unable to support." † Again, we find "in digging down from fifteen to twenty feet, the rock is generally struck; and as the signs of ore generally give out on coming to the rock, many of the pits are carried no further." $\ddagger$ Finally, in his visit to Dubuque's lead mines, performed in the year $1820, \mathrm{Mr}$. Schoolcraft observed, that the ore "had been chiefly explored in alluvial soil;" though he at the same time states, that "it generally occurs in beds or veins." $\$$ From the specimens which we have seen, as well as from

"Vicw of the Lead Mines of Missouri. New York, 1819. p. 67. † Ibid, p. 69.

¥ Ibid, p. 108.

\$ Schoolcraft's Narrative Journal of Travels, \&c. p. 344. 
ill that we have heard and read, we cannot hesitate in asserting it as our opinion, that no lead has as yet been discovered on the Merrimeg or Mississippi in a metalliferous limestone; * but that, wherever it has been found, it has always been in an alluvion, and never in regular veins or bods, nor even in masses, which might be considered as coeval with the substances in which they are imbedded.

On both banks of the Kishwake, not far from its mouth, there are many mounds in every respect similar to those met with on Fox river; but scattered along the bank without any apparent order. Mr. Say counted upwards of thirty of these mounds. It is probable that they were formerly the cemeteries of a large Indian population which resided along the banks of the Kishwake, and which had perhaps its principal village at the beautiful confluence of this stream with Rock river.

In travelling over a prairie country the party were often obliged to lengthen or shorten their day's journey, in order to accommodate themselves to the scarcity of water and wood. The afternoon of the 14th of June we encamped at three o'clock, as the distance to the next camping ground would have led us too far into the evening: The afternoon was employed in taking observations for longitude, and in making such repairs and alterations in

* By metalliferous limestone, we allude to that in which the leadmines of Cumberland and Derbyshire in England, of Vedrin in Belfilum, \&c. are found. This limestone is by most geologists considered as older than the coal, and probably in many instances connected with transition formations; according to Conybeare and Phillips, it is placed, under the name of mountain limestone, between the old red sandstone formation and the coal measures. (Vide Geology of Eng. land and Wales, London, 1822, part 1, plate, fig. 3.)

VOL. I. 
our travelling equipage as had become necessary. Our horses' backs had been chafed by the saddle, notwithstanding all the eare taken to keep them in a sound state, which was dictated not only by humanity, but also by a provident attention to our own interest; for very little experience is required to satisfy a traveller that much of his comfort and expedition, on such a journey as ours, depends upon the circumstance of his horse's back not being galled, as it otherwise worries and tires the animal before he has performed much work. For the information of other travellers, we may mention, that after having tried many applications, we have found none that succeeded so well as white lead moistened with milk, as long as this could be procured; after we had left the settlements, sweet oil was used as a substitute for milk; whenever the application was made in the early stage of the wound we have found it to be very effectual. It is likewise a convenient one to carry on an expedition, as a couple of ounces of white lead sufficed for the whole of our party during more than a month.

The succeeding morning the weather was very fair, and the party continued its course over fine undulating prairies, expanded in every direction so as to appear in some cases unbounded by woods. The only defect which we observed in the country between Chicago and the Mississippi is the scarcity of wood, which is more seriously felt on the west side of Rock river, than to the east of it. This will perhaps be the principal difficulty in settling the country; otherwise the land is good, not hilly, sufficiently watered, and would we doubt not prove productive if well worked. Limestone is frequently to be met with, cren west of Rock river; in other places the soil is underlaid with pebbles of white hornstone; the boulders are not sufficiently abun- 
dant to prove injurious to agriculture; we observed as a distinction between those seen within the two last days, and those met with east of Rock river, that the former contain principally hornblende instead of mica in their composition, while the boulders near Lake Michigan were chiefly granitic. The rock, which has given rise to the hornblendic boulders, is one of a peculiar and interesting nature ; it differs from sienite by the presence of quartz, from granite by the substitution of hornblende for mica. This rock has not received much attention from European authors; it does not appear to occupy a very important rank in the geology of Europe, while on the contrary it is very abundant in North America. Those, who are conversant with the mineralogy of New Jersey, know that it constitutes most of the primitive rocks which are found in West Jersey, and which have been described either as granite or sienite; however extensive that deposite may be, it bears no comparison to the extensive formation of this rock, which we shall have occasion hereafter to describe, and from which the fragments which constitute the boulders found in Illinois, Indiana, Ohio, \&c. have, as we believe, been detached.

After travelling eighteen miles, we reached a small stream, designated under the name of Pèk-tân-nỏñs, a diminutive of Péktâunỏn, ${ }^{*}$ a neighbouring stream into which it discharges itself a few miles below. The meaning of this last in the Sauk language is muddy, and it is remarkable that the

* As we have had frequent opportunities of observing a nasal termination in Indian words, belonging both to the Sauk, Dacota, and other languages, we have adopted the sign $(\overline{\mathrm{n}})$ to designate this sound, which is equivalent to the nasal termination of the French language, thus in the word Pektannon, the last syllable is pronounced by the Indians, exactly as the word non is by the French. 
same name has been applied to the Missouri by the Sauks. Our guide informed us that it was very common for the Sauks to form a diminutive of a word, by the addition of a hissing sound at the end, as in the above-mentioned instance. Observing that Le Sellier seemed to have gone beyond the limits of the country with which he was acquainted, Major Long thought it would be desirable to endeavour to procure an Indian, as a guide to Prairie du Chien: and as we were in the vicinity of an Indian village, Le Sellier. was sent ahead, to request one of the men to accompany us. The village to which he went was situated on the main stream, about three miles from the place where we had halted for dinner on the Pektannons; it consisted of seven permanent and three temporary lodges, inhabited principally by Sauks, Foxes, Winnebagoes, Menomones, and Potawatomis. Their chief is a Sauk; he was absent, but we saw his elder brother, whom we engaged to accompany us to Prairie du Chien. His name was W'àné'b'éít Nâmỏ'ẻtû, (spinning top,) the chief's name was W'àbẻ'tế'j'čc, (white cedar.) We visited the inside of their bark lodges, which were very comfortable; the number of men appear ed to us much greater than that of women in the village. Being aware of our approach, from the information received through Le Sellier, they had manifested their friendly disposition by hoisting flags, or white rags, all around their village and, among others, three white flags hung: from the head and arms of a large cross, rudely cut out, which marked the grave of some departed white man. Their behaviour was less familiar than that of the Indians whom we had last met with; but as they evinced the same curiosity to examine our arms, we were led to ascribe their greater reserve, to the admonition given that morning to the Frenchman, that the familiar manner with which he be- 
haved towards them, must be discontinued in our presence, as to that we ascribed their forwardness. The men of this village were distinguished from those observed in other places, by their unusually dark and expressive eyes, the playful smile of their mouth, and their well-formed nose. We found them very short of provisions; they offered us, however, a bowlful of maize, which was very acceptable, as our bread-corn had been consumed. One of the party observed in the lodge a large basket, full of acorns intended no doubt for food. We proceeded that afternoon a few miles further, and encamped on a beautiful spot near the Pektannon; it was on the verge of a fine wood. The adjoining prairie afforded our horses the finest pasture that could be wished for; an attempt to fish was made, but it: proved unsuccessful. It does not seem that these rivers abound in fish, and the Indians place no dependence upon the produce of the fishery for their support. While encamped this evening, we were visited by several Indians, who came from the village, and who behaved themselves in a very becoming manner. In order to compare the language of the Winnebagoes, as spoken here, with that conlained in the vocabulary obtained by Major Long in the year 1817, and which is recorded in the "Account of an Expedition to the Rocky Mountains," (vol. 2, p. Ixxxvi.) we read to one of these Indians, who was a Winnebago, the words as published in the vocabulary, with a view to ascertain whether or not he understood them; the attempt was rather a difficult one, as he had to convey the meaning of the Winnebago term in the Sauk language to Le Sellier, who translated it into French to one of the party by whom it was reduced into English. The result of this threefold translation was, however, that he recognised, without hesitation, about one-third of the words; 
the meaning of the remainder, which he did not readily understand, being conveyed to him through the Sauk language, he repeated about one-half of them with a slight vitriation, frequently no other than the addition of a terminattion in $*$, which appeared to be a sort of dialect. Some of the words he seemed not to recognise at all, even after their supposed meaning had been explained to him through the interpreter.

Major Long, whose health had been somewhat impaired for a few days previous, was so severely affected, on the 15 th, with fever and sick stomach, that we began to apprehend that his indisposition would prove a serious one, but the timely application of medical assistance fortunately relieved him.

Wennebea, of whom we have preserved a very good likeness, taken by Mr. Seymour, (plate III. middle figure,) is a young and good looking Indian, whose face denotes more cheerfulness than is generally observed in the countenance of man in the savage life. He seems to be of a lively, cheerful disposition, judging from the laughter which frequently animated his conversation with Le Sellier; to us he was always uniformly polite and obliging. Ilis dress consisted, as usual with the Indians of this country, of a blanket thrown over his shoulders, and reaching to his ankles; a breech-cloth of blue broad-cloth; buckskin leggings and moccassins of the same material. The leg-. gings are very similar to a Chinese garment that supplies the place of pantaloons; they reach up to the hips, covering the whole limb, and are secured to thongs tied to a leather belt around the waist. Garters, generally very much ornamented with porcupine quills, beads, and other fanciful articles, support the leggings immediately below the knee. His pipe was stuck into the plaited hair which he wore on 
the crown of his head. He was provided with a gun, of the kind distinguished by the name of Mackinaw gun, with a spare ramrod, shot-pouch, \&c. Wennebea rode a little bay mare, with a long untrimmed tail; she was so small that his legs appeared almost to sweep the ground as he travelled over the prairie; but the little animal was a fiery one, probably about four years old; her growth had doubtless been stinted by too early an application to labour. We could not help, frequently, expressing our admiration at the graceful and easy manner in which this man rode across the plain, occasionally allowing his blanket to drop upon his horse's back, and displaying the stout and symmetric shoulders and chest, which generally characterize man when in a state of nature, and unimpaired by the effeminating habits and vices of civilized life. We scarcely recognised our guide a few days afterwards, when we saw him with a calico shirt, which he had borrowed from Le Sellier and which concealed his well-formed limbs; on inquiring into the cause of this addition to his usual costume, we were told, that the sun being very hot on the prairie, he had accepted the offer to protect his shoulders, against its influence, by means of a shirt. This proves how ready these Indians are to abandon their natural manners, and to assume the artificial ones of civilized man. Wennebea wore this garment at first with an apparent air of ostentation, which confirmed us in our opinion, that the Indian is no wiser than the white man in this respect, often priding himself upon the acquisition of a garment, which detracts from, rather than adds to, his personal appearance. He seemed to be well acquainted with the country, and followed. no track across the prairie; but his course was directed by landmarks, such as hills, woods, \&c. He appeared to guide himself, likewise, by the situation of the 
sun in the heavens; but we were satisfied, on more than one occasion, of the inaccuracy of those who suppose that an Indian has an infallible method of discovering, at all times, the direction in which he wishes to travel, and that he never can be lost. His habits of observation, permit him, it is true, to discover signs, which would probably escape the attention of the less experienced white man. Thus, if the sun be obscured, his keen eye will sometimes detect, from habit, its place in the heavens; at other times, it is said that he can, by close inspection, discover very faint shadows, which would elude the observation of a less practised eyc. When these characters fail, he may, in a forest, point with certainty to the north from the circumstance, that the moss grows more abundantly upon that side of a tree than upon the others. But if left on a prairie, at a distance from trees, when the heavens are decply overclouded, or during the prevalence of a dense fog, the Indian, as well as the white man, will often be unable to direct himself properly. We frequently observed during the march, that he skreened his eyes with his hands, and seemed to study very attentively the distant points of woods and the surrounding prairie, whether to make sure of the proper route, or to discover signs of game or enemies, we know not.

Wennebea led us in a general north-westerly direction, at first through thin woods, which gradually disappeared, their place being supplied by an extensive and apparently boundless prairie, which occupied us a whole clay in crossing it. The woods consisted of small oaks without undergrowth; the prairie, upon which we were travelling, was undulated, and extended itself along the base of the dividing ridge between the streams tributary to the Mississippi and those which fall into Rock river. This 
ridge stretched on our left, in a direction nearly parallel to our general course; it appeared to be in some places from one hundred to one hundred and fifty feet high, and from six to eight miles distant. Soon after we entered the prairie, a deer crossed our route about two miles ahead of us; Wennebea started in pursuit, but returned in the course of an hour, after a fruitless and fatiguing chace. He brought back, however, a curlew, (Numenius longirostris,) a bird of which we occasionally roused a pair or two. We frequently observed the majestic sand-hill crane, (Grus Canadensis,) striding across the prairie. This animal, if taken young, can, it is said, be domesticated with ease. Two or three of them were kept last season at Chicago, being allowed to pass freely before the sentinels; but they never failed to return to their nests. We also saw on the prairie the fine swallow-tailed Hawk, (Falco [Milvus] furcatus,) flying over us. Our guide showed us a spot where an action had been fought, about sixty or seventy years ago, between the Sauks and the Peoras; the former were successful and lost but one man, while they killed ten of the enemy. This took place on an elevated hill, commanding an extensive view of the prairie, and crowned with a forest in which the engagement is said to have taken place:

The country becomes interspersed with hills, which contribute to vary the scenery; among others which were very distinct, we observed two, rising close alongside of each other, forming two twin peaks insulated in the midst of the prairie; the distance between the two being about one and a quarter mile in an east and west direction; they are visible for upwards of thirty miles, and constitute one of the best landmarks we have ever seen. They are called in the Sauk language $\mathbf{E}^{2} n-n$ 'é-sh'ò-tê'-n'ó, (which signifies the two mountains being composed of én-n'ès, VOL. I. 
two, and 'ü-tê'-n'ó, hills.) Our guide informed us that the hill marked on the maps as the Smoky-hill, (Montagne qui bouccene of the French,) lay at a longr day's march, (about thirty miles, in a north-easterly course from our noon encampment of the 16 th. This hill has received from the Indians the appellation of Mil-chis)w'â-ku'-n'in, (Smoky mountain,) from the circumstance of its summit being generally enveloped with a cloud or fog, and, as we were told, not from any tradition of smoke having ever issued from it. To the left a point of highland is in sight, which is said to be at the mouth of the Móscháokí, (always full,) a stream that falls into the Mississippi. In the evening we encamped on the left bank of the Wasse mỏn, a beautiful tributary of the Pektannon ; it is called after an Indian chief of that name, who resided on its banks : it means, in the Sauk language, lightning. On the banks of this stream we observed the limestone in place, forming cliffs of about fifty feet in height; the rock is in very distinct horizontal stratification; its structure is in many parts crystalline, or perhaps it may more properly be called gravelly and sandy; it contains many cells or cavities, some of which are filled with crystallizations of carbonate of lime; much white hornstone appears disseminated throughout the mass. The hornstone is sometimes seen to constitute small beds or layers from one to three or four inches in thickness, which are continued for several feet in length; frequently also appearing under the form of flattened irregular nodules, lying in an almost continuous line for a considerable distance, and with their long or fiattened side parallel to the stratification; resembling in this respect the disposition of the clay-iron stone in the slaty strati that accompany the bituminous coal. Organic remains are by no means uncommon, though they are not found as abundantly as in some other spots of our route; they consist 
of Terebratulites, Encrinites, and a Madreporite, (Linné;) the true nature of the last of these could not be ascertained without a comparison of characters, which we were unable to make on the spot, and which the loss of all the specimens collected between Fort Wayne and Fort St. Anthony has prevented Mr. Say from making since; the rock is of a grayish-yellow colour, with a loose structure. We are aware that some of the characters, which we have given of this rock, might lead to the opinion that it resembles the mountain or carboniferous limestone of Messrs. Conybeare and Phillips; and consequently that it is the same as the metalliferous limestone of other geologists; but we would consider this union as a very hasty, not to say, an incorrect one. Although its carernous nature, its indications of crystallization, and its organic remains, present an apparent correspondence with those of that limestone, as described by the Rev. W. D. Conybeare, in the excellent "Outlines of the Geolegy of England and Wales," (Part I. p. 353.) we incline to the opinion that this rock is of a much later formation; we believe it to be connected with a limestone which was subsequently observed on the Mississippi, between Prairie du Chien and St. Anthony, and in which we observed an oolite and a pulverulent limestone similar to the calcareous ashes described by Mr. Freiesleben in his elaborate account of the formations of Thuringen. If we compare the characters of this rock with those of the limestone observed by Mr. Freiesleben, and described by him under the name of zechstein and rauchwacke, we will be surprised at the great similarity in their appearance. The "zechstein is a compact, hard and tough limestone of an ash-gray colour passing into blackish-gray, distinctly stratified, without however presenting any slaty 
appearance, or at least much less so than the inferior beds; it contains specks and some veins of calcareous spar and gypsum; also crystals of quartz, \&c.; it likewise offers sometimes specks of galena. It generally presents but few petrifactions, Corallites and Millepores, as well as several species of Terebratulites; Ammonites, \&c. have been found in it."

"Above this compact limestone another stratum of calcareous rock is found which is known in the country under the name of rauchwacke, (smoky wacke;) it is a limestone probably intermixed with silex, of a dark-gray, sometimes blackish colour, with a somewhat scaly fracture, occasionally fine-giained, sometimes though seldom oolitic, hard, tough, and filled with pores or cavities; this last feature is characteristic; it may be observed even in those parts of the stratum which appear most compact; the cavities are angular, long, and narrow, (as in a cracked clay;) the interior of the cavities is lined with small crystals of calcspar, these cavities are sometimes large, being several yards in length and breadth, \&c."

He afterwards proceeds to describe the ashes or pulverulent substance found near it. This, from its great similarity to the residue of the combustion of wood, is designated in Germany by the name of asche, (ashes.) These characters, when taken into connection, appear to us to correspond so well with those observed on the Wassemon, on the Mississippi, and throughout the country between Rock river and Prairie du Chien, that we fecl strongly induced to consider the limestone of this country as analogous to that observed by Mr. Freiesleben. This limestone is by some European continental gcologists referred to the Lias of English geologists; but we would 
rather refer it, with Messrs. Conybeare and Phillips, to the newer magnesian or conglomerate limestone of England; to this, we think, it has the strongest analogy. It is probably connected, as we have already intimated, with the limestone situated above the coal fields of Wheeling and Zanesville; it extends over those parts of Ohio and Indiana, where salt has been found; it is observed cellular, cavernous, \&c. on the banks of the Wassemon; it is connected with real calcareous ashes on the Mississippi. The presence of the oolite which was observed here in a single spot, does not militate against the position which we have taken, as we find it stated, by Conybeare and Phillips, (page 302,) on the authority of $\mathrm{Mr}$. Wynch, thăt the magnesian limestone is occasionally oolitic. It presents in many of its points, the characters of the rauchwacke, and especially the cellular or cavernous structure; it is seldom found very abundantly strewed with organic remains; its colour is the pale buff passing to the ash-gray. In fine, the more attentively we examine it, the more closely do we find it to connect itself with the formations of Thuringen, and with those which cover so extensive a part of England, and more particularly with that observed in Yorkshire by Professor Buckland; offering thus, as it appears to us, a beautiful confirmation of the analogy established between the various kinds of this limestone, observed in divers parts of Europe. There is an experiment which would, as we conceive, place the matter beyond a doubt; this would be an analysis of the limestone with a view to ascertain the quantity of magnesia which it contains, and we regret much that the loss of our specimens has deprived us of the opportunity of making this analysis. But we think the case sufficiently strong to justify us in considering this as the formation corresponding to the magnesian limestone of 
England, and to the reuchwaclee and zechstein of 'Thu. ringen.*

In offering these remarks to geologists, we have not overlooked the very correct observation of one whose experience adds value to the advice which he gives to naturalists; indeed we have found the truth of Mr. D'Aubuisson's remark fully exemplified here. "Let us further" observe," says he, "that the influence of localities becomes more sensible as we draw nearer to modern epochas, and we will be convinced of the difficulty of drawing certain conclusions as to the identity of two calcarcous formations somewhat distant." If with this remark before us, we are thought to have ventured too much in supposing a connection between the formations of England and Germany, and those west of the Alleghanies, let it be remembered that we only offer this as a suggestion to the future investigator of our western limestone, in order that he may turn his attention to the subject with more favourable opportunities of observation than those afforded us by a transient visit through the country. We shall have occasion to mention some further facts which we consider as adding evidence to the opinion which we have advanced. But there is another question which naturally arises; if, as Mr. Freiesleben has described it, the zechstein presents specks of galena or sulphuret of lead; if, as Mr. Conybeare states, the galena is seen "occurring in strings in the magnesian limestone of Nottingham and Durham ;" if

- The reader is referred to the Outlines of the Geology of England and Wales, by the Rev. W. U. Conybeare and Wm. Phillips, \&c. London, 1822, p. 300, \& seq. Traité de Géognosie, par J. F. D'Aubuisson de Voisins, Paris, 1819. Vol. II. p. 336, 337, 343, 353. J. C. Freiesleben's Geognostiche Arbeiten, (Beytrag zur kentniss des kupferschiefer-rebirges.) 
it has been occasionally found in the conglomerate beds associated with this formation, particularly near Mendiphills, in England; if it contains veins of sulphate of barytes at the Huddleston quarry near Sherburn, between Ferrybridge and York; if it is traversed by veins of sulphate of barytes near Nottingham, at Bramham Moor, \&c. may it not then be asked, whether these considerations do not render it probable that the great lead deposite of the west is in this limestone? and is it not likely that all that has been worked in an alluvion has been detached from this formation? These are questions upon which, in the present state of our acquaintance with the western limestone, we must profess ourselves unable to give any decided opinion; but from various circumstances which we need not dwell upon, we should incline to consider the lead ore as probably existing in an older limestone which we think underlays this; and which may be connected with the mountain or carboniferous limestone of Messrs. Conybeare and Phillips, with the metalliferous limestone of other geologists.

The country becomes more undulated as we draw nearer to the Mississippi ; the ridges are low but somewhat steep, owing to the horizontal stratification of the rocks; one of their sides very frequently discovers the composition of the hills by a steep break. At other times the country presents the waved appearance of a somewhat ruffled occan; it. is covered with a short dry grass, the vegetation generally appearing inferior to that of the alluvial country through which we had previously passed. This waved appearance scems to have been caused by the production of valleys subsequently formed, and extending from north-east to southwest, all dipping to the latter point; these are said to continue almost in a straight line to the Mississippi. Our object being to strike that river at a point further north, our 
course, which approaches to a north-west direction, obliges us to cross all these ridges and valleys nearly at right angles. No granitic blocks are to be seen; this is accounted for by the fact that we are no longer upon the allurial formation, but upon the magnesian limestone which rises to a greater height, constituting the dividing ridge between the Mississippi, Rock river, and the Wisconsan, and perhaps connecting itself with what have been termed the Wisconsan hills.

The features, which we obscrved from the Wassemon to the Wisconsan, are extremely interesting. At a distance of a few miles north-west of the former stream, the vegetation presented a sudden and striking change, announcing a corresponding one in the geological character of the country. We ascended a rough, steep, and hilly ground, which was covered with heavy timber, and with a very thick underwood, consisting principally of young oak and aspen. This thick brush-wood continued for about two miles, when we struck the bank of a small stream, remarkable for the beauty of its scenery, which differed from any that we had hitherto met with. The brook runs in a deep and narrow glen, the sides of which are very steep and in some places vertical; they are covered at their summit with a dense vegetation, which extends over the edge of the rock, and imparts a character of austerity and of gloom to this secluded valley, which finds not its parallel in any that we recollect having ever seen. The dark colour, which the water receives from the deep shadows cast by the high steep bank and its overhanging vegetation, forms a pleasing relief to the glare, so uniformly fatiguing, of the unsheltered prairie. This spot conveyed so much relief to the eye and to the mind, that the party could not repress their delight on beholding it. The geologist who connects a change in the nature of the 
subjacent rock, with a diversity in the character of the country, or of its vegetation, would naturally find an explanation for the new features which the country assumes, hy observing that the high banks of this glen are formed of sandstone rocks, the nature of which we had an opportunity of studying with attention, during a great part of our journey of the 18th of June. We observed that the sandstone is distinctly superposed to the limestone; that it constitutes "pon it hills, which vary from thirty to one hundred feet and upwards; these hills are divided by valleys, in the bottom of which the limestone reappears in place. The sides of the hills are steep, and but few indications of stratification are observable, except where the valley is partly excavated in the limestone itself; in which case the lower part of the hill is less steep, but presents a distinct stratifcation. The line of superposition of the sandstone over the limestone, may also be traced with considerable accuracy, by the examination of the vegetation. Whenever the lattcr rock prevails, the surface is even and smooth, or modified by gentle swells, covered with a thick and long grass, and forming an uniform fine green, meadow-like rountry, while the sandstone invariably imparts to the surface an asperity which is as distinct as the vigorous growth of trees with which it is covered, and as its abundant undergrowth, which denotes a strong and productive soil, having a tendency to bear heavy forests.

The rock is a white sandstone, formed of fragments of fine transparent and colourless quartz, united by a cement, which in some parts appears to be ferruginous, while in others it is colourless, and probably of a calcarenus nature. In some parts the cement is quite invisible, and would almost lead to the belief that the union of the grains was a crystalline one. This sandstone appears in frag

YOI. I.

26

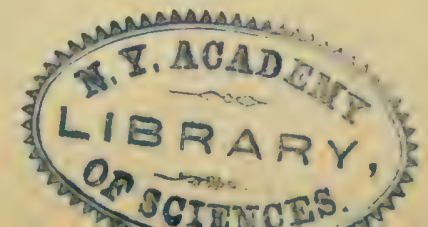


ments or tatters, and constitutes the remains of a formation, which probably covered the whole of the limestone, at least in this part of the country. That it is above the limeslone, no doubt can exist, in our minds, as we saw the immediate superposition. It sometimes appears, it is true, to sink below the level of that rock; and this led us at first to apprehend that there might be an alternation of strata, but a careful examination of all these spots has left no doubt in our minds, that in these cases the sandstone is deposited in coves or valleys formed in the limestone previous to the deposition of the sandstone; these cases are, however, not common, and we may safely state, as a general rule, that not only the sandstone is relatively above the limestone, but that it is even, in almost all cases, at a greater absolute clevation; and the spot, at which we first met with it, west of the IVassemon, was considerably elevated above the usual level of the limestone; for, wherever the sandstonc has retained its position, it has protected the limestone against. decomposition, and hence, in such places, the latter rock still continues to rise to a higher level than where it is laid bare, and exposed to the destructive influence of atmospherical agents. We also observed very distinctly, that while the valleys, formed in the limestone at a time anterior to the deposition of the sandstone, were few, those produced subsequently were numerous, as was indicated by the great roughness and unevenness of the sandstone country, and by the many undulations in the uncovered limestone which we have already had occasion to mention. From the observations made on the 18 th, it was thought very probable that all the hills observed at a distance on the 17 th, were formed of this sandstone; and from some characters which had appeared, at the time, to present an anomaly, it was inferred that the Enneshoteno or twin mountains, near which 
we had passed that day, without stopping, were probably also remains of the general sandstone formation which extended over the whole country. No organic remains were observed in the sandstone, or in the limestone which underlays it; but no doubt can exist that they may contain some, and that the limestone probably contains many.

Proceeding towards the Wisconsan, the country presents an alternation of rolling and undulated prairie, interspersed with hills composed of either one or the other of these rocks. The sandstone is found in most places to be covered with thin flattened fragments of a stone, differing in its nature and texture from the character of the other rocks, whether of limestone or sandstone. These fragments are generally observed to vary from three to twelve inches in length, from two to eight in breadth, and from one quarter to one inch in thickness; they present appearances of having been weathered, but not of having been rolled ; they are very abundant, and we could account for them in no other way than by admitting that they were the remains, probably the harder parts, of a stratum that had at one time covered the sandstone, but that had disappeared almost entirely, leaving only these fragments to attest its former existence and situation. On examining these fragments with care, we found them to be very uniform in their characters; their composition is in great measure calcareous, but from their greater hardness we consider it as partly siliceous; they are replete with organic remains ; these are principally referrible to the Productus, Terebratula, \&c. We saw none but what belonged to bivalves. The existence of these fragments was observed upon many elevations, over a considerable extent of country, while in the vallies no trace of them could be seen. Generalizing the observations made during the three last days of our journey pre- 
vious to our arrival on the Mississippi, we are led to admit that there are, or rather that there were formerly, two distinct formations of limestone in this country, and that they were separated by a thick stratum of sandstone; of these trvo limestone formations, the older one, which we have already described with minuteness, we have been induced to consider as cocval with, or analogous to, the magnesian limestone of England. The superior formation is distinguished by the circumstance of its containing harder fragments or nodules of limestone, which alone remain to establish the fact of its former existence; that it contained no hornstone or flinty quartz, as observed in the former, we are led to believe, because had they existed they must necessarily have resisted decomposition as well or better than the calcareous nodules which are now found alone. The much greater abundance of shells in these nodules, and the total absence of the Madreporites appear to us to be very characteristic distinctions between these and the underlaying limestone, though perhaps too much weight ought not to be assigned to the absence of the Madreporites, as these from their loose and more porous texture may have been unable to resist the decomposing causes which appear to have affected this formation. In some places a limestone bed was observed upon the sandstone, but these depositions were so partial, and in all cases the ground was so much overgrown with bushes, that we were unable to examine their characters with any degree of minuteness. 'This striking difference, however, we obscrved, and we are led to consider it as constant, that the inferior limestone, whenever it appears exposed, is covered with small scales or fragments of the hornstone nodules whose existence has already been alluded to, while none of the flat, calcareous fragments, abounding in shells, 
are found upon it; whereas these were uniformly observed to the exclusion of the scales of hornstone upon the surface of the calcareous stratum that overlays the sandstone. If contrary to the opinion which we have been led to adopt, the limestone be supposed to constitute but one formation, whether above or below the sandstone; then will we ask, whence come these flattened fragments, observed upon the sandstone? If from the remains of a more solid stratum in the limestone itself, why, let us again ask, are not these likewise observed upon the inferior limestone itself? Why is not the hornstone, which appears to characterize the lower limestone, also observed upon the sandstone? We might further ask, if the limestone above and below the sandstone bed be the same, ought we not to find signs of calcareous beds subordinate to the sandstone, and would we not have a right to expect an interposition of limestone in the immense bed of sandstone which, as we have previously stated, is often one hundred feet in thickness? Yet this we never observed to be the case.

If an alternation of sandstone and limestone strata belonging to the same formation were indicated by the characters previously alluded to, would we not be entitled to expect that the fragments and detritus of both should be found together? Yet in the valleys of the sandstone country, and particularly in the beautiful and romantic one which rested upon the limestone, and was enclosed by sandstone hills, we observed no fragments of the former rock, and but a few large blocks of sandstone which had cvidently fallen of late from the sides of the valley. While travelling on the hills we observed that they were covered, in certain parts, with a thin stratum of fine sand, resulting from a slight decomposition of the rock, as is observable in all sandstones of a loose texture. 
From what has been previously observed on the comparative age of the limestone of the Wassemon with the formations of Europe, we readily discover that this sandstone cannot be older than the variegated sandstone, (Bunt sandstein,) of Werner, and we have reason to consider it as an analogous formation. This of course corresponds with the new red sandstone or red marl of English geologists. In this formation in England the red marl certainly predominates; we are not, however, to be surprised if in America we should find the marl almost deficient, and the sandstone in its place; for it cannot be expected that the same uniformity, which exists between the primitive or general formations of the old and new continent, will be observed between the secondary or partial formations; if we can trace a general resemblance, we have perhaps gone further than we were justified in expecting. With the variegated sandstones of Germany this formation presents a great analogy, and perhaps its most remarkable difference, though undoubtedly a very trifling one in reality, is in the colour, which is seldom red, though it occasionally becomes so. This, among many other instances, proves the great desideratum that geologists should agree upon names more intelligible and less arbitrary than those which have been usually adopted; if the formations of Europe and America are to be compared, (and the daily progress of science proves that even those of $A$ sia and $A$ frica will soon be sufficiently investigated to enable us to take them into consideration,) we ought to have better names than those derived from the most fugitive of all characters, that of colour.

The limestone formation, the existence of which above the sandstone we think we have been enabled to establish, appears to us from its mineralogical as well as its geologi- 
cal characters to connect itself with the Lias of Englaml, and more particularly with that variety so well known in France and Germany under the name of Calcaire coquillici, (muschel kalk of Werner,) which constitutes, as is well known, the upper bed of what was formerly termed the Jura limestone; and which is inferior to the great oolitic series of England, of which it forms as it were the foundition. This oolitic serics must not be considered as including the oolites which have been occasionally observed in the Jura limestone of the French, the zechstein of the Germans, and the magnesian limestone of England. In all these instances the oolite forms but a partial and probably an accidental deposite in a limestone, which is certainly inferior to the variegated $(B u n t)$ sandstone, or new red sandstone formation. We have in this account of the western limestones studiously avoided, until this time, introducing the terms of Alpine and Jura limestones, and comparing them together: as it appears to us well established that the greatest confusion has prevailed from the indiscriminate application of these words. The truth of this will be acknowledged by those who recollect that, by some geologists, the two names have been used to indicate the same limestone, (at least in eertain cases,) while some have removed alınost all the Alpine limestone into the transition formations, and other's have extended the Jura limestone to make it include the muschel kalk of Germany, which we have good grounds for considering as coeval with the Lias of England. It will, doubtless, be observed by those who have made a particular study of the limestone formations to which we have alluded, that there are some apparent contradictions in our statement. That for instance, the asche and the oolite observed on the Mississippi cannot be considered as connected together, and with the cavernous limestone of the Wras- 
scmon, without bringing together limestones, which in Europe at least, are found of very different ages, unless we adopt the opinion that this oolite is subordinate to the magnesian limestone. This we are disposed to do, as we have no reason to believe that the formations of the Mississippi are superior to those of the Wassemon, or that they are separated by the new red sandstone formation; if we could venture to express an opinion, where much doubt really cxists, we would say that the oolite was of the same age as the asche, or pulverulent limestone, and that it probably constitutes merely an accidental modification of the magnesian limestone similar to that observed " at Hartlepool on the coast of Northumberland, where a stratum of hard white oolite exists, the grains composing it heing about the size of a mustard seed," and similar to the oolitic varieties which Mr. Freiesleben observed sometimes, though seldom, in the rauchwacke.

If in the rude and unsatisfactory sketch which we have presented of these formations, we have thrown any light upon a doubtful and obscure point, we doubt not we shall he excused, by the experienced geologist, for the apparent. contradictions which we may have revealed. Our object has been to state the facts as they came under our noticc, and without any intention to establish a connection befween the formations of Europe, and those which we have lescribed. If the facts militate against observations made abroad, we must regret it; but we have only stated them as they have appeared to us. Our opinion remains, however, unchanged, that whenever these obscrvations shall be repeated under more favourable circumstances, the difficulties will vanish, and the analogy between the formations of Europe and ours, will appear still greater; a dur allowance being of course made for those rliferences which 
result from the local circumstances that may have influenced these partial deposites.

Those geologists, who have been called upon to make observations in a wild and uncultivated country, where the rocks are frequently concealed by a luxuriant vegetation, where the industry of man has not penetrated by means of quarries, wells, \&c. into the bowels of the earth, and where no facilities exist to roam at large in search of breaks, will, we think, appreciate the difficulties which we have had to encounter in the examination of this section of the country; difficulties which have been increased by the loss of our specimens, whence we have been obliged to depend exclusively upon the descriptions recorded in our notes at the time, without being allowed an opportunity of comparing the characters of the rocks with those observed on former occasions.

Observations were made by Mr. Colhoun for the purpose of ascertaining the longitude of our encampment on the Wassemon, which he determined to be $90^{\circ} 4^{\prime} 45^{\prime \prime}$ West. The latitude was also obtained by observations made at midnight, and was found to be $42^{\circ} 30^{\prime} 10^{\prime \prime}$ North. We remarked with pleasure the surprise and delight expressed in Wennebea's face, during these observations. His astonishment at the characters of the mercury, used for an artificial horizon, showed that he had never seen any thing like it; his delight was strongly marked every time he placed his finger upon the bright and dense mercury, and observed the fluid, receding from his touch, and receiving an impression as though it had been water; yet, as he observed, not possessed of the property of wetting his finger like the latter fluid. He was shown the construction of the sextant, and very soon learnt the use of it. As soon as he saw the double image of the moon, he raised his two fingers in VOL. I. 
token of what he had seen. To one disposed to indulge in the sublime views of Plato, on the immortality of the soul, (Cic. de Senec. Cap. 21,) it would have appeared as if there floated in Wennebea's mind, at that time, an indistinct recollection of what had once been familiar to him. His mind seemed to have received a deep impression from the contemplation of the heavens, but it still remains questionable with us, whether his feelings were produced by the wonderful grandeur of the planets which he had beheld, and by the associations with which he connected them, or by the ingenuity of white men, who with a sort of talisman, had brought, within the sphere of his vision, objects which were previously unknown to him, and imparted to him thereby, as it were, a new sense. It seemed as if his mind was overflowing; and he very willingly answered the questions which were put to him, concerning his ideas of the objects he had been beholding. He believed the sun to be the residence of a male Deity, who looks placidly upon the earth, and who being propitious to man, exposes to his view the wild beasts and serpents which cross his path. He thought, that immediately after death, the soul quits its mortal residence, and journeys towards the setting sun, where, if its life had been spent in a manner agreeable to the Deity, it finds no difficulty in stepping over the agitated $\log$ which stretches across the gulf. It then becomes an eternal inhabitant of the "Village of the Dead," situated in a prairie, that abounds in all the pleasures which the simple imagination of the Indian can covet. The moon, on the contrary, he held to be inhabited by an adverse female Deity, whose delight is to cross man in all his pursuits. If during their sleep, this Deity should present herself to them in their dreams, the Indians consider it as enjoined upon them by duty, to become cinzedi; they erer 
after assume the female garb. It is not impossible that this may have been the source of the numerous stories of hermaphrodites, related by all the old writers on America.

Wennebea thought that the Great Spirit had a human form, was white, and wore a hat. It is remarkable that this personification of the Supreme Being under a different appearance from their own, is not peculiar to the Sauks; the Mexicans and the Muypuscas represented him as white, and wearing a beard; the Santees, according to Lawson, held the belief that he was white. "They made answer," says he, "that they had been conversing with the White Man above, (meaning God Almighty. ")" It would be curious to inquire whether there was any connexion between this white complexion attributed to the Deity, and the prophecies which are said to have prevailed among some of the Virginia tribes, as well as at Quizquiz near the Mississippi, of the coming of white men among them. $\dagger$

These reported prophecies, existing previous to the discovery of this continent, (concerning the arrival of white men,) are represented by the early writers as very common; whether they really existed in the country, or were artfully circulated by the invaders, may be a matter of doubt. Montezuma, in a speech to his subjects, in the presence of Cortez, is said to have alluded to this subject. An old writer, John de Laet, reports the same belief to have been prevalent in the island of Cozumel, on the coast of $\mathrm{Yu}$ catan, and distant from it about four leagues, in latitude $20^{\circ} \mathrm{N}$. This author enters into many particulars on this

- A New Voyage to Carolina, by John Lawson. London, 1709, p. 20.

† Purchas's Pilgrimage, p. 843. Narrative of De Soto's Invasion of Florida, written by a gentleman of Elvas, and translated by IJackluyt. London, 1609, p. 90. 
subject, which we are disposed to consider as altogether of his own invention.*

On the 17th of June our route was diversified by hills and valleys. The Smoky mountain to the east, and Dubuque's to the west, formed distinct objects of vision, while the long ridge, covered with forests, which extender to the left, indicated the course of the "Great river," as the Mississippi has been emphatically called in the Algonquin languages.

A badger was this day discovered by the dogs in the prairie, and after they had brought it to bay, the Indian killed it with his tomahawk; it was cooked for dinner, and those who eat of it, found it very good. This was near a small stream, called by the Indians Mé-k'à-bé-'it Sépé, or Small-pox river; it is the Riviere de la Fievre, which is said to enter the Mississippi opposite to Dubuque's mines.

On the morning of the 1Sth, the sun shone indistinctly through a mist, which offered us the singular phenomenon of a beautiful Iris without rain. We encamped that afternoon at an early hour, on a small stream which is a tributary of the Wisconsan and, as we supposed, at a distance of about twelve miles from the place where we intended to cross that river.

The next morning, after a fatiguing ride over a rough and hilly country, we reached the banks of the Wisconsan; as we could not ford it, we prepared a light raft, and sent Bemis across to obtain boats at Fort Crawford. From the account of our guides, we thought we were opposite to a point in the river, known by the name of the Petit cap au Gres, (little sand-stone bluff, situated about six miles above the confluence of the Wisconsan and Mississippi;

* Joannis de Laet, Americe utriusque Descriptio. Lugd. Bat. s633, lib. 5, cap. 27 , or p. 273. 
but we afterwards found that we were nine miles higher than our guides had reported us to be. The place where we encamped, until means of transportation across the river could be procured, was in a wood at the foot of a high and steep bank; it was almost the only dry place in the vicinity, the river bank above and below it being swampy. The river was about a third of a mile wide, and the current very rapid.

About sunset we observed two boats advancing up the river, in one of which Colonel Morgan, the commanding officer at Fort Crawford, had come up with Lieutenant Scott to meet our party. This polite attention on the part of the Colonel gave us a foretaste of the hospitable reception which we met with during our stay in his quarters.

Although it was late, yet as the weather was fine, the party effected a crossing of the Wisconsan, and having: relieved their horses of all unnecessary baggage, the gentlemen proceeded under Colonel Morgan's guidance towards the Fort. It was eight o'clock when they left the Wisconsan, and about eleven when they reached the Mississippi. This ride, at a late hour, was one of a most romantic character; the evening was fair and still; not a breath of wind interrupted the calmness of the scenery; the moon shone in her full, and threw a pale light over the trackless course which we travelled. Our way lay across a beautiful country, where steep and romantic crags contrasted pleasantly with widely extended prairies, which, seen by the uncertain light of the moon, appeared to spread around like a sheet of water. Our party was sufficiently numerous to form a long line, which assumed a more imposing character from the dark and lengthened shadows which each cast behind him. All seemed to have their spirits excited by the sublimity of the scene. Even the 
Indian, whose occupations must have accustomed him to such excursions, appeared to have received an accession of spirits, and the loud whoops which he occasionally gave, as he raised the summit of a hill, enlivened the ride. Our course was a winding one along the glens which divide the bluffs; and whenever we rode in the direction of the moon's rays, the vivid flashes of light, reflected by our military accoutrements, contributed to impart to the whole a character entirely new to many of the gentlemen of the expedition. It was impossible to be a sharer in this splendid prospect, without joining in the enthusiasm to which it naturally gave rise; and however much disposed the mind may be at such an hour, and in such a solitude, to recall, with deep feeling, the image of abodes endeared by the presence of far distant friends, it would have been impossible for any one of us to wish himself at that moment on any other spot, but in the deep and narrow valleys, or on the smooth prairies, which have imparted to this portion of the scenery of the Mississippi, a character of sublimity and beauty, which we would perhaps vainly seek for on any other point of the long extended course of the "Father of Rivers."

At Prairie du Chien we sojourned for five days; the object of this delay was to obtain the escort which was to accompany the party up the St. Peter. While Major Long's attention was engaged in superintending these preparations, the gentlemen attended to their respective departments. The distance from Chicago to Prairie du Chien, by the route which the party travelled, is two hundred and twenty-eight miles, which, having been performed in nine days, give an average of twenty-five miles per day. No person had ever gone through this route in a direct line before we did, which is surprising, when we 
consider the extent and antiquity of the trade carried on in this part of the country, and the facilities which the route affords. On no part of our journey have we travelled with more comfort to ourselves, the soil being dry and firm, well watered, and sufficiently interspersed with woods to afford us a constant supply of this article for fuel; the grass is generally fine, so that our horses fared well; the country only became rough as we approached the Wisconsan. This river, like the Ohio, scems to unite with the Mississippi in a hilly country; the hills rise to the height of from one hundred and fifty to two hundred feet; their sides are abrupt, and their soil is but indifferent. The Wisconsan has been, for a long time past, the usual communication between the lakes and the Mississippi. About one hundred and eighty miles above the mouth of the Wisconsan, this river comes so near to the Fox river of Greenbay, that a portage of two thousand five hundred yards, across a low and level prairie which is occasionally overflowed, establishes a connection between the two streams. From the portage down to the mouth of Fox river in the Greenbay of Lake Michigan, the distance is computed at from one hundred and fifty to one hundred and eighty miles. The Wisconsan river, which takes its rise near the hills of the same name, extends at least one hundred and fifty miles above the portage. It is represented as having, throughout its course, a rapid current, and but a shallow channel, from which circumstances the ascent is difficult and troublesome. Fox river is formed by the union of two branches, one of which rises at a short distance from the portage road; its course, which is at first westwardly, soon takes a general easterly direction, but the river is at all times very crooked; it falls into Greenbay near Fort Howard. 
The country, through which these rivers pass, is inlabiled by the Menomones, Winnebagoes, Sauks, and Foxe:, but principally by the two first mentioned nations; the NI:nomones being chiefly found near the mouth of Fox river, and the Winnebagoes near the portage road, and in the vicinity of the lake which bears their name. The latter are considered as being of distinct origin from the Algonquin tribes; their language is said to present much greater diffculties. It abounds in harsh and guttural sounds, and in the letter $r$, which does not appear to be common in the Algonquin languages. We have already had occasion to advert to the termination in $r a$, added to many of the words by the Winnebago whom we saw on the Pektannon. It is difficult to obtain correct information concerning their manners and characters, as a strong prejudice appears to prevail against them. They are considered unfriendly to white men, and this, instead of being viewed in the light of a favourable trait in their character, as indicative of a high spirit, which can resent injustice and oppression, and which will not crouch before the aggresssor, has been the occasion of much ill will towards them; they have been, probably without cause, charged with many offences which they did not commit. If we can place any dependence upon the character given to them by Carver, we should consider them as no worse than other Indians; indeed his acquaintance with them appears to have left a favourable impression upon his mind. Their appellation in their own language, is believed to be Otchagras; whence the term Winnebago has been derived we have not been able to ascertain, not having met with it in any author prior to Carver. By the French they were called Puants or Stinkers, which name is attributed by Charlevoix, to their feeding principally upon fish. "I judge," says he, "it was there, 
(on the borders of a lake,) that living on fish, which they got in the lake in great plenty, they gave them the name of Puants, because all along the shore where their cabins are built, one saw nothing but stinking fish which infected the air."

In a manuscript narrative of a journey from Bellefontaine on the Missouri to the Falls of St. Anthony, and to the Wisconsan portage, performed in 1817, by Major Long, we have obscrved the following account of their mode of conveying information by a sort of hieroglyphic writing.

"When we stopped," says Major Long, "to dine, White Thunder, (the Winnebago chief that accompanied me,) suspecting that the rest of his party were in the neighbourhood, requested a piece of paper, pen and ink, to communicate to them the intelligence of his having come up with me. He then seated himself and drew three rude figures, which at my request he explained to me. The first represented my boat with a mast and flag, with three benches of oars and a helmsman; to show that we were Americans, our heads were represented by a rude cross, indicating that we wore hats. The representation of himself was a rude figure of a bear over a kind of cypher representing a hunting ground. The second figure was designed to show that his wife was with him; the device was a boat with a squaw seated in it; over her head lines were drawn in a zigzag direction, indicating that she was the wife of White Thunder. The third was a boat with a bear sitting at the helm, showing that an Indian of that name had been seen on his way up the river, and had given intelligence, where the party were. This paper he set up at the mouth of Kickapoo creek, up which the party had gone on a hunting trip.".**

* Major Long's MS. Journal of a voyage, \&ce. 181T, No. 1, folio $2 \pi$.

VoL. I. 
While at Prairie du Chien, we cndeavoured to obtann from Wennebea as much information as we could concerning his nation; and this, together with the notices collected from him and Le Sellier during the journey, constitutes the basis of the following account of the manners of the Sauks. As they are eridently of $\Lambda$ lgonquin origin, and therefore connected with the Potawatomis, we have only retained such parts of the information as had not been mentioned before, or in which a difference was obscrved between the two nations.

The Sauks call themselves in their own language, S'à-kiw'e. They are a brave, warlike, and, as far as we could learn, a generous people. The great reduction in their numbers arose from their hostility to the French and their allies, and also to the wars which they formerly waged against the Indians on the Missouri and Mississippi, such as the Pawnees, the Omawhaws, the Sioux, the Iowas; \&c. Owing to the rapid advance of the white population, and the increasing influence of our government over them, they are becoming more peaceable, and from this circumstance their numbers are probably on the increase. Their historical recollections do not extend far back ; but they have been told that about sixty years since, when the French occupied the country, one of the Sauk chiefs by the name of Mè-né-tò-mêt, found himself surrounded with about sixty of his nation by a party of French and Indians, belonging to other tribes, amounting altogether to two thousand. Menetomet then addressed his men, bidding them not to fear, for he had been favoured with a vision from the Great Spirit that informed him that if they all fought bravely, not one of them should perish. Encouraged by this assertion, they fought with such desperation as to break the ranks of their assailants, and escape without the loss of a single man. 
They were afterwards led by their chiefs torvards the Butte de Mort on Fox river, and were on the point of being cut of by their enemies, when a peace was effected by the intervention of a French officer. Wennebea informed us that his grandfather was in this party; had it been cut off the nation would, as he thinks, have been totally annihilated; for these composed the whole force of the Sauks. Their numbers have since considerably increased, as according to his estimate, the nation now consists of upwards of a thousand warriors; in this number are included all the ac1ive, able-bodied, and middle aged part of the nation. This great accession to their numbers, results principally from their system of adopting their prisoners of war. The real number of warriors of pure Sauk extraction does not, in his opinion, exceed two hundred. The Fox nation, which appears to be very closely united with the Sauk, was at that time likewise much reduced; it is stated that at one time there were but three lodges of Fox Indians left; these reports are probably in some respects exaggerated. The system of adoption seems to be carried to a great extent, and the duties which it involves are of a peculiar character; it seems to have in a great measure stifled all patriotism and attachment to their kin. It is true, that men, reputed good among them, ought not to wander from tribe to tribe, nor from village to village; neither is it prudent for them to do so, for in case of hostilities breaking out, the new comers would always be the first sacrificed. If a man should marry in a different nation from his own, he continues to live with his wife's nation as long as they remain at peace, but should a war be declared he must leave his wife and return to his tribe. This does not, however, apply to one who has been made prisoner; if a captive br arlopted as one of the nation of his captors, he must for- 
sake all his former ties; he settles in the nation that adupt: him, forfeits all allegiance to his native tribe, and contracts new obligations. It is his duty, in case of hostilities, to side with his new friends against his old ones; it becomes even proper for him to do all in his power to promote the views of his adopted nation, by killing as many of their enemies as he can; he may even, (and it is his duty to do it,) kill his own father, and, as our guide added, "nay even his grandfather." In so doing he is not thought to violate any of the obligations of nature, for his adoption has altogether cancelled his former bonds. The expression of Wennebca, "nay even his grandfather," cannot surprise those who have visited the Sauks, or studied to make themselves acquainted with their peculiarities, as one of their most striking precepts is that the more distant, in the ascending line, a parent is, the more is he entitled to respect and affection; hence the killing of a grandfather would, under common circumstances, be considered as far more atrocious than the murder of a father.

To this high opinion of the duties incumbent upon adopted citizens, and to the general humanity which induces them to spare the lives of their prisoners, we may safely attribute the great accession of numbers which their nation has undergone within the last century. The Sauks have not always resided where they are at present found. Their recollection is that they formerly lived upon Saganaw Bay of Lake Huron, and that about fifty years since they removed, by the way of Greenbay, from the lake shore to their present abode. They seem to consider the name of their nation to be connected with that of Saganaw Bay, and probably derived from it. They have no account of any former migration, but entertain the opinion that the Great Spirit created them in that yicinity. 
With a view to ascertain what were their ideas of moral excellence, we asked Wennebea what, in their opinion, constituted a good man. He immediately replied, that in order to be entitled to this appellation, an Indian ought to be mild in his manners, affable to all, and particularly so to his squaw. His hospitality ought to be boundless; his cabin, as well as all that he can procure, should be at the disposal of any one who visits him. Should he receive presents, he ought to divide them among the young men of his tribe, reserving no share for himself. But what he chiefly considered as characteristic of a good man, was to be mild and not quarrelsome when intoxicated. A good man should keep as many wives as he can support, for this will enable him to extend his hospitality more freely than if he have but one wife. Being asked whether by this he meant that an Indian should offer his squaw to strangers, as is practised by the Missouri nations, he replied that no man of any feeling could do such a thing; he thought there was no man so base as to be guilty of this. Adultery is strictly prohibited; so also is an indiscriminate intercourse of sexes. No good man would encourage it, or partake in it; for men were not made like dogs for promiscuous intercourse; but there are some women, whose passions are not controlled by reason, and these will al ways find men clisposed to share in their shame; no good man would however do so. Neither would a virtuous man always put away his wife for adultery; he ought to admonish and reprove her. Should she continue in her evil practices, then he will be justifiable in discarding, or punishing her. There are among the Sauks some men so base that they will throw off their male garments, assume those of females, and perform all the drudgery allotted to the latter sex, becoming real cinxdi. They are always held in contempt, 
though by some they are pitied, as labouring under an tinfortunate destiny which they cannot avoid, being supposed to be impelled to this course by a vision from the female spirit that resides in the moon. Upon the subject of intoxication, Wennebea spoke with much feeling and philosophy. "Intoxication," said he, "is a bad thing; the Indian has been seduced to it by the white man; when our forefathers were first offered liquor they declined it; for they had seen its evil effects upon white men. At last two old men were bribed to taste it; they liked it and took more; they were then affected by it, their language became more voluble; they were merry in their wine. Pleased with the experiment they repeated it, and induced two others to join them; thus did the evil spread gradually. To drink a little is notimproper, but to drink to intoxication is not right; our ancestors have forbidden us to do it. You, white men, can take a little and refrain from more; while the red man follows but the impulse of his feelings; if he takes a little, he requires more, and will have it if he can get at it in any way. You encourage us in this practice; your agents, your traders, instead of withholding it, offer it to us, make us take it, and when we have had a little we lose all control over ourselves. We had no intoxicating draughts before the white man came among us, and we were better men; this has been the ruin of us; all our broils and our quarrels spring from intoxication; some of our women take to liquor; they lose all shame, and become common." It is melancholy to think of the truth contained in these words; not only do our traders, in violation of all law, sell or give liquor to the Indians, but even the agents frequently give them some when they visit the forts, either to keep up a sort of popularity among them, or to rid themselves of their impor 
tunities, thus encouraging this fatal propensity, instcad of checking it altogether. In this respect the Jesuits were wiser if not more humane than our countrymen, since they are reported by Grangula, an Iroquois chief, "to stave all the barrels of brandy that are brought to our cantons, lest the 'people getting drunk, should knock them in the head.".*

It is the duty of a good Indian to offer, on many occasions, sacrifices to the Master of Life; he ought to give feasts frequently, and expose the skins of white deer upon trees, as an offering to the Great Spirit. In such cases he never partakes of the entertainment himself; but his friends eat it all up, with the exception of a small part which is thrown into the fire. The business of men consists in hunting, fighting, building their lodges, digging their canoes, taking care of their horses, making wooden spoons, \&c.; while it is the duty of women to hew wood, to carry water, to plant and raise corn, to take care of their families, and, in the absence of the men, they must attend to their horses, build their lodges, \&c. Man's chief and best occupation is hunting; he will never fight unless aggrieved by his enemies, in which case it becomes his duty to resent the injury. A good hunter is held in high esteem and will obtain as many wives as he chooses, because they know that he can support them, but the good warrior is esteemed the first man in the nation.

A woman, in order to deserve the appellation of good, ought to be endued with most of the qualities which constitute virtue among civilized females. To be obedient and affectionate to her husband is her first duty. Kind to all her children, partial to none; affable and courteous to

* "Lahontan's new Voyages to North America, done into English, London, 1703." Vol. 1, p. 40. 
all men, avoiding, however, the appearance of familiarity with any. Her chastity should be inviolate, even at the risk of death; she ought to be industrious, in order that her husband may be wealthy, and able to extend his hospitality widely. When asked what were the qualifications which were most sought after in the selection of a wife, and if beauty had any influence, Wennebea replied, that they cared but little for a handsome wife, their object being to get a good one, who could attend to all their work, and hehave herself as became a good woman. "We are not absolutely regardless of beauty," said he, "but we think it a trifling acquirement compared with goodness, and therefore pay but little attention to it; some young men are foolish and attend to it, but these are few, and they soon Iearn to take good wives, without minding their charms." Being asked what constituted female beauty, he laughed and said, a light complexion, large hazel cyes, a well-formed nose, red lips, and a figure rather small and well proportioned; they seem to have a dislike to very fat women. When questioned as to other points of beauty, he seemed not to have made a study of them; their faces, he said, might be more or less handsome, but in other respects women were all the same. Feeling a little encouraged, he continued in a strain so obscene, as even to put to the blush our old interpreter, Le Sellier; which, for a Canadian trader, might be supposed not to be an easy thing.

It was impossible not to observe in the general tenour of Wennebea's conversation that he admitted a superiority on the part of white men over Indians, at least in foresight, judgment, and capacity to acquire information. Wennebea thought that when the Master of Life made the white man, he gave him the power to improve in knowledge and the arts; he taught him how to manufacture all the articles that he 
wanted, such as cloth, guns, \&c. To the red man he gave nothing but his bow and his dog; intending him therefore for no other occupation than that of hunting. This appeared to be a favourite idea with Wennebea; he frequently dwelt upon this partition of the good things of the earth, in which the poor Indian had received but his borv and his faithful dog. It was not alluded to in the spirit of complaint or as a hardship, but merely in support of a deep conviction on his part, that, while the white man was made capable of improvement in the arts, the red man was predestined to remain stationary, and to live by hunting, for which alone he had received, from the All-ruling Spirit, natural advantages. We related to him the belicf entertained by other Indians, who justify their hunting life by saying: that, in the origin, God divided all animals equally between the red and the white man; and that while the latter took great care of his share, the former merely wrapped his up, loosely, in his blanket, and having left it for a while, he found on his return that all the animals belonging to him had escaped into the woods: it was therefore to recover his lost property that he had addicted himself to hunting. Wennebea observed that he had never heard of this belief before; but he thought, if it were true, it was a wise decree of the Master of Life, for, he added, if the Indian had not suffered his share to escape into the woods, he would have destroyed and wasted it in a short time, and been ever after left to starve, as he wants the provident care of the white man; but as it is at present, the Indian can only use his property gradually and according as his wants require it.

Wennebea declined entering upon any particulars relating to their belief in after life, being apprehensive that any conversation on that subject would disturb the quiet Vor. I. 
of his cleparted relations. According to Le Sellier, he makes a difference between the soul and the spiril; the former being probably in his opinion nothing else but the principle of vitality; its seat is in the heart; all animals are gifted with souls, as they are endowed with vitality. He believes that the soul alone goes to the other world; the body decays after death. We observed in him, and in all the Indians whom we met with, that they entertained not the least belief of the resurrection of the body, as has been asserted of them by some authors; while they generally appeared to be convinced of the immortality of the soul or spirit, and of an after existence.

The Indians are particular in their demonstrations of grief for departed friends. These consist in darkening their faces with charcoal, fasting, abstaining from the use of vermilion and other ornaments in dress, \&c. They also make incisions in their arms, legs, and other parts of the body; these are not made for the purposes of mortification, or to create a pain, which shall, by dividing their attention, efface the recollection of their loss, but entirely from a belief that their grief is internal, and that the only way of dispelling it is to give it a vent through which to escape. Their outward signs of grief are not merely of a temporary kind; they are more lasting than among those who consider themselves as higher in the scale of refinement than the red man. Wennebea observed that he had abstained, for the last fifteen years, from the use of vermilion on account of the loss of a valued friend, and he meant to persist in this practice for ten years longer; the deceased was no relation, merely a friend. Public opinion requires of them some mourning for departed relations, but the Indian graduates his expressions of grief according to the value in which he held the deceased, not 
according to the mere relation in which nature or accident placed him in life; for his friend he entertains a feeling deep, warm, and unalterable. Their friendship is seldom divided between two objects, hence they have not those bands of brothers which are stated by Lewis and Clarke to exist among some of the tribes they visited; but the adoption of a brother is very common with them; it is always founded upon sincere friendship; and in the cxposed and wandering life of the Indian, opportunities are not wanting to display the extent of this feeling. An Indian will willingly endanger his existence to save the life of his adopted brother; and should one of the two be killed, there is no duty more strongly enjoined upon the survivor, o1 which he more willingly discharges, even at the risk of much personal danger, than that of avenging his friend's death.

Against the charge of cannibalism, Wennebea defended his nation with considerable zeal. This practice, he admitted, existed among the Winnebagoes, Chippewas, Dacotas, and other Indians, but he denied its ever occurring among the Sauks, except in a few instances, in which persons that were very lean and thin would eat a small piece of the human heart, together with other medicines, in order to fatten themselves. When asked whether this must not be considered as offensive to the Deity, he replied that he knew not, he had never held converse with the Great Spirit; he had heard other men say that they had enjoyed visions, and conversations of this kind, but, for his part, he never credited them.

Suicide is, according to Wennebea, common among the Sauks, more so with women than men. Grief and jealousy appear to be the predisposing causes with women, and envy, at the power or consequence of others, is the mo\&ive which impels men to this deed. Our guide, whose 
simple system of ethics agrees better with that of the white man than is generally admitted, considers suicide as an improper act; it does notappear to him to accord with the wishes of the Great Spirit; he that gave us life, say: Wennebea, has alone the power of taking it away.

Music secmed to have a powerful effect upon him, and particularly martial music; he expressed himself in enthusiastic terms on the subject; while at Fort Crawford he secmed delighted with the reveille. The bugle was his favourite instrument. When asked why he preferred it, his answer was, that its notes were so fine, he fancied they must reach the ear of the Great Spirit himself; whenever the sound of the bugle was heard, his attention was immediately directed to it; his eyes sparkled and his language became more animated.

The principal disease of the Sauks is one, the nature of which we could not well ascertain from his description of it; it is different from dysentery, (being at all times unattended by bloody discharges;) neither is it the hemorrhoids or hernia. It appears to be a mortification of the intestinal canal or duct, which is brought on by the use of green corn, unripe fruits and vegetables, \&c.; it is more common among men than women. If timely remedies be not applied, it proves fatal in the course of four days; the discase is unaccompanied by pain. He declined mentioning the remedies which have been successfully applied, as he entertains the common superstition on this subject.

Intermittents appear to be very prevalent. The small-pox has been known at different periods; our guide, who is about thirty-five years of age, recollects two periods, but does not know at what interval of time they happened; it is thought that it will shortly recur among them. Of parturition and gestation, his account agreed with that 
obtained at Chicago; being asked how long the pains of labour endured among women, he said they varied, sometimes four days, at other times two days or less, and in some cases scarcely long enough to give a man time to smoke a pipe.

We shall close this protracted account of Wennebea's information, with an anecdote which appears to us to connect itself with a point of some interest in our history; it was related to us spontaneously by Wennebea, and having been written down in his own words, shows the strain of ideas, of which he was susceptible.

"You know," said he, " that we always carry medicine bags about us, and that in these we place the highest confidence; that we take them when we go to war; that we administer of their contents to our relations when sick, \&c. The great veneration in which we hold them, arises from our deeming them indispensable to obtain success against our enemies. They have been transmitted to us by our forefathers, who reccived them at the hands of the Great Master of Life himself. We never venture upon a warlike undertaking unless, by their means, our chiefs should have previously had visions, advising them to do so. When we are near to our enemies, they impart to us the faculty of beholding, in the heavens, great fires passing from one cloud to another. If these fires be numerous, longcontinued, and extensive, it is a sure sign to us that in the part of the heavens where we behold them, there are enemies; that they are powerful and numerous, and that we must avoid them. If, on the contrary, they be few, faint and not frequent, then it is a token that our enemies are weak, and that we may attack them with a certainty of success. These are not visions, but realities; we do not dream that we see these fires, but we actually behold them in the hearens; for this reason do we value our medicine bags 
so highly that we would not part with them while life cudures. True, some of us did, at one time, at the instigation of the Shawanese prophet, ('Tecumseh's brother,) throw them away, but this proved to us the source of many heavy calamities, it brought on the death of all who parted with their bags. To this cause do we attribute the great mortality which we experienced, during the late war against the Americans. He, (the Shawanese prophet,) came to us, and by artifice induced us to throw away our medicine, a circumstance which we have since had cause to regret. His artifice was this; he convened all our chiefs, and told them that he had been favoured with an interview with the Great Spirit, who had imparted to him extensive porvers; that he could recall the dead to life, and perform many such astonishing deeds; that he could restore youth to the aged, \&c. that the medicine in our bags, which had been good in its time, had lost its efficacy; that it had become vitiated through age; he added that if we would throw away our medicines, he would execute, in our presence, the miracles which he had spoken of, and that if we followed him, he would ensure us a victory over our enemies. Induced by these promises and flattering expectations, many of our chiefs cast avay their bags, a circumstance much to be regretted. It is true, that some who were then assembled, challenged the Prophet to work the miracles which he had announced. 'There, said they, are the bodies of many who have been killed in battle, restore them to life, as thou saycst that thou canst do. But he evaded their challenge by saying to them, I cannot achieve these won. ders for you, unless you previously comply with my request to throw away your medicine bags; such of you as shall do so rvill, on your return, find your children or your friends, that have long since been dead, restored to life. Many 
were satisfied and did as he bid them; but not one of them ever returned to his home, to see if his promises were fulfilled; for they all fell in battle, on account, as we have always believed, of their having parted with their medicine bags. I," added Wennebea, "spoke to him plainly; I told him he wished to impose upon us; that our bags had not lost their virtue; that still in the hour of need we applied to them, and generally with success; that we kept them in our villages, and that when our friends were sick, we applied to them for relicf; and that if we were not successful in all cases, at least we were so in most in. stances. But he was very angry at me, and his brother Tecumseh who was near to us, laid his hand upon me and offered to strike me, which he would have done had he not been prevented."

Thus spoke Wennebea Namoeta, a Sauk Indian of the tribe of Pâ-cô-hả-mô-åa, (which signifies Trout;) his brother had succeeded to the dignity of chief, although he was younger, being considered a man of more talent; and so Wennebea himself admitted him to be. We regretted that we did not meet with this chief, we should have liked to see what his abilities are; he may be a better warrior or a more impressive orator, but we question much whether he surpasses our guide in genuine philosophy. We have with regret shortened the communication of the observations made by this interesting man; we should have wished to give them entire. They breathe throughout a wisdom which would have done honour to the philosophers of old, and a morality of which no Christian need have blushed. Indeed they speak strongly in favour of the doctrine, that wisdom and morality are the spontaneous growth of the human heart, the seeds of which have been implanted by the great Creator himself; 
that civilization does not produce them; that the real benefit, which results from it, is that, in some instances, it may curb the passions which would otherwise imperle their growth. The Indian appears to us to possess ideas of virtue and morality, which are full as valuable as those that are supposed by some philosophers to be the exclusive appanage of civilization. 'True, they are, perhaps but tou frequently checked in their growth by the uncontrolled sway which his evil propensities exercise over him; propensities which, as we believe, have been unfortunately increased, by an indiscriminate intercourse with the most worthless of white men who, to serve their own selfish ends, have not been ashamed to stimulate the Indian to deeds, which his own good sense would have prevented him from perpetrating.

On the route from Chicago to Fort Crawford we saw but one deer, at which, however, we had no opportunity of shooting. We likewise observed but a single wolf, which was of the kind called Prairie wolf. If to these we add the badger, which was killed on the 17 th of June, we shall have the list of the only quadrupeds seen upon upwards of two hundred miles of prairie land. The extreme scarcity of game in a country so remote from a white population as this is, must be striking to every observer; and it becomes the more so if we take into consideration the abundance of fine grass which grows upon it. We know of no other manner of accounting for this scarcity, than by attributing it to the pacifie state of the Indian tribes that own these hunting grounds. Being free from all apprehensions of enemies, they hunt without reserve, and destroy the game more rapidly than it can be reproduced. They appear since their intercourse with white men to have lost the samacious foresight which previously distinguished them. 
It was usual with them, formerly, to avoid litling the decr during the rutting season; the does, that were with young; were in like manner always spared, except in cases of urgency; and the young fawns were not wantonly destroyed; but at present the Indian seems to consider himself as a stranger in the land which his fathers held as their own; he sees his property daily exposed to the encroachments of white men, and therefore hunts down indiscriminately every animal that he meets with, being doubtful whether he will be permitted to reap the ensuing year the fruits of his foresight during the present and fearing lest he may not be suffered to hunt, undisturbed, upon his property, for another season. To this cause, and to the increase in their numbers produced by a long continued peace, we must attribute the scarcity of game at present observed; their population must however soon cease to increase if they do not betake themselves to agricultural pursuits, as the rapid diminution in the quantity of game will eventually deprive them of the means of subsistence. We are not to wonder that an Indian population, apparently so small as that which we know to exist here, should be comparatively large for the country to which it is restricted in its hunts, if we bear in mind the observations of Little Turtle on the subject, "You whites contrive to collect upon a small space a sure and plentiful supply of food. A white man gathers from a ficld, a few times bigger than this room, bread enough for a whole year. If he adds to this a small field of grass, he maintains beasts, which give him all the meat and clothes he wants, and all the rest of his time he may do what he pleases; while we must have a great deal of ground to live upon. A deer will serve us but a couple of days, and a single deer must have a great deal of ground to put him in good condition. If we kill two or three hunVoL. I. 
dred a year, 'tis the same as to cat all the wood and grass of the land they live on, and that is a great deal.".**

Among the birds observed, Mr. Say has recorded a single Red-headed Woodpecker, $\dagger$ together with the Ferruginous'Thrush, f'Towhee Bunting, § Song Sparrow, „Chipping Sparrow, *** Bartram's Sandpiper, t† Raven, 拉 Recdbird, and a Crow\$\$ which was first heard near the Wisconsan.

In the vegetable kingdom, the same gentlemin observed that the Gerardria was found, about the 15th, with its petals nearly of full length, but that afterwards they were found much shorter. A beautiful specimen of Cassida was likewise seen ; its elytra were of a fine green colour tinged with golden; and the exterior margins were pale.

* Volney, ut supra, p. 384. † †icus erythrocephalus.

* Turdus rufus.

|| Fringilla melodia.

tf Tringa Bartramia.

§ Emberiza erythropthalma.

* Fringilla socialis.

$\S \S$ Curvus corone.

$\neq \ddagger$ Corvus coras. 


\section{CHAPTER VI.}

Prairie du Chien. Indian remains. Division of the party. Mississippi. Dacota villages. Fort St. Anthony. Falls. River St. Peter.

OUR arrival at Prairie du Chien, at a late hour in the evening of the 19th of June, prevented us from obtaining a sight of the Mississippi; but early the next morning we hastened to take a view of this important river which, from its extent, the number and size of its tributaries, the importance of the country which it drains, will bear a comparison with any known stream of the old or new continent. It is one of those grand natural objects, the sight of which forms an era in one's life.

To have been the first civilized man, who viewed the mighty Mississippi, was, as we conceive, by no means an undesirable distinction. And however difficult it may be, at this distant epocha, to ascertain who that man may have been, the inquiry is not the less interesting or useful in the history of human discoveries. So far as our reading extends at present, injustice is done to Alvar Nuniez Cabeza de Vaca. He traversed North America from Espiritu Santo (Tampa) Bay to New Galicia, between the years 1528 and 1537 , and consequently must have seen this river, having crossed it above or at its mouth; though in his "Naufragios" he has given neither name nor description by which it can be identified; his curiosity was repressed by extreme suffering and the little hope he entertained of again secing his country. Hernando de Soto arrived at its banks below the Arkansaw in 1541, and found it there called "Chucagua ;" his body was thrown into it the next 
year, near the mouth of Red river. If we mistalic not, two ressels under the command of Wood, an Englishman, entered its mouth about 1636.* Father Marquette and the Sieur Jolict, to whom the discovery has been gencrally attributed, did not see the Mississippi before 1673. They entered from the Wisconsan and desecnded to the Arkansaw. Coxe tells us, that, among the sarages, for ahout half its course it was called Meschaccloe, afterwards Chucagua, Sassagoula and Malabanchia. It is said that at Guachoya, (probably an old place on the Mississippi abore Red river,) it was "called Tamaliseu; in the country of Nilco, Tapatu; and in Coça, Mico; in the port or mouth, Ri." $\ddagger$ The French first called it Colbert, then St. Louis river. The Spaniards had previously called it Rio Grande, Spirito Santo.

At Prairie du Chien the breadth of the river is estimated at one-half of a mile, including a long and narrow island. Its current, though rapid compared with that of many other streams, is gentle when contrasted with that of the same river lower down ; it is only when it has been swollen by the Missouri and the Ohio, that it acquires the extreme rapidity which characterizes it. The village of Prairie du Chien is situated four or five miles above the mouth of the Wisconsan, on a beautiful prairie, which extends along the castern bank of the river for about ten miles in length, and which is limited to the east by a range of steep hills rising to a height of about four hundred and thirty-five feet, and

* We have endeavoured, but in vain, to find our authority for this statement; but it has entirely escaped our recollection. This is not, however, the same Coloncl Wood of Virginia, whom Coxe mentions as having discovered several branches of the great rivers Ohio and Meschacebe-(Coxe's Carolana, p. 120.)

tDescription of the English province of Carolana, by Daniel Coxe. Lundon, 1741, p. 4.

$\$$ Narrative of de Soto's Invasion, ut supra, p. 122. 
running parallel with the course of the river at a distance of about a mile and a half; on the western bank, the bluffs which rise to the same elevation are washed at their base by the river. Pike's mountain, which is on the west bank, immediately opposite to the mouth of the Wisconsan, is about five hundred and fifty feet high. "It has received its name from having been recommended by the late General Pike, in his journal, as a position well calculated for the construction of a military post to command the Mississippi and Wisconsan. The hill has no particular limits in regard to its extent, being merely a part of the river bluffs which stretch along the margin of the river on the west, for several miles, and retain pretty nearly the same elevation above the water. The side fronting upon the river is so abrupt as to render the summit completely inaccessible even to a footman except in a very few places, where he may ascend by taking hold of the bushes and rocks that cover the slope. In general the acclivity is made up of precipices, arranged one above another, some of which are one hundred and one hundred and fifty feet high. From the top we had a fine view of the two rivers, which mingled their waters at the foot of this majestic hill." "* The Prairie has retained its old French appellation, derived from an Indian who formerly resided there, and was called the Dog. The village consists, exclusive of stores, of about twenty dwelling houses, chiefly old, and many of them in a state of deeay; its population may amount to one hundred and fifty souls. It is not in as thriving a situation as it formerly was. Carver tells us, that when he visited it, in 1766 , it was "a large town containing about three hundred families; the houses," he adds, " are well built after the Indian manner, and pleasantly situated on a very rich

" Major Long's MS. 1817, No. 1, p. 37. 
soil, from which they raise every necessary of lile in great. abundance. This town is the great mart where all the adjacent tribes, and even those who inhabit the most remotr: branches of the Mississippi, annually assemble about the latter end of May, bringing with them their furs to dispose of to the traders." "I should have remarked," says the same author, "that whatever Inclians happen to meet at La Prairie le Chien, the great mart to which all who inhabit the adjacent country resort, though the nalions to which they belong are at war with each other, yet they are obliged to restrain their enmity, and to forhear all hostile acts during their stay there. This regulittion has long been established among them for their mutual convenience, as without it no trade could be carried on." $\dagger$

The fort, which is one of the rudest and least comfortable that we have seen, is situated about one hundred and fifty yards from the river. Its site is low and unpleasant, as a slough extends to the south of it. 'The river' bank is here so low and flat, that by a swell which took place in the Mississippi the summer before we visited it, the water rose upon the prairie, and entered the parade, which it covered to the depth of three or four feet; it penetrated into all the officers' and soldiers' quarter's, so as to render it necessary for the garrison to remore from the fort and cneamp upon the neighbouring heights, where they spent about a month. The waters having subsided, at the end of that time, they returned to their quarters; the old men about the village say that such an inundation may be expected every seven years. The village also suffered much from the inundation, though the ground being somewhat higher, the injury done to it was not so great. The fort was

* Carver's Travels, Philadelphia, 1796, p. 31. † Iciem, p. G2. 
originally erected for the protection of the white population at the village; as a military post, its situation is by no means a judicious one, for it commands neither the Mississippi nor Wisconsan; but as the necessity which led to - its construction is daily becoming less urgent, this position will doubtless soon be abandoned; one of the blockhouses of the fort is situated upon a large mound, which appears to be artificial. This mound is so large, that it supported the whole of the work at this place, previous to the capture of the fort by the British and Indians during the late war. It has been excavated, but we have not heard that any bones or nther remains were found in it.

This is by no means the only mound found in the vieinity of the Prairie. There are very numerous remains of Indian works on the Wisconsan, near the Petit cup au Grés; Messrs. Say, Keating, and Seymour, went to examine them. They found the bluffs which border upon the IVisconsan, about four miles above its mouth, covered with mounds, parapets, \&c. but no plan or system could be observed among them, neither could they trace any such thing as a regular cnclosure. Among these works, they saw an embankment about eighty-five yards long, divided towards its middle by a sort of gateway, about four yards wide; this parapet was elevated from three to four feet; it stood very near to the edge of the bluff, as did also almost all the other embankments which they saw. From this circumstance, they were led to consider them as raised for the protection of a party placed there, either for the defence of the bluff, or to command the passage of the river. For either of these objects, it must be acknorvledged that the selection of the position would be very advantageous. No connexion whatever was observed between the parapets and the mounds, except in one case, where a parapet was cut off 
by a sort of gateway or sally-port, and a mound was placed in front of it, as it were, to command the gateway; but instead of being inside, in the mamer of a traverse, it was outside, and could have served no other purpose, that they could think of, but to allow some of the party to proceed a few steps in advance of the works and reconnoitre the enemy; though it must be acknowledged that the enemy might, under corer of this mound, hare approached, perhaps, without being perceived, or at least with the advantage of a breast-work. In one instance the works or parapets seemed to form a cross of which three parts could be distinctly traced, but these were short; this was upon a projecting point of the highland. The mounds, which the party observed, were scattered, without any apparent symmetry, over the whole of the ridge of highland, which borders upon the river. They were very numerous, and generally from six to eight feet high, and from eight to twelve in diameter. In one case a number of these, amounting perhaps to twelve or fifteen, were seen all arranged in one line, parallel to the edge of the bluff, but at some distance from it.

'These are not the only works in this vicinity; it appears that the mounds and parapets extend not only along the Wisconsan, but upon the bluffs which run parallel to the Mississippi and limit the Prairie to the east. From the description which Mr. Say and his companions gave to Major Long, of what they had seen, it appeared that these could not have been the same as those he observed in 1817 . According to his MS. Journal of 1S17, (No. 2, fol. 22,) " the remains of ancient works, constructed probably for" military purposes, were found more numerous and of greater extent, on the highlands, just above the mouth of the Wisconsan, than any of which a description has been 
made public, or that have as yet been discovered in the western country. There the parapets and mounds were lound connected in one series of works; whenever there was an angle in the principal lines, a mound of the largest size was erected at the angle; the parapets were terminated by mounds at each extremity, and also at the gateways; no ditch was observed on either side of the parapet. In many places the lines were composed of parapets and mounds in conjunction, the mounds being arranged along the parapets at their usual distance from each other, and operating as flank defences to the lines."

"The remains were observgd in the interior of the country in a direction towards Kickapoo creek; they were situated for the most part on the ridges, but a few also in the valleys. Those on the ridges had the appearance of having been intended to resist an attack on both sides, being for the most part a single parapet of considerable extent, crossed at right angles by traverses at the distance of twenty or thirty yards from each other; and having no ditch upon either side. Those in the valleys appeared to have been constructed to command the passage of the particular valleys in which they were situated. We saw no worlss which exhibited signs of having been complete enclosures, but the whole were in detached parts, \&c."

The following account of the nature of the country, back of the prairie, extending towards Kickapoo creek, (a tributary of the Wisconsan, which empties itself on the north bank about twenty miles above its mouth,) is extracted from the same MS.

"The country is divided into numerous hills or rather ridges, of various shapes and dimensions, but generally of an equal altitude, by valleys and ravines, some of which have fine streams of spring water running through

VoL. I. 
them. 'The hills are generally elevated from three hundred to four or five hundred feet above the valleys; they are handsomcly rounded upon their top, but abrupt and precipitous: on their sides, and almost inaccessible except through the numerous ravines by which they are cut. The valleys are many of them broad, and appear well adapted to tillage: and pasture; the highlands are also well calculated for the raising of grain. The country is generaily prairie land, but the hills and valleys are in some places covered with a scattering growth of fine timber, consisting of white, red, and post oak, hickory, white walnut, * sugar tree, maple, white and blue ash, American box, \&c."

It is probable that Prairie du Chien was formerly the seat of a large Indian population. The beauty of the coun. try, its favourable characters for hunting, its delightful situation on the banks of the river, must have made it a pleasant abode for Indians; it is doubtful, or at least we have not been able to ascertain, to what nation belonged the family of the Dog Indians, whose name it bears. 'This family has become extinct; the traditions concerning the fate of its members are very indistinct; it is said that a large party of Indians came down the Wisconsan from Greenbay, and after having massacred nearly the whole of them, returned again to the Bay; that a few of the Dogs, who had succeeded in making their escape to the woorls, returned after their enemies had evacuated the prairic, and reestablished themsclves in their former residence; and that these were the Indians found at that place by the first French settlers.

This spot, like many of those early settled, has been graced with traditions, which, if they contribute but little to the history of our north-west Indians, adorn at least with the

* Juglans cinerea. 
tharm of romance and fable some of its most beautiful scenery. Among these, that, which is related of one of the caverns on the banks of Kickapoo creek, appears to us to deserve notice. It is said that, in one of the niches or recesses formed by the precipice, there is a gigantic mass of stone presenting the appearance of a human figure. It is so sheltered, by the over-hanging rocks, and by the sides of the recess in which it stands, as to assume a dark and gloomy character. They relate, on this subject, that long since, a battle was fought on the banks of the Mississippi between the inhabitants of the prairie and their enemies; in which conflict the latter were victorious, and succeeded in killing a great number of the former; that an inhabitant of the prairie, who was a very good woman, having received several wounds during the engagement, effected her escape and withdrew to the hills, where she was near perishing with hunger; that while wandering along the banks of this stream, a kind spirit took pity of her, and converted her into this monument to which he, moreover, imparted the power of suddenly killing any Indian that approached near it. This power was exercised until the spirit, tired of the havoc which he had committed, ceased to display his vengeance any longer. Although the natives may therefore, at present, approach the statue with impunity still they hold it in fear and veneration, and none passes near it without paying it the homage of a sacrifice of tobacco, \&c.

- There are at present but few Indians in the immediate ricinity of the fort, and none can give an account of the works which are so abundantly scattered over the country. They say that the only means by which they can account for them is to suppose that the country was probably inhabited, at a period anterior to the most remote traditions, by a race of white men, similar to those of European origin, 
and that they were cut off by their forefathers. This suppo sition is grounded upon the circumstance of their having found human bones buricd in the earth at a much greater depth than that, at which they are accustomed to inter their dead; and in graves which differ from theirs, inasmucls as they are unaccompanied by instruments of any kind, whereas they never omit depositing the arms, \&c. with the corpse of the deceased. It is also said that tomahawks of brass (?) and other implements differing from those in common use among the present Indians, have likewise been found under the surface of the ground. The fortifications appear to them likewise to be a proof of the correctness of their opinion, as none of the Indians are in the habit of constructing works of a similar character, and as incleed they are unacquainted with the utility of them.

"Mr. Brisbois, who has been for a long time a resident of Prairie du Chien, informed me that he saw the skeletons of eight persons, that were found, in digging a cellar near his house, lying side by side. They were of a gigantic size, measuring about eight fect from head to foot. He added that he took a leg bone of one of them and placed it by the side of his own leg, in order to compare the length of the two; the bone of the skeleton extended six inches above his knee. None of these bones could be preserved as they crumbled to dust soon after they were exposed to the atmosphere." **

We saw a number of Indian graves on the prairie, but as they were modern they offered nothing peculiar. They resemble the graves of white men, but the sod over them is covered with boards or bark, secured to stakes driven into the ground, so as to form a sort of roof over the grave; at the head, poles were crected for the purpose of supporting flags; a few tatters of one of these still wared over the

* Major Long's MIS. No. 2, folio 25. 
grave. An upright post was also fixed near the head, and upon this the deeds of the deceased, whether in the way of hunting or fighting, were inscribed with red or black paint. The graves were placed upon mounds in the prairie, this situation having doubtless been selected as being the highest and least likely to be overflowed.

From a scries of observations, taken at this place, it results, that Fort Crawford is situated in latitude $43^{\circ} 3^{\prime} 31^{\prime \prime}$ north, and longitude $90^{\circ} 52^{\prime} 30^{\prime \prime}$ west. The magnetic variation amounts here to $8^{\circ} 48^{\prime} 52^{\prime \prime}$ east.

Previous to leaving the prairie, Major Long provided for the safe return of Bemis to his garrison, by placing him under the protection of Mr. Rolette, a gentleman of the American Fur Company, who was on the point of travelling to Greenbay by the Wisconsan and Fox rivers. Between the forts at the Bay and Chicago a regular intercourse existed at that time by means of an express sent, at stated times, with despatches. We have had great pleasure in ascertaining that this man, whose conduct had entitled him to the most unqualified praise, returned to his regiment without accident.

Our party was here reinforced by an escort, consisting of a corporal, and nine men, under the command of first Lieutenant Martin Scott of the 5th regt. United States? Infantry, who was selected to command the guard. Major Long secured the services of a half-breed interpreter, by name Augustin Roque. The object in taking this man, was to afford to the gentlemen, charged with the collecting of the Indian information, an opportunity of acquiring from him an insight into the manners and customs of the Dacota Indians, previous to the party's travelling through their country. They were, however, very much disappointed in the character of this man, who enjoys, in the 
country, a much higher reputation for intelligence and oisservation, than they were led to ascribe to him, and as the information which he contributed was but trifling, it has been thought proper to cmbody it with that resulting from personal observations, and from conversations with the interpreters who subsequently accompanied the expedition. With a view to proceed, with as much speed as possible, to Fort St. Anthony, where the last preparations were to be made, Major Long divided the party here, and travelled by land with Mr. Colhoun; while the other gentlemen ascended the Mississippi in a boat. The land party was accompanied by George Bunker, (a soldier,) John Wade, (a boy of the garrison, who acted as Sioux interpreter,) and Andrew, (the black boy.) Tommo, a Dacota (Sioux) Indian, acted as guide to the party; he was a tall, gaunt Indian, probably about fifty years old. After having crossed the river in the boat, the two parties separated; and Major Long continued his journey on horseback, along the right bank of the Mississippi.

The route from Prairie du Chien to Fort St. Anthony, was attended with greater difficulties than had been anticipated. It was extremely rough and hilly; there being no beaten track, the party were frequently led to the edge of a precipice, and compelled to retrace their steps and seck a more gradual descent. These difficulties arose from their travelling, for the most part, at a distance from the river, with a view to shorten the road; the highlands, which they had attempted to keep, were frequently cut by transverse valleys, opened by streams, tributary to the Mississippi. In the crossing of these streams, much difficulty was experienced from the swampy nature of the ground, in which the horses were frequently mired. The distance at which they travelled from the Mississippi seldom exeeederl 
five or six miles. The guide said it would be difficult to travel at a greater distance, although it might shorten the route, because the country was too thickly wooded, and water very scarce; this last circumstance can only be accounted for upon the supposition, that the water escapes through the numerous sinks observed in the ground. The forests, traversed by the party, consisted principally of oak, basswood, ash, elm, white walnut, sugar tree, maple, birch, aspen, with a thick undergrowth of hazel, hickory, \&c. In the bottoms the wild rice, horsetail, may-apple, \&c. were found. The eye is charmed by the abundance of wild roses which are strewed over the country, and the palate is not less delighted with the excellence of the strawberry, which is remarkable for its fine fragrance, and which was, just at that time, in a state of perfect maturity. A small Indian village, of five lodges, was passed on the 26 th; it is situated on a stream, supposed to be the upper Iowa. Judging from the number of women and children which the party saw, the population must be dense; there were but two or three men in the village; the rest were probably hunting, especially as a large herd of Elk were seen in the morning by the boys of the party, while in search of the horses, that had strayed during the night time to a distance of eight miles from the camp. The whole population of the village seemed to have no other culture than about two acres of maize, which was planted without order in hills and which had at that time risen but about eight inches above the ground.

At the encampment of the 27 th, observations were taken at three o'clock, A. M. (of the 28th, by which the latitude of this place was determined to be $43^{\circ} 47^{\prime} 57^{\prime \prime}$ north. About one mile north of this, the party crossed a river,

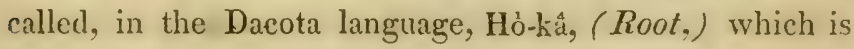


stpposed to be the Riviere Longue* or Riviere Morte of Lathontan, and the Mitschaoywa of Coxe; this is the same: stream which Coxe afterwards calls Meschaouay. + But it is impossible to read the Baron Lahontan's account of this river, without being convineed that the greater part, if not the whole, of it is a deception. By his own account he must have ascended it upwards of one hundred and eighty leagues, have met on its banks three distinct nations, the Eokoros. the Essanapes, and the Gnacsitares, the names of which are not recorded by any later traveller; have seen a population considerably greater than that which could have existed there: in a word, his description bears such evident marks of fiction, that we can credit no part of it.

Major Long's party passed on the 28th down a valley. bounded on both sides by high bluffs and precipices; their ride was a picturesque one; the green sward of the ravine contrasted richly with the grayish hue of the lime and sandstone bluffs, which rose like high walls on either side of them. At last the valley widened, and they found themselves almost instantaneously in sight of the majestic Mississippi, in whose broadly extended valley nature displayed herself with gigantic features. 'The river, one of the largest in the world, rolling its waters with an undiminished rapidity, in a bed checkered with islands, was a spectacle, which, however often observed, always filled the mind with awe and with delight. It was impossible to behold the great derastation in the earth's surface, whether considered as caused by the Mississippi or as pre-existing to

* Lahontan, ut supra, Let. 16, vol. 1, p. 112.

† Description of the English province of Carolana, by the Spaniards called Florida, and by the French la Louisiane; by Danit Coxc, Esq. London, 1741, p. 19. $\neq$ Idem, ibicl. p. 6 S. 
it, without being induced to look back to the causes which may have produced this phenomenon. But here man finds himself baffled in every attempt to dive into the abyss of past times; he may contemplate the scenery, but cannot unravel the mysteries of its creation. Deep strata of sandstone and limestone are disclosed; they have preserved, as yet, the elevation of the hills undiminished, but have not protected their sides from waste. "When we entered on the prairie, towards the close of the day," says Mr. Colhoun, from whose notes this description is chiefly extracted, "a landscape was presented, that combined grander beauties than any I ever beheld; far as the eye could follow were traced two gigantic walls of the most regular out. line, formed, as it were, by successive faces of pyramids. Between them, extended a level verdant prairie, the scene of the Python flexures of the Mississippi. My sensations were prolonged by the reflection that I had before me one of the noblest rivers in the world; they were enhanced when I saw the evidences of a grand catastrophe. Majestic as is the Mississippi, there was a time when it swept 2long, a stream, more than one hundred fold its present volume."

Whatever might be the reveries in which the party wore indulging, they were soon recalled to the dull realities of travelling, by the howling and barking of a band of dogs, that announced their approach to an Indian village consisting of twenty fixed lodges and cabins. It is controlled by Wă-pâ-shå, an Indian chief of considerable distinction. In his language, (Dacota,) his name signifies the red leaf. A number of young men fantastically decorated with many and variously coloured feathers, and their faces as oddly painted, advanced to greet the party. One of them, the son of the chief, was remarkable for the gaudiness and display VOL. I. 
of his dress, which from its showy appearance imparted to him a character of foppishness. In his hair he wore two or thrce soldiers' plumes; his moccasins of stained buckskin were tastefully puckered at the toes, and his breechcloth was quite tawdry. The chief is about fifty years of age, but appears older; his prominent features are good and indicative of great acuteness and of a prying disposition ; his stature is low; he has long been one of the most influential of the Dacota Indians, more perhaps from his talents in the counsel than his achievements in the field. He is represented as being a wise and prudent man, a forcible and impressive orator. His disposition to the Americans has generally been a friendly one, and his course of policy is: well spoken of. The major's party having no other interpreter than Wade, who proved less serviceable than had been expected, could hold but a short conversation with him, and therefore proceeded on their journey, and encamped two miles above the village. Near this place a number of mounds were seen, arranged in nearly a right line along the margin of the river; they were of inconsiclerable height, but covered a large surface. Indian remains were observed, in great plenty, for the ensuing two days, extending along the banks of the Mississippi, and especially near the shores of Lake Pepin, along which the land party travelled on the 30 th. These mounds and remains attest, of course, the former existence of a very dense population along the lake. It must have heen a stationary one, for these works could not have been executed in a short space of time. We are, likewise, led to believe that they were erected by the same nation that constructed the fortifications described by Carver as existing on the bank of the Mississippi a little below Lake Pepin. The latitude of the encampment, near the lower extremity of the lake, was 
found, by observations made on the evening of the 29 th of June, to be $44^{\circ} 18^{\prime} 37^{\prime \prime}$ north.

Having travelled twenty-two miles along its western shore, Major Long arrived on the evening of the 30th at an Indian village, which is under the direction of Shakea, (the man that paints himself red;) the village has retained the appellation of Redwing, (aile rouge,) by which this chief was formerly distinguished. The provisions of the party being almost consumed, and the boat having been seen the preceding day at a short distance below the land party, Major Long thought it more prudent to wait here the arrival of the other division, in order to get a fresh supply of provisions. About ten o'clock, on the morning of the first of July, the boat appeared in sight of the village, and signals having been made, the gentlemen landed. The whole party being again united, the chief invited them to his lodge, with a view to have a formal conversation with them.

Shakea is one of the most distinguished of the present leaders of the Dacotas. It does not appear, however, that he is entitled by birth to rank as a chief; but the influence, which he has attained, is founded altogether upon his great military attainments; it is said that he has never been defeated, although he has shared in more actions than almost any other Indian. The respect with which he is treated, which far exceeds that usually paid to a partisan chief, has induced him to assume an importance and a formality, seldom to be met with among the Indians of the present day. As a compliment to the party, the United States' flag was hoisted over his cabin, and a deputation of some of his warriors waited at our encampment to invite us to his lodge. We were received in due ceremony; the chief and his son, 'Tâttủnkâmânè, (the walking buffalo, ) were seated 
next to the entrance. We took our stations near them, on the same bed-frame, while his warriors seated themselves on the frame opposite to us; as soon as we entered, the chief and his son rose, and shook hands with each of us. The calumet of peace was placed in the centre of the cabin; the bowl resting on the ground, and the stem supported in. an inclined position by a forked stick, planted in the ground for the purpose. The chief then rose, shook hands with the party a second time, raised the pipe from the ground, and holding the bowl towards himself with the stem elevated, he commenced a speech which was delivered with much vehemence; the purport of it was an acknowledgment of satisfaction, at seeing a party sent by his Great Father, (the President,) and a general expression of good will and respect towards the American government; he inquired as to the nature of the expedition and its object. Very often during his speech, the commencement of a sentence was in the concluding terms of the preceding one; the warriors, at each sentence, testified their approbation of his sentiments, in deep-toned responses, sounding like the syllables $a h-h a h$, pronounced strongly, and in a nasal and guttural manner. Major Long stated, in reply, the nature and object of the expedition, the views of the government in sending it among the Indians, the friendly disposition of the President towards all his red children, \&c. With all this the chief appeared well pleased, as also with the presents of tobacco, powder, shot, \&c. which were given to him; but he stated that his warriors had been much distressed of late, by the loss of numerous friends and relatives, on which account their faces were painted black, that they had not a single drop of spirits to comfort them in their afflictions, and " hoped that their Father would give them some of their Great Father's milk to gladden their 
hearts." But they were informed that the expedition was totally unprovided with this article, as it was their Great Father's wish, that the Indians should not receive, from white men, liquor, the effect of which was to drive away their senses, make them quarrclsome and sick. Shakea assented to the truth of this, and acknowledged that the use of liquor was very injurious to them, but seemed, however, to regret that he could not make himself merry on the occasion of the glad tidlings which he had received from his Great Father. Both he and his son made speeches which were not remarkable for the beauty or originality of the ideas; these may, however, have lost their force through our interpreter's inelegant and unanimated translation. But the gestures, which accompanied the words of the orator, wcre more remarkable for force, than for grace or significance. A young Indian who acted as pipe-bearer to the chief, (an office of dignity,) then lighted the pipe, passed it round to all, commencing with Major Long, proceeding with our party, and concluding with the warriors and interpreter. The pipe-bearer supported the bowl, while each person present drew two or three whiffs. He then smoked of it himself, and, drawing out the stem, presented it to Major Long in token of respect. The bowl, which he kept, was of the red stone found on the St. Peter; the stem was of wood, and made in the usual manner of the Dacota pipe. Its length is about three feet, it is flattened, being about two inches wide, and three-eighths of an inch thick. It tapers a little towards the upper extremity; a hole is perforated through it, with a hot iron; the pipe stem is painted with a blue clay, which, by long exposure to the air assumes a green colour; the upper extremity, to about one-third of its length, is ornamented with porcupine quills variously dyed, so as to present beautiful de- 
signs; it is also adorned with the small feathers of birds, pigeons, \&c. and with the hair of the deer, stained red. Some of these pipes are very elegant, and require a great deal of time in their preparation; they are made by the females. The chief distinction, between the Dacota and Chippewa pipe, is, that the latter is cylindrical and about an inch in diameter; while the former is, as we have just mentioned, flattened. Both nations use bowls of the same stone, which is generally red, sometimes, however, black; they are often curiously carved, \&c.

The conversation concluded with another general shaking of the hand. The frequency of this ceremony, during the interview which we had with the Redwing chief, who is considered as pertinaciously adhering to all their old customs, led us to inquire whether the practice of shaking hands originally existed among the Indians, or if it was not introduced among them by Europeans. An acquaintance with many nations has proved, that the modes of salutation varied, according to the diversity which exists in their manners, languages, \&c. It would, therefore, be singular, that the same practice, which prevails among us, and which we received from our British ancestors, had existed among the Indians, whose neighbours we have, in the course of ages, become. With a view to clear this point, we have collected a number of authorities, relating exclusively to the North American Indians, from which we have been led to believe, that the practice of shaking hands, was acquired by their intercourse with white men.

We find that anong many Indians a different mode of salutation formerly prevailed. Probably one of the most usual methods, for an Indian to welcome a stranger, was to pat his own breast, arnis, and legs, and then those of the 
siranger. We are told that the Indians on the Canada coast receired Jacques Cartier by "fecling him and rubbing his arms and breast, with their hands, according to their custom of caressing." And again a chief "desired the captain to give him his arms that he might kiss and touch them, as is their practice of welcoming in the said land." $\dagger$ The practice of rubbing down the limbs of the stranger was, probably, first introduced for the purpose of relicving him from his fatigue, at least we infer it from the words of Father Hennepin, who says, "At the entry of the Captain's Cabin, who had adopted me, one of the Barbarians, who seem'd to be very old, presented me with a great Pipe to smoak, and weeping over me all the while with abundance of Tears, rubb'd both my Arms and my IIead. This was to show how concern'd he was to see me so harass'd and fatigu'd: And indeed I had often need enough of two Men to support me when I was up, or raise me when I was down. There was a Bears-Skin before the Fire, upon which the youngest Boy of the Cabin caus'd me to lie down, and then with the Grease of Wild Cats anointed my Thighs, Legs, and Soles of my Feet." $\ddagger$ This treatment was among the Dacotas.

Alvar Nunez also observes, that the rubbing of the body was a mode of salutation with many nations, about and west of the mouth of the Mississippi, and indeed at a great distance in-land. In the account of the first expedition to Virginia in 1584, the narrator expresses himself thus; Gran-

- Lescarbot, Ilistoire de la Nouvelle France, à Paris, 1618. p. 254. † Ilem, ibid, p. 302.

* A New Discovery of a Vast Country in America, by L. IIennepin. L.ondon, 1698, p. 210. 
ganimen, an Inclian on the coast of what was then called Virginia, made "all signes of joy and welcome, striking on his head, and his breast, and afterwards on ours, to shewe that we were all one."* When they reached the north end of the island of Roanoak, they were entertained by Granganimeo's wife, in a house that had five rooms; their feet were washed in warm water.t The practice of washing the feet is also mentioned by Joutel, in his Account of de la Salle's Expedition; and the Chevalier de Tonti says, "the chiefs of the Nation came towards us; we were conducted through a double file of armed young men, to very neat calins; the remainder of our entertainment was as grotesque as it was wild; women of a darls complexion, but very well formed and half naked, washed our feet in wooden troughs." $\ddagger$ Different practices prevailed among other nations. The Clamcoets near the Bay of St. Bernard sometimes saluted a stranger by rubbing his breast and arms with their hands, sometimes by blowing in his ear; $\$$ while the Cenis, who reside on their northern limit, had a different usage. Twelve old men, with the right hand raised to the head, ran up with loud cries and embraced the French.|| In Carolina the practice of scratching the shoulder probably prevailed. "At noon," says Lawson, "we stay'd and refresh'd ourselves at a Cabin, where we met with one of their

* Account of a "Voyage of Captains Amadas and Barlowe to part of" the countrey now called Virginia," (in Hacliluyt's collection.) London, 1589, p. 729.

† Idem, ibid, p. 731.

\$ Relations de la Louisianne et du fleuve Mississipi. Amsterdam, 1720, being Vol. 5, of a "Recueil de Voyages," \&c.

§ournal historique du dernier Voyage de M. de la Salle, par Joutel. Paris, 1713, p. 74. 84 .

II Idcm, ibid. p. 220. 
War-Captains, a Man of great Esteem among them. At his Departure from the Cabin, the Man of the House scratch'd this War-Captain on the Shoulder, which is look' $d$ upon as a very great Compliment among them ;" " and again, "They are free from all manner of Compliments, except Shaking of Hands, and Scratching on the Shoulder, which two are the greatest Marks of Sincerity and Friendship, that can be sherv'd one to another." $\uparrow$ Of the Esquimaux we find the following related, in the account of Davis's first voyage in 15S5; "At length one of them, poynting up to the Sunne with his hande, would presently strike his brest so hard that we might here the blowe." $\ddagger$ When John Ellis imi. tated their action the Esquimaux approached with confidence. In a tribe of Esquimaux discovered by Captain Ross, the practice of pulling noses is said to exist. "Sacheuse called to us to pull our noses, as he had discovered this to be the mode of friendly salutation with them." \$ This was in latitude $75^{\circ} 55^{\prime} \mathrm{N}$. and longitude $65^{\circ} 32^{\prime} \mathrm{W}$.

The practice of shaking hands is, however, related of scveral Indians; Du Pratz states it to exist among the Natchez in particular, and Indian nations generally, referring however to those on the Mississippi.|| Miantonimo, a Narraganset chief, after a conference with the Governor, gave him his hand for the absent Magistrates; * but this was subsequent to 1637. The habit of embracing or kissing is alluded to more frequently. At Hochclaga, now

* A new Voyage to Carolina, by John Lawson, Gent. London, 1709 , p. 42 .

†Idem, ibid, p. 201.

† Hackluyt's Collection, p. 778.

§ Ross' Voyage, London, 1819, p. 86.

II Histoire de la Louisianne, par Du Pratz, à Paris, 1758. T'one?. p. 237.

* IIubbard's Narrative of Indian Wars, Brattleborough, 1314, p. 54 Vor. I. 
Montreal, the French were welcomed by the women who kissed their faces.* In the fourth voyage made to Virginia in 1587, it is said that the Indians of the island of Croatoan, (on the coast of North Carolina, " threwe away their bowes and arrowes, and some of them came unto us, embracing and entertaining us friendly." $\dagger$ So also of the Esquimaux in Davis's second voyage in 1586; "they came ruming to mee and the rest, and embraced us with many signes of hartie welcome." $\ddagger$ Wherever the Spanish authors are consulted, we find that, in addition to the ceremony of embracing generally, they mention the kissing of hands and prostrating themselves; thus, although it is stated, that the chief Muscoço welcomed Juan Ortiz who fled to him for protection by embracing him and kissing his face, $\S$ yet we find, that when the same chief went to the Spanish camp, he kissed De Soto's hands. || The Cacique of Casqui, (on the Mississippi,) is also stated to have prostrated himself before De Soto. ** Garcilaso de la Vega mentions, as a mode of salutation, prostration and kissing of the hands; but these were probably to superiors, and in token of veneration. The following practice, observed at Kecoughtan, (near Chesapeake Bay,) is a curious onc, hut. whether used as a mode of salutation or not, we are unable to tell. "Landing at Kecoughtan, the Savages entertained them," (the voyagers, "with a doleful noyse, laying their faces to the ground and scratching the earth with their nayles." + †

* Lescarbot, ut supra, p. 327.

† Hackluyt's Collection, ut supra, p. 767 .

$\neq$ Idem, ibid, p. 781.

$\S$ La Florida del Inca, en Madrid, 1722. p. 28.

II Idem, ibid, p. 33.

** Narrative of De Soto's Invasion, written by a gentleman of Elvas. and translated by Ilackluyt. London, 1609, p. 96.

† Purchas his Pilgrimage, London, 1614, p. 768. 
From the instances which we have cited, and we might have adduced many more, we are led to believe that, wherever the practice of shaking hands has been observed, it had probably been received from the English; for the only three instances which we have mentioned are those from Hubbard, Du Pratz, and Lawson. The first of these authors states it of the New England Indians; the second is comparatively a modern writer, his book having been published as late as 1758; and Lawson's authority, though generally very good, is less decisive in this instance, because, being himself an Englishman, he might be more ready to ascribe this practice to the Indians, than any other, and because he speaks of Indians who had already some acquaintance with the English; besides we find that he describes twice the practice of scratching the shoulder, as a mark of great respect, from which circumstance, we are led to believe, that this was the original practice of the Carolina Indians. The practice of kissing hands and of prostration, being: only mentioned by Spanish writers, was probably the consequence of an intercourse with Spaniards. That of embracing appears more general, but it is also restricted chiefly to French authors, or to those who treat of Indians that had been in habits of intercourse with the French. One exception presents itself, horvever, to our recollection, it is in the first reception of Captain Lewis by the Shoshonees. "The three men leaped from their horses, came up to Captain Lewis, and embraced him with great cordiality, putting their left arm over his right shoulder and clasping his back, applying at the same time their left cheek to his, and frequently vociferating ah-hie! ah-hie! 'I am much pleased, I am much rejoiced.' The whole body of warriors now came forward, and our men received the caresses, and no small share of the grease 
and paint of their new friends.". Notwithstanding this instance, we consider the practice of embracing as not oriGinal with the Indians in general, but probably in most cases derived from the French. Indeed we have ourselves heard the Indians ridicule the frequent kissing, which they observed among the Canadians, and consider it an unworthy of men.

The Redwing chief is, at present, very much superannuated, but he is still respected on account of his former distinguished achievements. When Major Taliaferro, the Indian agent, visited him, not long since, with Morgan the principal war chicf of the Sauks, the latter told Tatumlamane to his face, when shaking hands with him, that he considered him as a very unimportant personage, and that he only took him by the hand, out of respect to his father, who had been, to them, so brave and active an encmy. The Saulis will long remember the injury this chicf did them. Some of the warriors, whom we saw in the chief's cabin, were very fine looking men. One of them, whose face was covered over with charcoal, bore so strong a resemblance to the portraits of Napoleon, that all our party were struck with it. It was rather to Bonaparte as first consul, than as emperor, that the resemblance was great, for he had not the corpulence which the ex-emperor had acquired. Not only his features, but even the conformation of his head, shared in the general resemblance. We could not learn that he was a distinguished man in the nation.

Anong the many Indians whom we saw at the village, one

* Ilistory of the Expedition under the command of Captains Lewis and Clarke, Philadelphia, 1814, vol. 1, p. 363. 
of those, who frequented our company most, was an old man, by the name of Wà-zé-kơ-tîl, (Shooter from the pine-top,) who was an intolcrable beggar. He professed much friencship for us, was very fond of showing his knowledge of our langunge by the frequent repetition of the English. monosyllable of Indian John in the Spy. This, together with a few of the most common expressions, such as how d'ye do, good bye, \&c. completed his whole stock of English words. This man's name bears a striking analogy to that of the principal chief of the Issati or Nadouessis whom Hennepin met on the Mississippi, and whom he calls "Ouasicoude, (that is to say the Picrc'd Pine.")" He accompanied Major Long on part of his journey in 1817, but scarcely recollected the circumstance, being at present very old. 'These Indians were much pleased with the sight of our travelling map; they displayed great intelligence on the occasion, understanding it immediately ; tracing several rivers with their fingers; mentioning their names; pointing to the portages, \&c. Wazekota laid his finger upon the Falls of St. Anthony, which he called Hảhả wờtẻpà. They appeared quite suprized to find that so large a district of country could be represented on so small a compass, and at the same time be so distinct. The magnetic needle and the mercury, likewise attracted their notice; they expressed much surprize on observing that iron floated upon this fluid. with the same buoyancy that cork would upon water. They considered all these things as mysterious.

Three Menomone Indians were here on a visit, haring just returned from the St. Peter, where they had been hunting. It is supposed that sixty or seventy warriors of

* Father Hennepin's Works, ut supra, London 1698, p, 217, an? Relations de la Louisianne, \&c. p. 292. 
their nation will unite with Redwing's band, although the principal of the three, a fine looking stout man, thought proper to apologize for this band, saying to us, that the Sioux were hogs and beggars, destitute of food, and ignorant of the duties of hospitality; but that when we should arrive among the Chippewas, we would be received as strangers should be; a subsequent experience has by no means satisfied us of the superiority of the Chippewas over the $\mathrm{Da}$ cotas. The complexion of these Menomones was lighter than that of any Indians we saw on the journey; one of them spoke French; the principal one had abundance of wampum about his ncck, together with a necklace of Cowries, (Cypræa moneta.) We afterwards learned from the Indian agent at $\mathrm{St}$. $\Lambda$ thony, that this is an eminent war leader, and that, when his party unite with Redwing's, he will be recognised as the principal war chief. This Menomone told us, that the tumuli observed back of the village were artificial, and ancient cemeteries. Tommo, and the Sioux, whom we consulted on the subject, all considered them as natural elevations. As they do not bury their dead, but dispose of them on seaffolds, they seem to be unacquainted with the ancient practice of interring.

After a very interesting visit to this village, the gentlemen again separated. Major Long's party, being provided with a proportion of the boat's provisions, which were becoming scanty, continued their journey by land that afternoon, and reached Fort St. Anthony the next evening without mecting with any accident. The route from the Indian village was off from the river, it was rolling, less hilly than had been previously travelled; the tumuli increased in number, exceeding in abundance any that the party had ever scen before, at times upwards of one hundred of them were in view. A stream about thirteen yards wide, which they 
crossed a short time after leaving the village, is called by the Indians Eảmỏzindảảủ, (High rock, from a white pyramidal rock which rises to a considerable height near this stream, a few miles above the place where they crossed it. Being aware of its existence, and knowing that it would not lengthen the journey much, they were anxious to pass near it; but, whether from superstitious motives or not, Tommo seemed unwilling to guide them in that direction. This man was not one of the pleasantest that the party could have had to accompany them; although he was selected as one of the best in the vicinity of Prairie du Chien, he rvas not agreeable. He was a listless, indifferent kind of man; an incessant smoker; his pipe, which was connected with his tomahawk, was in constant use; it was made in the form of a shingling hatchet. The part which corresponded with the hammer was hollowed out for the borvl, and the handle was perforated so as to serve as the stem of the pipe. He adverted to the pipe as the Indian's only solace in hunger. This man had a curious specific when unwell; it was to climb a tree, cut the top so that it would bend, and then let himself drop down from it to the ground.

The first boulders which had been seen from Rock river, were observed by Mr. Colhoun at about seven miles from Fort St. Anthony; they consisted of granite. $\Lambda$ very great change in the country above Lake Pepin was visible. The bluffs were not so high, they were more frequently interrupted, and gave a nerv character to the scenery of the river. The distance, by land, from Prairie du Chien to the St. Peter, is two hundred and eleven miles; it was travelled in eight days, hence at an average of twenty-six and a half miles per day. This may be considered as the first section of our journey; the whole dis- 
tance from Philadelphia to this place, was near thirtecn hundred miles, which were travelled in sixty-four days, stoppages included. This affords an average of twenty miles per day.

Having followed Major Long's division from the Prairic to this place, we shall take a hasty glanee at the observations made by the other division, during their progress up, the river.

This division consisted of Messrs. Sity, Keating, and Seymour, with Roque, (the interpreter.) The boat was manned by the corporal and eight soldiers, under the command of Lieutenant Scott. They were provided with an eight oar barge with a sail, or rather their tent $f y$, which was used as a substitute for one. After parting with Major Long, on the west bank of the river, the barge proceeded up the Mississippi, but had not been long on its course before symptoms of misconduct broke out among the men; and Mr. Scott then discovered that, while the whole party were conversing with Major Long, on the river bank, the men had broached the lieg of liquor and helped themselves to its contents so bountifully as to be soon affected by it. As soon as they were heated by the exercise of rowing, the effects of the whiskey became but too evident. They lost all respect for their officer, and but for the firm stand which he took upon the occasion a mutiny would incvitably have broken out; but having called for his pistols and loaded them in their presence, he assured them that the first man who attempted a mutiny must do it at the risk of his life; the crew being, however, too much affected by the liquor to be able to stem the strong current of the Mississippi, the boat was ordered to the shore, and the party lay by for a few hours.

In the evening the men being a little subered, they re- 
sumed their journey, and encamped at night above the Painted Rock river, on the west bank of the Mississippi. The distance travelled that day did not exceed nine miles. The bluffs, which appear to be limestone, (but we were at too great a distance to determine the fact with certainty,) continue on both sides of the river, and rise to a considerable height. In one place the rock is very steep and apparently inaccessible; the difficulty of the undertaking was probably the motive which induced the Indians to attempt to climb it; and having succeeded, they wished to perpetuate the recollection of their success by painting upon it, with red colours, a few grotesque figures. It is said that, when these are effaced by time or washed away by the rain, they are soon replaced by other sketches left there by the Indians who are constantly passing up and down the river. The Painted Rock, like every frail attempt to distinguish, by artificial means, those things which nature, in her wild designing, has clothed with an uniform garb, seizes more porverfully upon the imagination of the trading voyager on our western streams, than the finest natural features of their splendid scenery; it has become, therefore, as it were, a landmark which assists the traveller in tracing his progress through these desert regions. The weather was fair and warm; the wind slight but adverse, so that the sail was not hoisted. This first day's voyage on the Mississippi was delightful to those who had never been on that river before; the magnificence of the scenery is such, its characters differ so widely from those of the landscapes which we are accustomed to behold in our tame regions, its features are so bold, so wild, so majestic, that they impart new sensations to the mind; the very rapidity of the stream, although it opposes our ascent, delights us: it conveys such an idea of the extensive volume of water VoL. I. 
which this river ccaselessly rolls towards the ocean. The immense number of islands which it imbosoms, also contributes to the variety of the scenery by presenting it constantly under a new aspect.

On the 26th of June the wind was fair, and starting early, the party proceeded up with considerable speed; the country and its scenery presenting pretty nearly the same characters as on the preceding day. In the course of the morning, they saw the appearance of a cavern in the rocks, and landed to explore it, but found it to be merely a small excavation of no account; this however gave Mr. Keating an opportunity of observing that the bluff consisted of limestone, which in the upper parts became very loose, and assumed the characters of the asche as mentioned in the preceding chapter. Fragments of a beautiful oolite were observed below it; they were loose and angular, some of them of a large size. No doubt could exist that they were in the immediate vicinity of their original sites, but the necessity of taking advantage of the fair wind, did not permit a search after the rock itself. On the left bank of the river, a small stream was observed to put in; at its mouth two Menomone lodges were situated; but they were closed, the inhabitants haring doubtless gone on their summer hunts. At some distance beyond this they passed, on the right bank, the mouth of the Iawa, a river celebrated in Indian warfare as the spot of a bloody rencounter between the Sioux and Sauks. At forty-five miles from Fort Crawford there is a Winnebago village of a few huts; it was surrounded by handsome cornfields. At the mouth of Bad-Axe river, a little beyond this, the party exchanged a few words with two Menomone Indians who were descending in a canoe. Two remarkable capes or points were observed on the right bank of the Mississippi below Iawa river; the lower one 
is designated by the name of Cape Puant, because at a time when the Sioux and Winnebagoes, (Puants,) were about to commence hostilities, a party of the latter set out on an expedition to invade the territory of the Sioux and take them by surprise; but these being informed of the design, collected a superior force, and lay in ambush near this place, expecting the arrival of their enemies. As soon as the Winnebagoes had landed, the Sioux sallied from their hiding places, pressed upon them as they lay collected in a small recess between the two capes, drove them into the river, and massacred the whole party. Garlic cape, just above this, strikes the voyager by the singularity of its appearance. In shape it represents a cone cut by a vertical plane passing through its apex and base; its height is about four hundred feet. The peculiarity of its appearance has made it a celebrated landmark on the Mississippi. Mr. Seymour, whose pencil was frequently engaged in sketching the beautiful features of the Mississippi, took a hasty view of this as the boat passed near it. The valley is, in this part, almost entirely filled by the river which laves the base of the bluffs on both sides. The river spreads in some places to the width of three or four miles; its channel being very much interrupted by numberless islands, which render the navigation difficult. The bluffs are generally from four hundred to five hundred feet high, intersected with numerous ravines, and exhibiting signs of being the commencement of a hilly and broken inland country.

One of the soldiers was this day very sick of mania a potu. At times he was perfectly insane, probably from having suddenly given up the use of strong liquor, in which he had previously indulged himself very freely. He continued sick during the rest of the voyage up 
the Mississippi. It was a horrid sight, in a small boat, not more than thirty fect long, in which the party were much cramped for want of room, to bchold a man affected with occasional fits of raving, and these of the most distressing kind; he made frequent aftempts to throw himself overboard, which at last induced Mr. Scott to have him secured to the mast; he was very loquacious in his insanity, replying as he thought to the voice of his officers at Prairie du Chien, whom he fancied he heard calling him; at times he became ironical, bursting into a wild and convulsive laughter, then launching out into profane and abusive language; in fine, exhibiting all the workings of a disordered imagination. At one of the encampments, he broke his bonds and wandered near a swamp; men were sent after him who were out a long time before they overtook him; he was for a while given up for lost, and it was by the most fortunate chance that he was at last discovered by one of the men wading through a swamp; had he proceeded much further he must have perished in this fen. Mr. Say having administered to him the proper remedies, he gradually recovered, but finding it agreeable to abstain from work, feigned sicliness, and his insanity was observed apparently increasing while the other symptoms indicated a general improvement in his health; suspecting that he was playing the old soldier, Mr. Say prescribed the use of an oar as a sudorific, by which he soon recovered the use of his lost senses.

The party had encamped for the night on a prairie, between Raccoon and Bad-Axe rivers, but the mosquitoes, which had hitherto proved very tormenting, becoming still more so, they determined, at eleven o'clock at night, to resume their journey. If a sleepless night was to be spent, it was better to pass it in the boat, in the middle of 
the stream, where at least they would be relieved from the torment of the mosquitoes. The breeze, which was favourable, allowed the barge to proceed with considerable rapidity for three hours, when the wind increased into a gale, which rendered the navigation dangerous. After having attempted, for a time, to continue, in despite of the violence of the storm, they were obliged to draw near the shore. $A$ very heavy rain fell for several hours, to which they remained exposed in the boat, having no protection but that afforded them by their blankets. Notwithstanding the comfortless situation in which they found themselves, there was an irresistible interest in the scene. A storm is at all times one of the most splendid phenomena in nature; but when experienced in the gloomy forests of the Mississippi, in the midst of a solitude, with no companions but a few fellow sufferers, standing in a shivering attitude in a small boat, it receives an additional interest; every flash of lightning displays a scene which the painter would wish to fix upon the canvass. The loud peals of thunder resound more forcibly when reverberated by the rocky bluffs, which border upon the river, and they contrast sublimely with the low but uninterrupted muttering of the rolling waters. About sunrise the storm ceased, the weather cleared up, the party resumed their journey, and continued it until breakfast time, when they were gratified to stop and make a fire to dry their clothes and repair the damage occasioned by the storm. While at their encampment of the preceding evening, the attention of the party was suddenly roused by the faint and indistinct sounds of a human voice, singing at a distance. It was soon evident that the words were English, and the air a familiar one to all the party; after a while the noise of a paddle was distinctly heard, and by hailing they brought to the shore a canoc 
that was gliding down the river, with two discharged sul. diers from Fort St. Anthony. The country which borders upon the river abounds in rattlesnakes, the party killed several during their journey to Lake Pepin, aloove which it has been said that they are never seen. In examining the head of this serpent, Mr. Say's thumb was punctured by several of the small acute tecth, while it pressed upon the roof of the mouth; and on laying open the vesicle of poison, a portion of the fluid flowed under the thumb and found its way into one of the punctures, and although the quantity must have been very small, it gave rise to much pain and numbness in the part; it however soon subsided, producing but little swelling.

The travelling on the 27 th was not very rapjid owing to a head wind, but no time having been spent on shore, the party reached the Prairie de la Crosse in time to encamp there; this has been incorrectly called the Cross, (cruar,) prairie. The name of this spot is derived from a game very much in favour among the Inclians; it is played with a ball, and is probably not very unlike some of the games of white men. This prairie being very level and fine, is admirably well calculated for this purpose; and was formerly much frequented by the Indians. There were a few remains of Indian encampments upon it, of one of which the party took possession, for the purpose of sheltering themselves during the night. Within a few yards of their encampment they discovered several graves, over which flags were hanging, indicating that the deceased had been men of some consequence. The party proceeded, early the next morning, and passed the mouth of Black river, one of the most important tributaries of the Mississippi ; it is much resorted to for the purpose of obtaining timber, as the forests, which grow upon its banks, are 
much finer than those on the Mississippi. Not only does it supply the fort at Prairie du Chien, but even, as we are informed, much of the " pine timber, used at St. Louis, is cut here." "* The voyagers have remarked that the number of islands, in this part of the Mississippi, is so great, that there are but few spots where both banks of the river can be secn at the same time; this is, however, the case, at a short distance, above the mouth of Black river; and one mile above this place the bluffs, on both sides of the river, approach within eight hundred yards of each other. The wind being ahead, and strong, the progress of the boat was slow. On the evening of the 2sth, the party reached the spot which has been described, by all travellers, as a great natural curiosity, though, in fact, it presents nothing extraordinary. It is termed, by the voyagers, the Montagne qui trempe dans l'eau. This, which we understand to be but the translation of the Indian name for it, means "the mountain that soaks in the water." It is a rocky island corresponding with the adjoining bluffs, and separated from the left bank of the river by a narrow sluice. This insulated portion of highland appears, when seen from a distance, to stand in the middle of the stream, and its base is washed by the water; but on approaching towards it, it is found to be very near the east bank of the river; and as well as the party could judge from the opposite bank, along which they were coasting, there was at that time but little or no water between the "mountain" and the left bank. Pike has, in his journal, stated its height at about two hundred feet; from a trigonometrical admeasurement of it, made in 1817, Major Long estimates its elevation at five hundred feet; although his instruments did not allow

* Major Long’s MS. 1817, No. 2, folio 4. 
him to take his measurements with the greatest accuracy, yet this must be very near the true height; since the island is as elevated as the adjoining bluffs, which are among the highest that are to be seen above the Wisconsan.

Mr. Schoolcraft has been led into error, in his account of it, when he represents the island, on which it stands, as being four or five miles in circumference. Mr. Scott, who travelled down the Mississippi a week after we ascended it, measured it, and found it to be only about a mile in circumference. Neither can we agree with the same author when he states that it "divides the river into two equal halves, and gives an immense width to the river." Perhaps the most remarkable feature about this mountain is that "it is the third island of the Mississippi from the Gulf of Mexico to this place that has a rocky foundation similar to that of the neighbouring bluffs, and that rises nearly to the same height as these." $†$ The other islands in this river are merely formed by the alluvion collected by the stream, and are chiefly sandy; many of them are covered with a fine vegetation.

Early on the 29 th, the boat reached Wapasha's village; the gentlemen landed, and were disappointed on being informed that they had failed in seeing Major Long's party by about an hour. Being anxious to become better acquaintcd with an Indian, who is held in such high esteem among the powerful and extensive nation of the Dacotas, as Wapasha is, they gave the old chief an invitation to enter into their boat, which he readily accepted, but declined acrompanying them up to Fort St. Anthony, as his band had heard, that morning, of the approach of their enemies,

* Narrative Journal of Travels, \&.c. by H. R. Schoolcraft, p. 335.

† Major Long's MS. NTo. 2, folio 5 . 
the Chippewas, on the river of the same name; he had sent out some of his warriors to scout, and thought it incumbent on him to remain and watch over his band; but as our party was ascending in the direction in which his warriors had gone, he said he would proceed with us that far. The gentlemen were interested by the apparent calmness with which he spoke of the approach of his enemies. No consternation prevailed in the village; the men were, it is true, all painted, as for war, and a number of them were absent; but the old chief was lying down with the greatest unconcern; his preparations for departure were, however, soon made, and he accompanied the party in the boat; his son-in-law and another Indian paddling: his canoe in the rear. Wapasha spoke of the advantages of the arts and agriculture; of his wish to see them introduced; he expressed his desire to accept the invitation, given him by the Indian agent, to accompany him to the seat of government, as he was anxious to see how every thing was managed among white men. One of the objects of which he spoke with the greatest rapture was the steam-boat, which had ascended the river in the spring, and which he considered as a wonderful invention. We were told that when this boat had come up, he was taken on board, and the machine was exhibited to him; he appeared to take great interest in the explanations of it, which. were given to him. During Major Long's visit to Wapasha's village in 1817 , he witnessed part of a very interesting ccremony known by the name of the bear dance. "It is usual to perform it when a young man is anxious to bring himself into notice; and it is considered as a sort of initiation into the state of manhood. On the ground, where it was performed, there was a pole supporting a kind of flag, made of a fawn's skin clressed with the hair on; upon VoI. I. 
the flesh side of it, were drawn certain figures indicative of the dream which the candidate had enjoyed; for none can go through this ceremony, who has not been faroured with dreams. To the flag a pipe was suspended as a sacrifice; two arrows were stuck up at the foot of the pole; and painted feathers, \&c. were strewed upon the ground near it. These articles appertained to the religious rites, which accompany the ceremony, and which consist in bewailing and self mortifications; the object of these is that the Great Spirit may be induced to pity them and assist them in the undertaking. At two or three hundred yards from the flag there is an excavation which they call the bear's hole, and which is prepared for the occasion; it is about two feet in depth, and has two ditches, each one foot deep, leading across it at right angles. The candidate places himsclf in this hole to be hunted by the rest of the young men, all of whom, on this occasion, are dressed in their best attire, and painted in their neatest style. The huntcrs approach the hole, in the direction of one of the ditches, and clischarge their guns, which were previously loaded with blank cartridges, at the youth, who acts the part of the bear; whereupon he leaps from his den, having a hoop in cach hand, and a wooden lance; the hoops serving as forefeet to aid him in characterizing his part, and his lance to defend him from his assailants. Thus accoutred, he dances round the plain, exhibiting various feats of activity, while the other Indians pursue him and endearour to trap him, as he attempts to return to his den; to effect which, he is permitted to use, with impunity, any violence that he pleases agninst his assailants, even to taking the life of any of them. This part of the ceremony is performed three times, that the bear may escape from his den and return to it again, through 
three of the arenues communicating with it. On being hunted from the fourth, or last arenue, the bear must malse his escape through all his pursuers, if possible, and fly to the woods, where he is to remain through the day. This, however, is seldom or never accomplished, as all the young men exert themselves, to the utmost, in order to trap him. When caught, he must retire to a lodge prepared in the field for his reception; there he is to be secluded from all society during the day, except that of one of his particular friends, whom he is allowed to take with him, as an attendant. There he smokes and performs various other rites which superstition has led the Indian to consider as sacred; after this ceremony is ended, the youth is considered as qualified to act any part, as an efficient member of the community. The Indian who has had the good fortune to catch the bear and overcome him, when endeavouring to make his escape to the roods, is considered a candidate for preferment, and is, on the first suitable occasion, appointed a leader of a small war party, in order that he may have a further opportunity of testing his powers, and of performing some essential service in behalf of his nation. It is accordingly expected that he will kill some of their enemies, and return with their scalps." "*

Wapasha informed the gentlemen in the boat, that the Chippewa Indians had been very troublesome, frequently descending the river that bears their name, and cutting off small parties of the Dacotas that were hunting. He spoke also of the advantages of having a mill built at the rapids of Chippewa river, as had been promised to them by the American government; finally, after a few hours' conversation, he left the boat, and crossed over in his canoe to the spot where his out-posts were supposed to be. The

* Major Long's MS. 1817, No. 2, folio 6. 
party encamped that evening on a sandbar in the Mississippi, opposite to the mouth of Buffalo rirer. 'The nest morning, a head wind detained the boat a long while, but it afterwards shifted, and the party ascendeci so rapidly, that carly in the afternoon they found themselves willin a few miles of the lower extremity of Lake Pepin; they were very desirous of visiting the fortifications desrribed by Carver as being on the Mississippi, "some miles below Lake Pepin." Mr. Schoolcraft states, upon the authority of a Mr. Hart, a trarler, that they are on the west bank of the river, a circumstance not mentioned by Carver. We spolie with the oldest traders in the country; with those who had been all their lifetime in the ha!hit of cncamping in that ricinity, but met with none who had cver seen them or heard of them. Mr. Folctte, a partner in the American Fur Company, mentioned that he supposed the most probable place was at a well-known spot on the river, called the "Grand Encampment," situated a few miles sonth of Lalie Pepin. This grentleman, who had encamped there very frequently, had, however, never obscrved any thing like fortifications. On drawing near to the bank at this place, a regular elevation of the ground, parallel to the water's edge, struck us as an artificial embankment; but on landing, and inspecting it, the gentlemen of the party unanimously agreed, that there was here no appearance of ancient works, but that the features observed were natural. The next question was, whether this was the place risited and described by Carver, and whether he had seen artificial works, or mistaken for them the natural peculiarities of the surface; upon this point there was a difference of opinion. Messrs. Say and Scott thought that the description of the locality, given by Sarrer, was sufficient to identify it with this spot, and that as it was impossible that they should not have olserved fortifi- 
cations corering near a mile of ground, upon a prairic that is not more than two and a hall miles wide, it was probable that this traveller had mistaken a natural for an artificial embankment. Agreeing in the fact that there were no ar1ificial worls here, Mr. Keating considered this as proof that the Grand Encampment was not the spot alluded to by Carver; for although the general description agrees with that given by the traveller, yet the same might be said of many other spots; the minuteness of the description which Carver gives of these remains, precludes, as he thought, the opinion that he had mistaken a natural embankment. Although no gentleman of the party would he willing to ascribe to Carver a scrupulous adherence to truth, (personal observation having convineed them all of the many misrepresentations contained in his work, yet the description of these mounds appeared to one of them entitled to more credit, because, as it is believed to be the first which was given by travellers in America, it cannot be supposed to have been copied from others; becuuse the authority of Mr. Ilart's testimony seems to be on that side of the question, as well as that of General Pike, who probably saw the spot mentioned by Carrer, as we find in his journal this observation: "Stopt at a prairis: on the right bank descending, about nine miles below Lake Pepin; went out to view some hills, which had the appearance of the old fortifications spoken of, but I will speak more fully of them hereafter." ": Whether these were similar to those which he describes as having scen on the Prairie de la Crosse, $t$ we have not been able to ascertain. But the strongest argument in favour of the existence of

* An account of Expeditions to the Sources of the Mississippi, \&c. by Major Z. M. Pike, Philadelphiu, 1810, p. 98.

fIdem, p. 18. 
the fortifications described by Carver, is the circumstance of the many mounds and remains observed by Major Long and Mr. Colhoun, between Wapasha's village and the St. Peter, many of which were scen near the southern extremity of Lake Pepin. Although it does not appear that they met with any parapets, yet as these were found near the Wisconsan, in connection with the mounds, there is reason to believe that they may liliewise have been erected in this vicinity. Taking all these facts into consideration, Mr. Ireating was led to the conclusion, that Carver had really seen the works which he has deseribed, but that they probably were not at the Grand Encampment." The party landed at another place abore this, which appeared to correspond with the description of the locality, but their search here was likewise unsuccessful. At a late hour in the afternoon they reached the southern extremity of Lake Pepin, and proceeded until sunset, when the weather appearing stormy, they encamped upon a sandy point that projects about six miles above its southern extremity. They had not been there many hours before a high northerly wind began to blow, which proved the propriety of their encamping there; for the navigation of this lake is represented as very dangerous whenever the wind blors fresh. Le luc est petit, mais il est malin, was the reply of the interpreter to a question as to the propricty of continuing our course during the night. The next morning the weather was fair and calm, we resumed our journey through the lake, with great ease, until we came within about three miles of its upper extremity, when the wind increased; we were soon satisfied, by our own observation, that

* Vide Three years Travels through the Interior parts of North America, \&c. bv Captain Jonathan Carves, Philadelphia, 1796, p. 35. 
the slightest breath of wind will produce a heary sivell "1pon this lake. From this circumstance, it is usual, with the voyagers, on the river, to eross it, if possible, at night; experience having satisfied them that it is generally calmer then, than during the day. The lake is about twenty-one miles long, and its breadth, which varies from one to three miles, may be areraged at about two and a half. Towards its southern extremity the valley widens considerably, from the circumstance that Chippewa river unites with the Mississippi at this place. That river is about five hundred yards wide, at its mouth, and is navigable at all seasons of the year by pirogues for fifty miles; and in time of freshes they can proceed much further up. Lake Pepin, in most places, fills nearly the whole of the valley between the contiguous bluffs. In two spots, however, a handsome piece of meadow land is observed, which will offer great inducements for the establishment of farms. The general direction of the lake is from west-north-west to east-southeast. 'The scenery along its shores contrasts strongly with that of the river. Instead of the rapid current of the Mississippi winding around numberless islands, some of which present well-wooded surfaces, while others arc mere sandbars, the lake presents a smooth and sluggish expanse of water, uncheckered by a single island, and whose surface at the time we first observed it, torvards the close of the day, was unrufled; nothing limited the view but the extent of the lake itself; the majestic bluffs, which enclose it, extend in a more regular manner, and with a more uniform elevation than those along the river. When seen from the top of one of these eminences, the country is found very different from that in the vicinity of the mountain island, passed on the 2Sth of June, for it is rather rolling than hilly ; and the quantity of timber upon it is comparatively. 
small, especially to the west, where it assumes the gencrel characters of an elevated pruirie land. Alonut half way " the lake, its eastern bank rises to a height of ncar four fundred and filty feet, of which the first one hundred and lifty are formed by a perpendicular bluff, and the lowes three hundred constitute a very abrupt and precipitous slope, which extends from the base of the bluft to the edese of the water. "This forms a point, projecting into the lake, and bounded by two small basins, each of which is the e'stuary of a brook that falls into the lake at this place. The wildness of the scenery is such, that eren the royager, who has gazed with delight upon the high blufts of the Mississippi, is struck with uncommon interest on beholding this spot. There is in it what we meet with on no other point of the far-stretching valley of the Mississippi, a high projecting point, a precipitous crag resting upon a stecp bank: whose base is washihed by a wide expanse of water, the calmness of which contrasts with the savage features of the landscape; but this spot receives an additional interest from the melancholy tale which is connected with it, and which casts a deep gloom over its brightest features. Cold and cailous must be the heart of the royager who can contemplate unmored and uninterested the huge cliffs that enclose this lake, for "wild as the accents of lovers' farewell are the hearts which they bear, and the tales which they tell."

"There was a time," our gुuide said, as we passed near the base of the rock, "when this spot, which you now admire for its untenanted beauties, was the scene of one of the most melancholy transactions, that has ever occurred among the Indians. There was, in the village of Keoxa, in the tribe of Wapasha, during the time that his father lived and ruled over them, a young Indian female whose name was Winona, which signi- 
fies "the first born." She had conceived an attachment for a young hunter who reciprocated it; they had frequently met, and agreed to an union in which all their hopes centred; but on applying to her family, the hunter was surprised to find himself denied; and his claims superseded by those of a warrior of distinction, who had sued for her. The warrior was a general favourite with the nation; he had acquired a name, by the services which he had rendered to his village when attacked by the Chippewas; yet notwithstanding all the ardour with which he pressed his suit, and the countenance which he received from her parents and brothers, Winona persisted in preferring the hunter. To the usual commendations of her friends in favour of the warrior she replied, that she had made choice of a man who, being a professed hunter, would spend his life with her, and secure to her comfort and subsistence, while the warrior would be constantly absent, intent upon martial exploits. Winona's expostulations were, however, of no avail, and her parents, having succeeded in driving away her lover, began to use harsh measures in order to compel her to unite with the man of their choice. To all her entreaties, that she should not be forced into an union so repugnant to her feelings, but rather be allowed to live a single life, they turned a deaf ear. Winona.had at all times enjoyed a greater share in the affections of her family, and she had been indulged more, than is usual with females among Indians. Being a favourite with her brothers, they expressed a wish that her consent to this union should be obtained by persuasive means, rather than that she should be compelled to it against her inclination. With a view to remove some of her objections, they took means to provide for her future maintenance, and presented to the warrior all that in their simple mode of living an InVoL. I. 
dian might covet. About that time a party was formed to ascend from the village to Lake Pepin, in order to lay in a store of the blue clay which is found upon its banks, and which is used by the Indians as a pigment. Winona and her friends were of the company. It was on the very day that they visited the lake that her brothers offered their presents to the warrior. Encouraged by these, he again addressed her, but with the same ill success. Vexed at what they deemed an unjustifiable obstinacy on her part, her parents remonstrated in strong language, and even used threats to compel her into obedience. "Well," said Winona, "you will drive me to despair; I said I loved him not, I could not live with him; I wished to remain a maiden; but you would not. You say you love me; that you are my father, my brothers, my relations, yet you have driven from me the only man with whom I wished to be united; you have compelled him to withdraw from the village; alone, he now ranges through the forest, with no one to assist him, none to spread his blanket, none to build his lodge, none to wait on him; yet was he the man of my choice. Is this your love? But even it appears that this is not enough; you would have me do more; you would have me rejoice in his absence; you wish me to unite with another man, with one whom I do not love, with whom I never can be happy. Since this is your love, let it be so; but soon you will have neither daughter, nor sister, nor relation, to torment with your false professions of affection." As she uttered these words, she withdrew, and her parents, heedless of her complaints, decreed that that very day Winona should be united to the warrior. While all were engaged in busy preparations for the festival, she wound her way slowly to the top of the hill; when she had reached the summit, she called out with a loud voice to her 
friends below; she upbraided them for their cruelty to herself and her lover. "You," said she, "were not satisfied with opposing my union with the man whom I had chosen, you endeavoured by deceitful words to make me faithless to him, but when you found me resolved upon remaining single, you dared to threaten me; you knew me not if you thought that I could be terrified into obedience; you shall soon see how well I can defeat your designs." She then commenced to sing her dirge; the light wind which blew at the time, wafted the words towards the spot where her friends were; they immediately rushed, some towards the summit of the hill to stop her, others to the foot of the precipice to receive her in their arms, while all, with tears in their eyes, entreated her to desist from her fatal purpose; her father promised that no compulsive measures should be resorted to. But she was resolved, and as she concluded the words of her song, she threw herself from the precipice, and fell, a lifeless corpse, near her distressed friends. Thus," added our guide, "has this spot acquired a melancholy celebrity; it is still called the Maiden's rock, and no Indian passes near it, without involuntarily casting his eye towards the giddy height, to contemplate the place, whence this unfortunate girl fell a victim to the cruelty of her relentless parents."

In the annals of civilized life, the sad tale of Winona's adventures has been but too often realized; and the evidences of the powerful influence of feeling over women are too well known to produce any sensation of surprise at their recurrence. But it is seldom that the wild inhabitant of the forest is admitted to possess the same depth of feeling. Judging of both sexes from the instances which have been related of the apathy, assumed or real, of the Indian warrior, too many are induced to be- 
lieve, that the uncivilized condition of the savare deprives him of, or stifles in him, all passion; but his is not the case. The fate of Winona has many parallels, which are not all equally well known. There were in the eircumstances of this case, several conditions which tended to impart to it a peculiar interest; the maid was one who had been a favourite in her tribe; the warrior whom her parents had selected was one of note; her untimely end was a public one: many were the witnesses to it; it was impressive in the highest degree; the romantic situation of the spot, which may be thought to have had some influence over the mind of a young and enthusiastic female, who found herself at that time "perplex'd in the extreme," must have had a corresponding effect upon those who witnessed it. Wazecota, who was there at the time, though very young, appeared to have received an indelible impression from it, and when relating it to Major Long in 1817 , the feelings and sensations of his youth seemed to be restored; he lost the garrulity of age, but spoke in a manner which showed that even the breast of the Indian warrior is not proof against the finest feelings of our nature. Had Winona, instead of taking the fatal leap, put an end to her existence in the midst of a forest, by suspending herself to a tree, as is generally practised by those Indian women whom distress impels to suicide, her fate would still have been unknown to us; a few of her friends might have wept over her untimely lot, but the traveller would have passed orer the spot where she had ended her woes, without having his sympathies awakened, as they now are, by the recital of this terrible catastrophe. While the circumstances of this tale were related to us, Mr. Seymour was engaged in sketching this interesting spot. We have introduced his vierv of it here, (Plate IV.) as it gives a correct idea of 


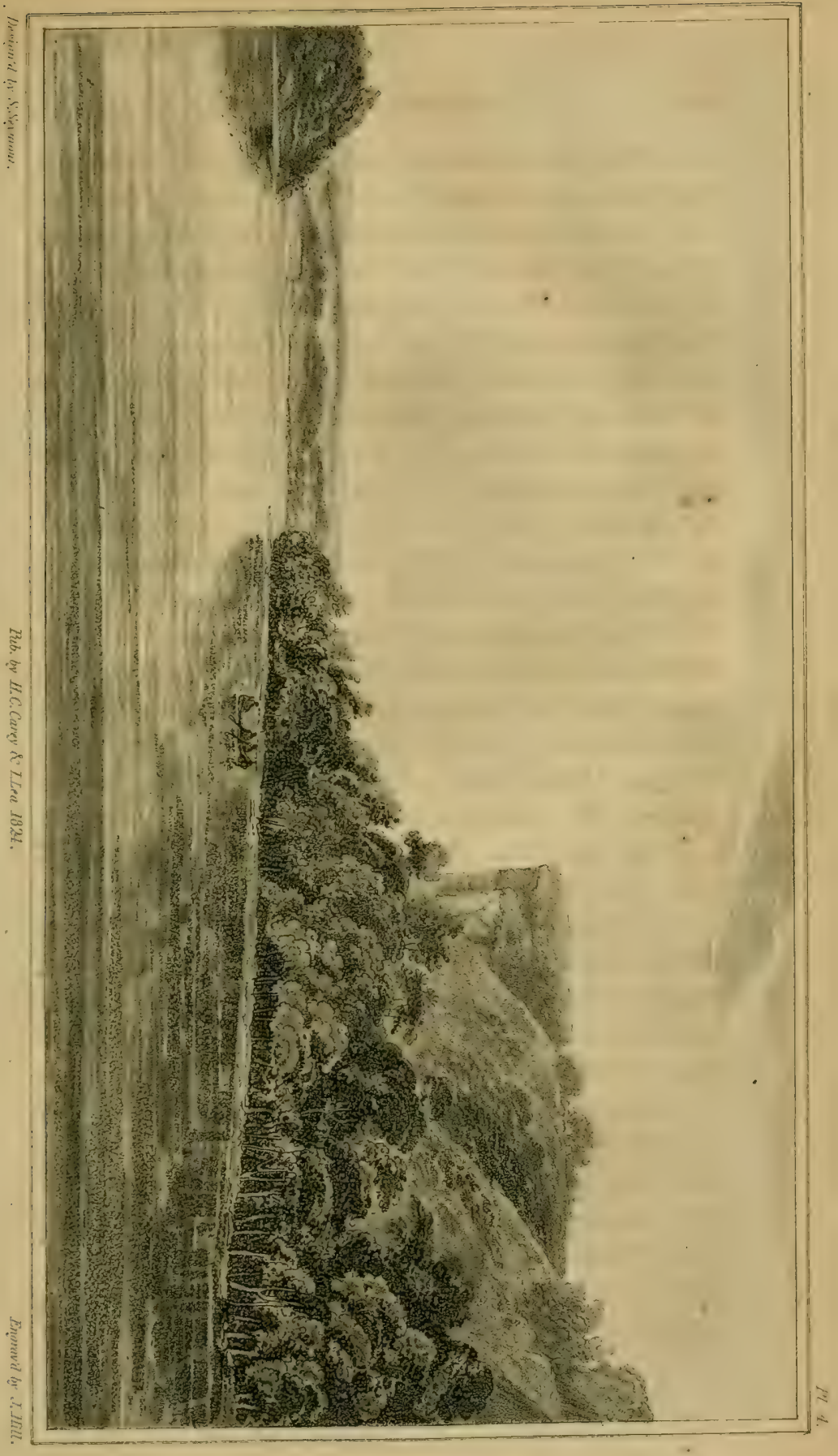



the scenery of the upper part of the Mississippi, which has never, we think, been accurately represented. We regretted that it was not possible to reduce, to the proper size, a fanciful delineation of the tragic event which we have related. Mr. Seymour painted one of this kind, in which the landscape was represented with the most faithful accuracy, but which he animated and enlivened by the introduction of a numerous party of Indians, in whom the characteristics of the Dacotas were strikingly delineated. The unfortunate Winona was represented at the time when she was singing her dirge, and the various groups of Indians below indicated the corresponding effect upon the minds of the spectators.

The first European that ever reached this lake was Father Hennepin, who saw it in the month of April, 1650, and who gives the following description of it: "A bout thirty Leagues above Black river we found the Lake of Tears, which we named so, because the Sarages, who took us, as it will be hereafter related, consulted in this place what they should do with their Prisoners; and those who were for murthering us, cryed all the night upon us, to oblige, by their Tears, their Companions to consent to our Death. This Lake is formed by the Meschasipi, and may be seven Leagues long and five broad. Its Waters are almost standing, the Stream being hardly perceptible in the middle." We have not been able to discover the origin of the name which the lake now bears, it is evidently a Fiench name. While ascending the lake, we obscrred floating upon the surface, a large fish which had been wounded with a harpoon or lance; we caught it, and found it to be a Paddle-fish.* This fish is distinguished by a protu-

* Platirostra Edentula, (Lesueur.) Vide Appendis I. B. 
berance or rostrum, which extends from the nose about fourtecn inches, and which from its resemblance to the form of a paddle, has obtained for it the common appellation of Paddle-fish. The Mississippi unites with the uppor extremity of the lake by three channels, which are separated by islands. Upon one of these we landed, and found the passenger pigeons to be very numerous, so that in a few minutes a number of them were killed. We likewise saw here a rattlesnake, which disproves the assertion of some authors that this animal is not found above Lake Pepin. It is probable, however, that they are scarce above this place, as this was the last one seen by our expedition. Mr. Schooleraft states, that Governor Cass' expedition likewise met with it above Lake Pepin, and he even observes that it exists as high on the Mississippi as the Falls of St. Anthony. One of the guides, Joseph Reinville, whom we shall have occasion to mention hereafter, informed Mr. Colhoun that he had killed them on Big Stone Lake, which is near the head of the St. Peter.

About four miles above the lake is the site of Redwing's village, at the mouth of Cannon river. Immediately below the village there is a singular hill, which, from its form, which is supposed to resemble a barn, has been called the Grange, it is about three quarters of a mile long, and four hundred feet high. Its acclivity on the east or river side is very abrupt, on the west or prairie side it is quite vertical; it stands insulated from the rest of the highlands. Immediately upon the highest point of the Grange, Major Long, who ascended it in 1817, observed an artificial mound, whose elevation above its base was about five feet.

Having left the Redwing village early in the afternoon of July Ist, the party continued to ascend the river; the current had again become very strong; they proceeded 
that evening to a place below the St. Croix river; this stream enters the Mississippi on its left bank; at its mouth it is about one hundred yards wide, but immediately above it expands to a breadth of from three-fourths to two miles, and forms what is called St. Croix Lake. Pike, in his journal, describes the Mississippi, for a considerable distance below the St. Croix, as of a reddish appearance in shoal water, but black as ink in deep. ${ }^{*}$ The red colour is owing to the sand seen at the bottom, which is of that complexion; the dark colour is no more than what is common to deep water that is moderately limpid.

On the $2 \mathrm{~d}$ of July we passed what is termed the narrowest place on the Mississippi below the Falls of St. Anthony; the river is here clear of islands, and not more than one hundred or one hundred and twenty yards broad. Piket states that his men rowed across in forty strokes of the oar, but Major Long found in 1817, that his "boat crossed it, from a dead start, in sixteen strolkes." $\ddagger$ A great change in the scenery of the river is perceptible; instead of running between two parallel walls of considerable altitude, the river there passes through a rolling prairie country, where the eye is greeted with the view of extensive undulated plains, instead of being astonished by the sight of a wild and gigantic scenery. At the St. Croix the bluffs seldom rise to two hundred feet above the water level. The valley, through which the river runs, is more uniform in its breadth, but the river is crooked and its channel impeded by sandbars, the current rapid so that the progress of the boat was slow. The party landed, for a few minutes, to examine a stone which is held in high veneration by

" Pike, ut supra, p. 24.

†Idem, ibid.

\$ Major Long’s MS. 1817, folio 12. 
the Indians; on account of the red pigment with which it is bedawbed, it is generally called the painted stone. They remarked that this was the first boulder of primitive rock, which they had seen to the west of Rock river, and this place corresponds well with that at which these boulders were first observed by $\mathrm{Mr}$. Colhoun while travelling by land. It is a fragment of sienite, which is about four and a half feet in diameter. It is not surprising that the Indians should have viewed this rock with some curiosity, and deemed it wonderful, considering that its characters differ so materially from those of the rocks which are found in the neighbourhood. A man who lives in a country where the highest hills are wholly formed of sandstone and secondary limestone, will necessarily be struck with the peculiar characters of the first specimen of granite that comes under his notice, and it is not to be wondered at, that one who "sees God in all things," should have made of such a stone an object of worship. The Indians frequently offer presents to the Great Spirit near this stone; among the offerings of their superstition, the party found the feather' of an cagle, two roots of the "Pomme de Prairie," (Psoralea esculenta, Nuttall,) painted with vermilion; a willow branch whose stem was painted red, had been stuck into the ground on one side, \&c. The gentlemen broke off a fragment of this idol, to add to the mineralogical collections, taking care, however, not to leave any chips, the sight of which would wound the feelings of the derotee, by conrincing him that the object of his worship had been violated. The party landed at a short distance abore, to visit the cemetery of an Indian village, then in sight. The cemetery is on the banks of the river, but elerated above the water's level; it exhibits sereral scrffolds, supporting coffins of the rudest form; sometimes a trunk, (purchased. 
firom a trader, ) at other times a blanket, or a roll of bark, conceal the bodies of the deceased. There were, also, several graves, in which are probably deposited the bones, after all the softer parts have been resulved into their elements, by long exposure to the atmosphere. Returning to the boat, the party ascended and passed an Indian village consisting of ten or twelve huts, situated at a handsome turn on the river, about ien miles below the mouth of the St. Peter; the village is generally known by the name of the Peiit Corbeau, or Little Raven, which was the appellation of the father and grandfather of the present chief. He is called Chê-tân- $w^{2}-k^{2} 0$-ćt-mả-nè, (the sood sparrow hunter.) 'The Indians designate this band by the name of $\mathbf{K}$ 'if $\mathrm{o}^{\prime} \mathrm{j} \mathrm{j}$, which implies that they are deemed lighter and more active than the rest of the nation. As the village was abandoned for the scason, we proceeded without stopping. The houses which we saw here were differently constructed from those which we had previously observed. They are formed by upright flattened posts, implanted in the ground, without any interval except here and there some small loopholes for defence; these posts support the roof, which presents a surface of bark. Before and behind each hut, there is a scaffold used for the purpose of drying maize, pumplins, \&c. The present chief is a good warrior, an artful, cunning man, remarkable among the Indians for his wit, and, as is saicl, for his courtesy to white men, endeavouring, as far as he can, in his intercourse with the latter, to imitate their manners.

Above this village, there is a cave which is much visited by royagers; we stopped to examine it, although it presents, in fact, but little to admire; it is formed in the sandstone, and is of course destitute of those beautiful appearances, which characterize the caverus in calcareous rock. It is the same which is described by Mr. School-

VoJ., I. 
craft, whose name, as well as thuse of several of Governot Cass' party we found carved on the rock. In his account of it, Mr. Schooleraft states it to be the carern that was visited by Carrer, but adds that "it appears to have undergone a considerable alteration since that period." It appears from Major Long's MS. of 1S17, that there are two caves, both of which he risited, the lower one was Carrer's; it was in 1817 very much reduced in size from the dimensions given by Carver; the opening into it was then so low, that the only way of entering it was by creeping in a prostrate position. Our interpreter, who had accompanied Major Long, as a guide, told us that it was now closed up; it was probably near the cemctery which we have mentioned. The cavern which we visited, and which MIr. Schoolcraft describes, is situated five miles above; it was discovered in 1811, and is called the Fountain eare; there is a beautiful stream running through it, whose temperaure, as observed by Major Long on the 16 th of July, was $46^{\circ}(\mathrm{F}$.$) and by Mr. Schooleraft, on the 2 \mathrm{~d}$ of August, $47^{\circ}$. 'The temperature of the atmosphere, the day that Major Long made his observation, was $\$ 9^{\circ}$. From these results, as well as from several others which we obtained, we have been led to adopt about $46^{\circ}$ as the average temperature of springs in this latitude, and in this clistrict of country.

At a late hour, in the night of the $2 \mathrm{~d}$ of $\mathrm{July}$, the boat cntcred the St. Peter, and proceeded up the river opposite to the fort; but it being too late to approach the works, the gentlemen spent the night on the south bank of the river, preferring to lay out in the open air, than to share with a Frenchman and his Indian family the shelter of a hovel. The distance, by water, had always been estimated at about ninety leagues or two hundred and serenty miles. In Mr. Schooleraft's journal it is estimated at two hundred and sixty-five miles. It was measured on the ice in February: 
1S22, by Sergeant Heckle, of the garrison, who reduced the distance to two hundred and twelve miles; his measurement was made by means of a perambulator of his own invention ; he is said to have made allowance for the crooked channel followed by voyagers; from the time which we consumed in ascending, making a due allowance for the speed of the opposing current, we should have estimated the distance at two hundred and twenty miles. The time required for this journey varies from eight to twenty and twenty-five days, according to the wind; for it is impossible to row against the current with a strong head wind. Our boat made the trij) in seven days and a half, which was considered the shortest that had been known of at the fort. In 1817, Major Long ascended in eight days to the falls, which are nine miles higher. Pike was eighteen days in reaching the same spot. Mr. Scott, who returned to Prairie du Chien the next day after his arrival at the fort, reascended the river, completing his voyage to and from the Prairie in nine days and a half, a speed hitherto unlnorvn. The average passage down the river is three days; it has been performed in forty-eight hours.

The streams that enter the Mississippi between the Wisconsan and the St. Peter are numerous, but for the most part unimportant. Those which alone deserve to be mentioned are, on the west side, the Cannon, Root, and Iawa rivers; on the east side, the St. Croix, Chippewa, and Black rivers. Of these the St. Croix and Chippewa head near some of the streams tributary to Lake Superior. It was the Chippewa river that Carver ascended after having visited the Falls of St. Anthony, and thence descending one of the neighbouring streams, probably the Montreal river, reached Lake Superior. The St. Croix rises near the head waters of the Bois Brulé, which also falls into the Lake ; there is a portage of iwo miles between these streams. This is one of the routcs 
upon which most trade has been carried on. Lake Si. Crois cxtends thirty miles, beyond which the river continues na. vigable for about twenty miles, when its navigation is said to be obstrueted by a rapid; but above this, the stream is a very pleasant one to travel, and sufficiently deep for loaded canoes.

Game seems to be disappearing very rapidly from the face of the country. Buffiloes of the largest size were formerly found here; a few were still to be seen in 1S17, on the river that bears their name, and that discharges itself into the Mississippi below Lalie P('pin; but since the establishment of the garrison at Fort St. Anthony, they have all been destroyed or have removed further west. 'The party that travelled in the boats, saw abundance of pigeons, but with the exception of these, no other kind of game; the only animal observed beside these was the rattlesnakc, (Crotalus horridus,) of which they killed four or five.

The land party, although provided with an excellent. hunter, killed but a few pigeons; some of them saw a large herd of Fllss. Game will be judged to be very scarce where two parties travelling by land and by water can kill but two or three dozen of hirds upon a distance of upwards of two hundred miles.

The river abounds in turtles, (Testudo [Trionyx] ferox, Linn., and T. [Emys] geographica, Lesueur,*) at least. judging from the great number of eggs which our men picked up in the sand; it appears that the animal deposits her eggs on the sand islands, which abound in the river, generally at a distance from the water, she covers them up with sand, and abandons them; the heat of the sun supplies the place of incubation. The men collected them in great number, and appeared to be very fond of them.

* Journal Acad. of Nat. Sciences, vol. I. p. 86. pl. 5. 
The mineralogical observations were unfortunately prerented by the circumstanees under which the party trarelled. Hastening towards the St. Peter, and apprehensive lest a delay on shore might deprive them of the advantage of a fair wind, they landed near the bluffs but seldom, and never for any length of time. Their usual stoppages were on smithar's, and even there but for a short time; they frequently travelled laie at night, and sometimes even the whole night. Under these circumstances, the only feature that could be observed, was that the country was formed of limestone and sandistone; that the former was, in one instance at least, oolitic and pulverulent; that the sandstone was white, loosely aggregated, and horizontally stratified, but its comnexion with the limestone was never determined; the sandstone prevails above Lalke Pepin, the limestone below it; and probably to this we may attribute the difference observed in the characters of the stream and its banks after we harl passed the lake. 'The sand appears to be chiefly formed by the detritus of the :andstone; it not unfrequently contains cornelians, agates, jaspers, \&c. which present characters analogous to those sbserved on the Rhine below Oberstein, and in Scotland, where they are distinguished by the name of Scotch pebbles. They bear evident marks of having been washed away from a secondary trap formation. We shall have occasion to observe, at a future period, that a formation of this kind was traversed by the expedition. In one or two instances, while examining the sand with the microscope, a white transparent topaz was extracted from it ; it is probable that had more time been taken, on land, many would have been found. Although much rubbed, still the form of the prism of the topaz, with its dihedral summit, could be well made out. 
The party in the boat experieneed much fatigue, durings this portion of the journey, from the want of rest at night, and the eramped situation in which they were in the boat, but a stay of a few days at Fort St. Anthony refreshed them, and prepared them to resume their journey.

Fort St. Anthony is situated on the high bluff which rises on the right bank of the Mississippi and the left of the St. Peter, at the confluence of the two streams. Although this spot had been visited and described by Pike in 1806, and subsequently by Major Long in 1517, who in his report to the War Department recommended the cstablishment of a permanent post at this place, it was not until the summer of 1819, that military works were commenced here. Col. Learenworth, with part of the fifth regiment, arrived here in August, 1S19, and all that has been done here rwas subsequent to this period. The fort is in the form of a hexagon, surrounded by a stone wall; it stands on an clevated position which commands both rivers. The height of the half-moon battery which fronts the rirer is one hundred and five feet above the level of the Rississippi. It is not, however, secure from attacks from all quarters, as a position within ordinary camnon shot of it rises to a greater elevation; but as long as we have to oppose a sarage foe alone, no danger can be apprehended from this. If a resistance against a civilized enemy prorided with artillery, were required, possession might be taken of the other position, which would command the country to a considerable distance, and protect the present fort, which is in the best situation for a control of the two rivers.

The garrison consists of five companies of the 5 th infantry, under the command of Col. Snelling. The great actirity, which has been displayed by the oflicers and men. 
has already imparted to this place, situated as it is at an immense distance from civilization, many of the comforts of life. The quarters are well built, and comfortable. Those of the commanding officer are even elegant, and suitable for the principal military post to the north-west. There were, at the time we risited it, about two hundred and ten acres of land under cultivation, of which one hundred were in wheat, sixty in maize, fifteen in oats, fourteen in potatocs, and twenty in gardens, which supply the table of the officers and men with an abundant supply of wholesome vegetables.

On the 6th of July we walked to the falls of St. Anthony, which are situated nine miles, (along the course of the river, seven by land,) above the fort. The first glimpse which we caught of the fall was productive of disappointment, because it yielded but a partial view, but this was amply redecmed by the prospect which we obtained of it when the whole fall opened itself before us. We then discovered that nothing could be more picturesque than this cascade. We had been told that it appeared like a mere mill dam, and we were apprehensive lest a fall of sixteen feet would lose all its beauty when extended upon a breadth of several hundred yards: but we soon observed that this was by no means the case. The irregular outline of the fall, by dividing its breadth, gives it a more impressive character. An island, stretching in the river both above and below the fall, separates it into two unequal parts, the eastern being two hundred and thirty yards wide, and the western three hundred and ten. The island itself is about one hundred yards wide. From the nature of the rock, which breaks into angular and apparently rhomboidal fragmentș of a. huge size, this fall is subdivided into small cascades, which adhere to each other, so as to form a sheet of water, unrent 
but composed of an alternation of retiring and salient: angles, and presenting a great varicty of shapes and sharles; cach of these forms in itself a perfeet cascade, lut when taken together in one comprehensive virw, they asiume: a beauty of which we could have scarcely decmed ther: susecptible. We have seen many falls, but few which present a wilder and more picturesque aspeet than those of Si. Anthony. The vegetation which grows around them is of a corresponding character. 'The thick growth upon the island, imparts to it a gloomy aspect, contrasting pleasingly with the bright surface of the watery shect which reflects the sun in many differently-coloured hues. The foree of the current above the fall is rery great, bul. as we were told that it could be forded, we determined to attempt to cross immediately above the fall. The place at which we forded was within a few yards of the edge of the rock, and as we passed we could not repress a feeling of apprehension at the danger which we were incurring. The: water never, it is true, rose above two feet and a half, but the rock upon which we were treading was very smooth, and the force of the current such that we were frequently exposed to slip; while at the same time we were convinced that if we made but a single false step, we must in cvitably perish, as it would have been impossible to regain a foothold had it once been lost. We crossed over to the island, and having gone round it to the eastern part of the fall, Messis. Say and Colhoun forded over from this to the left bank of the river; in this they experieneed even greater difficulty than before, as the water was decener and its current more impetuous. Mr. Tieating attempted it, but found himself unable to accomplish it, being at the time considerably delbilitated by a fever, which he had had for the two or three preceding days; finding himself 
alone upon the island, and being apprehensive that his companions would not return in that direction, but would rross below the fall, he determined to regain the western bank; in this he met with great difficulty. Twice he attempted to cross, but before he had reached the middle of the stream, finding his strength failing, he was compelled to return to the island; at last, the recollection that he would not recover it by a longer stay there, and the conviction that the waters of the stream would probably continue to roll on undiminished to the end of time, induced him to make a final effort to reach the shore, in which he succeeded. Some time after, Messrs. Say and Colhoun were seen returning with difficulty, and one of the stoutest of the soldiers went over and assisted them; their strength was nearly exhausted at the time they reached the bank. However fatiguing this excursion may have been, it was very gratifying, as it afforded them a fine view of the fall under all its aspects. None of the party had seen a waterfall for some time past, and to this may probably be attributed the great pleasure which they derived from it; for it bears no comparison to many which they subsequently met with. Concerning the height of the fall and breadth of the river at this place, much incorrect information has been published. Hennepin, who was the first European that visited it, states it to be fifty or sixty feet high. It was this traveller that gave it the name which it now bears, in honour of St. Anthony of Padua, whom he had taken for the protector of his discovery. He says of it, that it "indeed of itself is terrible, and hath something very astonishing." This height is, by Carver, reduced to about thirty feet; his strictures upon Hennepin, whom he taxes with exaggeration, might with great propriety be retorted upon him, and we feel strongly inclined to say of VoL. I. 
lim, as he said of his predecessor, "the good father, I fear, too often had un other foundation for his accounts than report, or at least a slight inspection." Pilie, who is more correct than any traveller whose steps we have followed, states the perpendicular fall at sixteen and a half feet; Major Long: measured it in 1817 with a plumb line, from the table rock from which the water was falling, and found it to be the same. Mr. Colhoun measured it while we were there, with a rough water level, and made it about fifteen feet. The difference of a foot is trifling, and depends upon the place where the measurement was made; but we cannot account for the statement, made by Mr. Schoolcraft, that the river has a perpendicular pitch of forty feet, and this as late as fourteen years after Pike's measurement. The same author states the breadth of the river, near the brink of the fall, to be two hundred and twenty-seven yards, while Pike found it to be six hundred and twenty-seven yards; which agrees tolerably well with a measurement made on the ice. Messrs. Say and Colhoun obtained an approximate admeasurement of five hundred and ninety-four yards ; this resulted from a trigonometrical calculation, the angles having been measured with a compass that was small and not nicely graduated, and the base line having been obtaincd under unfavourable circumstances. Below the fall, the river contracts to about two hundred yards; there is a considerable rapid both above and below; a portage of two hundred and sixty poles in length is usually made here; the whole fall, or difference of level between the place of discmbarking and reloading, is stated by Pike to be fiftycight fect, which is probably very near the truth; the whole fall to the foot of the rapids, which extend sereral miles down the river, may be estimated as not far short $n t^{\circ}$ one hundred feet.

* Pike, ut supra, App. to Part 1, p. 51. 
Two mills have been erected for the use of the garrison, and a sergeant's guard is kept here at all times. On our return from the island we recruited our strength by a copious and palatable meal, prepared for us by the old sergeant; whether from the exercise of the day, or from its intrinsic merit, we know not, but the black bass, (Chicla nenea, Lesucur, $\left.{ }^{*}\right)$ of which we partook, appeared to us excellent.

The vegetation consists of oak, hickory, walnut, pine, birch, linden, cotton-wood, \&c.

This beautiful spot in the Mississippi is not without a tale to hallow its scenery, and heighten the interest which, of itself, it is calculated to produce. To Wazekota, the old Indian whom we saw at Shakea's, we are indebted for the narration of the following transaction, to which his mother was an eye-witness. An Indian of the Dacolat nation had united himself early in life to a youthful female, whose name was Ampato Sapa, which signifies the dark day; with her he lived happily for several years, apparently enjoying every comfort which the savage life can afford. Their union had been blessed with two children, on whom both parents doated with that depth of fecling which is unknown to such as have other treasures besides those that spring from nature. The man had acquired a reputation as a hunter, which drew round him many families, who were happy to place themselves under his protection and avail themselves of such part of his chase as he needed not for the maintenance of his family. Desirous of strengthening their interest with him, some of them invited him to form a connexion with their family observing, at the same time, that a man of his talent and importance required more than one woman to wait upon the numerous guests whom his reputation would induce to visit his lodge. They assured him that he would soon be acknow-

* Journal Acad. Nat. Sci. viol. II. p. 214, plate. 
ledged as a chief, and that, in this case, a second wite wa: indispensable. Fired with the ambition of obtaining higl? honours, he resolved to increase his importance by an union with the daughter of an influcntial man of his tribe. He had accordingly taken a second wife without having ever mentioned the subject to his former companion; being desirous to introduce his bride into his lodge in the manner which should be least offensive to the mother of his children, for whom he still retained much regard, he introduced the subject in these words: "You know," said he, "that I can love no woman so fondly as I doat upon you. With regret, have I scen you of late subjected to toils, which must be oppressive to you, and from which I would gladly relieve you, yet I know no other way of doing so, than by associating to you in the huuseliold duties one, who shall relieve you from the trouble of entertaining the numerous guests, whom my growing importance in the nation collects around me. I have therefore rcsolved upon taking another wife, but she shall always be subject to your control, as she will always rank in my affections second to you." With the utmost anxiety, and the deepest concern, did his companion listen to this unexpected proposal. She expostulated in the kindest terms, entreated him with all the arguments which undisguised love and the purest conjugal affection could suggest. She replied to all the objections which his duplicity led him to raise. Desirous of winning her from her opposition, the Indian still concealed the secret of his union with another, while she redoubled all her care to convince him. that she was equal to the task imposed upon her. When he again spokc on the subject, she pleaded all the endearments of their past life; she spoke of his former fondness for her, of his regard for her happiness and that of their mutual offspring; she bade him beware of the consequences 
of this fatal purpose of his. Finding her bent upon withholding her consent to his plan, he informed her that all opposition on her part was unnecessary, as he had already selected another partner; and that if she could not see his new wife as a friend, she must receive her as a necessary incumbrance, for he had resolved that she should be an inmate in his house. Distressed at this information, she watched her opportunity, stole away from the cabin with her infants, and fled to a distance where her father was. With him she remained until a party of Indians with whom he lived went up the Mississippi on a winter hunt. In the spring as they were returning with their canoes loaded with peltries, they encamped near the falls. In the morning as they left it she lingered near the spot, then launched her light canoe, entered into it with her children, and paddled down the stream singing her death song; too Iate did her friends perceive it; their attempts to prevent her from proceeding were of no avail; she was heard to sing in a doleful voice, the past pleasures which she had enjoyed, while she was the undivided object of her husband's affection; finally her voice was drowned in the sound of the cataract; the current carried down her frail bark with an inconceivable rapidity; it came to the edge of the precipice, was seen for a moment enveloped with spray, but never after was a trace of the canoe or its passengers seen. Yet it is stated by the Indians that often in the morning a voice has been heard to sing a doleful ditty along the edge of the fall, and that it dwells ever upon the inconstancy of her husband. Nay, some assert that her spirit has been seen wandering near the spot with her children wrapped to her bosom. Such are the tales or traditions which the Indians treasure up, and which they relate to the voyager, forcing a tear from the eycs of the most relentless. 


\section{CHAPTER VII.}

Geology of the Mississippi. The Expedition ascends the St. Peter. Character of the Country. Arrival al Lake Travers.

THE country about the fort contains several other water falls, which are represented as worthy of being seen. One of them, which is but two miles and a half from the garrison, and on the road to St. Anthony's, is very interesting. It is known by the name of Brown's Fall, and is remarkable for the soft beauties which it presents. Essentially different from St. Anthony's, it appears as if all its native wildness had been removed by the hand of art. A small, but beautiful stream, about five yards wide, flows gently until it reaches the rerge of a rock, from which it is precipitated to a depth of forty-three feet, presenting a beautiful parabolic sheet, which drops without the least deviation from the regular curve, and meets with no interruption from neighbouring rocks, or other impediments, until it has reached its lower lerel, when it resumes its course without any other difference, than that produced by the white foam which floats upon its surface. The spray, which this cascade emits, is very considerable, and when the rays of the sun shine upon it, produces a beautiful Iris; upon the surrounding vegetation the effect of this spray is distinct; it vivifies all the plants, imparts to them an intense green colour, and gives rise to a stouter growth than is observed upon the surrounding country. On the neighbouring rock the effect is as characteristic, though of a destructive nature; the spray striking against the rock, which is of a loose structure, has undermined it in ? 
curred manner, so as to produce an excavation, similar in form to a Saxon arch, between the surface of the rock and the sheet of water; under this large arch we passed with no other inconvenience than that which arose from the spray. There is nothing sublime or awfully impressive in this cascade, but it has every feature that is required to constitute beauty; it is such a fall as the hand of opulence daily attempts to produce in the midst of those gardens upon which treasures have been lavished for the purpose of imitating nature; with this difference, however, that these falls possess an easy grace destitute of the stiffness which generally clistinguishes the works of man from those of nature. The stream that exhibits this cascade falls into the Mississippi about two miles above the fort; it heads in a lake situated a few miles above. A body of water, which is not represented upon any map that we know of, has been discovered in this vicinity within a few years, and has received the name of Lake Calhoun, in honour of the Secretary at War. Its dimensions are small. Another lake of a much larger size is said to have been discovered about thirty or forty miles to the north-west of the fort. Its size, which is variously stated, is by some supposed to be equal to that of Lake Champlain, which, however, from the nature of the country and the knowledge which we have of the course of the rivers, appears scarcely possible.

An object, which had appeared to us worthy of inquiry long before we visited the Indian country, was to ascertain whether the natives, who are accurate observers of every natural occurrence, had any tradition or recollection of having witnessed the fall of meteoric stones. Since the fact of the fall of these heary bodies from the atmosphere has been proved to the satisfaction of the most sceptical, numerous observations, recorded by ancient historians, 
have been collected to prove that the occurrence is much more frequent than one would at first be led to expect. On being informed of the existence of a painted stone, which was held in great veneration by the Indians of the Mississippi, we entertained a hope that it might prove of this nature; we experienced therefore no slight degree of disappointment in finding it to be merely a boulder of sienite. We have, as we think, in our intercourse with the Indians, been able to trace an indistinct notion on the subject of meteorites. The following belief, which is common to several nations, but which principally prevails among the Sioux, appears to bear upon this point. They state that whenever a. tree is affected by lightning, a stone of a hlack or brown colour may be found at its foot; it is said to be very heary, and to have heen, in some cases, picked up while hot; several of our guides stated that they had seen them, and had owned some of them. These stones are held in some esteem, as being uncommon, but no supernatural or mysterious property is attached to them. We think it probable, from the respectable sources from which we received this report, that the Indians may have mistaken the phenomena which attend the fall of these acrolites for the effects of lightning, and having in a few instances observed these stones and picked them up while still hot, been led to consider them as the usual attendants upon lightning. There seems to be reason to believe that an aerolite fell a few years since at St. Anthony; but all attempts to find it proved fruitless.* We have, with a view to obtain fur-

* Col. Snelling has kindly communicated to one of the party, the circumstances observed on that occasion; and we have his permision to insert the annexed letter on the subject.

"Fort St. Anthony, July 8th, 1823.

"SrR-On the evening of Sept. 20th. 1822, while crossing the pararle: 
ther information on the subject, examined every stone which we observed as having been held in veneration by the Indians, but in no case have we been able to detect any meteoric appearance in them.

of this post, from the store to my own quarters, I was startled by a brilliant light in the atmosphere, and looking "p, saw a meteor passing in a direction nearly from north-west to south-cast, and as well as I could judge at an angle of about fifty degrees with the horizon; it appeared of uncommon magnitude, and passed so near me that I distinctJy heard its sound, which resenbled that of a signal rocket ; in its descent any view of it was intercepted by the Commissary's store, but I heard it strike the ground, when it souncled like a spent shell, though much louder. I went immediately to the sentinel at the corner of the store, and asked him if he had seen any thing extraordinary; he replied that a large ball of fire had passed very near him and struck in the public garden which borders the river St. Peter; he appeared much agitated; after requesting him to mark the spot where it fell, I proceeded to the other sentinels, whose accounts, as far as their stations allowed them to judge, agreed with his. The next morning I went early to the spot where the meteoric stone was stipposed to have fallen, but could not find it; the ground is alluvial and much broken into holes or hollows. I continued my search until the breakfast hour; but my ordinary avocations called of my attention, and I did not look for it again; which I have since regretted, as I think it might have been found by going to a greater depth in search of it. The evening was uncommonly fine, and the concurring testimony of all the persons who saw it, with my own observation, I presume, will be sufficient evidence that it was no illusion.

"I have communicated this incident, as the question whether me. reoric stones do or do not fall from the atmosphere has recently ex. cited much interest, and it may be decmed in some measure of importance in support of the affirmative proposition.

\section{"Respectfully,}

"I am, sir, your obedient servant,

\section{" J. SNELLING,}

"ITm. H. Keating, Esq. Col. U. S. Ariny.

"Extract from Dr. Purcell's meteorological register, Sept. 20, 1822. Thermometer at 7 A. M. $54^{\circ}$; at 2 P. M. $70^{\circ}$; at 9 P. M. $56^{\circ}$. Wind N. W. weather clear-light fresh wind." 
A singular appearance was observed in the heavens, between three and four o'clock on the morning of the 9th of July. The night had been stormy, much rain had fallen, and frequent flashes of lightning had been observed, but at that time the heavens presented to the north a vivid sheet of light of a yellowish hue, and brighter than the most intense lightning we recollect witnessing. Although the light was constant, it was not a steady one; frequent coruscations were observed, they were rather of the nature of the beams, than of the arches described by Captain Franklin.* The light which it produced was such, that the reflection of it from the parade ground awoke us, though our windows opened to the south-west. The effect was the same as if the whole row of barracks had been on fire. This light continued without interruption for about fiftecn minutes; during the first five minutes, the rain fell with an impetuosity which we do not recollect to have ever seen surpassed. It might truly be said to fall in torrents; loud peals of thunder were occasionally heard. After the phenomena had continued about a quarter of an hour, the light vanished, and sunk into the dark gray usually observable of a misty morning before sunrise. The atmosphere appeared to be very highly charged with electric fluid, but we were unfortunately not prepared to observe the influence of this Aurora upon the magnet, \&c. The heat had been great the day before; the wind was high all night and from the south-south-west.

The bluff upon which the fort is built, offers a good opportunity of observing the geological structure of the country. It consists of several strata, all disposed in parallel and horizontal superposition. On the surface of the ground,

* Narrative of a journey to the Polar Sea, by John Franklin, Captain. 3. N. London; 1823. 
blocks of limestone are found, which appear to be the remains of a stratum that has in great measure disappeared; these are in most cases of a compact and earthy texture, destitute of any organic remains, exhibiting occasional specks of a crystalline nature, which are observed to be calcareous, as, notwithstanding their small volume, they present a distinct rhombohedral cleavage. The first stratum which is observed is about eight feet thick, it is formed of limestone, presenting a very distinct slaty structure. The texture of the rock is compact, its fracture splintery and uneven; organic remains abound in it. These are, as far as we saw, exclusively Producti, they lie in the rock as thick as possible; a small vacant space is generally observed between the inner and the outer casts of the shell. This is however generally filled up with a crystallization of calcareous spar; the form of the crystals cannotbe made out on account of their extreme tenuity. The colour of this limestone, as well as of the loose blocks found upon it, is a light grayish-yellow. This stratum rests upon another calcareous bed, which differs from the preceding, in the total absence of organic remains, and in its colour, which is of a light blue. Its structure is more compact, so is its fracture; its horizontal stratification is distinct, but the stratum being thicker, it is more susceptible of being used in building. It produces, in fact, an excellent stone, which admits of being hewn, and which is the chief material used in the construction of the fort; this bed is from fifteen to twenty feet thick. When examined with the microscope, the rock presents very general signs of crystallization, its texture becomes subsaccaroidal, and veins of calcspar, of an inconsiderable thickness, traverse it in every direction. There are also cavities in which crystals of carbonate of lime, (the cuboüde? of Haüy, are distinctly 
seen. In this bed the workmen state that they find substances rescmbling their eatfish, (Silurus, Linn.) and which they consider as prifiactions of the same; we saw nothing of the kind, neither could they discover any at the time we were there. We at first, however, thought they had probably olsserved icthyolites, but a subsequent and more minute description of the objects observed by the worlimen, satisfied both the naturalists, that they were probably not organic remains, but mere accidents of fracture, or lusi natura. Independent of the building stone which it yields, this bed is likewise valuable, as produeing the best lime of any found in the vicinity. Immediately under this bed of limestone, in parallel stratification, we observed the sandstone which constitutes the principal mass of the bluff, being about sixty feet in thickness. It is a very friable stone, and in some cases the grains, of which it is formed, are so loosely united, that it appears almost like sand. Every fragment, if examined with care, seems to be a regular crystal, and we incline much to the opinion that this sandstone must have been formed by a chemical precipitation, and not by mere mechanical deposition. The process of its formation may have been a very rapid one, such as is obtaincl in the manufacture of fine salt, and to this may be attributed the circumstance of its loose texture. The grain is very fine; its colour is white, sometimes a little yellowish, in which case, it resembles in texture, colour, \&c. the finer varietics of Muscovado sugar. The loose texture of the rock is probably the cause of its presenting but few indications of stratification. The rock which we have just described, rests upon a slaty limestone, which has a striped aspect; the stripes or zones are curved. This limestone appears to be very argillaceous, and is a little softer than the preceding; its structure is quite 
earthy; it effervesces strongly in nitric acid; its colour is a light yellow. The thickness of this bed is about ten feet. Below this another stratum of limestone is found, which imbeds small black pebbles of quartz, and assumes, therefore, in a slight degree, the characters of a pudding stone or conglomerate. Its grain is more crystalline than that of the preceding stratum. It is filled with small cavities, probably the result of a contraction during the consoliclation of the mass. Its colour varies from a bluish to a yellowishgray. This stratum is about seven feet thick. It rises but four feet above the level of the water, and the only rock visible under it, is another variety of limestone which differs from the preceding, inasmuch as its grain is much finer and its texture more earthy. It is only visible for four feet; the bed of the river appears to be excavated, near the fort, in this stratum of limestone. Neither of these limestone formations under the sandstone contain any traces of organic remains. If we consider the three inferior beds of limestone, as being modifications of the same formation, as we doubtless ought to do, then we shall find this bluff to be composed of three different formations; a superior one of limestone, with abundant impressions of shells in one of its beds; an intermediate one of sandstone; and an inferior calcareous formation, without any organic remains. The latter certainly bears some resemblance to the limestone found on the Wassemon, though we are unwilling to pronounce upon their identity.

The river runs upon a bed of sandy alluvion, resulting from the destruction of the bluffs, but in many places the rock is laid bare. These observations upon the geology of the bluff upon which the fort is erected, correspond with those made at the Falls of St. Anthony, with this exception, that at the latter place our observations are limited 
to the three superior strata, viz. the slaty limestone with organic remains, the blue limestone destitute of these, and the sandstone with a loose texture. The falls are occasioned by the fissures which occur in the superior limestone, and which allow the water to penetrate through this bed to the sandstone, which, being of a loose texture, is soon washed away; in this manner thick plates of limestone are lefe unsupported, and soon fall by their own gravity. This process is constantly causing the fall to recede towards its source. What time has been required, what lapse of centuries has been consumed, in bringing the falls to their present situation, it is not in the power of man to decide; but we may well see that it must have been immense. The difference of level between the head of the fall, and the level of the river at the fort, being, as we have stated, estimated at about one hundred feet, and the strata running in a horizontal position, we can readily account for the additional strata observed under the sandstone at the fort. and which are concealed at the falls.

It would remain for us, in order to complete this view of the geology of the falls, to inquire whether the limestone, observed at the falls, corresponds with that superior to the sandstone south of the Wisconsan, and if that, found near the level of the river at the fort, be analogous to that observed under the sandstone, between the Wisconsan and Wassemon. We shall not affect a degree of certainty which we do not possess, but we may be permitted to ackvance an opinion that the sandstone is probably of analogous formation, and that, therefore, the strata of limestone, which we found at the falls, correspond with that stratum of whose existence at a former period, between the IVassemon and the Wisconsan, we think we have evident proofs. We have in our possession, specimens taken it? 
both places, filled with apparently the same organic remains, and exhibiting characters in the rock which correspond as well as could be expected from pieces, collected at three hundred miles distance from each other. We must regret that the circumstances under which we ascended the Mississippi have not enabled us to offer a more conclusive opinion upon this point, or upon the identity or difference between the limestone inferior to the sandstone at the fort, and that observed previous to our arrival at Prairie du Chien.

To one fond of the pleasures of hunting and fishing, a residence at Fort St. Anthony rould offer an opportunity of enjoying these occupations. Catfish has been caught at the falls weighing one hundred and forty-two pounds. Among the birds, observed by Mr. Say, were the Woodcock, * the House Wren, $\dagger$ the Flecker, $\ddagger$ the Hairy Woodpecker, $\S$ the Towhee bunting, \&c. \&c.

The soldiers, that had accompanied us from Fort Crawford, having proved unequal to the fatigues of the journey, and the term of enlistment of some of them having almost expired, Col. Snelling ordered them back to their garrison, and furnished us with a guard consisting of a sergeant, two corporals, and eighteen soldiers, selected from his command. Licut. Scott was appointed to conduct the detachment to Prairie du Chien, and return with all convenient speed, and Lieut. St. Clair Denny, of the 5th Infantry, received the command of the new guard, until Mr. Scott should overtake the expedition; after which he had the option of continuing with the party, or returning to Fort St. Anthony.

* Scolopar minor, Gmelin. † Certhia familiaris, Linn.

$\div$ Picus atratus, Linn. $\quad$ Picus villosus, Linn. 
Provided with this new and more efficient escort, the party left Fort St. Anthony late in the afternoon of the 9th of July. They had exchanged their interpreter for another, Joseph Renville, a half-breed of the Dacota nation, who undertook to act both as interpreter and guide. The very able manner in which he performed these dutics; the valuable information which he communicated concerning this nation of Indians, and the unirersal satisfaction which he gave to every member of the expedition, requires that something should be stated of this man, whose influence among the Sioux appears to be very great.

Joseph Renville was the son of a French trader on the Mississippi, probably the same mentioned by Pike. His mother being a Sioux resident at the village of the Petit Corbeau, he was brought up among the Indians, and deprived of all education excepting such as his powerful mind enabled him to acquire, during his intercourse with white traders; it was, therefore, rather an education of observation than of study. We have met with few men that appeared to us to be gifted with a more inquiring and discerning mind, or with more force and penetration than Renville. His mother being connected with an influential family among the Indians, he was early brought into notice by them; his object appears to have been, from his first entrance upon the pursuits of life, to acquire an ascendancy over his countrymen. This, he knew, could not be obtained except by the most daring and persevering course of conduct; and, accordingly, we have it from respectable authority, that he never desisted from any of his pretensions, and that whatever he had undertalien, he never failed to achieve. As a trader, he was considered actire, intelligent, and faithful to his employers; his usefulness depending, in a great measure, upon the influence which he 
possessed orer the Indians. When, at the commencement of the late war, the British government determined to use the Indians as auxiliaries, Col. Dickson, to whom the chief direction of this force had been entrusted, selected Renville as the man upon whom he could place most dependence; to him, therefore, was the command of the Sioux given, with the rank, pay, and emoluments of a captain in the British army. In this new situation he distinguished himself not only as an active, but as a humane offcer; to him the Americans are, we doubt not, indebted for the comparatively few injuries done by the Sioux; he repressed their depredations, and prevented them from sharing in those bloody and disgusting transactions which disgraced the conduct of the Chipperwas, the Potawatomis, Miamis, Ottowas, \&c.

After the war, he retired to the British provinces, retaining the half-pay of a captain in the line; he then entered the service of the Hudson's Bay Company, for whom he traded several years at the head of Red river. Being dissatisfied with their employ, he left them, and finding it impossible to retain his pension as a British officer, unless he continued to reside in the British territory, he voluntarily relinquished it, and returned to his old trading post towards the sources of Red river. This being within the territory of the United States, he, with several of the former agents and clerks of the British traders, established a new company under the name of the Columbia Fur Company. Of this Renville may be considered as being the principal prop, as it is to his extensive acquaintance with the Indian character that they are indebted for the success which has hitherto attended their efforts.

Renville's character has not been exempt from the obloquy which always attends those who take decisive and VoI. I. 
independent measures. It has been thought that, having been born on the Mississippi, and therefore within the actual limits of the United States, he ought not to have joined the British during the late war. In extenuation, it ought to be remembered, that he was of Canadian origin; that all the French traders have uniformly considered themselves as British subjects; and that the trade upon the upper Mississippi was entirely in their hands. His separation or, as it has been termed, his desertion from the Hudson Bay Co.'s service has also been objected to; but we believe there were grounds of complaint on both sides, and having heard him commended by those who were interested on neither side of the question, we are unwilling to believe that any blame attaches to him in this transaction. We found him uniformly faithful, intelligent, and as veracious as any interpreter we ever had in our company.

Mr. Joseph Snelling, son of the Colonel, volunteered to accompany the expedition as an assistant guide and interpreter; for which situation he had qualified himself by a winter's residence among the Indians; his services were accepted. Thus reinforced, the party amounting in the aggregate to thirty-three persons, took leave of the officers of the garrison by whom they had been kindly received; by none more so, than by Colonel Snelling and Lieutenant Nathan Clark; who hospitably entertained the party during: their stay at the fort. In order to examine both the river and the adjacent country, the party was divided; Major Long ascended in a boat with Messrs. Keating, Seymour, and Renville. A corporal, twelve soldiers, and the black boy accompanied them. The men were divided into four canoes, in which the bulk of the stores and provisions was embarked.*

* An Italian whom we met at Fort St. Anthony attached himsclf to 
The land party consisted of Messrs. Say, Colhoun, and Lieut. Denny, with a sergeant, a corporal, seven soldiers, and a boy, Louis Pellais, hired as a Chippewa interpreter. It was determined that the two divisions should as far as practicable keep company together, and encamp every aight, if possible, at the same place.

At the point where we embarked, which may be consilered as the mouth of the St. Peter, this stream is about ninety yards wide; it lies in latitude $44^{\circ} 53^{\prime} 49^{\prime \prime}$ north, longitude $93^{\circ} \mathrm{S}^{\prime} 7^{\prime \prime}$ west. The magnetic variation amounts to $10^{\circ} 28^{\prime} 40^{\prime \prime}$ east. These result from a series of observations made by Mr. Colhoun during our stay there. The river is called in the Dacota language Wảtâpân Mẻn'ésốtă, which means "the river of turbid water." The term Watapan, which in that language signifies river, is always prefixed to the name of the stream; thus the Mississippi is called Watapan Tancha, (the body of rivers, because all the other streams are considered as branches or limbs, this being the trunk,) the Missouri is termed Watapan Mene Shósh' $\mathbf{a}$, "the river of thick water." In the Potawatomi, Sauk, and other languages of Algonquin origin, the substantive follows the adjective, as Mésẻ Sẻpé, Pektannon Sepe, \&c.

The name given to the St. Peter is derived from its turbid appearance, which distinguishes it from the Mississippi, whose waters are very clear at the confluence. It has been erroneously stated by some authors to signify clear water. The Indians make a great difference, however, between the terms sota and shosha; one of which means turbid,

the expedition and accompanied us to Pembina. He has recently pubIished a book entitled, "La Découverte des Sources du Mississippi," \&cc. which we notice merely on account of the fictions and misrepresentations which it contains: S. H. L. 
and the other muddy. At the mouth of the St. Peter there is an island of considerable extent, separated from the main land by a slough of the Mississippi, into which the St. Peter discharges itself. The Mississippi is here, exclusive of the island, about 250 yards wide. In ascending it, particularly in low water, boats pass through this slough, as it affords a greater depth than the main branch on the cast side of the island. It was probably, as Carver suggests: this island which, being thickly wooded and lying immediately opposite to the mouth, concealed the St. Peter from Hennepin's observation. No notice of this river is to be found in any of the authors anterior to the end of the 17th century. Indeed, it is only by close research that we hare been enabled to trace the discovery of this river so far back. Charlevoix states," that le Sucur was sent by M. d'Iberville to make an establishment in the Sioux country; and to take possession of a copper mine that he had there discovered, (que le Sueur y avuit découverte;) he ascended the St. Peter forty leagues to "la Riviere Verte," which comes in on the left. Though only the last of September, the ice prevented him from ascending that river more than a league. He therefore built a fort and spent the winter at that spot; in April, 1702, $\$$ he went up the Riviere Verte to the mine, which was only three quarters of a. league above his winter establishment. In twenty-two day's they got out more than thirty thousand pounds of ore, (de matiere,) of which four thousand pounds were selected and sent to France. The mine was at the foot of a mountain ten leagues long, that seemed to be composed

* Charlevoix, Histuire de la nouvelle France, ì Paris, 174t, tome 4. p. 165 and 166 .

† As he ascended, right bank?

\& This ought probably to be 1701 . 
of the same substance. After removing a black burnt crust as hard as rock, the copper could be scraped with a knife. Several reasons, but particularly the want of pecuniary means, prevented le Sueur from following up the discovery. This account corresponds in part with that contained in a very interesting manuscript belonging to the American Philosophical Society, and which appears to have been written with considerable care and accuracy. We find it therein stated, that the said "le Sueur arrived at the mouth of the Mississippi with M. d'Iberville in Dec. 1699; that he brought over with him thirty workmen. He had been," says the author of the MS. "a famous traveller from Canada, and was sent by M. L'Huillier, a principal contractor, (fermier general,) under government, in order to form an establishment near the source of the Mississippi. The object of this enterprise was to obtain from that place, an ore of green earth which that gentleman had discovered; the following was the origin of this undertaking, in 1695. M. le Sueur, by order of the Count de Frontenac Governor General of Canada, caused a fort to be erected on an island on the Mississippi, upwards of two hundred miles above the Illinois; in order to keep up peaceful relations between the Sioux and Chippewa nations, which reside on the shores of a lake upwards of five hundred leagues in circumference, which lake lies one hundred leagues east of the river; the Sioux reside upon the upper Mississippi. In the same year, according to his orders, he descended to Montreal with a chief of the Chippewa, named Chingouabé, and a Sioux, called Tioscaté, who was the first of his nation that ever was in Canada; and as they expected to draw from his country many articles valuable in trade, the Count de Frontenac, the Chevalier de la Cailliere, and de Champigny, received him very amicably. 
Two days after their arrival, they presented to the Count de Frontenac, in a public assembly, as many arrows as there were Sioux villages, and they informed him that all those villages entreated him to receive them among his children, as he had done to all the other nations which they named one after the other; which farour was granted to them. M. le Sueur was to have reascended the "Mississipi" as early as 1696 , with that Sioux chief who had only come down upon an express promise that he should be taken back to his country; but the latter fell sick in Montreal, and died after thirty-three days disease. M. le Sueur, finding himself thus released from his pledge to return into the Sioux country, where he had discovered mines of lead, copper, and earth, both blue and green, resolved upon going over to France, and asking leave of the court to open those mines; a permission to this effect was granted to him in 1697. About the latter end of June in the same year, he embarked at la Rochelle for Canada: as he was crossing Newfoundland banks he was captured by a British flect of sixteen ships, and by them taken to Ports. mouth; but peace having been soon after concluded, he returned to Paris to obtain a new commission, as he had thrown his overboard, lest the English should become acquainted with his scheme. The French court directed a new commission to be issued to him in 1698. He then went over to Canada, where he met with various obstacles which compelled him to return to Europe. During this interval of time, part of the men whom he had left in charge of the forts which he had erected in 1695, being without intelligence from him, abandoned them, and proceeded down to Montreal." **

* "Journal historique concernant l'êtablissement des Francais à $l_{\text {s }}$ Lonisianue, tiré des mémoires de Messrs. d'Iberville \& de Bienville 
Thus it appears from this manuscript, that le Sucur's discoveries of blue earth were made in 1695, but that all further operations were interrupted until 1700; we find in the same manuscript, under the date of the 10th of February, 1702, that le Sueur arrived at the mouth of the Mississippi that day with two thousand crvt. (quintaux,) of blue and green earth. An extract from a narrrative of his voyage is then given from the time that he left the Island of Tamarois, (12th July,) unto the 13th December, 1700. From this extract, which is fraught with interest, as it is the first account we can find, in which St. Peter's river is mentioned, we gather that he reached the mouth of the Missouri on the 13th of July, 1700, and the mouth of the Wisconsan on the first of September; and that, on the 14th, he passed Chipperva river, on one of the branches of which, he had, during his first visit to the country, found a piece of copper weighing sixty pounds. He next

commandans pour le Roi au dit pays, et sur les decouvertes et recherches de M. Bénard de la IIarpe, nommé au commandement de la Baye St. Bernard; par M. Bénard de la Harpe," MS. This is stated to be a copy of the original, which was, in the year 1805 , in the possession of Dr. Sibley, as appears from a note, annexed to it, certifying it to be a true copy, and dated Natchitoches, October 29th, 1805. From the manuscript it appears that $\mathbf{M}$. de la Ilarpe was on the lower Mississippi, in the early part of the 18 th century, and that he continued there until the commencement of the year 1723. His appointment to the command of St. Bernard's Bay, was made in the year 1721 . IIe appears to have proceedecl to it at that time; but owing to the weakness of his garrison, he found limself unable to continue his post there. His journal throws considerable light upon the history of the Alscoverics of the French on the lower Mississippi, and is closed with a memoir upon the importance of the colony of Louisiana, and upon the situation of that colony in 1724 ; together with some observations upon the best passage to the Westem Ocean, and upon the origin of the Indians of America; 
entered Lake Pepin, which is designated by that name in the manuscript, although Hennepin had, in 1680, called it the Lake of Tears, and notwithstanding the appellation of Lac de Bon Secours, which Charlevoix applies to it. On the 16 th he passed the St. Croix, so called from the name of a Frenchman, who was wrecked at its mouth. Finally, on the 19th of September, he left the Mississippi, and entered the St. Peter's river, which comes in from the west, bank. By the first of October, he had ascended this river forty-four and a quarter leagues, when he entered the Blue river, the name of which is derived from the blue earth found on its banks. At the mouth of this river he made an establishment, situated, as la Harpe states, in latitude $44^{\circ} 13^{\prime}$ north. He met with nine Sioux, who informed him that this river had its course through the lands of the Sioux of the west, the Ayavois, ( Iawas, ) and the Otoetata, who lived further back. We infer that these were the same streams which he had ascended in 1695, from the circumstance that they are mentioned as well known, and not as recently discovered; and more especially from the observation of la Harpe, that the eastern Sioux having complained of the situation of the fort, which they would have wished to see at the confluence of the St. Peter and Mississippi, M. le Sueur endeavoured to reconcile them to it. "He had foreseen," says la Harpe, "that an establishment on the Blue river would not be agreeable to the eastern Sioux, who are the rulers of all the other Sioux, and of the other nations which we have mentioned, because they were the first with whom the French traded, and whom they provided with guns; nevertheless, as this undertaking had not been commenced with the sole view of trading for beavers, but in order to become thoroughly acquainted with the quality of the various mines which he had prea 
viously discovered there, he replied to the natives that he was sorry that he had not been made sooner acquainted swith their wishes, \&c. but that the advanced state of the season prevented his returning to the mouth of the river." No mention is made, in this narrative, of the stream being obstructed with ice, a circumstance, which, had it really occurred, would, we think, have been recorded by de la Harpe, who appears to have been a careful and a curious observer, and who undoubtedly saw le Sueur's original narrative. On the 14th of October the works were completed and were named Fort L'Huillier.

On the 26th, M. le Sueur went to the mine with three canoes, which he loaded with green and blue earth; it was taken from mountains near which are very abundant mines of copper, of which an assay was made in Paris by $\mathbf{M}$. L'Huillier in the year 1696. This is the last historical fact of any interest contained in the extract from le Sueur's journal. M. de la Harpe observes, "la suite des mémoires de Monsieur le Sueur n'a point paru," which would seem. to imply that the former part had been published; yet we find no notice taken of this traveller's memoirs in any of the catalogues of works on America, to which we have had access. It is not mentioned in the "Bibliothecæ Americanæ Primordia," published by a member of the Society for the propagation of the Gospel in foreign parts, London, 1713; nor in the "Bibliotheca Americana, or Chronological Catalogue of curious Books in print or manuscript on the subject of North and South America," in London, 1789; nor in the "Catalogue of Mr. Warden's Books on America, Paris, 1820," from which circumstance we are induced to doubt whether it was ever made public. We even find no account of de la Harpe's manuscript, whence we suppose that it has not yet been brought into notice.

VoL. I. 
The river St. Peter is found traced on some of the old maps of Louisiana; for instince, on that which accompanies the Recueil de Voyares, published in Amsterdam in 1720, upon which Fort L'Huillier is marked. Upon this map a coal mine is also designated, as existing about ten leagues up the St. Peter. If this be not purely ideal, it must have resulted from mistaking lignite for that mineral, as this is not a coal country.

Coxe, whose general accuracy entitles him to considerable praise, and who appears to have taken great pains to collect information on the subject of the discoveries made in Louisiana, has, by a strange oversight, left out St. Peter's river, and introduced on his map, the Riviere Longue, the Lake of Thoyago, and all the fables of Lahontan. in whom he secms to place much confidence. This is the more remarkable, as the Carolana, published in 1741, was twenty years later than the Amsterdam Recueil. The: St. Peter is mentioned in an incidental manner by Charleroix in his Journal Historique, but he attempts no description of it.* We have sought in vain for the origin of the name; we can find no notice of it; it appears to us at present not unlikely, that the name may have been given by le Sueur, in 1795, in honour of M. St. Pierre de Repantigni, to whom Lahontan incidentally alludes, as being in Canada in the year 1789.t This person may have accompanied le Sueur on his expedition. It has been, we know not upon what authority, suggested that the French name. of this river, St. Pierre, was a corruption of the term Sans pierres, (without stones,) said to have been given to it, because no stones occur along its banks for a considerable distance from its mouth. It is very strange, that notwith-

- Ut supra, pages 110, 295, and $296 . \quad$ † Lahontan, vol. I. p. 156. 
xtanding the great importance which seems to have been attached in France to le Sueur's discoveries, so little should have been said by other authors, concerning this explorer and the regions which he discovered.

Carver is the only traveller who states that he visited this river, merely from motives of curiosity ; but a close perusal of his book, has satisfied us that he professes too much. He asserts that he "proceeded upon the river about two hundred miles, to the country of the Naudowessies of the plains, which lies a little above the forks formed by the Verd and Red Marble rivers." He states that he resided five months among the Naudowessies, and that he acquired their language perfectly. We are inclined to doubt this; we believe that he ascended the Mississippi to the Falls of St. Anthony, that he saw the St. Peter, and that he may even perhaps have entered it; but had he resided five months in the country, and become acquainted with their language, it is not probable that he would have uniformly applied to them the term of Naudowessies, and omitted calling them the Dacota Indians, as they style themselves. It is probable that Carver derived his name from the source from which the other travellers received that of Nadiousioux, from which Sioux has been derived by abbreviation. This is the term given to strangers by some of the North American Indians, (the Iroquois, as we believe, and with them is synonymous with that of enemy. The term Dacota, by which the Sioux call themselves, signifies in their language the united or allied, because the whole nation consists of several allied tribes. In his account of the river St. Peter, Carver attributes to it a breadth of neariy one hundred yards for two hundred miles, whereas at the distance of one hundred and thirty miles it was but seventy yards wide, and was found to be 
rapidly diminishing in sizc. He also ascribes to it "a great depth," which is not the case at any distance above its mouth.

We saw no branch of the river coming in from the north but a few small tributaries not entitled to notice. Carver's river, which had been inserted on most of the maps made since the publication of his book, has therefore been omitted on that which accompanies this work. It is scarcely possible that if Carver had ascended the St. Peter two hundred miles, he would have reported without contradicting them, the exaggerated accounts of the great extent of this river, or attributed to it a rise near the Shining, (Rocky,) Mountains; but besides these inaccuracies, some of which may perhaps be partly accounted for by his having seen the river at a time when it was unusually high, and when a mere brook may have been so much swollen as to be mistaken for a small branch of the river, yet we cannot place any confidence in him on account of the many misrepresentations contained in his work. Almost all that he relates as peculiar to the Naudowessies, is found to apply to the Sauks, or some other nation of Algonquin origin. Thus on reading to Renville, Dickson, (the son of the late Colonel Dickson, and to several other of the halfIndian interpreters whom we saw on the St. Peter, that part of chapter 12th of his work, in which he relates that "the Naudorvessies have a singular method of celebrating their marriages which seems to bear no resemblance to those made use of by any other nations that he passed through," these men all exclaimed that it was fabulous, that such a practice had never prevailed among any of the Dacotas, though they believed it to be in use with some of the Algonquin tribes. The practice of having a totem or family distinction, exists, as we have already stated, 
among the Sauks, \&c. but it is quite unknown to the Sioux, to whom it is attributed by this writer. It is, we believe, clearly proved at present, that the land which he claimed by virtue of a grant from the Indians, was never conveyed to him by them. Attempts were made in 1817, by two of his grandsons, to have the claim recognized by some of the Indians now living; they ascended the river at the same time that Major Long did, but were not successful. An instrument purporting to be the original treaty was afterwards sent to Canada, and placed in Renville's hands by those who had an interest in the claim; he was requested to show it and explain its nature to the Indians, and to endeavour to obtain a confirmation of it from them; but, as he informed us, he could find no individual among them, who had the least recollection or tradition of this conveyance, or even of the names which are purported to have been affixed to the deed; the Indians have no hesitation in asserting that there never were among them any Dacota chiefs of the nume. When chapter 5th of Carver's work was read to Renville and the ollier men, they denied the 1ruth of its contents; but immediately recollected the designs of a snake and a tortoise, which were affixed to the treaty, no doubt to make it tally with the account of their family distinctions contained in that chapter of his travels. His vocabulary appears certainly to have been taken from the Dacota language; it may have been obtained from the Indians along the banks of the Mississippi, but was more probably copied from some former traveller, for a reference to old works will prove that Carver derived much of his information from them, though no credit is given to their authors for it. A comparison of his account of the manners of the Indians with that given by Lahontan, shows that he was familiar with that author. His state- 
ment of the division of the year by the Indians into twelve moons, with the addition at the end of the thirticth, of what they term the lost moon, Sc. is extracted, and in some places copied almost rerbatim, from Lahontan's; his account of the qualifications of men is undoubtedly drawn from the same author; and a comparison of chapter 12th of Carver's Description of the Indians, with Lahontan's "Account of the amours and marriages of the Savages," will show too close a coincidence to consider it as merely accidental. Yet no reference is made by Carver to the work of his predecessor. We have introduced these observations upon the work of Carver, because as he was the only traveller that published an account of the St. Peter, he has been frequently quoted as an authority. WVe might have enlarged the list of errors, whether wilful or unintentional, into which this author has fallen, but we have said enough to show that his statements cannot be relied upon as correct.

Major Long's party ascended the river five and a half miles, and stopped for a few moments at a village called

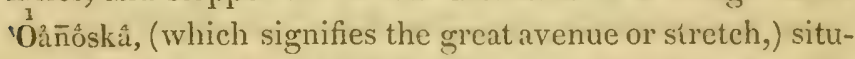
ated on the right bank; they then proceeded about one mile higher up, where they lay by in a deserted cabin on the left. bank. The cabin having been carefully closed in order to secure it against injury from wild animals; they took down the skins which hung at the door, and made themselves comiortable in it. While at supper, they received a visit from an old squaw, who came from the village below, to see what they were doing. The lodge, as she informed them, was her's, but as the men had all gone out hunting; she had removed down to live with her daughter. Having observed a fire near her cabin she was apprehensive that some injury would be done to it; they however satisfied 
hor that their intentions were friendly; and Renville informed the gentlemen that no offence could be taken at their intrusion in the house, as they were travelling in an official capacity, but that if other Indians, or voyagers that were not known, had taken that liberty, it would have been held highly improper. There was something gratifying and yet melancholy in the recollection that we had thus for awhile bid adicu to civilization, and that before us we had none but a wide and untravelled land, where no white men resided except such as had forsworn their country and the friends of their youth; who either out of aversion from society or for the sake of lucre had withdrawn from its social circle, to divell in the midst of the uncivilized tenants of the forest. It was while indulging in these reflections, by the light of a few embers, that we received this unexpected visit from the owner of the lodge. Her mrinkled brow, her decrepid mien, her slovenly appearance, gave her a somewhat terrifying aspect, as seen by the uncertain light that played upon her haggard features; her shrill voice contributed also to heighten the awfulness of this untimely visitor; but our interpreter having explained to us the object of her visit, we had leisure to observe her companions, who were two of her grand-daughters; these were as handsome and as good looking as Indian females can probably be; they were young, about fifteen or sixteen; their complexion was so light that we could scarcely credit the assertion of our guide that they were full-blooded Indians; their features were regular; the largr. dark eye which distinguished the elder would have been deemed beautiful any where; their forms, which were good, were perhaps taller than those which we usually found among Indian women. But what added most to their charms, was the gay, good-humoured appearanee 
which brightened their eye and animated their fcatures. While the old hag was muttering her discontent, they were smiling, and as she extended her bony hand to re. ceive the present offered her, the damsels burst out into 2 laughter which displayed a beautiful set of teeth. Their observations upon our party seemed to afford them as much gratification as we derived from the examination of theirs, and the merriment which it occasioned them was displayed in the most unreserved manner. After a visit of about half an hour they all withdrew, leaving us to the undisturbed occupancy of the lodge. This visit offered us food for conversation until we retired to enjoy, what had been for the last two months the object of our anxious anticipations, a night's rest upon the secluded banks of the St. Peter. We this day met Major Taliaferro going dowa the river in a canoe. In order to afford us an opportunity of studying the manners of the Indians in council, he had kindly undertaken to ascend to the village of the Sisiton band of the Sioux, for the purpose of holding a council with them in our prescnce, and with this view had left the fort that morning; but being informed on the river that they had all dispersed on their summer hunts, he returned the same evening. *

The next day we travelled about thirty-five miles; at six miles from the night's camp, we passed the small rillage of Tetankatane; all the men were absent on their hunts

* Swarms of an insect of the Linnean genus Ephemera, were oiserr. ed by the party, along the banks of the rive:. It has been clescribed by Mr. Say under the name of Baitis bilincata, \$. (Appendix I. Ento. mology.) The surface of the river was in many places absolutely co. vered with the remains of these insects, who, having gone through thei: short-lived existence, fell unon the water and were cavied down tise stream. 
We proceeded up the river, and, at a distance of about twenty miles, Mr. Say was spoken to on shore. Instructions were sent through him to the land party, to meet Major Long, at a village two miles higher, in order to take advantage of the canoes, for the transportation of the baggage across the river, as the right bank becomes here better for travelling than the left. The flotilla reached this village about twelve o'clock, and waited five hours, during which the land party did not join them; men were sent out in various directions and guns fired, but no answer being returned, we concluded that they had proceeded higher up the river. We re-embarked and ascended ten miles to a small wood, where we encamped for the night. The village at which we had expected to meet the other party, is called Tảoảpâ; it consists of fifteen large bark lodges, in good order; they were arranged along the river. Some of them were large enough to hold from thirty to fifty persons, accommodated as the Indians usually are in their lodges. The ground near it is neatly laid out, and some fine corn-fields were observed in the vicinity. There were scaffolds annexed to the houses, for the purpose of drying maize, \&c.; upon these we were told that the Indians sleep during very hot nights.

The river banks had thus far been low, and covered with a fine rich vegetation; the trees attained a large size near the river, but they were not found far into the interior of the country. Near Fort St. Anthony there is a fine piece of bottom, exposed to occasional inundations. The line of bluffs, which borders upon the Mississippi, does not extend far from that stream, but gradually sinks in height, until it finally disappears near the village of Oanoska. The soil along the river is of the best quality. After ascending about thirty miles, the bluffs reappear, and rise to an ave-

Vox. I. 
rage height of serenty-fire feet on the left bank. In the bottoms, the elm furms the principa! growth of the country, and thrives. In the rear of the village of Taoapa, a swamp extends, and divides it from the bluffs. The grass grows in some places to the height of six feet, as was priacipally observed, east of the village, by some of the party who undertook to walk down to the place where Mr. Say had been spoken to. We sarv about the village no stones of any lind, but, on the right bank, Najor Long observed a number of fragments of primitive rock, and also some secondary limestone, which appeared to him to be in situ. There were some scaffolds upon which sereral corpses were raised. In the midst of the corn-fields a dog was found suspended, his head decorated with feathers, and with horsehair stained red; it was probably a sacrifice for the protection of the corn-ficlds, during the absence of the Indians. On the right bank Major Long observed numerous ancient tumuli or artificial mounds, some of which were of a large size. They occupy a consiclerable extent of the prairic upon which they are situated. In one part, they formed a line of about half a mile, in a direction parallel to the river, from which they were distant about thee hundred yards. The mounds were erected at a distance of from twelve to fifteen yards asunder, and when observed from one end of the line, presented the appearance of a ridge or parapet.

Proceeding carly the next morning, the land party was found cncamped six miles above the village, on a fine piece of rising ground, which the voyagers have called the Littie Prairie. They had not been able to reach the village from the inexperience of their guide, who had kept them in the rear of the swamp. The river was observed to widen much at places; it was here about seventy yards broad; its current, which had always been inconsiderable. 
compared with that of the Mississippi, increased as we advanced. The cause of this is, that the great volume of water, which the Mississippi rolls down, backs up the waters of most of its tributary streams, and produces a real pond at their mouth. This is no doubt the cause of the lake formed by the St. Croix, \&c.

Our flotilla assisted the land party in crossing the river, after which we again separated; and the boat, having ascended a few miles, came to rapids formed by two bars of sandstone, which extend across the river, producing a fall of about four feet within twenty yards. The water in the river, at the time we ascended, was of an average height, remarkable neither for its abundance nor scareity; and at this stage we found at the falls just water enough to float our boats and canoes, with the baggage and stores in them, the crew and passengers walling alongside and dragging them up the rapid. A shoal below, had likewise required that our canoes should be lightened. Another rapid about half a mile above, proved more difficult to pass. There being a sufficient depth of water, we ascended in the boat and canoes; one of the latter missed the channel, which is narrow, and in which there is a rapid current; the canoe drifted down against the rock, and fears were entertained that it would be lost; but with considerable labour, and after about half an hour's detention, it was at last brought up safe. The aggregate fall of the two rapids is seven feet. At a short distance above this we stopped for an hour; this gave us an opportunity of observing the nature of the country. The stream is there incased by a vertical bank, about ten or twelve feet high, the base of which is washed by the river. Ascending this bank we find a level valley, which is about a quarter of a mile wide; this is limited by a steep and rugged bank, of about twenty feet in height. 
Having ascended this bank, a beautiful prairie, apparently very extensive, displayed itself to our view. The steep bank, which exposes the disposition of the rock, shows it to be a sandstone formation, in a horizontal stratification, and of a fine crystalline grain; the colour varying from white to yellow; this sandstone is, in every respect, similar to that found at Fort St. Anthony. Six miles above the rapids, there is a small Indian settlement, called Weâkâoutẻ. It was deserted, but consisted of two lodges and the ruins of a third, near which there were two scaffolds. On these scaffolds, which are from eight to ten feet high, corpses were deposited in a box made from part of a broken canoe. Some hair was suspended, which we at first mistooli for a scalp; but our guide informed us that these were locks of hair torn from their heads by the relations, to testify their grief. In the centre, between the four posts which supported the scaffold, a stake was planted in the ground; it was about six feet high, and bore an imitation of human figures; five of which had a design of a petticoat, indicating them to be females, the rest, amounting to seven, were naked, and were intended for male figures. Of the latter, four were headless, showing that they had been slain; the three other male figures were unmutilated, but held a staff in their hand, which, as our guide informed us, designated that they were slaves. The post, which is an usual accompaniment to the scaffold that supports a warrior's remains, does not represent the achievements of the deceased, but those of the warriors that assembled near his remains, danced the dance of the post, and related their martial exploits. A number of small bones of animals were observed in the vicinity, which were probably left there after a feast celebrated in honour of the dead. The boxes in which the corpses were placed are so short that a man could not lie 
in them extended at full length, but in a country where boxes and boards are scarce, this is overlooked. After the corpses have remained a certain time exposed, they are taken down and interred. Our guide, Renville, related to us, that he had been a witness to an interesting, though painful circumstance, that occurred here. An Indian who resided on the Mississippi, hearing that his son had died at this spot, came up in a canoe, to take charge of the remains, and convey them down the river to his place of abode; but, on his arrival, he found that the corpse had already made such progress towards decomposition, as rendered it impossible for it to be removed. He then undertook, with a few friends, to clean off the bones; all the flesh was scraped off and thrown into the stream; the bones were carefully collected into his canoe, and subsequently carried down to his residence.

The two parties having exchanged a few words at this place, continued their journey. The boats proceeded but three miles beyond this to an encamping ground. The navigation had been an easy one except at the rapids. In a few places, however, snags were seen, which partly impeded the main channel. The next day they were found more numerous, as were also the sandbars, which sometimes rendered the navigation of the river troublesome. 'The skiff, which had been obtained for Major Long and the gentlemen's use, as more pleasant than a canoe, was found very inconvenient, being leaky and slow of motion, so that the party gladly embraced the opportunity of exchanging her for a fine canoe belonging to a trader whom we met returning to Fort St. Anthony. The forests, which had principally consisted of cotton-wood, birch, \&c. were observed to become more luxuriant, and to be replaced by a heavy growth of oak and elm. The soil appeared ex- 
cellent and deep, the roots extending sometimes three feet under ground. The sandbars and small islands are covered with groves of willow. A few hills, composed principally of loose sand, were observed during the journey of the 12th; one of which, distant about half a mile east from the encampment, was estimated at about one hundred and fifty feet in height. The latitude of the camp on the evening of the 12th of July was observed to be $44^{\circ} 33^{\prime} 59^{\prime \prime} \mathrm{N}$. which shows that the general direction of the river thus far is south of west. We reached the extremity of the forest the next morning, and found on the prairic a small party of Indians encamped. We were told that the principal of these was the old chief who formerly resided at Weakaote. He has thirty or forty warriors under his command, who intend to remove from their old residence to this spot, as the other place is considered unhealthy; by white men it is called Fever Sandbar.

Notwithstanding these circumstances, the St. Peter is generally deemed very healthy, and in despite of the unfavourable name applied to the sandbar, it is said to be free from intermittent fevers. Our party continued all in health except one of the soldiers, who had a ferv chills and fits of fever, which were soon checked. It was supposed that he had brought the seeds of it from the Mississippi.

Prairie land was again observed to border upon the river, the number of islands increased, and the navigation became extremely tedious. At one of the landing places, we observed a block of granite of about eighty pounds weight; it was painted red and covered with a grass fillet, in which were placed trvists of tobacco offered up in sacrifice. Feathers were stuck in the ground all round the stone.

In the afternoon, one of the canoes was unfortunately 
upset; the men who were in it regained the shore with some difficulty, but much of the cargo was lost or damaged. Among the articles lost, the most important was a keg of tobacco, which was intended for presents to the Indians, and a considerable part of our ammunition, which, getting wet, became either totally unfit for use, or very much damaged. We had scarcely repaired, as much as lay in our power, the bad eflects of this accident, when we observed the heavens overcast with dark clouds portending an approaching storm. We immediately landed with a view to shelter our stores and our persons against the rain. About seven in the evening, the storm broke out with more violence than usually happens in our climates. The precautions which we had taken proved of but little or no avail. The stores, which had been carefully packed up in a canoe and covered up as well as our means permitted, were much damaged by the water which half filled the canoe. Among them was our biscuit, coffee, sugar, \&c. The tent had been pitched in as favourable a spot, with respect to the trees, as the ground would admit of, but not sufficiently so to render it either safe or comfortable. Several trees, in the vicinity of the tent, were struck with lightning, and the wind blew with such force that the crash of falling timber was frequently heard during the night. The rain continued to pour down with great abundance until morning, when we werc pleased to observe the sun rise fair, and afford us a chance of drying our baggage and stores. That spot being inconvenient for the purpose, we proceeded a few miles higher up, to an old wintering camp of the traders; we remained there several hours; our canoes being occupied in transporting the baggage of the land party to the left bank of the river. The St. Peter is here fordable for korses. During our stay at this place Major Long found 
that the combined effects of the two calamities, experienceut within the last twenty-four hours, had required a change in our mode of travelling. The navigation of the river had been very slow, since we had advanced but about one hundred and thirty miles in six days; and it threatened to become still more tedious on account of the increasing shallowness of the water. Our provisions were not sufficient to support so large a party; and the country being destitute of animals, afforded us no supply. The only game killed from the time that the party left the fort were two ducks. Our guide further informed us, that if we continued to ascend the St. Peter in canoes, we should lose much precious time, arrive on Red River after the buffalo had left it, and find it, probably, impossible to reach the head of Lake Superior before the winter season had commenced; in which case we should be compelled to winter somewhere west of the lakes. As this comported neither with Major Long's wishes, nor with the instructions which he had received from the War Department, it induced him to relinquish the plan of ascending in canoes, and to send back nine soldiers, retaining but twelve men as a guard, which in the present dispersed state of the Indians promised sufficient protection. By proceeding all in one party on land, much time would necessarily be saved, and the bends of the river need not be followed Although this plan did not afford us as good a prospect of becoming acquainted with the nature of the country as the mode we had heretofore followed, yet in the present state of our affairs it was judged to be the only one that could be adopted with prudence; and as this modification in our manner of travelling required a corresponding change in the arrangement of our baggage, we proceeded a few miles higher up, to a fine prairie, where we found good pasture 
for our horses. The spot, upon which we encamped, has received the name of the Crescent, from a beautiful bend which the river makes at this place. The two parties having united here, a day was spent in drying the baggage, and separating the damaged provisions from those that were still fit for use. The acetous fermentation having commenced in our biscuit, such parts of it as were not too much injured were roasted over the fire.

As this was the highest spot on the St. Peter which we reached in canoes, it may be well to recapitulate the general characters of this stream, as we observed it from its mouth to the Crescent, a distance of one hundred and thirty miles by water.

The breadth of the river varies from sixty to eighty yards, but averages about seventy; its depth is such that it cannot be forded for about forty-five miles from its mouth. At Fort St. Anthony the St. Peter is said to be about sixteen feet deep. The depth diminished rapidly as we proceeded up the river, and in some places our canoes had barely water enough to float them; yet the river was not considered very low at that season. In times of floods it can be ascended much higher, without inconvenience, by loaded canoes. The current, which is almost imperceptible at Fort St. Anthony, increases, and in some places is quite rapid; during the three last days it was found to average about one mile and a half an hour. The bed of the river is chiefly sand, arising from the destruction of the sandstone in which it is excavated. The banks usually rise to about twelve or fifteen feet, and are chiefly, if not altogether, composed of sandstone. On the last day, we saw a bluff that rises to sixty or eighty fect; it consists of white sandstone, and is called the white rock; limestone is, however, found in the country in various places. The graVOL. I. 
nitic boulders, which appear to be quite deficient in the lower part of the river, are found tolerably abundant after passing the village of 'Taoapa. In some cases they assume a very large size; one of them was of an elliptical form; it was twelve yards in periphery, and five fect high; it is evidently out of place, and forms a conspicuous object in the prairie. 'The designs made upon it by the Indians, consisting of thick lines divided by intermediate dots, prove that it was with them an object of veneration. There are likewise amphibolic boulder's scaitered over the country. The bed of the river presents but few islands below the rapids, but above these it is checkered with numerous small sandy islands, which change the direction of the channel, and contribute to the rapidity of the current. The largest of these islands does not exceed three hundred yards in length, and thirty in breadth. The river is a very meandering one; so much so, that the canoes were seldom steered for five minutes at a time in the same direction. The courses of the river varied from south-rvest to north-east, and in some cases even were south-east. The situation of Camp Crescent was estimated, by Mr. Colhoun, from observations taken under unfavourable circumstances, to be about latitude $44^{\circ} 21^{\prime} 27^{\prime \prime}$ north, longitude $94^{\circ} 15^{\prime}$ west; so that, during our progress up the St. Peter, we had made but $65^{\prime}$ of westing, and $32^{\prime} 22^{\prime \prime}$ of southing. The river receives in this extent no tributary of any importance; a few small rivulets, not exceeding ten or twelve in number, enter it occasionally from the right or left bank. Those only which deserve any mention are, Elk, which enters from the right bank, about twenty miles above the fort; and the small rivulet which comes in from the left bank about forty miles above the fort, and which is probably the same as Carver's river; at about twenty-five miles below the 
Crescent, a shallow stream six yards wide enters from the left bank.

In our description of the observations recorded by the party in the canoes, we have included those made upon the nature of the river, \&c. by the land party, and it may suffice to mention that the difficulties which they expericnced were very great, owing to the nature of the country over which they travelled. At times it was so marshy, that they could not proceed without much danger to themselves and their horses; and in one or two instances, the ground was so soft, that they were obliged to construct causeways or bridges, to enable their horses to pass over it. The forests which they traversed, consisted chiefly of maple, white walnut, hickory, oak, elm, ash, linden, (Tilia Americana,) interspersed with grape-vines, \&c. The absence of the black walnut on the St. Peter, and near Fort St. Anthony, was particularly observed. The rosin plant was not seen after leaving Prairie du Chien. The yellow raspberry was abundant in many places and ripe at the time the party passed through the forests. The course of the party was generally in the valley of the St. Peter, not far from, and frequently in sight of, the river, which offered them some fine water scenery, presenting, however, a great degree of sameness; its principal defect is the want of objects to animate the scenes; no buffalo ranging across the prairie, no deer starting through the forests, no birds interrupting the solemn stillness which uniformly reigns over the country; the St. Peter rolls in silence its waters to the Mississippi; where game is scarce, the Indian of course finds no inducement to hunt, and hence the party frequently travelled for whole days, without seeing a living object of any kind. This appeared, however, to be the track of Indians going out on their hunts, and accordingly 
traces were occasionally observed upon trees. In such places the trees were generally barked to a proper height; in one instance, four adjoining trees bore the representation of an Indian with wings, painted with red earth; a number of transverse lines were also drawn across the tree. This design was intended to convey the information that the Redwing chief had passed in that direction with a party, the strength of which was designated by the number of transverse streaks. From the numerous tumuli observed along the river, they were confirmed in the belief, that this scarcity of game has not always prevailed in this part of the country, but that this stream was once inhabited by as extensive a population as can be supported by game alone, in the most favoured regions.

On the 15th of July, the party, reduced in number to twenty-four, left the Crescent. They were provided with twenty-one horses, two of which were disabled. Nine were allotted to the officers and gentlemen of the party; the remaining ten being required as pack-horses to convey the provisions and baggage, the soldiers were all obliged to walk; which, however, as the country was fine prairie, and the days' march short, was not considered a very hard duty. We proceeded across some fine rolling prairies, in a course south of west, for about nine miles, when we saw the remains of Indian habitations; they were deserted. Upon a scaffold, raised eighteen feet above the ground, and situated upon an elevated part of the prairie, the putrefying carcass of an Indian lay exposed to view. It had not been enclosed in a box, but merely shrouded in a blanket. which the wind and atmospheric influence had reduced to tatters. Fifteen horizontal black marks, drawn across one of the posts that supported the scaffold, designated, as we were informed by Renville, that as many scalps had becn 
oflered in sacrifice to the deceased, by those who danced at the funeral.

Our guides told us, that the mouth of the Terre Bleue River was about six leagues to the south-east of this spot. This is the principal tributary of the St. Peter, and is said to furnish about two-thirds as much water as the main branch of the river which retains the name of St. Peter. It enters from the right bank, and rises in the "Cotean des Prairies," a highland that stretches in a northerly direction between the Missouri and the St. Peter, and of which we shall have occasion to speak hereafter. By the Dacotas it is called Mảkâtồ 'ôsả Watapa, which signifies " the river where blue earth is gathered." We never were nearer to this river than at this place, and we regretted that circumstances prevented our visiting it in order to acquire some knowledge of its character. We were unsuccessful in our attempts to obtain some of the blue earth from the Indians, an object which appeared to us of some importance, in order to determine its composition by analysis. It is evident that this is the same thing that was worked by le Sueur at the close of the 17th century, for a copper ore. From its colour, we are inclined to consider it as more probably a phosphate of iron; but we have had no means of ascertaining its nature. Our guides informed us, that had we proceeded in our canoes it would have required two days to reach the mouth of the Blue Earth river, on account of the great bend which the river makes at the Crescent, but by the route which we pursued we avoided the bend. It has been stated, that the locality of this blue earth, as well as that of the red stone used for pipes, were considered as neutral grounds, where the different nations of Indians would meet and collect these substances without apprebension of being attacked; but we have not heard this re- 
port confirmed. 'The mouth of the T3lue Farth river is the chief residence of a tribe of the Dacotas, who cali themselves the Miakechake's's, and who are generally known by the traders by the name of Sisitons. They are a warilie and powerful band, and at that time were considered as unfriendly to the Americans on account of the government's having arrested, and sent to St. Louis for trial, one of their tribe who had killed a white man. It was chicfly from them that hostilities had been apprehended, and the force which we had taken at Fort St. Anthony was intended to protect the party against an attack from them; but in order to evince a friendly disposition on the part of our government, Major Taliaferro had intended to hold a council with them at the same time. The news of their being dispersed on their summer hunts, was the principal reason which induced Major Long to desist from his intention of visitirg the mouth of the Terre Bleue, and which determined him to order back part of our escort.

In the evening, the party encamped on the bank of a small pool, which forms one of a group of ponds, dignified with the appellation of the Swan Lakes, on account of the abundance of these birds said to exist in their neighbourhood. The Indian name is Mâñhẩ tânkâ ôtâ mêndà, which signifies the lake of the many large birds. Observations were made by $\mathrm{Mr}$. Colhoun to determine the longitude of this place; although taken at a time when the sun was very low, they served to correct the observations made at the Crescent. These lakes are more properly marshes, the quantity of water in them varying according to the seasons. We had passed several of them during the day; in one of these marshes our pack-horses were several times exposed to much difficulty; and the mule that carried the biscuit having stumbled, part of our provisions were wet 
and damaged. Proceeding the next day on our course, we struck the St. Peter about noon, and found its current very rapid, but its size reduced to nearly one-half of that which it presented at the Crescent. This confirmed the report of our guides, that the Terre Bleue almost equals the St. Peter in the quantity of its waters. We had been able to trace the course of the river during the morning, by the line of roods which skirts it, and by the bluffs which border upon its right bank, rising to a height of from sixty to eighty feet; on the left bank, the bluffs are neither so high, nor so abrupt. The country, hovever, almost every where discovers its horizontal stratification by the steep acclivities which it forms even in the prairies; the country presenting rather the appearance of steppes than of the rounded swells which generally characterize prairie land. At a small distance from our course, we observed horizontal ledges of rock, which we were inclined to consider as the limestone that overlays the sandstone, Animals of every kind still continued very scarce. A garter-snake was killed near Swan Lake, upon which our guides took occasion to inform us that the rattlesnake had sometimes been found near these lakes, but never to the north of them; this appearing to be their northernmost limit in this direction. The botany of the country was diversified by the reappearance of the Gerardria, a plant which we had not seen since leaving Chicago. Near Swan Lake two elevations were observed, which appeared to be artificial tumuli. Some depressions were also seen, and these were by Renville called forts, but by whom they were scooped out, if indeed they be artificial, he could not inform us.

We crossed the St. Peter, at noon, immediately above a ripple; our horses sank to their girths in the water; one 
mile further, we passed a small stream about fifteen yards wide, and cighteen inches deep, having a white sandy bot$10 \mathrm{~m}$; it is ciesignated by the name of the Riviere aux Lietrds, (Cottonwood, ${ }^{*}$ ) from the abundance of this tree on its banks; by the Indians it is called Warboju Watapa. A bicody fray is stated to have occurred at the junction of the Aux Liards and St. Peter; it arose between two tribes of Sioux, who met there with traders. The latier having furnished them with liquor, the Indians drank to intoxication, quarrelled among themselves, and lilled seven of their number. In traveling through an Indian country, many places are pointed out that have acquired a similar melancholy celebrity, and that tend to confirm the traveller in the conviction of the heavy responsibility which attaches to those who have introduced, and still persist in carrying, liquor among the Indians.

Our journey during the afternoon was continued along the valley of the St. Peter, which was observed to be from one to one and a half mile wide. The adjacent prairie is elevated about eighty fect above the level of the river. $A$ feature which struck us was the abundance of fragments of primitive rocks which were strewed in this valley. They were for the most part deeply imberdled in the ground, and bore but few traces of attrition; their bulk was very large. For a while we doubted whether we were not treading upon the crest of a formation of primitive rocks, which pierced through the superincumbent formations, but a close observation evinced such a confusion and diversity in the nature of the primitive blocks, as well as such signs of fric-. tion, as satisfied us that these were out of place, still they appeared to warrant the geologist in his precliction, tha:

- Populus angulata. 
the party was approaching to a primitive formation, and that certainly the valley of the St. Peter had been one of the channels through which the primitive boulders had been removed from their original site. This assertion was fully substantiated two days afterwards by the discocovery of the primitive rocks in situ. A very considerable swell between the river and the right bank of the valley, was supposed to be formed by the primitive rocks rising to a greater level than usual. If it be occasioned by an accumulation of fragments and boulders, as the nature of its surface might lead to believe, it is a very interesting feature in the valley.

We passed soon after two Indian lodges, in one of which was the chief Wamendetanka, (War Eagle, generally known by the name of the Black Dog. He rules over the small village of Oanoska, situated near the mouth of the St. Peter. He is not a man of note, neither is he acknorvledged as an independent chicf, but being the head of an extensive family, he separated from his tribe some years ago; he leads about forty warriors. We stopped but a short time at his lodge, to exchange a few words with him; we admired much the appearance of his sons and daughters, who are tall, graceful, and well-formed. He is about fifty years of age, and has much dignity in his appearance.

The journey of the 1sth of July, being across the prairie, offered but little interest. The monotony of a prairie country always impresses the traveller with a melancholy, which the sight of water, woods, \&c. cannot fail to remove. During that day we enjoyed no view of the river, and the great scarcity of springs, and wood for cooking, made the travelling uncomfortable; to these we must add a temperature of about $94^{\circ}$, exhibited by the thermometer when in the shade, and protected against all radiation of heat. But the VOL. I. 
greatcst annoyance, which we had to encounter, was the mosquetoe, which arose in such swarms, as to prove a more serious evil than can be imagined by those who have not experienced it. Wenever were tormented at any period of our journey, more than when travelling in the vicinity of the St. Peter. The mosquetoes generally rose all of a sudden about the setting of the sun. Their appearance was so instantaneous, that we had no time to prepare ourselves against them; whenever wc had the grod fortune to encamp pierious to their sallying from their hiding places, our great object was to complete our evening meal, before they commenced their attack, for this we found ourselves unable to resist; and we have not unfrequently been so much annoyed by these insects, as to be obliged to relinquish an unfinished supper, or to throw away a cup of tea, which we could not enjoy, while stung on all sides by countless numbers of mosquetoes. When a high wind reduced their numbers, we found some relief from remaining in a dense cloud of smoke; but even this prored of no avail, when, from the calmness or heat of the atmosphere, their numbers were undiminished. In such cases, our only alternative was to endure their stings, or to smother under the weight of a blanket in which we wrapped ourselves up, covering our faces, hands, \&c. 'T'o protect our feet and legs, we were obliged to lie with our boots on. The annoyance continued until sometime after sunrise, when the increasing heat of the day, drove them back into their recesses. The sleepless nights which we frequently passed, when exposed to this torment, rendered this part of our journey the most fatiguing. Our horses fared even worse, for they were exposed like us, during the night, to the sting of the mosquetoe, and during the day the big horseny proved equally noxious. 
The soil of the prairies is not uniform in quality; in some instances it was remarkably fine, and of an intense black colour; the grass, consequently, grew to a considerable size, was luxuriant, and of a rich green hue. In other parts the soil is sandy, grayish, and appears to be of an inferior quality; its produce then presents a similar inferiority; the blades of grass are scattered, short, of a yellowish and sickly aspect. The earth appears dry, and scorched with the heat of the sun.

The party had frequent opportunities of remarking the difficulty which exists, to determine with accuracy the nature or size of objects seen at a distance. Sand-hill cranes, seen on the prairie, were by some of the company mistaken for ellks.

Among the birds observed on the prairie, besides the sandhill crane, are the reed-bird, black-bird, yellow-headed black-bird, $\dagger$ the black-breasted tern; $\ddagger$ the last of which was very abundant. Mr. Say shot the female of the Mergus cucullatus, and a bluc-winged teal. Among the reptiles, besides the common garter-snake, $\$$ there was one with lateral red spots. \| A coluber, like the melanoleucus, but spotted, and similar to that found on the Missouri, was killed on these prairies. In several of the marshes, the huts of the muskrat were found very abundant. The herbarium was enriched by the addition of a beautiful specimen of the Lilium Philadelphicum, which was still seen flowering, though it had nearly ceased to bloom. Another great ornament of the prairies is the Lilium Superbum. The Gerardria was still occasionally seen. This plant is, as we were informed, considered by the Indians to be a specific against the

* Oriolus, [Zanthornus, Cuvier,] phoniceus.

† Oriolus, [Zanthornus, Cuvier,] icterocephalus.

*. Sterna.

$\$$ Coluber ordinatus.

If Coluber parietalis. 
bite of the rattlesnake; the root is scraped and the scrapings applied to the wound; it is said that if used upon a recent wound, a single application will suffice. The boulders, which are so common in the valley of the St. Peter, are but seldom seen on the prairies.

After proceeding another half day on the prairie, the party found itself on the banks of the Chảnshatyatpé watapa, or the stream of the "tree painted red." This is a beautiful rivulet, which was about eight yards wide where we crossed it. It runs in a wide and romantic valley. The bluffs which rise on both sides, are formed of a fine white sandstone. We stopped for a few moments on the edge of the bank, previous to descending into the valley, to enjoy the beautiful and refreshing scenery which offered itself to our view, and which formed a pleasing contrast with the burned and blasted appearance of the prairie. The junction of the valley of the St. Peter with that of its tributary, about two miles below the place where we stood, occasioned an expansion of both valleys at that spot. The beautiful and diversified vegetation, springing luxuriantly on the banks of both streams, the rapid current of the waters rushing to one common point, formed a landscape, which, at that time, appeared to us as smiling and as beautiful as any we had ever beheld. But it is probable that much of its charms arose from the contrast which it presented, with the wearisome views of the boundless prairies. Perhaps, also, we found ourselves in better spirits to enjoy the scenery, from perceiving, near these banks, the first trace of the buffalo, whence we drew prospects of a speedy change in our fare, together with hopes of soon sharing in the sports of an active and interesting chase. Though narrow, the Redwood, whose course is a long one, has its sources in the Coteau des Prairies. Red pipestone is said 
to exist on its banks, at three days' journey from its source.

At the confluence of these two valleys, a very interesting fragment of rock was observed; it was evidently out of place; its mass was enormous; it was of an irregular hemispherical form, about forty or fifty feet in circumference; it had been cleft, as we thought, by lightning. The rock was blackened, and a fer bushes and trees near it, bore signs of having been on fire. The conflagration does not appear to have spread to a distance; and from its situation, the fire could scarcely have been made by a traveller. We searched in vain, during the short time that we stopped near it, for traces of fusion upon the rock. This mass is granitic, and presents very distinctly the appearance of a formation in concentric shales. Rocks were observed at some distance which, from their white colour, were presumed to be sandstone. Above the junction of the rivulet with the St. Peter, a rapid occurs in the river, called Patterson's rapid. We were too far to see it, but it is not very considerable. We were, from observations made higher up on the river, induced to consider the rocks which occasion it, as primitive.

On the evening of the 18th of July, we encamped on the banks of the river. When descending into the valley from the prairie, with a view to select a suitable spot for our evening's camp, our attention was suddenly called to the new features which it displayed. High rocks of a rugged aspect arose in an insulated manner in the midst of the widened valley, through which the St. Peter winds its way. We improved the rest of the afternoon in examining them, and experienced no little satisfaction in finding them to be primitive rocks in situ. The pleasure we experienced sprang not from the mere associations of home, 
connected with the view of a primitive formation which we had not seen since the first five days of our journey; but it resulted also in a great measure from the certainty that we had at last arrived at what we had long been looking for in vain. We had traced those scattering boulders, which lay insulated in the prairies, from the banks of the Muskingum to this place. We had seen them gradually increasing in size and number, and presenting fewer signs of attrition, as we advanced further on our journey. Two days before, their number, size, and features, had induced the geologist of the party to predict our speedy approach to the primitive formations, and it was a pleasing confirmation of his opinions to find that these rocks had really been seen in situ, within thirty miles, in a straight line, of the place where he had made this assertion. The character of these rocks was examined with care, and found very curious. It seemed as if four simple minerals, quartz, feldspar, mica, and amphibole, had united here to produce almost all the varieties of combination which can arise from the association of two or more of these minerals; and these combinations were in such immediate contact, that the same fragment might, as we viewed one or the other end of it, be referred to different rocks; while in some places granite was seen perfectly well characterized, varying from the fine to the coarse-grained; in others, a gneiss, mica slate, greisen, (quartz and mica,) compact feldspar, (Weisstein of Werner,) sienite, greenstone, and the sienite with addition of quartz, forming the amphibolic granite of D'Aubuisson, were equally well characterized. The only rock composed by the union of two of these principles which we did not observe, but which may perhaps exist there, is the graphic granite, (Pegmatite, Haüy.) These rocks are not very extensive; the circumference 
of the largest probably does not exceed one quarter of a mile; they rise to about thirty-five feet above the level of the water. Their form is irregular; their aspect rugged and barren compared with the fertile bottom of the valley; their general colour is of a dark gray; they appear to be the summit or erest of primitive rocks which underlay this valley, and which protrude at this place through the superior strata. As the adjoining prairies are elevated about fifty feet above the level of the river, these primitive rocks are observable only in the valley; they doubtless constituted at one time a continuous ridge, but have been divided into insulated masses by the corroding action of the stream, whose very circuitous bed winds between them. They extend upon a distance of about six miles in the direction of the valley. After having examined almost every one of these masses, we feel unwilling to decide with certainty, which of the primitive combinations predominates; for the passage of the one into the other is more constant and more sudden than in any other primitive formation that has ever come under our notice. Indeed we know of none with which to compare it, except it be that which we observed at a subsequent period of the expedition, between Lake Winnepeek and the Lake of the Woods; but even there the features were somewbat different, for they were on a larger scale. The passages, which we there observed, were sometimes to be traced only upon large masses; whereas on the St. Peter, it would have been difficult to break off a fragment of a cubic foot in size presenting an uniform character of composition. It is, however, probable, as far as our observations extended, that granite is the predominating rock. These masses bear very evident signs of a crystalline origin, but the process must have been a confuser one. Tourmaline is found disseminated 
throughout the rock, yet in no great abundance. In one or two spots where the mass assumed a more slaty appearance than in other places, a faint tendency to a stratification, directed from north-north-east to south-south-west, with a dip towards the south, was observed. Viewing the insulated masses from the prairie, they appeared to be directed in a transverse line through the valley, and in a north-easterly course, so that this may be the remains of a dike which existed across the valley, but which was finally broken. This observation was, however, a partial one, and it would be improper to attach much weight to it. When calling the attention of our guide to the difference between these rocks and those observed below, he appeared to have been aware of it himself, and stated that rocks similar to these extended down the valley, to about four miles below Redwood rivulet; it was partly from this circumstance that we inferred that Patterson's rapids were probably formed by a bar of these rocks rising across the bed of the river. 'This appeared to us to be the more probable from the circumstance that a rapid, known by the name of the Little Falls, occurs just above the place of our encampment of the 18 th, and that it is occasioned by a ledge of granitic rocks, over which the river passes at this place. In the examination of this spot two points appeared to us chiefly to deserve our attention, in order to avoid all source of error; the first was to ascertain that the rocks were really in situ; the second, that they were primitive and crystalline, not conglomerated or regenerated rocks, such as are sometimes observed. But upon these two points we think that not the least doubt can be entertained. The immense mass of these insulated rocks, the uniform height to which they attain, the uniform direction in which they lie, prove them to be in place; while an attentive in- 
sjection of their nature shows them to be really crystalline. There is a gradual though rapid passage of the granite into the sicnite, which proves them to be of contemporancous formation, and which precludes the idea that the rock is formed by the union of fragments of granite, sienite, \&c. cemented together.

The discovery of this granitic formation here appeared to us the more interesting, that its small extent might easily have prevented us from observing it, had not chance brought us to the river at that place; for if we had been travelling on the prairie, within half a mile of the edge of the bank, the greater height of the bluff would have concealed these rocky islands from our view. We feel therefore unable to decide whether they do not recur at some of the other bends of the river, which we avoided; yet from the character of the stream itself, we doubt it; for we find that as soon as these rocks protrude into the valley, they occasion rapids and falls in the river, while otherwise its course is smooth. Had we not scen the "Little rapids," which we passed on the 11th, we might have been induced to consider them as resulting from the appearance at the surface of primitive rocks, but having examined with care the sandstone rocks, by which they are produced, and having ascertained that no other rapids are found in the St. Peter, between these and the Patterson falls, we are induced to believe that this is the only place where the granite may be seen in situ. In attempting to connect this primitive formation with those observed elserwhere, we find that it lies in a direction about west-south-ivest, at a distance probably not exceeding eighty miles, of the "granitic and hornblende rocks," which Mr. Schoolcraft states as having scen, "occasionally rising in rugeger peaks and beds," on the

VoL. I. 
Nississippi.* We feel, however, disposed to consider all this section of our country as underlaid with this granite, and we entertain but little doubt of its identity with the sienitic sranite, observed at a later period of our journey, and which we first struck near Fort Alexander, at the? mouth of Winnepeek river.

The latitude of our encampment on the banks of the St. Peter, that evening, was determined by observations, to be $44^{\circ} 41^{\prime} 26^{\prime \prime}$ north. The variation of the compass at this place was $12^{\circ} 21^{\prime} 20^{\prime \prime}$ east.

From the interesting features which the valley displayed at this spot, the geologist felt desirous that the party should ascend along the banks of the river, with a view to examine these granitic masses, should they recur; but this was deemed impracticable, on account of the length of time which would be consumed in following the bends of the river. The reports which we had previously received of the abundance of game, had not been confirmed; we had, on the contrary, found none at all, and our stores were wasting away too fast to permit any delay. It was then proposed to divide the party, and while the main body proceeded with the necessary expedition towards the trading establishments at the head of the river, to allow the greologist, with one or two companions, to continue his route in the valley. But this Major Long did not deem prudent, for in the present dissatisfied disposition of the Sisitons, the dirision of the party must necessarily expose it to he cut off by them, should they fall in with it. The regret which this occasioned was, however, dissipated, on observing that the primitive rocks did not continue long in the vallcy; for having been allowed to travel along the

* Schoolcraft's Narrative, ut supra, p. 288. 
banks of the river for half a day, Mr. Keating saw the last of them, at about four miles above the little falls; and he was assured by his guide that they did not recur for a considerable distance. We had, nevertheless, an opportunity of seeing from a distance, in the bed of the river, a rocky island, which appeared to us to bear the character of the primitive rocks near Patterson's rapids. Our guides insisted that it was a sandstone. We have generally found them to be such accurate observers of natural objects, that we wished to visit the rock, and see how far their reports could be depended upon, but that would have required several hours; a waste of time which it was thought the object did not warrant. In the evening we again observed the primitive rocks in the valley, and encamped upon one of these knolls; it was composed of a rock partaking alternately of the characters of micaslate and gneiss which appeared stratified nearly east and west. The strata being almost vertical. This knoll was so small, that we could not presume from the direction of its strata, to draw conclusions as to that of the rock in general.

The occurrence of these primitive knobs disturbs the current of the river, and renders the navigatiois difficult and hazardous. Five miles below the encampment of the 19 th, there is a place where the boats and their loads are carried for the distance of a mile; from which circumstance the place is called the Grand Portage. By this portage the canoes avoid thirteen rapids; these with twenty-six other rapids, constitute all the obstructions to the navigation of the river, from its source to its mouth. In a good stage of the waters, there arc, however, but two portages, of which this is one. Among the tributaries passed on that day, only one de, serves to be mentioned; it is called the Pojthatût Zézé Watapan, the yellow medicine. It is about the same size as 
the Redwood, and rises, in like manner, at the base of the Coteau des Prairies. Nearly opposite to it a small stream falls in; the Indians call it the Chátâuâ, (that hutches sparrowhawhs,) the traders term it L'Eau de Vie. On our map we have retained the term Fpervier, which, being in use among some of the traders, and intelligible both to French and English travellers, appears likely to prevail.

While riding across the prairic that day, we were met by two Indians, who ran towards us with great speed. 'They proved very friendly in their disposition, and informed us, that on the preceding day, they had lilled a buffalo bull in that vicinity, and that the Indians on Lake 'Travers had already killed many, the buffalo being unusually abundant that season. This news was the more gratifying to the party, that they had been for the last fow days on short allowance. Fiaving informed the Indians of the spot where we proposed to encamp, they came to it in the evening with their families, and pitched their tents near ours; they then offered us a feast, which we of course accepted, and at which we partook of the buffalo meat, that had been cut into long and thin slices, about one-eighth of an inch thick, eight inches wide, and eighteen long. These had been jerked in the sun, and were subsequently boiled without salt, and served out to us in wooden dishes. It was tough and tasteless, and disappointed those gentlemen of the party who had never eaten of the buffalo meat, and who had heard it highly extolled; this disappointment arose, however, from the circumstance of its being jerkecl, instead of fresh meat. What remained of the feast was: according to the Indian usage, our property, and we thercfore had it conveyed to our tents. The feast was ushered in with the usual ceremonies of shaking hands, smoling, Sic. 
The St. Peter dwindles into a very small stream, probably not more than fiftecn or twenty yards wide in any part, above Patterson's rapids. It is fordable every where. The valley presents a fine rich soil, rather swampy in places, and covered with high grass and wild rice; it is often woody. Wherever the primitive rocks are found, they are bare. The trecs consist principally of cotton wood and ash. In the prairies, Mr. Say found the spotted frog, (Rana halecina of Kalm and Daudin,) figured by Catesby. It was very plentiful near the marshes. The young whippoorvill was found at that time, nearly strong enough to fly. The mosquetoes increased in abundance and virulence as we advanced.

A short day's journey brought the party to the Lac qui. 2) arle, which is an expansion of the river about seven and a half miles long, and from one quarter to three quarters of a mile wide. The name of this lake is a translation of the Indian appellation, Mêndà ê a, but whence it has reccived it, we know not. We have not been able to discover or to hear of any remarkable echo in its vicinity, which might have griven rise to it. It is not, we believe, an uncommon name for Indians, and we know of at least one river that has a somewhat analogous appellation; it is the Riviere qui appelle, a tributary of the Assiniboin, and whose Indian name has merely been translated by the traders. Previous to reaching Lake qui parle, we passed two small tributaries of the St. Peter, on the right bank; one of which is called by the traders, Beaver, by the Indians, Watapan intâpâ, which signifies the "river at the head," as they consider the lake to be the head of the St. Peter. Six miles above our encampment of the 19th, a larger -iream, called by some Chippewa river, but by the $\mathrm{Da}_{2}$ cot:rs Meit Wakkin watapan, the river of the spirit banks, 
falls in from the left side. The Mea Wahkan is said to take its rise near the head waters of Red river, with which it interlocks. On Beaver rivulet, the bank, which was high and steep, was found to consist of loose white sand. Near this bank there were seven or eight artificial tumuli, all placed on a straight line except one, which was in advance of the other. On the two largest, which were five feet high, and thirty feet in diameter at the base, recent graves of a kind now much used by the Indians, were observed. In these the corpse is deposited in a very shallow excavation, or more frequently upon the surface of the ground, and stakes placed over it, forming a sort of a roof. These stakes are very necessary to protect the remains of the dead against the rapacity of wolves, who, if they were merely interred, would dig them up. In this case, notwithstanding the great strength of the stakes, the grave had been broken open, and its contents scattered over the ground. The wolves appear to be very abundant in these prairies. We have frequently heard them barking in the night, and occasionally seen them Two young wolves were seen near Beaver rivulet, and easily caught by the soldiers, to whom a reward was offered if they would carry them alive to Mackinaw; but they both made their escape during the night. In the dull monotony of a journey across the prairie, destitute of interest, and uninterrupted by any incident, the canture of these wolves created such a sensation in the yarty, as will not be readily conccived by those, who have not experienced how eagerly man seizes the first oppor1 unity of being relieved from his own thoughts, when he has been left to the uninterrunted exercise of them for a certain length of time.

We spent half a day in the ricinity of Lake qui parle; our tents were pitched on an eminenee near the lower ex- 
tremity of the lake, commanding an extensive prospect, adorned with this beautiful sheet of water. The country, as we adranced, evidently became more elevated, but no hills of any magnitude were visible except the bluffs of rivers and rivulets. The elevation to which they attain, frequently equals, and sometimes exceeds, one hundred feet. The precipices, to which these bluffs give rise, are the boundaries of extensive and undulated plains, destitute of woods; trees are only seen skirting the banks of the water-courses. Above the lake the bluffs diminish in height; those along the valley of the St. Peter not exceeding forty fect; in some cases they disappear, and gentle slopes blend gradually the prairie and the valley of the river. At the upper end of the lake, the St. Peter has lost all its characters; it is a rivulet of from twenty to thirty feet wide; its bed is very much obstructed with high grass and wild rice; its waters are almost stagnant. Five leagues above this, a brook from the right bank joins with the St. Peter; this is called the IIrà Wâhkan, or Spirit Mountain, from the name of a hill near which it rises. The primitive rocks are again seen in place, scattered here and there across the valley; one of these was remarkable for the beauty of its feldspar, which is very lamellar; it has an easy cleavage, and is intermixed with quartz, giving it almost the appearance of a graphic granite. As we advanced, the rocks assumed a more decided character, and were found to be principally either a common or a sienitic granite. Besides those in place, vast numbers of fragments of primitive rocks, presenting little or no alteration, lie scattered in every direction, and attest that this has been the seat of a great destruction. An Indian family were met near the banks of the river, who stated that they had descended it in order to ascertain the prospects of the ensu- 
ing harvest of wild rice, and informed us that they were very promising; the grain, they thought, would be ripe in the middle of August; the weather was, in fact, very favourable to its growth, the temperature having licpt up for the last few days at near $90^{\circ}$. We were likewise informed by them, that an inroad had been made by the lower Sisitons upon the lands of the Sauks on the Des Moines river, and that, not meeting with their encmies, they had attacked the Iawas, killed a number, and taken many prisoners.

It is interesting, as we proceed, to find that the same devotional spirit which we observed below still exists. Many rocks are used as consecrated spots, at which the Indian pauses to offer a sacrifice to the ruling Spirits. A very large block, covered with circles, crescents and crosses, designed with red paint, was considered sacred to the heavenly bodies, and these marks were held to be designations of the sun, moon, and stars. The party were likewise occasionally gladdened with a view of fresh tracks of the buffalo.

On the $22 \mathrm{~d}$, we reached another, and the last, expansion of the river. It is also improperly called a lake; by the Indians it is termed E'âtikẻkả, which has been interpreted "Lac des Grosses Roches," Big Stone Lake. Our view to the west was this day bounded by an extensive ridge or swell in the prairies, known by the name of the "Coteau des Prairies." It is distant from our course about twenty or thirty miles; its height above the level of the St. Peter is probably not short of one thousand fect. According to the best information which we have obtained, this ridge commences about the 49th parallel of north latitude, and between the 9Sth and 99th degrees of west longitude, from Greenwich. It procecds in a direction nearly south-south- 
sast, passes east of the group of small lakes called Devil Lake, divides the tributaries of the st. Peter from those of the Missouri, and extends southerly as far as the head of the Blue Earth, where it gradually widens and sinks to the level of the surrounding country.

A sccond ridge or Coteau des Prairies is said to run in a direction nearly parallel to that which we have just described. It commences at the southern bend of Mouse river, near the 43th parallel of latitude, and procceds, in a course nearly south-east, for about cighty miles, when it turns to the west of south, and continues probably beyond the 44 th, where it likewise sinks and disappears. In the valley hetween these two ridges, the Rivicre de Jacques, or James River, runs and empties itself into the Missouri about the $43 \mathrm{~d}$ degree of latitude. Thus the $\mathrm{Co}$ teau des Prairics may probably be considered as changing the course of the Missouri, above the Mandan villages, from an easterly to a southerly direction, and as keeping it in that direction for nearly three hundred miles, when the river reassumes a course east of south, which it lieeps until it unites with the Mississippi. It is to the vicinity of the Coteau to the St. Pcter, on the one side, and of the Mississippi, on the other, that we are to attribute the small size of the tributaries of the St. Peter. In fact, they are mere brools conveying the waters on the east side of the ridge; but, probably, about the spring of the year, they are much swollen by the thawing of the snow and ice upon the ridge; it is in this manner that we may account for the water-marks found along the bluffs which enclose their ${ }^{\circ}$ comparatively large valleys.

Its distance from our course prevented us from visiting the Cotean, which we should otherwise have done. It was intended that MI. Keating should examine this remarka.

Vor.. $\mathrm{I}$. 
ble feature in the country, in order to ascertain what its geological characters are, but as we were generally informed that no rocks are seen at its surface, that it presents an uniformly smooth prairie-like appearance, the ascent being gradual and easy on both sides, and as it would have taken three days to go to its summit and return, this excursion was not made.

The Coteau des Prairies may truly be considered as the dividing ridge between the tributaries of the Mississippi and those of the Missouri. It is probably formed by the clevation of the granitic or other primitive rocks, above the usual lerel of the prairies. These may have been corered in a mantle-formed manner by the secondary and alluvial rocks, so as to be entirely concealed from view, and to be made to assume the general features of prairie land. We cannot, howerer, resist the belief, that a geologist who would follow it, in its whole course from the Assiniboin to the Blue Earth, would be rewarded by the discovery of the granitic formations, if not along the whole of its crest, at least in some of the ravines which head near it, and in which perhaps a superposition of secondary rocks might be observed.

After having left the Big Stone Lake, we crossed a brook which retains the name of the St. Peter, but which cannot be considered as part of that river; the St. Peter may, in fact, be said to commence in Big Stone Lake, and this to be but a small tributary from the Coteau des Prairies; it was less than seven yards wide. This stream soon leaves the main valley and turns to the west, where a lateral trench in the prairic, known by the name of a "Coulée," grives it a passage. Had we risited the Coteau, we should have ascended this Coulée, to trace the stream to its source. It divides itself, as we are informed, into two branches; one of which runs in a dircction west by south. 
for about twelve miles. The source of the northern and larger branch is in Polecat Lake, about twice that distance, and bearing from the point at which it leaves the main valley, about west by north. The length of the stream, following all its windings, is about forty or fifty miles. Polecat Lake, whose dimensions are one and a half mile in length by half a mile in breadth, is frequently dry, and the stream often conveys but little water to the Big Stone Lake.

By the route which we travelled, the distance, from the mouth of the St. Peter to the head of Big Stone Lake, is three hundred and twenty-five miles, of which we ascended one hundred and thirty by water. We entertain no doubt that the distance, in a direct line by land, would fall short of two hundred and thirty miles; and that the whole length of the river, including all its bends, does not exceed five hundred miles. The traders, whose estimates almost always exceed the truth, do not ascribe to it a length of more than six hundred miles. How different these observations are from the opinions formerly entertained of this stream, may be judged from the assertion of Breckenridge, that it is a thousand miles long. Other authors allow it twelve hundred miles. Carver states it, on the authority of the Indians, to take its rise in the same neighbourhood as, and within the space of a mile of, the source of the Missouri; he adds that the northern branch rises from a number of lakes near the Shining Mountains. But we can place no dependance upon the information which he gives from second hand, when we find it blended with such fictions as are contained in the following extract. "The river St Pierre, which runs through the territory of the Naudowessies, flows through a most delightful country, abounding with all the necessaries of 
life that grow spontaneously, and with a little cultivation it might be made to produce even the luxuries of life. IVild rice grows here in great abundince, and every part is filled with trees, bending under their loads of fruits, such as plums; grapes, and apples. The meadows are corered with hops and many soris of regetables, while the ground is stored with uscful roots, with angelica, spilienard, and groundnuts as large as hen's corgs." We were not so fortunate as to mect with those apples, plums, anil other good things, which grew spontancously sixty ycars since in the country.

The St. Peter, in our opinion, probably never can be made a commodious stream; for although it flows over gradations, and not upon a slant, yet as these graclations are accumulated into the upper third of the distance between Big Stone Lake and the mouth of the rircr. the expense of rendering it navigable, by damming and locking, would far exceed the importance of the object. The plan would doubtless be found very practicalsle, but the searcity of water during the greater part of the year would render these works unarailing. From considerations upon which it is unnecessary to dwell, and the accuracy of which might be disputed, though they appear to us to lead to correct results, we have estimated the fall in the river, or difierence of level between the Lac qui parle and the mouth of the river, at aboutfifty or sixty feet. According to this estimate, the average fall does not exceed two or three inches per mile.

The river having taken a bend to the west, we confinued our route in what appeared to have been an old water-course, and, within three miles of the Big stone Ialke, found ourselves on the banks of Jake Travers; which discharges its waters by means of Swan or Sioux 
river into the Red river of Lake Winnepeek, whose waters, as is well known, flow towards Hudson's Bay. The space between Lakes Travers and Big' Stone, is but very Iittle elevated above the lerel of both these lakes; and the water has been known, in times of flood, to rise and cover the intermediate ground, so as to unite the two lakes. In fact, both these bodies of water are in the same valley; and it is within the recollection of some persons, now in the country, that a boat once floated from Lake Travers into the Sl. Peter. Thus, therefore, this spot offers us one of those interesting phænomena, which we have already alluded to, but which are no where perhaps so apparent as they are in this place. Here we behold the waters of two mighty streams, one of which empties itself into Hudson's Bay at the 57 th parallel of north latitude, and the other into the Gulf of Mexico, in latitude $29^{\circ}$, rising in the same valley within three miles of each other, and even in some cases offering a direct natural navigation from one into the other. We seek in vain for those dividing ridges which topographers and hydrographers are wont to represent upon their maps in all such cases, and we find a strong confirmation of that beautiful observation of a modern traveller, that "it is a false application of the principles of hydrography, when geographers attempt to determine the chains of mountains, in countries of which they suppose they know the course of rivers. They suppose that two great basins of water can only be separated by great elevations, or that a considerable river can only change its direction, where a group of mountains opposes its course; they forget, that frequently, either on account of the naiure of the rocks, or on account of the inclination of the strata, the most elevated levels give rise to no river, while 
the sources of the most considerable rivers are distant lion the high chains of mountains." *

The country which extends between the forty-fifth and forty-eighth parallels of latitude, and between the ninetythird and ninety-seventh of longitude, presents perhaps an cxample of the interlockage of the sources of rivers, which few, if any other spot on the surface of the earth, can equal. Here, no high ridge extends to divide the sources of three of the largest streams that are known. The mighty Mississippi and many of its tributaries run from the same lakes or swamps, which supply the rvaters of Nelson's river and of the St. Lawrence. This limited tract of country includes the head of the Sioux river, and Red fork of Red river, of the grand fork of Rainy Lake river, of the St. Louis river of Lake Superior, of Rum river, the Mississippi proper, the Riviere de Corbeau, and the St. Peter. The Indian and the trader constantly pass in their canoes, from one to another of these rivulets, and without meeting with half the difficulties which they experience lower down upon the same streams, when sivelled to the size of mighty rivers, for in fact the whole of that country is an immense swamp. Carver, who states this important feature of the country, destroys all the value of his information, by placing in the same district, the sources of the Oregan, or Great River of the West.

In tracing the general aspect of the country, of its ridges and streams, we have omitted the little incidents which attended our progress from Lake qui parle to Lalie Travers, and although the trifling adventures, which attend a travelling party, lose all their importance, when compared to

* Introduction to "flumboldt's Political Essay of the Fingdom of New Spain, translated by John Black, London, 1811," page Ixxxri. 
the constant and invariable features of the natural scenery, yet as this part of our route was more diversified by incident than any that had preceded it, we may be permitted to dwell upon it for a moment. While travelling over the prairie which borders upon that part of the St. Peter, that connects Lake qui parle with Big Stone Lake, our attention was aroused by the sight of what appeared to be buffaloes chased across the prairie. They, however, soon proved to be Indians; their number, at first limited to two, gradually increased to near one hundred; they were seen rising from every part of the prairie, and after those in the advance had reconnoitred us, and made signals that we were friends, by discharging their guns, they all came running towards us, and in a few minutes we found ourselves surrounded by a numerous band. They had at first been apprehensive that we might be enemies, and this was the cause of the different manœuvres which they made previous to discharging their guns. The effect of these guns, fired upon the prairie in every direction, and by each, as soon as he had acquired the requisite degree of certainty that the strangers were friends, was really very beautiful. As they approached, we had an opportunity of observing that these Indians were good-looking and straight; none were large, nor were any remarkable for the symmetry of their forms. They were, for the greater part, destitute of clothing, except the breechcloth, which most of them wore. A few, however, and these adults, had divested themselves of this almost indispensable article of dress. We were indeed surprised to see some old men among them quite naked, and no notice appeared to be taken of it by the others. Some of them, and particularly the young men, were dressed with care and ostentation; they wore looking-glasses suspended to their gar. ments. Others had papers of pins, purchased from the tra- 
ders, as olnaments. We observed that one, who appearcei to be a man of some note among them, had a livesparrowharwk on his head, by way of distinction; this man wore also a buffalo robe, on which eight bear tracks were painted. Some of them were mounted on horseback, and were constantly drumming upon the sides of their horses with their heels, being destitute both of whip and spur. Many of them came and shook hands with us, while the rest were riding all round us in different directions. They belonged, as we were told, to the Wahkpatuatin, one of the tribes of the Dacotas. Their chief being absent, the principal man among them told us that they had thirty loclges of their people at the lower end of the lake, and invited us to visit them, which invitation was accepted. These Indians demonstrated the greatest friendship and satisfaction at seeing us. As we rode towards their lodges, we were met by a large party of squaws and children, who formed a very motley group. These squaws had no ornament, nor did they seem to ralue themselves upon their personal appearance. We observed that both they and the men had very handsome small feet and hands. The moccassins, which they usually wear, prevent their feet from spreading, as is the case with those who walk unrestrained by any kind of shoe. From the use of these, as probably also from the habit of walking with caution, their feet retained a bcautiful arched form. 'The dress of the women consisted of a long wrapper, with short sleeves, of dark calico; this covered them from the shoulders to the waist; a piece of blue broadcloth wound two or three times round the waist, and its end tucked in, extended to the knee. They also wore leggings of blue or scarlet cloth. Their forms were rather clumsy; their waists not very delicate; they exhibited a great breadth of hips. Their motions were not 
graceful, and their walk reminded one of the party of the praise in the song of the modern Greek, as recorded by Dodwcll, "My love wallss about like a goose."

The village, to which they directed us, consisted of thirty skin lodges, situated on a fine meadow on the bank of the lake. Their permanent residence, or at least that which they have occupied as such for the last five years, is on a rocky island, (Big Island,) in the lake, nearly opposite to, and within a quarter of a mile of, their present encampment. Upon the island they cultivate their cornfields, secure against the aggressions of their enemies. They had been lately engaged in hunting buffalo, apparently with much success. The principal man led us to his lodge, wherein a number of the influential men were admitted, the women being excluded; but we observed that they, with the children, went about the lodge, peeping through all the crevices, and not unfrequently raising the skins to observe our motions. They soon brought in a couple of large wooden dishes, filled with pounded buffalo meat boiled, and covered with the marrow of the same animal; of this we partook with great delight; it was the first time that several of the party had tasted the fresh buffalo meat; and it was the first meal made by any of us upon fresh meat, since we had left Fort St. Anthony. During the entertainment, Major Long made known to them the objects of the expedition, at which they appeared very much gratified. As we rose to depart, we were informed that another feast was preparing for us in one of the adjoining tents, of which we were invited to partake. We were too familiar with Indian manners, not to know that the excuse of having just eaten a very hearty meal, would not be considered as sufficient among them; and șo we readily resigned ourselves to the necessity of again testifying our friendly dispo-

Vor. I. 
sition, by doing honour to their meal. In order to save time, we had it brought into the same lodge. It consisted of a white root, somewhat similar in appearance to a small turnip; it is called, by the Dacotas, têpsin, by the French, the "Pomme blanche or Navet de Prairic." It was boiled down into a sort of mush or hominy, and was very much relished by most of the party; had it been seasoned with salt or sugar, it would have been considered delicious. This was held, even by the guides, to be a great treat. As we were rising from this second meal, we were informed that a third one was preparing for us; we begged to decline it, having a considerable distance to travel that afternoon; but we were informed that this would be a great disappointment to him who had prepared the feast, as in order to outdo all others he had killed a dog, which is considered not only as the greatest delicacy, but also as a sacred animal, of which they eat only on great occasions. In order to meet his wishes we deferred our journey for an hour, but the repast not being then prepared, we were compelled to leave the village, to the great and manifest morfication of our third host, and to the no small disappointment of most of our party, who were desirous of tasting of the sacred animal. In order to make a return for the civilities which we had reccived at the hands of the Indians, we informed them that if they would despatch a messenger with us, we should send them, from a neighbouring trader's house, some tobacco, all ours having been lost on the river. They gladly accepted the proposal, and sent two lads with us for it. In the afternoon, we reached a house belonging to the American Fur Company. It is situated about half way up the lake. Mr. Moore, the super-

* Psoralea Esculenta, Nuttall. 
intendant, showed us every attention, and supplied us with as many of the articles which we required, as he could dispose of. In the vicinity of Mr. Moore's house, we saw lamb's quarter, ${ }^{*}$ which was more than seven feet high. This plant was, at that time, almost too old for use, but until then it had proved a very valuable addition, at our meals, to the extremely small ration of biscuit, which at that time was reduced to about one ounce per day for each man. At Mr. Moore's we ate of a very good fish, called the buffalo fish. We had met, on the bluff which commands his house, two Indian lodges, in one of which was Tătảnkả Wéchảchẻtã, (the buffalo man,) an Indian who claims the command of the Wahkpatoans. We had declined his invitation to stay at his lodge in the afternoon, being desirous of reaching $\mathrm{Mr}$. Moore's house as early as possible, but we promised to return about sunset, and he accordingly made all due preparations to receive us. The chief, and his principal men, were in waiting. We entered the skin lodge, and were seated on fine buffalo robes, spread all round; on the fire, which was in the centre of the lodge, two large iron kettles, filled with choicest pieces of buffalo, were placed. When the chief took his seat, he had near him a large pouch or bag, decorated with but little taste, although he seemed to have gathered up all that he could collect in the way of ornament. Among other things, we observed an old and dirty comb. He had, since our first visit, bedawbed his face with white clay. Tatanka Wechacheta is a young man, slender, but well-formed, rather tall, with a wide mouth, large eyes, which, when we saw him, had an unusual expression of ficrceness, from being remarkably bloodshot; otherwise we should judge that his appearance

* Chenopodium album. 
would be prepossessing. Among the many Dacotas with whom we have met, few present any remarkable expression of cunning, still less those dreadful looks which distinguished the Potawatomi partizan, Metea. Their faces are faithful indices to the equanimity of their souls; yet the action of the muscles and the bones of the face are not concealed, as they often are in the white man, by a load of flesh. This, together with his deep sunk eye, renders the Indian capable, on great provocation, of assuming and exhibiting the most terrific passion. On the right of the chief sate one who is held in high veneration by his tribe, being the greatest medicine or magic man among them. His cures are considered as miraculous; thcy are wrought by spells as well as by herbs, with which he is considered to be very conversant. In his countenance it was not difficult to discover a mixed expression of knavery and hypocrisy. Soon after our arrival at the lodge, an Indian entered it, whom it required but little skill in physiognomy, to mark out immediately as a stranger; his complexion was at least one shade darker than that of the Dacotas; his features differed materially; his face was rounder and shorter; his mouth was wider; his eyes had more of the European than native American character; he appeared to be very old; his locks were hoary; his face bore perhaps the character of an old Frenchman, more than of any other nation. We were informed that he was an Assiniboin, who had been made a prisoner many years since. He seemed to be kindly treated, though a sort of butt for the jokes of the Dacotas, whether men, women, or children. After the customary preliminaries of shaking of hands, smoking the pipe of peace, \&c. we proceeded to the feast, which was found excellent. The buffalo meat had been selected with care, the fat and lean judiciously portioned out, the whole 
boiled to a proper degree, and in fine, though our appetites were not stimulated by a long fast, this repast appearto us one of the best of which we had ever partaken. Our hosts were gratified and flattered at the quantity which we ate; the residue of the feast was sent to our soldiers. In this, and every other instance where we have been invited to a feast by the Indians, we observed that they never eat with their guests.

Tatanka Wechacheta is the nephew of a man of considerable distinction among the Wahlspatoan Dacotas. Since the death of his uncle, which took place lately, he has attempted to be considered as his successor; but the former was never duly acknowledged as chief, this title residing in Nunpakea, a man of considerable bravery who, by the influence of his family and of his talents, acquired that dignity, in preference to his first cousins, on the death of their father.

Our host boasted of the many flags and medals which his uncle had obtained from our government, and which were then in his possession; these, and the influence of his great magician, may probably secure to him the dignity to which he aspires, if he has talent enough to uphold it. After the feast was over, our host rose, shook hands with all the gentlemen of our party, then resumed his seat, and delivered a speech, which, at the time, appeared to us very pertinent and interesting. It was delivered with apparent feeling, but not without some hesitation; his gestures were vehement and unmeaning. Having expressed to Renville our satisfaction at the speech, he immediately observed that it expressed too much adulation, and too much whining; had 'Tatanka Wechacheta been the chief that he professed himself to be, his tone would have been more imposing, and 
his style more dignified and decisive. We have preserveù the following very imperfect sketch of this speech :-

"Brothers, The subject, upon which I am to address you, is grievous to me; and this grief is the motive which has thus far prevented me from speaking to you. Since the lamented death of my revered uncle, who died last year, I have been called upon to succeed to him, but as I am not endued with experience to know how to direct myself, I shall follow the advice which $I$ have received from him, and therefore I rejoice at sceing you, and I am gratified by your visit.

"I regret that my followers are now all absent. This is not the season when we the Indians are together; this is our hunting season. In the autumn, we collect in our villages to meet the traders. Had you seen us thus collected, you would have found me at the head of a large and powerful band of men; at present I am alone; still I am pleased to see you.

"Brothers, There are two roads which we the Dacotas usually travel; my uncle trod both these paths. The first led him to the British, far towards the rising sun. From them he received both kindness and honour; they made him many presents, among which were flags and medals. The other road led him to the Americans at St. Louis; this road he subsequently travelled. From them he, in like manner, received flags and medals. These he has bequeathed all to me.

"I should have unfurled my flags at your approach, but I am unacquainted with the customs of your nation, and I am new in the duties of my rank. I am ignorant how to act; but I am desirous of following the advice of $\mathrm{my}$ dying uncle, who bade me remain at peace with the Ame- 
ricans, and always consider them as my friends; and as such I hold you.

"My Friends, I am poor and very destitute; not so was my uncle. But I have as yet followed neither of the roads which he travelled. Since I have been called upon to rule over my people, I have dwelt among them, and have not been able to visit St. Louis, in order to obtain presents of powder and tobacco.

"I have already told you, that my followers are absent. They are hunting to the north; I have left with them my flags; I know not whither you are going; but I presume you may meet with them. They will exhibit to you my flags; and you will know them, for they are those of your nation. I shall send them word of your intention to travel that way, and bid them, if they see you, treat you with becoming respect, assist you, supply you with provisions, and with whatever else you may require.

"My Friends, I am poor, and could not do much; but I have prepared this little feast; you have partaken of it, and it has gratified me. I am young and inexperienced in speaking, but I have done my best. Again, I thank you for your flattering visit." 


\section{CHAP'IER VIII.}

Afecount of the Ducotas or Sioux Indiuns. Theiv divisions into tribes. Their numbers, language, manners and customs. Notice of Wanatun, principal chief of the Yantitoanan tribe. Description of the Columbio. Fur Company's establishment on Lake Travers.

WE have collected together all the information which we have obtained on the subject of the Dacotas. It results, either from our own observations, or from conversations with those able to communicate facts, either at Prairie du Chien, Fort St. Anthony, or Lake Travers. He, who has contributed most to it, is Renville; we are aware that all the information which he has given us cannot be depended upon. He was uneducated, not free from prejudices, not entirely exempt from the superstitions of his mother's countrymen. His opportunities of improvement, but more especially his inquiring mind, had made him sceptical upon many points; still upon some he appeared credulous. We believe it not impossible, that he may sometimes have attempted to give information which he did not possess, or to exaggerate truths into fictions: We, at the time, carefully recorded all that he told us, and have since made use of but such parts as appeared to us correct, endeavouring fo omit all that may have sprung from ignorance, credulity, or a taste for the marvellous.

The Dacotas are a large and powerful nation of Indians distinct in their manners, language, habits, and opinions, from the Chippewas, Sauks, Foxes, and Naheawak or Kil- 
listeno, as well as from all nations of the Algonquin stock. They are likewise unlike the Pawnees and the Minnetarees or Gros Ventres. They inhabit a large district of country which may be comprised within the following limits:From Prairie du Chien on the Mississippi by a curved line extending east of north, and made to include all the eastern tributaries of the Mississippi, to the first branch of Chippewa river; the head waters of that stream being claimed by the Chippewa Indians; thence by a line running west of north to the head of Spirit Lake; thence by a westerly line to the Riviere de Corbeau; thence up that river to its head near Otter-tail Lake; thence by a westerly line to Red River, and down that river to Pembina; thence by a south-westerly line to the east bank of the Missouri near the Mandan villages; thence down the Missouri* to a point probably not far from Soldier's River; thence by a line rumning east of north to Prairie du Chien. This tract includes about seven degrees of latitude, viz. from the $42^{\circ}$ to the $49^{\circ}$, and nine of longirude, viz. from $90^{\circ} 30^{\prime}$ to $99^{\circ}$ $30^{\prime}$. These boundaries, as well as all the subsequent facts which we shall state, do not apply to the Assiniboins, a revolted band of the Dacotas, who separated from them a long time ago, and who reside to the north of the 49th degree of latitude. We will have occasion to recur to them hereafter.

This immense extent of country is inhabited by a nation calling themselves, in their internal relations, the Dảcòtit, which means the allied, but who in their external relations style themselves the Ớchẻntẻ Shâkơañn, which signifies the nation of seven, (council,) fires. This refers to the fol-

* According to Lewis and Clarke, they hunt on both banks of the Missouri and its tributaries, from the $4.3 \mathrm{~d}$ to the 47 th degree of latitude, (vol. I. p. 61.)

VoL. I. 
lowing division which formerly prevailed among them, viz:-

1. Mencle Wahkan toan, or people of the Spirit Lake.

2. Wahkpa toan, or people of the Leaves.

3. Sisi toan, or Mia Kechakesa.

4. Yank toan an, or Fern leaves.

5. Yank toan, or descended from the Fern leaves.

6. Ti toan, or Braggers.

7. Wahkpako toan, or the people that shoot at leaves.

These form two great divisions, which have been distinguished by the traders into the names of Gens du Lac, and Gens du Large. Those that resided about Spirit Lake, and who are now principally found along the banks of the Mississippi; and those that rove in the prairies; these may be considered as including all the six last tribes.

All the Dacotas speak the same language; yet some distinctions of the nature of dialects appear to prevail in some words, as spoken by the roving or by the stationary Indians. From the circumstance of these differences being: trifling, we are led to believe, that the seven tribes were originally one, and that the name of Dacota, or allied, must not be considered as implying an union or amalgamation of different nations. We hope we shall not be accused of indulging in a fanciful comparison, when we observe that we see, in the use of this word by them, the same meaning as it has with us; probably they sprung from one common root, divided into tribes according to their local distribution upon the surface of the country, and then, speaking the same language, and having the same enemies, they found it convenient to unite in one confederacy for their mutual safety. We do not, however, profess to have a sufficient acquaintance with their language, or with philology in general, to decide the question. Perhaps one 
skilled in this science could discover in their language a combination of several originally distinct tongues. If such ever existed, all recollection of it has been effaced among them.

To ascertain the number of any Indian tribe has always been considered one of the greatest desiderata, but at the same time one of very difficult attainment. The numbers of this nation have been variously stated by different travellers. We have had no opportunity of forming any opinion of our own on this subject; but they have been represented to us by all who knew them as extremely numerous. We have already stated, in another place, that we had seen lodges large enough to hold fifty inhabitants. We have likewise to observe, that they chiefly subsist upon the buffalo, an animal which exists in herds* of tens of thousands on the prairies between the Missouri and Mississippi, and which, within a few years past, was extremely abundant east of the Mississippi ; from this it may be argued, that the means of subsistence far exceed the consumption of a much larger population than has ever been ascribed to the Dacotas. It must likewise be remembered, that it is a characteristic of the Indian never to destroy more than he can consume; in this, differing much from the white hunter, who will frequently kill a buffalo for its tongue or its marrow bones, leaving the rest of the animal as a prey to the wolves. In the destruction of the buffalo, the white man cannot even plead the inducements of trade, since a great many are killed whose hides are never turned to use. With these observations we will offer a census of the population of the Dacotas, as furnished to us by Renville, re-

* The term band, as applied to a herd of buffalo, has almost become technical, being the only one in use in the west. It is derived from the French term bande. 
marking, however, that it is usually considered as exaggerated.

Names of villages or parties of Dacotas. No. of lodges. WVarriors. Suuls. Gens du lac, or Menderuhkantoan.

1. Keoxa, (Wapasha's, \&c.) - $\begin{array}{llll}40 & 70 & 400\end{array}$

2. Eanbosandata, (Red Wing's,) - $\begin{array}{lll}10 & 25 \quad 100\end{array}$

3. Kapoja, (Petit Corbeau's,) - $\begin{array}{llll}30 & 70 \quad 300\end{array}$

4. Oanoska, (Black Dog's,) - - $30 \quad 40 \quad 200$

5. 'T'ctankatane, - $\ldots \ldots$ - $\quad \begin{array}{llll} & 10 & 30 & 150\end{array}$

6. Taoapa, - - - - - $-30 \quad 60300$

7. Weakaote - . - . - $10 \quad 10 \quad 50$

Gens du large, or roving Dacotas.

S. Miakechakesa, (or Sisitons,) - $\begin{array}{llll}130 & 260 & 1000\end{array}$

9. Wahkpakota, - - - - - - $100 \quad 200 \quad 800$

10. Wahkpatoan, - - - - - $120240 \quad 900$

11. Kahra, (a band of the Sisitons,) $160 \quad 450 \quad 1500$

12. Yanktoanan, - - - - - $4601300 \quad 5200$

13. Yanktoan, - - - - -2 - $200 \quad 5002000$

14. Tetoans, - - - - - - - $9003600 \quad 14,400$

Adding for stragglers _ - $\quad \begin{array}{lll}100 \quad 200 \quad 800\end{array}$

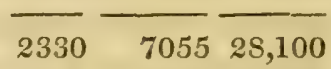

Strength of the Hoha or Assiniboins, 30007000 28,000

Total force of the Dacota, (before?

their division,) _ . - $\} 5330 \quad 14,055 \quad 56,100$

Previous to their division the Assiniboins belonged to the Yanktoanan tribe.

The above estimate falls somewhat short of that which Renville made some time before, when he was in the service of the Hudson's Bay Company. He then visited all the Dacota villages, camps, \&c. and by a close calculation estimated the number of warriors, exclusive of the Assini- 
boins, at 7600. This band having always been estimated at very nearly the same number as all the other Dacotas, will give an aggregate, (according to these data,) of 15,000 warriors. Admitting the proportion of one-fourth the nation able to bear arms, which is probably very near the truth, it would give as a total 60,000 souls; who would occupy about 6000 lodges. In counting the lodges we allude to the skin tents which contain from eight to ten individuals, young and old; for the permanent cabins on the Mississippi contain from three to ten families each, and it is said that one cabin has, in some cases, furnished from fifteen to twenty warriors.

As almost every traveller, who has visited the Dacotas, has given a different enumeration of their divisions; some reckoning but seven, while others admit as many as tiventyone tribes; it may be well to observe that this distribution into fifteen partics is merely introduced with a view to facilitate a better acquaintance with the nation. Webelieve that there are but seven tribes among the Dacotas, as their name of Ochente Shakoan implies; the divisions which we have admitted in the Mende Wahkantoan, are probably not very important, and we know that similar ones exist among the several tribes of roving Dacotas; we have no doubt that the Tetoans are divided into many parties, such as the Tetons of the Burnt wood, the Tetons Okandandas, Tetons Mennakenozzo, Tetons Saone, \&c. as enumerated by Lewis and Clarke. If we have not made use of any of these divisions in most of the other tribes, it is because we could not obtain them so accurately; and also because they are less important; a hunter, who has no fixed residence, will willingly pass from one party of Indians to another, belonging to the same tribe as he does, and this he will be ready to do at any time; but he who has his lodge, his cornfields, 
\&c. is much more inclined to attach himself to the village in which he lives; and, accordingly, we find that the residences of the Dacotas, on the Mississippi, \&c. are still, for the most part, kept up in the same places, where Carver saw them in 1766 .

The population of the Dacotas varies, according to the different travellers. Carver estimates the Naudowessies of the plains, (independant of those of Spirit lake,) at upwards of two thousand; but as he includes in these the Shiennes and Omawhaws, who, at present at least, form distinct nations, it is evident that we can draw no conclusions from his statement. Lewis and Clarke establish their numbers at about two thousand five hundred and fifty warriors, which, upon the data of one warrior to four souls, admits a population of about ten thousand, but this is undoubtedly far under the truth. Pike states their population at tiventy-one thousand six hundred and seventy-five, including three thousand eight hundred and thirty-five warriors. We believe the aggregate which he gives is nearly correct, but that he allows too few warriors. Among such Indians as have partially acquired habits of civilized life, the proportion of one warrior in five souls may be very nearly true; but among the roving bands, which constitute the majority of the Dacotas, we would not admit the ratio to be less than one to four; for the number of children and old men is proportionally much smaller. Youths are, at a very early age, counted as warriors; probably every male, above the age of sixteen, may, in reality, be enumerated as such.*

From these observations we are led to admit, that the

- Vide Carver, ut supra, p. 50.-Lewis and Clarke, vol, 1, p 60.Pike, appendix to Part I. p. 66. 
population of the Sioux nation cannot be under twentyfive thousand souls, and that it includes at least six thousand warriors.

The following synopsis of the usual residence of the $\mathrm{Da}$ cotas, and of the actual state of the villages or parties above alluded to, may be of use as a term of comparison for future travellers.

1. Keoxa. Their chief is Wapasha; they have two villages on the Mississippi, (one on Iawa river, the other near Lake Pepin ;) they hunt on both banks of the Mississippi, near Chippewa river and its tributaries. The chief holds his situation by hereditary tenure; his father was a great warrior; the present chief is a wise man, addicted to agriculture. Keoxa signifies "relationship overlooked," because they unite or have connexion between nearer relations than the other Dacotas; first cousins, uncles and nieces, and even brothers and sisters intermarry.

2. Eanbosandata means "vertical rock," from a rock on Cannon River. Their chief is Shakea, who has always been considered as dependent upon Wapasha; he rose to his station by military talents. They have two small villages, one on the Mississippi, the other on Cannon river; they hunt on the head ivaters of that stream.

3. KAPoJA, means "light;" they are supposed to be more active than the other Dacotas. Their present chief is a very distinguished man, and belongs to one of the oldest families of chiefs among the Dacotas, he being the fourth of his family in direct line. At a meeting of many Indian nations, which took place at Lake Travers about four or five years ago, there were present, besides some men from all the tribes of Dacotas, many from the Assiniboins, Mandans, Minnetarees, Iawas, and other nations, who all addressed him by the name of "Father," acknorr. 
ledging thereby not only his superiority over all the other Dacota chiefs, but even that of the Dacota nation over theirs. At this meeting, they exchanged and renewed pledges of friendship, \&c. The festivities, which lasted about a fortnight, consisted of dances, songs and repasts; the principal feast was celebrated on the 25th of June. Buffaloes were then very abundant in the country, and a great number were killed. The chief to whom the flattering distinction of Father was thus applied, is the same that is generally called Petit Corbeau by the traders, Chetanwakoamane by the Dacotas.* Renville interpreted for this Indian at the time when he visited Drummonds island, in 1815. He reproached the British government for the situation in which they left the Indians. When told by Col. M'Coy, the Indian agent for the British, that he acted in compliance with one of the stipulations in the treaty with the United States, the chief replied, that the British government had deceived them; they were at peace with the Americans in 1812; but they had been excited to acts of hostility; at the time that he spoke, they were at war with the United States, having been instigated to it by the British, who then deserted them. He could not believe that it was on account of their stipulations; he summoned them to fulfil their promises, or he must charge them with fraud and cowardice. When he was invited to settle in Canada, and assured of support and maintenance for himself and his band, he indignantly replied, that he required none of their support; he would fight, and himself obtain peace for his nation, and they would support themselves upon their own lands. The Kapoja Indians have but one village,

* This chief formed one of the deputation who visited the City of Washington in July, 1824. 
which is on the Mississippi, below the St. Peter; they lunt on the St. Croix river.

4. OAvosra significs great arenue. Wamendetanka, (War Eagle,) their chief, was formerly a dependant on Petit Corbeau. IIe has but one village on the St. Peter; he hunts on the Mississippi, above the Falls of St. Anthony.

5. Tetankatane, (old village.) This is the oidest rillage of the Dacotas. At the time when Wapasha's father ruled over the nation, there were four hundred lodges thcre. Wapasha formerly lived in that village, but having removed from it with the greater part of his warriors, a few preferred remaining there, and chose one of their number as a leader. His son, Tâkỏpépéshẻnè, (dauntless,) now rules over them. $\mathrm{He}$ is considered a dependant of the next following chief; he has but one village on the St. Peter, three miles above its mouth; he hunts on this river and the Mississippi.

6. TAOAPA. The chief of this party is called Shâkpà, which means six. He inherited his station, and is a distinguished man, ranking in the nation third only to Wapasha and Petit Corbeau. He has but one village; it is situated on the St. Peter, between which river and the Mississippi he hunts.

7. WeAKaоte. A small band which is dependant upon the preceding.

8. Meakecharesa derives its name from a point in the river, which has been cut off and forms an island. Their chief is called Wahkanto, or "blue spirit;" he rules by right of his family. His tribe has no fixed villages, no mud or bark cabins like all the preceding tribes; they reside all the year round in skin lodges, which they shift from place to place. Their chief rendezrous is on the Blue Earth VOI. I. 
river; they hunt upon that stream in winter; during the summer scason they pursue the buffalo as far as the Missouri.

9. WАнкрАко'A, or the "Shooters at leares," which they mistake for deer. Their last leader was Shakeska, (white nails,) who died in 1822. 'This tribe has a very bad name, being considered to be a lawless set of men. Shakeska rose to his station by his military talents. They have a regular hereditary chief, Wiahuga, (the raven,) who is acknowledged as such by the Indian agent, but who, disgusted by their misbchaviour, withdrew from them and resides at Wapasha's. This measure would have been disapproved of in ordinary cases, but, owing to the bad name. which they have, he is considered as justifiable in deserting his tribe. They have no fixed villages; they inhabit skin lodges, and rove near the head of Cannon and Bluc Earth rivers. Their hunting grounds are in that vicinity and west of it.

10. Wahkpatoan, means "the people beyond those that shoot at leaves," because they live higher up on the river. Nunpakea, (twice flying,) is the name of their chief. One of the deeds, by which he has acquired respect as a warrior, was achieved at the age of twenty. He was, with a party of Dacotas, on the lands of the Chipperwas, and was encamped on the edge of a lake; an island opposite to his camp was occupied by a considerable party of Chippewas; in the middle of the night, he swam over alone to the island, killed one of the enemies, scalped him, and returned unobserved to his friends with the scalp of his enemy. This tribe hunts near Ottertail Lake, one of the sources of Red river.

11. Kump, (TVild rice.) 'These Indians dwell in very large and fine skin lodges. The skins are well prepared 
and handsomely painted. They have no permanent residence, but frequently visit Lake Travers. Their hunting grounds are on Red river. They follow Tatankanaje, (the Standing Buffalo,) who is a chief by hereditary right, and who has acquired distinction as a warrior.

12. Yanktoanan, (the Fern leaves.) This is one of the most important tribes, as its population amounts to onefifth that of the whole nation. They have no fixed residence, but dwell in fine skin lodges, well dressed and decorated. Their hunting grounds are very extensive, spreading from Red river to the Missouri. They frequent, for purposes of trade, Lake Travers, Big Stone Lake, and the Shienne river. Their principal chief is Wanotan, (the Charger,) of whom we shall speak hereafter.

13. Yanistoan, (descended from the Fern leaves,) are in every respect similar, and probably separated from the last mentioned. Their leader, Tâtânkâ Yủtèshèné, (he who eats no buffalo, is distinguished both as an hereditary chief and as a warrior. They frequent the Missouri, and generally traffick with the traders upon that river. Their hunting grounds are east of, and adjoining to, the Missouri.

14. Teroans, (Braggers.) According to Renville, this tribe includes one-half of the Dacotas, and it is probably here that his calculations are most likely to be erroneous. They reside in skin lodges, and are constantly roving between the St. Peter and the Missouri. They trade on both rivers, and are held to be very hostile to white men; they are great boasters, and hence their name. They are not considered braver than the other tribes. Their chief, Chântàpètâ, (Heart of Fire,) is a very powerful warrior.

We may add of the $\Lambda$ ssiniboins, whom the Dacotas call the Hoha, (revolted,) that they formerly belonged to the tribe of the Yanktoanan. They boast of having upwards of 
3000 skin lodges, of which Renville once saw three hundred pitched in one place. Their grounds are north of $\mathrm{Pem}$ bina towards the Assiniboin river, and west of Lake Winnepeck. 'They are at war with the Blackfeet Indians, and are said to send war parties every year, as far as the Rocky Mountains. They have been fighting the Dacotas ever since their separation; but there seems to be at present a mutual tendency to a reunion. Their present chief rose by his military achievements; his name is Minayolka, Knife bearer.

The cause of the separation of the Assiniboins from their former friends is variously related. The following has appeared to us to be the prevalent tradition on this subject. It is said that, about fifty ycars* ago, a quarrel arose between two influential families of the Yanktoanans, at the time that they were hunting in the vicinity of Lake Travers. A young man, belonging to one of these families, seduced the wife of one of the warriors of the other family, and conveyed her to his camp. The injured husband pursued them, and, in his attempt to rescue his wife, was himself slain. His father and two brothers, accompanied by two of his uncles, went to the seducer's camp, with a view to obtain the corpse of their deceased relation. On their way to the camp, they met with a party of the friends of the murderer; a quarrel ensued, and three out of the five perished, without having succeeded in killing one of their opponents. The distressed parent survived this conflict, and, swearing that he would avenge his losses, he betook himself to a camp of his friends, stated his wrongs, and ob-

* The separation probably occurred at a much earlier period. Dates are soon forgotten by Indians. Hennepin mentions a nation of the Assinipoils, who probably are the same. Charleroix calls them Assiniboils. 
tained a party of sixty warriors who marched out with him. They proposed to the aggressor's friends to compromise the matter, by delivering over two of their party to the parent, so that he might offer them as propitiatory victims to the spirits of his four departed kinsmen. This offer having been rejected, a battle was fought, in which the seducer lost kwenty of his party; his opponents lost but five. It would be needless to go through the long list of engagements Pought, or to relate how each party, as often as it was vanquished, swore revenge against its enemies, and recruited itself among its friends. Suffice it to say, that the breach widened; the nation was divided; a long and bloody eivil war ensued; the aggressor and his friends withdrew to the north, ceased to pay any allegiance to the confederacy, and formed a new nation, to which the term Hoha, which means revolted, was applied by the Sioux. The Chippewas, who call the Dacota nation Boines, distinguished the insurgents by the term of Assini Boines, which, according to some interpreters, means revolted Boines, but which, by the greater number, is supposed to be derived from the Chipperva word Assin, which signifies stone. Ever since this band has been known under the name of Assiniboin, or of Stone Indians. Whence the Chippewa derived this last appellation, we know not; but we believe we have been told, that it was from the frequent use of stones, as a weapon of defence by the Hohas. Henry describes the instrument and the manner of using it.

The Dacotas have no tradition of having ever emigrated, from any other place, to the spot upon which they now reside; they believe that they were created by the Supreme Being on the lands which they at present occupy. Of the origin of white men they have no idea, having never rcflected upon the subject; they have preserved a faint tra- 
dition of their first meeting with a white man, but who this was, and when it took place, they are unable to tell. They believe that he was a Frenchman, and that he was first discovered by a party of Mende Wahkan toan; as soon as the Dacotas saw him they were much surprised at his dress and complexion; they took him prisoner, secured him, and brought him to their camp. He had in his hand a gun. By means of signs they asked him the use of that instrument; he pointed out to them that with it he could take away the life of any object he pleased; they then placed a man before him, challenging him to the proof of what he had advanced, upon his refusal to do it, they placed a dog before him, which he immediately shot and killed. Terrified at the report of the gun, they all ran off, considering him as the spirit of the thunder; as he remained there, they returned to him, called him by the name of Thunder, and held him in great awe and veneration.

Their first discovery by white men is referred by Charlevoix* to the year 1660 , when he states that they were met by two Frenchmen proceeding west from Lake Sum perior. Father Hennepin's visit to the Falls of St. Anthony, did not take place till upwards of twenty years after this. Previous to Charlevoix's writings, the Dacotas had been referred to a Chinese origin. This idea is supported by Carver, but upon such weak analogies of language as must surprise us, when advanced by one who certainly was not destitute of judgment and observation. Pike ascribes to them a Tartarean origin, on the ground of "their guttural pronunciation, their high clieek bones, their visages and distinct manners, together with their own traditions, supported by the testimony of neighbouring nations."

* Hist. de la Nouv. France, tom. 2. p. 98. 
The Dacotas have a rery simple system of religion. They believe in the existence of a Supreme Being, and of a number of subordinate ones, whose powers, privileges, and attributes vary much. The Supreme Being is by them called Wahkan Tanka, or Great Spirit. They worship him, considering him as the Creator of all things that exist, and as the Ruler and Disposer of the Universe; they hold him to be the source of all good, and the causc of no evil whatever. The next spirit in respect to power, is the Wahkan Shecha, or evil spirit; his influence is far less extensive than that of the Wahkan Tanka, and it is exclusively exerted in the performance of evil. He is co-eternal with the former, incapable of doing any good, the promoter of all wars, strifes, \&c. Although partially under the control of the Great Spirit, yet it is not in the power of the latter entirely to check him. Their third divinity is the Thunder, for which they have the greatest awe. They fix its residence to the west, and some believe it to dwell upon the summit of the Rocky Mountains. It is almost unnecessary to add, that all thunder storms in that section of the country, proceed from the west. To each of these spirits they extend their worship. It has been incorrectly stated of the Dacotas that they do not worship the Supreme Being, thinking it unnecessary to supplicate an all-bountiful power. On the contrary, they offer sacrifices to the Great Spirit, in gratitude for farours received. In sacrificing to the evil spirit, their object is to propitiate him, to induce him to arert his anger from them, or to extend to them his support in war. But it is the Thunder which is considered as the main agent in warlike operations, and to it do they chiefly apply for victory. Sacrifices to these three porrers are offered nearly in the same manner. They begin by elevating a pipe towards the spirit. He who gives or ordains the 
sacrifice, after having addressed the being to whom it is offered, takes up the calumet, and raises the stem upwards towards the sky, if it be intended for the good spirit; if for the evil deity, he points the stem towards the south; if for the thunder, the pipe is directed to the west. When it is intended that the object sacrificed shall remain exposed to the atmosphere, it is fastened upon a stake, which is elevated or inclined in like manner. Human sacrifices are not known to have ever been resorted to, except in one instance about forty years ago. The Sioux had destroyed several Chippewa lodges, and taken a few women and children. Wamendetanka's father, who was a partizan warrior, expressed his belief that the sacrifice of a child would ensure him good luck. Accordingly he offered one to the evil spirit to obtain success in war. The child was fixed upon a pole, which was inclined towards the south; the death of the victim was procured by tying a rope round its neck. In addition to these three principal deities, the Dacotas acknowledge many subordinate ones; a female spirit, for instance, resides in the sun, a male inhabits the moon; both these are connected; they are considered as benevolent beings. No particular doctrine prevails, as to the nature of the stars. The sacrifices of the Dacotas are accompanied with prayers, but not with dances. If one of the nation should observe any object elevated by another on a pole, as a sacrifice to a spirit, and he be at that time in need of the same, he will not hesitate to take it, substituting some tobacco or other offering in its place. This is, however, practised only with the offerings to the inferior spirits; for no Dacota would dare to remove that consecrated to the Supreme Being.

The ideas of the Dacotas, respecting a future state, differ but little from those of other Indians; and we may re- 
ceive them with less diffidence, as they have had but little intercourse with missionaries, whether Catholic or otherwise; still, in some of their credences, as related to us, it was impossible not to discover a few of the doctrines of Christianity, which had probably crept in unnoticed by them. The Dacotas admit that there are in man two distinct essences, to which they respectively apply the terms of Wằnåré and Wâhkåñ, which our interpreters translate by soul and spirit. They believe that after death the souls go to the Wanare Tebe, or dwelling place of the souls. 'That in order to reach it, they have to pass over a rock, the edge of which is as sharp as that of a knife; those who fall off go to the region of the evil spirit, where they are kept constantly chopping wood, carrying water, \&c. being frequently flogged by their relentless master.

Those, on the contrary, that have passed safe over the rock, have a long journey to travel; and as they proceed, they observe the camping places of the souls that have preceded them; at these spots fires are ready made for their accommodation; finally, they reach the habitation of the Wahkan Tanka, or Great Spirit. There they find many villages of the dead; they meet with some spirits there, who point out to them the way to the residence of their friends and relations, with whom they are reunited. Their life is an casy and a blissful one, they hunt the buffalo, plant corn, Sc. It is believed, that when children are on the point of death, their departed relations return from the land of souls in order to convey them thither. Women are liable to go to either of the places, but all are entitled to a situation in the land of the blessed, except such as have violated their chastity, committed infanticide or suicide.

Their system of Ethics is as simple. Men are held to go to the residence of the Great Spirit if they be good and Vor. I. 
peaceable, or if they die by the hand of their enemy. If they perish in a broil with their own countrymen, their souls are doomed to the residence of the Evil Spirit. Suicide is with them attended with the same penalty as with women, but it is of very rare occurrence. Women are, in their opinion, bound at all times, whether single or married, to be chaste. If an unmarried female prove otherwise, she usually endeavours to conceal her shame by procuring abortion; this is held to be highly criminal; but it is the cause and not the act of abortion which is censured; for married females frequently obtain miscarriages with the knowledge and consent of their husbands, and to this no objection is made. Widows, that prove with child, seldom resort to the same means, but they endeavour to conceal the birth of their offspring; and this is considered as equally criminal. Suicide is very common among the Dacota women; they are impelled to it by extreme sorrow and affliction; but it is held dishonourable. As most women inflict it upon themselves by hanging; they are said to go to the regions of the wicked, dragging after them the tree to which they were suspended. This fact has already been recorded by Bradbury, who adds, that they are doomed for ever to drag this tree, and that for this reason they always suspend themselves to as small a tree as can possibly sustain their weight.

The Dacotas repel the charge of cannibalism with great horror ; they assert that they have never been guilty of it, but charge their neighbours with the crime. Renville states, as a circumstance for which he is willing to vouch, that he was present at the siege of Fort Meigs, in the year 1813. The fort was besieged by general Proctor, at the head of the British army, attended by a corps of about three thousand Indians, consisting of Dacotas, Potawato- 
mis, Miamis, Ottowas, Wolves, Hurons, Winnebagoes, Shawanese, Sauks, Foxes, Menomonies, \&c. They had all shared in the battle except the Dacotas, who had not yet engaged against the Americans, and who were then on their way to Quebec. While Renville was seated, one afternoon, with Wapasha and Chetanwakoamane, a deputation came to invite them to meet the other Indians, the object of the meeting not being stated; the two chiefs complied with the request. Shortly after, Frazier, (an interpreter,) came and informed Renville that the Indians were engaged in eating an American, and invited him to walk over to the place. He went thither, and found the human flesh cut up, and portioned out into dishes, one for each nation of Indians. In every dish, in addition to the flesh, there was corn. At that moment they called upon the bravest man in each nation, to come and take a portion of the heart and head; one warrior from each nation was allowed a fragment of this choice morsel. In the group of Indians present, there was a brave Dacota, the nephew of Chetanwakoamane, known by the name of the "Grand Chasscur." They invited him to step forward and take his share, and among others a Winnebago addressed him, and told him that they had collected their friends to partake of a meal prepared with the flesh of one of that nation that had done them so much injury. Before the Sioux warrior had time to reply, his uncle arose and bade his nephew rise and depart thence; he then addressed himself to the Indians: "My friends," said he, "we came here, not to eat Americans, but to wage war against them; that will suffice for us; and could we even do that if left to our own forces? we are poor and destitute, while they possess the means of supplying themselves with all that they require; we ought not therefore to do such things." His com. 
rade, Waprasha, added, "We thought that you, who live near to white men, were wiser and more refined than we are who live at a distance; but it must indeed be otherwise if you do such deeds" They then rose and departed. Renville is positive that he could not have been deceived, for it was the head, heart, both hands and feet of a man that he saw in the dishes; and he saw some of the warriors partaking of them. The British officers were in their camp, and not aware of the transactions that were going on among the Indians. When informed of them they expressed great dissatisfaction. Col. Dickson, having sent for the Winnebago who had first set this thing on foot, asked him what could impel him to such horrid deeds, when he coolly replied, that it was better for him to do as he did, than to behave as the Americans had done, who had burnt his house, killed his wife and daughter, and mutilated their corpses. Col. Dickson then bade him depart, and never again appear in his presence. Gen. Proctor gave him the same directions. It appears that the victim of this feast, whose name we could not ascertain, was a prisoner of the Winnebagoes, who killed him with a view to prepare the entertainment. It was not done for want of provisions, for at that time the camp was plentifully supplied; neither does it appear that, in this case, it was fondness for the taste of human flesh, but, doubtless, a desire to vent their rage and spleen upon their prisoner, which induced them to prepare and partake of this disgusting repast. The Dacotas have always spoken of such deeds in terms of the highest reprobation; and we heard of one case only as having happened among them; it occurred in the year 1811, during a very general famine, three women partook of the flesh of a man who had previously died of hunger; but even in this case where they were urged by a necessity which 
probably no white man could have resisted, their conduct was generally blamed; and two of them having died a short time afterwards, their death was supposed to have been brought on by this food. The third still lives; she is regarded with horrour by the rest of the nation, who also consider her present state of corpulence as produced by that fatal food; they state it, as their opinion, that she will die choked with the fat of the man of whom she ate.

We have heard some cases of cannibalism related of them by their neighbours, but none appeared so well substantiated as to be entitled to belief, especially as the opinion which we have adopted, is supported by the uniform testimony of all the travellers who have visited them, from Hennepin to the present day.*

The treatment of their prisoners, by the Dacotas, has generally been considered as kind; and we find that even as far back as the visit of that traveller, they deserved that character. Hennepin, who certainly was much addicted to exaggeration, and who might have been alarmed at innocent gestures, the intention of which he might mistake, has given such an account of the treatment which he received

*It appears that Tommo, (the Dacota who guided Major Long's party from Prairie du Chien,) told Mr. Colhoun that he had eaten of a Chippewa, called Hahatong; he spoke of it without any repugnance, pointed to his breast, saying that he had found that part to be the most delicate. This appears to be a solitary instance, and we only mention it because we wish to avoid the charge of concealing any fact that may affect our general position, that the Dacutas do not imitate their neighbours in this gratification of a depraved appetite. Otherwise, we should have taken no notice of the fact, as the only interpreter at that time was George Wade, a youth whose qualifications in that capacity, both as to the knowledge of the language and integrity, we strongly suspect. 
from them, as fully confirms our statement. Their cliemies seem to place great confidence in this virtue of theirs, as is manifest from the following transaction, which happened about thirty years ago. $\mathbf{A}$ battle had been fought on Knife Lake between the Chippewas and Dacotas; two hundred warriors of the latter had surprised and cut up about fifteen of the former, killed their wives and children amounting to about forty, and taken eight or ten prisoners. They then withdrew to the village of Tetankatane on the St. Peter, which at that time consisted of about three hundred lodges. They were engaged in celebrating their victory and dancing the scalp dance; on looking round, one of the party was surprised to behold a warrior painted all over with black, and marked with ten streaks of vermilion which covered fresh wounds. He was immediately recognised to be a distinguished Chippewa chief, called in his own language, Keche Wabesches, by the Sioux, Natapa Hecha, both which terms signify the Big Martin; it was the same chief who commanded the small party, the defeat of which they were then celebrating. Under cover of a blanket he had approached thus near undiscovered, passed through the village, and it was only when he found himself in the presence of the warriors, that he dropped his mantle. In his left hand he held a calumet of peace, his right was raised to the heavens, as if calling for mercy. But his attitude was firm, his manner imposing and undismayed. He was immediately seized, and made to sit down; the warriors formed a circle to protect him against the insults of the women and children, the weak and the coward, who are generally prone to triumph over the unprotected. The intrusion of an enemy, while they were engaged at their sacred rites, was by many considered a mortal offence; those disposed to spare him sent word to Renville's father and 
some other French traders, who were encamped on the opposite side of the river; by the influence of the traders he was permitted to go over to their camp until his fate should be decided. After some deliberation, they determined upon sparing him; they formed a large ring of warriors convened in council and, having summoned the chief, they asked him what had induced him to venture among them; he replied that, having searched the field of battle after their departure, he had not discovered the body of his young daughter, who was but five or six years of age, and concluding that she was a prisoner, he had resolved to eome and claim her from them; the black colour, with which he was painted, was a symbol of his mortification; his wounds were still fresh. The Dacotas having agreed to release her, the prisoners were all brought up; he immediately recognised his daughter, wept over her, and embraced her. He remained two days among them, and was much feasted, the Dacotas expressing the greatest admiration of his valour. On his departure, they loaded his canoe with presents, and one hundred of them accompanied him as a protection, as far as Rum river. During his stay he observed the scalps of his wife, brother, and other relations, and pointed each out. When asked by the warriors why he had not fought with the same desperate courage to resist their attacks, which he had manifested when he surprised them on the St. Croix river? he replied, it was not his courage, but his strength which had failed, he had fought until he fell senseless, being wounded in many places both by arrows and fire-arms.

Instances exist, however, in which the Dacotas have killed their prisoners of war, and in some cases, long after they had been taken. Thus, for example's sake, it is re- 
lated of the mother of Takopepeshene, that she once killed a young Chippewa girl whom she had adopted as her daughter four or five years before. 'This she did to avenge the death of her nephews, who had been killed by the Chippervas; this occurrence took place in 1507; and some of the circumstances attending the engagement between the two nations, exhibit the great animosity which prevails between the Chippewas and Dacotas. The latter had, it is said, ascended Chippewa river on a hunting excursion, under the command of Shakea, the Redwing chief, when their leader informed them that he had dreamed of the near approach of their encmy. This prediction was unheeded, but the subsequent night, at about two o'clock, the camp was assaulted by the Chippewas, who gained some advantage over the Dacotas; finding them, however, more numerous than they had anticipated, the Chippewas withdrew, leaving the field to them. The Dacotas pursued and overtook them on an island covered with aspen; they fired the woods; the conflagration spreading over the island, many of the Chippewas perished. It is stated that the Sioux boys afterwards amused themselves in cutting off the lower joint of the fingers of the slain, as well as strips of skin from their arms, and of these they made necklaces; \&c.

'The difficulties, misfortunes, and ill-treatment which attend prisoners among Indian nations, as well as the equanimity and perseverance which they manifest in order to effect a rescue, appear almost incredible to those who are unacquainted with the Indian character, yet there can be no doubt in the minds of those who have made a study of it. The following narrative of the perils and adventures of a Yankton woman, whom we saw near Lalie Travers, has 
been related to us under circumstances, which have almost banished scepticism, although it at first appears miraculous.

Her name was Shènânskî, or the White Buffalo Robe. When we saw her, she was about seventy years of age. She relates that, in her youth, while yet under twenty, she was taken captive by a party of Chippervas; the man to whose lot she fell was cruel and relentless; among other hardships, he obliged her to walk naked, for three days, before the whole party; and whenever, from fatigue, she slackened her pace, she was scourged by her captors. At last, on the third day, they reached a stream where, fancying themselves secure from all pursuit, they prepared to sojourn some time, and that evening she was doomed to undergo a still more barbarous treatment, when a Chippewa warrior came in, whose mind was more generous than that of the others; he declared himself her protector, and said he would adopt her as his daughter. Whether from his influence as a brave man, or from his decisive manner, or from some other motive she knows not, but she was relinquished, though reluctantly, by her former master; and her adopted father conveyed her to his family, which was far to the north. In the autumn they returned towards the Dacota lands in pursuit of buffalo. Although the treatment which Shenanska had received from her adopted father was mild, yet her life was rendered unpleasant by his wife, who used her in an unfeeling manner. Considering the infant child of the Chippewa mother to be, in part at least, the cause of her troubles, Shenanska determined to destroy it, and on one occasion, while both parents were away, she stabbed it in the side with a moccassin awl. The infant immediately expired; she replaced it in

Vor. I. 
its cratle. When, on her return to the lodge, the mother saw her child in the cradle, she inquired if it had been long sleeping, Shenanska replied in the affrmative. Having gone nearer to the infant and discovered that it was dead, although she did not observe the wound, the mother instantly seized an axe, and struck a blow on Shenanska's head, who fell into a swoon. The blow was not a mortal one, she soon recovered from the effects of it, and having determined to make her eseape, succeeded in leaving the lodge unobserved. She travelled towards the lands of her countrymen, and after eleven days of a fatiguing march, during which, she at one time suffered so much from hunger, that she was forced to feed upon bits of skin and leather, collected at a deserted encampment, she found herself in sight of her native Cotean, and was flattering herself with the hope of soon meeting with a party of her friends, when she fell in with a band of Assiniboins, mortal enemies to her trilse. From these she would have met with instant death, had not their chief interfered in her favour. By him she was treated kindly, but after remaining a day in his camp, he advised her to make her escape, as otherwise she must fall a victim to the rescntment of the party. He supplied her with provisions, a horse, and every thing she might require for the route. $\Lambda$ gain she started on a solitary journey, which lasted forty days, when she met her friends. On approaching their ramp, her appearance was so much altered that they knew her not. Her own father hesitated in recognising her as his daughter; at last, when she spoke and mentioned her name, her friends all collected around her, while she related to them her adventures; after she had finished her narrative, her father seized his knife and stabbed himself, in testimony 
of the grief he experienced at all she had suffered. $\Lambda$ mode of expressing sympathy for past troubles which, however, is not common among Indians.

The Dacotas appear to take but little pains in the education of their children; they follorv no regular system. What the children learn, on the subject of their religious opinions and traditions, is collected gradually, and altogether in the course of unpremeditated conversations. The only attention which they receive is torvards the development of those qualifications, both of mind and body, which shall enable them to make active hunters and dauntless warriors. To rise early, to be enured to fatigue, to hunt skilfully, to undergo hunger without repining, are the only points to which the Dacota thinks it important to attend in the education of his children. Corrections are never resorted to, they are never flogged; indeed, with the exception of occasionally throwing cold water upon them, to make them rise in the morning, they never resort to any authoritative measures, all which they consider as cruel and unnatural. Their fondness for their children is extreme, especially that of mothers for their daughters. It is not an uncommon thing, to see a mother carry water, hew wood, and undergo much fatigue, to spare it to her daughters. This is especially the case with the mothers of those young Indian females, whom the traders take as their companions. It does not appear that the daughters feel the least compunction at the trouble which their parents undergo ; they consider it all as a matter of course, being doubtless prepared to go through the same drudgery for their children when they shall require it.

No event appears of more importance to a Dacota parent than the bestowing of a name upon his offspring. It is attended with much eeremony; a large feast or sacrifice 
is prepared; the relations and friends are invited. T'he name which is given is generally one derived from some visible object in the heavens or earth. The infant is made to support a pipe, the stem of which is direeted towards the object from which the name is taken; a sacrifice is offered to the spirit which is supposed to reside in that object. These sacrifices are extensive and costly, they consist of dogs and other animals, of skins, of scarlet cloth, tobacco, \&c. It appears to us well established that this rvas originally an Indian institution, and not, as we at first apprchended, a mere imitation of the rejoicings which among some Christian sects attend the ceremony of naming a child. We are told of some Indian nations endeavouring to stimulate their youths into dreams, visions, \&c.* but this has not appeared to us to be the case with the Dacotas; when dreams do occur they are held to be favours, and much importance is attached to them, but no attempt is made to give rise to them.

Polygamy is allowed, and no regulations whatever exist upon this subject; it appears to be rather tolerated than encouraged; every man follows his inclination upon that point, and is esteemed neither more nor less on account of the number of his wives, or children. It is probable that most men have more than one, though few have many wives. The Dacotas destroy neither their children nor their old relations; to the latter their conduct is perhaps not as kind and attentive as it ought to be; but they make up for it by their attachment to their children, who receive care and kind treatment in proportion to their wants. The practice of shaping the hearls of infants is unknown to them.

* Transactions of the Historical and Literary Committee of the Amcrican Philosophical Society. Philadelphia, 1819, vol.I. p. 238. 
The Dacotas have prophets among them, but none that are so distinguished as those of the Shawanese. They are always prepared to oppose the incredulous with several stories, or anecdotes, to which they assert that they were in most cases witnesses. It would be vain to attempt to convince them of their error on this point, probably because they are pleased with it, and are in no manner desirous of being convinced that it is but a delusion. Even the halfbreed interpreters share in this belief; at least they profess themselves unable to account otherwise for the success that attends those prophecies. In relating two or three of these stories, we deem it unnecessary for us to premise them, by stating that we are not believers in them, as Carver appears to have been in the prophecies of his friend, the Chief Priest of the Killistinoes, but that we merely recite them in order to show how far credulity will extend.

About twenty years ago, a large party of Indians, collected near Lake Travers, were quite destitute of tobacco; not knowing how to procure any, they applied to Tatankanaje, (Standing Buffalo,) a prophet of some distinction, and the uncle of the present chief of the Kahras. This man usually carried about him a little stone idol, carved into a human shape; this he called his little man, and to it he always applied when consulted in the way of his profession. Tatankanaje being requested to advise the best means of obtaining tobacco, made answer to them, that if they would go to a certain place, which he pointed out to them, they would find his idol, and by examining it they would observe in its hand a piece of tobacco. They did as he bade them, and found in the little fellow's hand, a piece about four inches long; this was brought to the camp, and was thought to redound much to the credit both of the prophet and the idol; but Tatankanaje then observ- 
ed, that he would consult the little man, and ascertain where he had found the tobaceo, and how he came by it. This he did by putting interrogatories to him, to which he pretended that audible answers were returned, though of the many present, not one heard them beside himself. The purport of these answers, howerer, as he subsequently informed them was, that at a spot on the St. Peter, near to Redwood river, there was a boat, loaded with goods; that her commander, a French trader, having been murdered by the Sioux, the crew had been alarmerl, and had run away, leaving the boat unguarded, together with her cargo, consisting principally of tobacco; that the little man had seen her, and finding a piece of tobacco on a keg, had brought it up. 'The prophet having invited them to seek for it, they repaired to the spot, found the boat, took the tobaceo, and returned the rest of the goods to the first French traders that passed up the river. This event happened, as we were informed, in the presence of Renville and Frenieres, two French traders of reputation, both considered as intelligent and enlightened men; they were the fathers of the two half-breed traders with whom we were acquainted. The story is given with all the particulars that might be wished for ; the name of the owner of the boat was Benjamin La Goterie, a name well known in that country. The story has been current erer since. The traders, who appear to credit it, state that it was impossible for the prophet to have visited the spot and returned without his absence being known, as the distance exceeds one hundred miles; from whom he received his intelligence they never knew. As to the Dacotas themselves, they never considered it possible that it might be a knarery of the prophet's, but attributed it altogether to his " mystic lore." 
On another occasion, Tatankanaje acquired great reputation in consequence of a prediction that he rould lead a war party ; that on the day which he appointed, and at a particular spot, which he described, he would fall in with a camp of fifteen $A$ ssiniboin lodges, that he would attack and defeat them, kill a certain number of the enemy, and make a stated amount of prisoners; he predicted in like manner the loss of lives, which would attend this victory. The event justified, as it is said, the prediction; not only, as to the general results, but even as to the circumstances of time, place, number of killed and wounded on both sides, and amount of prisoners taken from the enemy. Of course, so valuable a prophet was constantly resorted to, for the recovery of stolen property, or of goods that were lost, for a knowledge of the fate of persons that were travelling, for the cure of diseases, and for all such other important points, upon which the credulity both of civilized and savage man induces them to lend a willing ear to the impositions of knaves. Of his talent in recovering property, we regret that we can only mention a circumstance in which the object at stake was very trifling. Some one had ventured to steal away the prophet's bridle; it was concealed in a lodge that formed one in a camp of one hundred lodges. The prophet took a mirror in his hand and walked round the village, until, as he said, he sarv the lost bridle reflected in his mirror; he cntered the adjoining: lodge and recovered his property.

Not only they prophecy, but they perform tricks of legerdemain, all which they ascribe to the success of their incantations. We are inclebted to Mr. Charles Hess, a French trader, with whom Mr. Say had several conferences at Fort St. Anthony, for the account of a trick performed by an Assiniboin. The magician asserted, in MIr. 
IIess' presence, as well as in that of many Indians, that he could cause water to flow into an empty keg, though he might, at that time, be upon a dry prairie, and at a distance from any spring or stream. Mr. Hess having told him that he did not believe him, but that, if he succeeded, he rvould give him a $\mathrm{keg}$ of whiskey, the Indian offered to repeat the trick. He exhibited to them his $\mathrm{keg}$, which they cxamined, and all judged to be empty. The bung was removed, the cask turned over, and no liquid issued from it. The Indian then commenced his incantations, raising his $\mathrm{kcg}$ towards the heavens, dancing and performing many unmeaning gestures; after which he presented it to the Indian chief that was present, bidding him to drink of the water which it contained; the latter drank of it, found it very good, and passed it to his neighbour; the cask was circulated, to the great satisfaction of all the Indians who drank of its contents, and even Mr. Hess was convinced that the keg really held pure water. He was, however, unable to detect the deception, but supposed, that a bladder filled with water had been fastened within the $\mathrm{keg}$, and that, owing to the agitation communicated to it, the bladder had been burst by means of spikes driven into the ends of the keg, for that purpose; and that in this manner the water had been diffused throughout the keg. The magician claimed and obtained his reward; but when alone with him, Mr. Hess charged him with being an impostor, and told him the manner in which he suspected that the trick had been performed. The magician confessed the iruth of Mr. Hess' statement, but begrged that he would not disclose it to the Indians.

The person who communicated this fact to us, is one of the most respectable traders whom we have seen; at the time that we met with him he was in great distress, owing 
to the recent loss of part of his family, aggravated by a very painful calculous disease under which he was then labouring, and which had induced him to visit the fort in hopes of obtaining relief from the surgeon of the garrison.

Having always traded with the Chippewas, married among them, and been considered as connected with them, he had entertained great apprehensions of the Dacotas; for the Indians generally extend to those that trade with their enemies the same animosity which they bear to those nations. About a year before the time when we saw him, he was residing at Pembina on Red river. Provisions became so scarce at that place, that the settlers were reduced to live upon lettuce seasoned with salt; about one hundred and fifty of them had gone out to hunt buffalo, and he at last resolved to go and join them, with four of the settlers and his family, consisting of two daughters. They had travelled five days across the prairie, killing game enough for a bare subsistence, and kecping a constant guard for fear of being surprised by the Yanktons, who rove over those prairies. The extent to which he carried his precautions shows the deep presentiment which oppressed him at the time; often, as he informed us himself, after his party had passed over the top of a gentle swell or little elevation in the prairie, he would cause them to halt, while he would turn back, and crawl along the ground to the top of the hill, then, raising his head above the surface, concealing it at the same time behind a little grass which he had cut for the purpose, observe whether there were Indians to be seen in any direction. His friends ridiculed his fears, and two of them separated from him, but the event proved how well-founded his apprehensions were. On the 6 th day his horse having broken the halter by which he was fast. VoL. I. 
ened, Mr. Hess left the camp in search of him, and suon: caught him; his companions, at that moment, observed two buffaloes on the prairie, and, as his horse was the fleetest, they called out to him to chase them; he did so, and was for a while separated from his party. In leaving the cncampment, the anxious parent advised them to be watehful, and it was with the utmost reluetance that he separated from them. While he was killing the buffilo, a dog came up to him; this excited his suspicions; he followed the dog back, and, after a long ricle across the prairie, came to a small valley where he observed his cart, and flattered himself with meeting with his family. On approaching, his consternation was extreme, when he saw one of his companions feathered with arrows, scalped, and his feet separated from his legs. A little further lay his daughter, murdered, and with a knife still lodged in her breast; with streaming eyes, he withdrew it, but it was too late, she was lifeless. He in vain rode three times round the place, in search of his other daughter, he could find no trace of her. At some distance he discovered the corpse of his other companion likewise pierced with arrows.

The distracted parent remained for a while unable to resolve in his mind what course he ought to pursue; he attempted to dig a grare for the unfortunate victims, but being only provided with a knife, he soon gave up this attempt as a vain one; he then determined to leave his dog to watch the corpses, and to return to Pembina for assistance. We cannot dwell upon the sad particulars of the feelings and sufferings of the agonized father, as he left the body of one of his daughters, swearing that he would follow, even into the camp of his enemies, his other offspring who, he still hoped, might have survived this calamity. After three days and nights spent in travelling on foot, 
without cither rest or food, he at last reached Pembina. On hearing his sad tale, the inhabitants were so much panic-struck, that none at the settlement would venture with him in the prairie to inter his friends, and remove his cart and other property. Hearing, however, that his surviving daughter was in one of the Yankton villages, he set out with the desperate resolution of recovering her or perishing in the attempt. At the termination of another arduous journey across the prairie, he reached the camp and was met by many Yanktons, one of whom, a tall athletic man, inquired of him whether he was a friend or foe; "You know me," said Charles Hess, "as your foe; you know me by the name of the Standing Bull; you know you have killed one of my daughters and taken the other prisoner." The Indian stepped backwards and pointed his arrow at him; Mr. Hess levelled his gun at his opponent. The Dacota seeing this, relaxed his bow and extended his hand to him. The Indians all complimented him upon his valour; they invited him to feast at most of the lodges. He saw his daughter; she informed him that she had been kindly treated, and that her master was unwilling to part with her. Two horses were offered for her release by some Indians of a neighbouring nation, who were passing that way, and who were friendly to Hess; these were refused; four horses were in like manner offered and refused. At last her master consented to release her for the following ransom, viz. two fathoms of scarlet cloth, two white blankets, two fathoms of blue strouding, a chief's coat, a tin kettle, two guns, one pair of fine pistols, a framed looking-glass and a paper one, two knives, six double handfuls of gunpowder, two hundred bullets, and a quantity of blue beads.

So high a ransom fell heavy upon this poor man, who had lost his little all at the same time that his danghter was 
taken prisoner; he had to resort to the other trader's for assistance; and they bestowed it upon him with that generous sympathy which is more casily found among rude and uncivilized men than among the more refined. They supplied him with goods on a long credit; with these, he returned to the camp, and ransomed his daughter, who, while he was relating this sad tale to us, was sitting by, engaged in decorating a piece of leather with porcupine quills, a work in which the Chippewas excel. A circumstance which we believe added to the distress of the parent, was that he found some difficulty in prevailing upon his daughter to leare the Yanktons; she had been so kindly treated that she cared but little about returning to her own father. We have not learned in what light she was considered, whether as a prisoner, or as an adopted daughter.

The uniform but laborious life, which these Indians lead, protects them against many of the diseases incident upon civilization, though it at the same time exposes them to some direful complaints, which their total ignorance of the healing art, and their superstitious confidence in their magicians, prevent them from curing. Among the diseases which are said to be unknown to the Dacotas, may be ranked the following, viz. intermittent ferers in the prairies which are distant from the Mississippi, and probably even in those which border upon that river above the Falls of St. Anthony, Plica Polonica, baldness, (?) nymphomania, spina bifida and St. Vitus's dance, scurvy, coup de solcil, chlorosis, and leucorrhœa. Among those which are known, but which are of very rare occurrence, we will mention jaundice, decayed tecth, and tooth-ache; in dentition children suffer much; in such cases the gum is never cut, but the children are allowed smooth stones and other hard substances to rub against their gums. As a palliative 
for tooth-ache the root of the Gerardria is not unfrequently applied. Hydrophobia is prevented by cutting out the wounded part. Dysentery is not common; it is cured by the free use of sassafras. Deafness is rare, and deaf and dumb cases are exceedingly scarce. Their most prevalent disease is hepatitis, which is hereditary and very frequent. They use for its cure the oil of rattlesuakes and of other serpents, they say with some benefit; but Renville informed us that he had never seen a person affected with it, that was cured. Frozen limbs are common, and are sometimes lost. They have been cured by the use of a plant known by the traders under the name of the Vinaigrier, or Vinegar Plant. The Dacotas resist cold much better than white men. Hypochondriasis is very common; it affects them as it does white men; they attempt no other remedy but songs and dances. A woman, that was once affected with it, imagined that nothing would relieve her but cold water; she jumped into a stream where the water was only two feet deep, and she was drowned. Hernia is known, but not cured. Hysteria is also known. For dropsy they have no remedy. Diseases of the breast are very common, and are attributed to their constant smoking. Rickets occur in children, in which case they receive a great deal of nursing. Syphilis appears to have been communicated to the Dacotas by white men, and through the women who had intercourse with them; this disease was totally unknown to those residing on the St. Petcr, prerious to the establishment of the garrison at Fort St. Anthony; and it is generally believed, that the first case among them was that of Tommo, (our guide, who was infected with it at Prairie du Chien. The small-pox was in like manner originally unknown to them, but it has 
proved very destructive, at different times, since their intercourse with white men; it exerted its influence very fatally about fifteen years ago; among the many instances of its baneful extension, it is related that, at that time, of forty or fifty individuals who resided in five lodges, only one survived this plague. The Dacotas appear to entertain no prejudice against the use of the vaccine matter; they have in many cases applied it when offered to them; the absence of the surgeon from his post at St. Anthony, at the time that we passed through, prevented our ascertaining the success which he had met with among them; all the surgeons of our frontier posts ought to be abundantly supplied with the virus, and their stock of it occasionally renewed, until its increased consumption by the Indian will enable them to obtain from them fresh virus, as often as they may require it. The Dacotas have no mode of curing the small-pox, and almost every person affected with this disease falls a victim to it.

Venesection is resorted to by the Sioux in cases of contusions, head-aches, and pains in the breast. To a wooden handle they fix a small blade of flint, which is covered with sinew except at its point; they apply it to the vein, which is then cut open by a slight fillip of the finger. They also draw blood by scarifying, and by suction. Poisoned weapons are used by them in their wars; Mr. Cameron, a trader, was poisoned by an Indian, who administered to him some of the plant used for that purpose.

The steam bath is prepared by them as by other Indians; but is not so usually practised as a remedy; it being resorted to for the purpose of obtaining good luck, and as a religious ceremony, in the manner which Dr. Richardson describes, as haring seen practised by a Crec, (Kil- 
listino, at Carlton House.* It is, however, sometimes used to cure rheumatism, which disease is not a very common one among them. To cure swellings they rub the skin with roots and plants; and sometimes use aromatic herbs, to impart to their bodies a pleasant odour. When the pain is internal, they very frequently make incisions in the skin and suck up the blood, accompanying the operation with songs. It is probable, from the relief which they derive from this operation in certain cases, that they have been led to expect the same abatement to their grief, or disease of the mind, by resorting to a similar remedy, and hence the practice of lacerating their arms, thighs, legs, breast, \&c. after the death of a friend. They generally, however, accompany this with lamentations, which they consider as affording great relief. In such cases they also resort to liquor when they can get it, in order to drown all care. Colonel Snelling mentioned to us, that when a Dacota in the vicinity of his garrison loses any of his relations, he generally repairs to him with a note from the Indian agent, desiring that he may receive a bottle of whiskey. When asked by the Colonel what is the use of the liquor on so melancholy an occasion, the Indians uniformly answer, that it is to produce a flow of tears, for indeed, without it, they are unable to cry.

Sterility among women is by no means uncommon, neither is it disreputable. It frequently happens, that a woman, reputed barren, will bear children if she change her husband. Menstruation commences later among the Dacotas than among the Potawatomis, for, with the former, it seldom comes on before the age of fifteen or sixteen, while

* Franklin's Narrative of a Journey to the Shores of the Polar Sea, philadelphia, 1824, p. 67 . 
the latter menstruate at fourteen; this difference is easily accounted for by the more severe climate which the Dacota: inhabit, and by their greater exposure to privations of every kind; they have various emmenagogues. Women are frequently liable, during pregnancy, to lethargy and sick-stomach, and we are informed that the Dacota women have their faces covered with spots, in the same manner as white women. Being hardened to exercise, they attend to their usual occupations even in the last stages of gestation. This has frequently been brought up as a proof that the delicacy of white women, in that situation, was rather the result, than the cause, of the great care which they take of themselves; but it appears to us very probable, that the proportion of accidents, which oceur to Indian women during the period of pregnancy, is greater than among white women; and that this would be much diminished if they were permitted to take the same care to avoid the causes of accidents, as is common among civilized nations. The process of parturition is generally easy, though in some instances the labour has lasted from two to four days. They administer medicines in such cases, and among these the rattle of the rattlesnake, in doses of one segment at a time. Inflammation and absecss of the breast are known, but are not of very common oceurrence; for these the only remedies are singing and sucking. A custom, which has been improperly ascribed to all Indian women, is that of bathing in cold water immediately after parturition; we have already stated that it does not exist among the Potawatomis; but the Dacotas adhere to it very pertinaciously. We have heard of an instance of a very delicate female who resides at Prairie du Chien. Her mother is a Dacota, but her father being a white man, she was educated among civilized women, and has acquired their habits. She marri- 
ed a respectable inhabitant of the place, and having been delivered of a child, she was confined to her room with the precautions usual among white women; her mother, who was absent at the time, hearing of her situation, came to see her, and finding her in bed, chided her severely, asked her if she was going to imitate all the nonsensical tricks and fashions of white women, and then dragged her out of bed to the astonishment of her husband and of all the by-standers, and ducked her in the Mississippi, according to the manners of her nation. We have not heard that any accident resulted from this harsh treatment; nor that any evil arises from the practıce which prevails among them of breaking the ice in winter, in order that both mother and child may bathe immediately after parturition.

Among the Dacotas there are professed midwives, but the women are sometimes delivered by their husbands, brothers, sisters, \&c.; the medicine man is generally present but never operates, his only business is to sing, and to assist by his prayers and incantations. They never bleed during labour. Children are suckled for a long while; from two to five years, generally until a new pregnancy interrupts the secretion of milk. When the mother's milk fails, the child is suckled by another.

We have said that there exists among the Sioux no marriage ceremony, properly speaking. When a white man wishes a wife, as it is usual for all the traders to take Indian women, he has only to express his wish to the parents and relations, who always consent to it, stipulating the amount of the presents which he shall make to them. One of the gentlemen of the Columbia Fur Company informed us, that he had given for his wife, to her brother a keg of rum, and to her mother a complete dress; but he calculated that the presents which he was obliged to make

VoL. I. 
to the relations, amounted annually to sixty or seventy dollars in goods, worth about thirty dollars in cash. To an Indian it does not of course cost so much, as less is expectcd from him than from a trader. Our informant added that it was always better to make these presents, because otherwise the wife would make greater ones, as it would be impossible for her to resist the importunities of her friends, and particularly of her mother.

According to the best information which we have obtained, the number of cinædi is very small among the Dacotas. We heard of but two, one in the village of Keoxa, the other among the Miakechakesa; there are probably a few others, but the number is certainly very small, and they are held in the utmost contempt.

What struck Lewis and Clarke most, among the Sioux, "was an institution, peculiar to them and to the Kite Indians, from whom it is said to have been copied. It is an association of the most active and brave young men, who are bound to each other by attachment, secured by a vow never to retreat before any danger, or give way to their enemies." "* of this interesting institution we have collected the following features. It constitutes what is called the "Dance of the Brave," or more properly perhaps, "those who perform the Dance of the Brave." There exists in some of the bands of the Dacotas, and probably also among some of the other Missouri Indians, an association called the Nâñảshén'é, those who never fly or retreat. A society of this kind originates in an union of two friends, who, when a warlike expedition is projected, propose to form an association. They send for a third warrior, and these three appoint the whole number, which seldom exceeds thirty or forty. When

*Vol. I. p. 60. 
they are all collected, the two founders state to them that the object of the meeting is to form a company of "the Dauntless," and they advise them to prepare their dresses, which generally requires about a fortnight. In the meanwhile, the two founders prepare the lodge of the association, which none but its members arc suffered to enter.

When all the members are collected together, they commence their songs and dances, and their fasts which last three days, during which time they reside in the lodge, but occasionally sally out to sing and dance in the camp. This fast is of the most strict nature, as they dare take neither food nor drink during the three days. One of the most striking features of the association is, that it is limited in its duration, and that its activity is suspended by the death of any one of its members. The duty which it enjoins is not destruction to its enemies, but the rushing into danger with songs and dances. It matters not whether they inflict any injury upon the enemy at the time. Indeed, as long as the association is in activity, they cannot kill one, for it is one of their obligations to go out unarmed. A society of this kind sometimes continues actively employed for a whole year, during which time its members cannot provide themselves with food or drink, but they must wait until it is offered to them by their friends. When a person once enters into the Nanpashene, he is bound to it for life; for although its duration is limited, yet it may be renewed at the call of any of its members, in which case all are bound to join in; but during the term of its suspension, each may act for himself as he pleases. It is not always that an Indian is willing to enter into this society, for though it is held in high honour, yet it requires a more than usual courage to expose one's self passively to the greatest dangers, under a strict obligation, which none 
dare violate, never to retreat from it. In the commencement of the association, the two founders having selected a third, and this one nominated a fourth member, these meet in the lodge appropriated to their purpose, and as soon as they have entered it, and smoked the pipe of war, they cannot retract. These four assume the appropriate dress. and issue out of the lodge singing and dancing; they select such of the warriors, as they think will be good members of the band, and convey them, whether willing or not, to their lodge. If the warrior enter it, even but for a moment, he is bound to the association and cannot withdraw; but if he succeed in effecting his escape before he enters the lodge, he is free. Vacancies in their body are never filled; the association continues until it is annihilated by the death of all its members, when a new one may be formed. They have occasional meetings for feasts and sacrifices. Their fasts are both frequent and rigid. It is difficult to determine, with precision, what the object of the institution is, but it seems to be to convince the enemy, that there are, in their band, a number of men so heedless of danger, that they will rush into it, under a solemn pledge never to retreat, and also without the usual motive of selling their lives at a high price, by the number of the enemy whom they will have previously destroyed. It must be admitted that the passive courage, which this association requires of its members, presents perhaps the highest degree, which man has ever manifested; for they are not even animated by a religious or a superstitious feeling; they do not believe that this self-devotion will ensure success to their party. They, it is true, entertain the opinion that it is more difficult to kill them than other warriors; yet this does not detract in the least from their merit, as they know they must, sooner or later, fall victims to the dangers to 
which they expose themselves. The great divinity to which this association looks up for support, is the thunder, to which frequent sacrifices are offered, especially by the two founders who are its leaders. The sacrifices are made at the door of the lodge, and consist of pieces of meat stuck upon a wooden fork, and inclined to the west. The members of this association have a costly and splendid dress, made of antelope's skin; they wear feathers upon their heads. Every band of the Sioux has not an association of this kind; some have two or three societies, one of which has alone the title of the brave; the others being called the soldiers, the buffalo, \&c. The object of these appears to be different, as they are not bound to that passive exposure to danger, which characterizes the Nanpashene.

The Dacotas that reside along the Mississippi and St. Peter, raise maize in tolerable abundance; they also cultivate beans, pumplins, and other vegetables; some of them, such as Wapasha, appear to be aware of the advantages which attend agriculture, but all are not equally so; and the occasional supplies of these articles which they receive from the Indian agents and officers of our government, whenever they are in want of food, no doubt tend to encourage their lazy habits. Col. Snelling once offered a chief the use of a plough, and of a person to teach him the manner of working it, in order that his band might raise potatocs. The chief made no answer for some time, but continued to smoke his pipe with great deliberation; when this was exhausted, and he had earefully laid it aside, he rose, advanced towards the colonel, shook his hand, and observed that he had taken the offer into consideration, and had concluded, that he would be a great fool were he to accept of it, when he recollected that his father always supplied him with provisions as often as he was in need of 
them. The Dacotas do not profess, as the Potawatomis do, to have been acquainted with the preparation of sugar from the sap of the maple tree previous to their intercourse with white traders. Their food is usually prepared by boiling it in iron pots, which they procure from the traders, and as far as we have observed, they appear to prefer their meat well done. In their degree of cleanliness they vary much, some being far more particular than others. The Dacotas may upon the whole be considered as not very uncleanly; and, as far as relates to their persons, they attend much to this particular. They had no substitute for ardent spirits, and were completely unacquainted with intoxication previous to their intercourse with Europeans.

Of their divisions of time it is difficult to obtain correct information. The interpreters, even the most intelligent, are so prone to connect their own opinions with those of the Indians, that they can scarcely be trusted in this particular. We have not been able, however, to trace among them any idea of the lost moon, ascribed to them by Carver. The following division of the year was furnished by Renville, and is added, though we place but little confidence in its accuracy, at least as having been in use among the Indians previous to their intercourse with white men. They are said to divide the year into twelve moons, commencing with the September one, and distinguishing them as follows. (Wè signifies moon.)

September, Wajopi we, Commencement of wild rice.

October, Siushtaupi we, End of wild rice.

November, Takehuha we, Rutting deer.

December, Tahechapshon we, Deer shedding itshorn.

January, We tarhe, Hard moon.

February, Wechata we, Raccoon.

March, Wishta wasa we, Sore-eye. 
April, Mahahahandi we, Hunting.

May, Mahahakanda we, Oviparous game.

June, Wajustechasha we, Strawberries.

- July, Tschanpasha we, Cherries.

August, Tatanka kehowa we, Rutting buffalo.

Among the Indians whom we saw at Fort St. Anthony, there was one who was called the fool. His countenance had a great appearance of simplicity, being totally devoid of expression; his face was long, his eyes downcast and vacant; his person was much ornamented; the upper part of his face was painted with bright vermilion, the lower part was black, leaving but a narrow strip along the upper lip which was of the natural colour; his ornaments were more childish and toyish than those which the Indians usually wear. This man was formerly gifted with a common share of intellect, but he has, through the wantonness of some Indians, been reduced to his present state of idiocy. He was a long time since taken prisoner by his enemies, who with a view to amuse themselves with his fears, tied him to a stake, and threatened to burn him alive; a little fire was kindled, so as merely to scorch him; but when he was loosened, his intellect was disordered, and has continued so ever since. In some instances, however, he still displays his natural sagacity. He is a good hunter; being at one time very poor, he made a sort of pike, with which he went out to hunt, and was very successful, particularly in killing raccoons; the skins which he sold on his return enabled him to purchase a gun, blanket, \&c. He is much trusted by the officers of the garrison, and had just returned from Prairie du Chien with despatches, having travelled the distance on foot in four days.

Like all the Indian nations with whom the white man has come into contact, the Dacota presents to us at this 
day but a noble ruin. No longer united for purposes of common defence, they have long since ceased to meet at the same council fire; their alliances with other nations are now mere mockeries; their wars have dwindled into petty conflicts. Instead of marching as they formerly did by hundreds, they now issue forth in small detachments, presenting rather the character of a band of marauders than of an expedition of warriors. When they lighted the common calumet at the General Council Fire, it was always among the Mende Wahkantoan, who then resided near Spirit Lake, and who were considered as the oldest band of the nation; their chiefs being of longer standing than those of the other tribes; among themselves they use the appellation of brothers. They are related with the Shiennes, and with the Arricaras, and by marriages they are connected with the Pawnees, Osages, \&c.; but to these nations they only apply the term of friend. With the Omawhaws they wage a deadly warfare. We were told that the Iawas were formerly a band of the Dacotas, and that they were distinguished by the term of the Titatons, but that they separated long since, and that their language had been so much altered as to be unintelligible to the Dacotas. But this information is probably incorrect, for Governor Clarke, during his late visit to the seat of government, with a deputation of Indians from many nations, informed Mr. Colhoun, that the Iawas, Winnebagoes, and Otoes, appeared to him to be of common descent, and to speak dialects of the same language, and he expressed his opinion, that an inquiry into the matter would result in determining them to be of that nation, which, as we learn from Mr. Jefferson's "Notes," emigrated from Ocoquan. Mr. Joseph Snelling, who accompanied that deputation, likewise informed Mr. Colhoun, that in a speech made by the Iawa 
clief while in the city of Washington, the former union of hile Winnebrgoes and Otoes with his nation, was distinctly asserted. This confirms the information obtained by Mr. Say on the former expedition, (Vide Account of an Expedition to the Rocky Mountains, vol. I. p. 338, 339, and 342 ,) and disproves the assertion that the Iawas were ever connected with the Dacotas. It may likewise be questioned, whether the Omarwhaws, whom Carver connects, as well as the Shiennes and Arricaras, with the Naudowessies of the plains, were not descended from a different stock.

Of the history of the Dacotas very little is known; they have been engaged from time immemorial in a destructive war against the Chippewas. All the efforts of our government have tended to produce but temporary suspensions of arms, which have been in all cases violated within a short time after they had been made. Lahontan informs us, that they defeated a party of Iroquois, on an island of the Mississippi, prior to the year 1688. In 1697, * they destroyed a party of Miamis, on the southern coast of Lake Michigan, between St. Joseph and Kikalemazo rivers; and Charlevoix states that in 1701, $\uparrow$ the Sauks, Winnebagoes, Menomonies, Foxes, Potawatomis, and Kickapoos, assembled at Green Bay to go to war with them, but that they were dissuaded from it by a French emissary. The Chippewas informed Carver, in 1767, that a war had continued without any interruption between them and the Dacotas for upivards of forty winters. They appear to have no tradition or knowledge of the Lenni-Lenape,

* Charlevoix's Hist. de la Nouv. France, tom. 3. p. 310.

†tbid, p. 405.

Tot. 1 . 
Aligawi, or other nations that were found east of the Aileghany Mountains. In speaking of the early impression made by the Dacotas on Europeans, Charlevoix observed, that they were considered to have a better conception than any other Indians of the attributes of the Supreme Being.

Our visit to Lake Travers having been announced to the gentlemen of the Columbia Fur Company, by a messenger sent to them from Big Stone Lake, the party were received on their arrival with a national salute; and other demonstrations of friendly hospitality were manifested, not only at that time, but also during the few days which they spent there.

The Columbia Fur Company was created in 1822; it consists of but few individuals, who being all practically acquainted with the Indian trade, in which they had previously been engaged in the service of the Hudson's Bay or North-West Company, resolved after the consolidation of these two companies into one, to establish themselves on the United States' territory, and to trade with the Indians south of the boundary line, under licences granted by the Indian agent at the mouth of the St. Peter. Their capital is not very large, but being all active, intelligent, and experienced, they will, we doubt not, succeed. Their principa! establishment is at Lalke Travers; its situation is judiciously selected, as it is at the head of the navigation of the St. Peter and Red Rivers, in the midst of a country which abounds in buffalo, so that they can lay in ample stores of provisions for their wintering parties. By extending their excursions to the head waters of the Mississippi, and as far on the Missouri as the Indians will permit, they will be able to obtain large supplies of beaver and other valuable skins, and as their object appears to be merely to trade with the Indians, and not to hunt upon their lands, they 
will, it is to be hoped, continue on amicable terms with them.

The following statement of the amount of furs formerly packed up by the British companies, and produced altogether by the trade on Red River and its tributaries, has been communicated to us by the gentlemen of the Columbia Fur Company. As this statement is restricted to the value of the fur trade on the South side of the boundary line, we think there can be no impropriety in publishing it. All that relates to the British territories, and that we have been able to collect from our own observations, or which has been kindly communicated to us in the course of conversations with the officers of the Hudson's Bay Company, we have no wish to publish, and we would consider it highly censurable so to do, but as this relates to a trade in which they can have no further interest, no objection can we trust be taken to it.

Names. No. of packs. No. of skins, or Value of pack. Total. wt. of each pack.

\begin{tabular}{|c|c|c|c|c|c|}
\hline Beaver, & -10 & $100 \mathrm{lbs}$. wt & - & $\$ 400$ & $\$ 4000$ \\
\hline Bear, & -20 & 12 skins & - & $75^{*}$ & 1500 \\
\hline Buffalo, & -400 & 10 skins & - & 40 & 16,000 \\
\hline Martin, & - 10 & $100 \mathrm{lbs}$. & - & 300 & 3000 \\
\hline Otter, & -10 & $100 \mathrm{lbs}$. & - & 600 & 6000 \\
\hline Fisher, & -25 & $-\quad-$ & 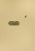 & 450 & 11,250 \\
\hline Elk, & -40 & 16 skins & - & 80 & 3200 \\
\hline Mynx, & -10 & $-\quad-$ & & 200 & 2000 \\
\hline & & & & & 46,950 \\
\hline
\end{tabular}

* This item we find stated in our notes at $\$ 4.50$ per pack, but we ap. prehend that the statement is very much overrated, although it is said co refer to the finest quality. Six dollars per skin is probably a fair price. 
Brot. forward 525

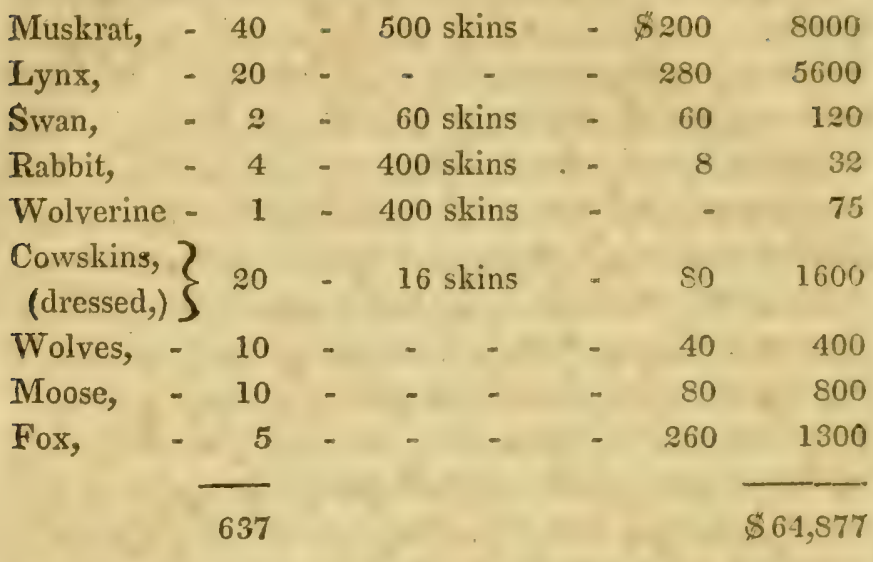

The above prices are, we believe, those of the Montreal market. This statement establishes the average value of the packs at about one hundred dollars, and if we exclude the buffalo robes, which are sold at forty dollars a pack, the other furs will average upwards of two hundred dollars. The amount of the less valuable furs, such as those of wolves, wolverines, rabbits, \&c. might be increased if there were a market for them.

In addition to these, the country supplies annually one thousand bags of pounded buffalo meat, (Pemmican, ${ }^{*}$ ) va:

* Pemmican is the meat of the buffalo, prepared for preservation in the following manner: The fiesh is cut into thin slices, which are jerked in the sun or smoke, the latter being preferable; it is then dried before the fire until it becomes crisp, after which it is laid upon one stone, and pounded with another fixed into a wooden handle; after it has been reduced into as fine a powder as possible, which is, however, far from being very minute, it is mixed up with an equal weight of buffalo grease, or marrow fat poured on when hot and liquid. Before the mixture cools, it is introduced into skin bags, and well shaken, so that it may settle into a compact mass. Sometimes, in order to give it a 
Jued at four thousand dollars. The Columbia Fur Company can, if it be active, share this trade with the American Fur Company; these are the only associations that trade at present with the Indians in that part of the United States. Independent of this the trade of the Missouri and its tributaries may probably prove very valuable. It will be the interest of both the companies to keep on amicable terms. The practice which has too often prevailed among Indian traders to endeavour to increase their business by injuring the interests or the reputation of their competitors is as injudicious, as the means which they adopted were frequently criminal. They lower the eharacter of the white man in the opinion of the Indians, and excite them to deeds at which they would otherwise revolt.

The principal interest which we experienced in the neighbourhood of Lake Travers, was from an acquaintance with Wânôtân, (the Charger,) the most distinguished chief of the Yanktoanan tribe, which, as we were informed, is subdivided into six bands. He is one of the greatest men of the Dacota nation, and although but twenty-eight years of age, he has already acquired great renown as a warrior. At the early age of eighteen, he exhibited much valour in the war against the Americans, and was wounded several times. He was then inexperienced and served under his father, who was the chicf of his tribe, and who bore a mortal enmity to the Americans. Wanotan has since learned to form a better estimate of our nation. He is arrare that it

pleasant tastc, it is mixcd with a sort of wild cherry, which is pounder' and introduced, stone and all. The Pemmican forms a wholesome and strong food, which, when prepared with care, and from good materials, is very palatable. It has the advantage that it may be caten with. out any preparatory conking. Sometimes it is leated in a pan, an. is equal to the best hashed meat. 
is the interest of his people to remain at peace with $u$ : and would, probably, in case of another war between the United States and England, take part with the former. Those, who know him well, commend his sagacity and judgment, as well as his valour. He is a tall man, being upwards of six feet high; his countenance would be esteemed handsome in any country; his features being regular and well-shaped. There is an intelligence that beams through his eye, which is not the usual concomitant of Indian features. His manners are dignified and reserved; his attitudes are graceful and easy, though they appear to bc somewhat studied. When speaking of the Dacotas, we purposely postponed mentioning the frequent vows which they make, and their strict adherence to them, because, one of the best evidences which we have collected on this point, connects itself with the character of Wanotan, and may give a favourable idea of his extreme fortitude in enduring pain. In the summer of 1822 he undertook a journey, from which, apprehending much danger on the part of the Chipperwas, he made a vow to the Sun, that, if he returned safe, he would abstain from all food or drink, for the space of four successive days and nights, and that he would distribute among his people all the property which he possessed, including all his lodges, horses, dogs, \&c. On his return, which happened without accident, he celebrated the dance of the sun; this consisted in making three cuts through his skin, one on his breast, and one on each of his arms. The skin was cut in the manner of a loop, so as to permit a rope to pass under the strip of skin and flesh which was thus divided from the body. The ropes being passed through, their ends were secured to a tall vertical pole, planted at about forty yards from his lodge. He then began to dance round this pole, at the commencement 
of his fast, frequently swinging himself in the air, so as to be supported merely by the cords which were secured to the strips of skin cut off from his arms and breast. He continued this exercise with few intermissions, during the whole of his fast, until the fourth day about ten o clock, $\mathbf{A}$. M. when the strip of skin from his breast gave way. Notwithstanding which he interrupted not his dance, although supported merely by his arms. At noon the strip from his Ieft arm snapped off. His uncle then thought that he had suffered enough; he drew his knife and cut off the skin from his right arm, upon which Wanotan fell to the ground and swooned. The heat at the time was extreme. He was left exposed in that state to the sun until night, when his friends brought him some provisions. After the ceremony was over, he distributed to them the whole of his property, among which were five fine horses, and he and his two squaws left his lodge, abandoning every article of their furniture.

As we appeared upon the brow of the hill which commands the company's fort, a salute was fired from a number of Indian tents which were pitched in the vicinity, from the largest of which the American colours were flying. And as soon as we had dismounted from our horses, we received an invitation to a feast which Wanotan had prepared for us. The gentlemen of the company informed us that as soon as the Indians had heard of our contemplated risit, they had commenced their preparations for a festival, and that they had killed three of their dogs. We repaired to a sort of pavilion which they had erected by the union of several large skin lodges. Fine buffalo robes were spread all around, and the air was perfumed by the odour of sweet scenting grass which had been burned in it. On entering the lodge we saw the chief seated near the further end of 
it, and one of his prineipal men pointed out 10 us the place which was destined for our accommodation; it was at the upper end of the lodge; the Indians who were in it taking:no further notice of us. 'These consisted of the chief, his son, a lad about eight years old, and eight or ten of the principal warriors. The chief's dress presented a mixtur: of the European and aboriginal costume; he wore moccassins and leggings of splendid scarlet cloth, a blue breech. cloth, a fine shirt of printed muslin, over this a frock coat. of fine blue cloth with scarlet facings, somewhat similar to the undress uniform coat of a Prussian officer; this was huttuned and secured round his waist by a belt. Cipon his head he wore a blue cloth cap, made like a German fatigue cap. A very handsome Mackinaw blanket, slightly orna mented with paint, was thrown over his person. His son, whose features strongly favoured those of his father, wore a dress somewhat similar, cxeept that his coat was party-coloured, one-half being made of blue, and the other half of scarlet cloth. He wore a round hat with a plated silver band and a large cockade. From his neck were suspended sereral silver medals, doubtless presents to his father. 'This lad appeared to be a great favourite of Wanotan's, who scems to indulge him more than is customary with Indians to do. As soon as we had taken our seats, the chief passed his pipe round, and while we were engaged in smoking, two of the Indians arose and uncovered the large kettles which were standing orer the fire, they emptied their contents into a dozen of wooden dishes which were placed all round the Indge. These consisted of buffalo meat boiled with tepsin, also the same vegetable boiled, without the meat, in buffalo mrease, and finally, the much-estecmed dog meat, all which were dressed without salt. In compliance with the estainlished usage of travellers to taste of every thing, we al! 
partook of the latter with a mixed feeling of curiosity and reluctance. Could we have divested ourselves entirely of the prejudices of education, we should doubtless have unhesitatingly acknowledged this to be among the best meat that we had ever eaten. It was remarkably fat, was sweet and palatable. It had none of that dry stringy character, which we had expected to find in it, and it was entirely destitute of the strong taste which we had apprehended that it possessed. It was not an unusual appetite, or the want of good meat to compare with it, which led us to form this farourable opinion of the dog, for we had, on the same dish, the best meat which our prairies afford; but so strongly rooted are the prejudices of education, that, though we all unaffectedly admitted the excellence of this food, yet few of us could be induced to eat much of it. We were warned by our trading friends that the bones of this animal are treated with great respect by the Dacotas; we therefore took great care to replace them in the dishes; and we are informed that, after such a feast is concluded, the bones are carefully collected, the flesh scraped off from them, and that after being washed, they are buried in the ground, partly, as it is said, to testify to the dog species, that in feasting upon one of their number no disrespect was meant to the species itself, and partly also from a belief that the bones of the animal will rise and reproduce another one. The meat of this animal, as we saw it, was thought to resemble that of the finest Welsh mutton, except that it was of a much darker colour. Having so far overcome our repugnance as to taste of it, we no longer wonder that the dog should be considered a dainty dish by those in whom education has not created a prejudice against this flesh. In China it is said that fattened pups are frequently sold in the market place; and it appears that the invitation to a Vor. I. 
feast of dog meat is the greatest distinction that can be offered to a stranger by any of the Indian nations east of the Rocky Mountains. That this is not the case among some of the nations west of those mountains, appears from the fact that Lewis and Clarke were called, in derision, by the Indians of the Columbia, Dog Eaters.

In the Dacota's treatment of his dogs, during life and after death, we observe one of those strange inconsistencies which so frequently prevail in the character of man, whether civilized or savage. While living, the dog is a beast of burden, and as such exposed to undergo much fatigue and ill-treatment; it is at the same time a most valuable animal. The traders, who have imitated the Indians in their use of the dog, speak of it as almost indispensable to them. Mr. Jeffries, one of the partners of the Colum. bia Fur Company, informed us, that he had the preceding winter transported in a $\log$ cart one thousand pounds weight of goods, with the assistance of six, and rarely eight, dogs, and that he travelled from Lake Travers to the Mandan villages in eleven days. On a long journey, the allowance of load is one hundred pounds per dog. For winter travelling, in a country so frequently covered with snow, the $\operatorname{dog}$ is the most convenient beast of burden, as it may be fed either on dried meat, or on the fresh meat which is occasionally procured. In travelling on the snow with dog trains, it is usual for a man to walk ahead of the dogs, with snow shoes, in order to trample down the snow, in which otherwise they would sink. We learn from Mr. Back's notes, ${ }^{*}$ that the feet of the dogs are sometimes very much injured, and that in one instance, where they were perfectly raw, he attempted to tie shoes on them, which did not

* Franklin's Journey to the shores of the Polar Sea, ut sup. p. 251. 
succeed. Whether it be usual for the Dacotas to doso, we very much question; though it would appear from Purchas' Pilgrim, that these have been used by some nations, and we are told by Olaus Magnus, that in the north of Europe, a somewhat similar practice existed as regards korses' feet," and probably at the time that he visited the country, which was in 1518. The dogs are a great assistance to the squaws, who would otherrvise be compelled to carry all their baggage and provisions themselves, but who frequently beat and abuse them. After death, the dog forms one of the best articles of food for the Indian, and is reserved for great occasions, as it is, in their opinion, invested with a sacred character, which makes it a fit offering in sacrifices, and in feasts to strangers. The respect paid to the bones of the dog contrasts strongly with the ill usage which the animal met with during life.

The feast, which Wanotan had prepared, seemed to be destined rather for one hundred than for ten persons; as soon as we had finished eating, the Indians requested that our soldiers might be allowed to come and partake of it, a request which was of course granted. When the soldiers appeared, the dishes were placed before them, and the Indians, who had probably been fasting all day, made a violent inroad upon the meal, evidently preferring the dog to the buffalo meat; according to the Indian usage, it would have been proper for us to have waited until they had finished their repast, when probably some speeches would have been made; but the feast appeared likely to be prolonged to a late hour; and the heat was so oppressive in the

- "Transeunt homines et cqui quasi super clypeos militares. Crates seu arcus levi ac lato subere, seu cortice tiliano contextos, peJibus propriis ac equorum alligant."-Olai Magni Gentium Septentrio:alium Historiz Breviarium. Amstelorlami, 1669. L. A. C. 13. 
lodge, owing to the season, and to the number collected therein, as also undoubtedly to the immense quantities of hot meat exposed in the dishes, that we were compelled to apologize to Wanotan for our sudden departure.

Upon the whole, we were much gratified at this feast; it was worthy of the powerful chief who gave it; it was offered with an open hand and a free heart; it was served up with the usual ceremonies and it included abundance of their best and most highly prized food.

The next day Wanotan came to pay us a formal visit; he was dressed in the full habit of an Indian chief; wo have never seen a more dignified looking person, or a more becoming dress. The most prominent part of his apparel was a splendid cloak or mantle of buffalo skins, dressed so as to be of a fine white colour; it was decorated with small tufts of orvl's feathers, and others of various hues, probably a remnant of a fabric, once in general use among the aborigines of our territory, and still worn in the northeast and north-ivest parts of this continent, as well as in the South Sea Islands; it is what was called by the first European visitors of North America the feather mantles and feather blankets, which were by them much admired. A splendid necklace, formed of about sixty claws of the grizzly bear, imparted a manly character to his whole appearance. His leggings, jacket, and moccassins, were in the real Dacota fashion, being made of white skins, profusely decorated with human hair; his moceasins were variegated with the plumage of several birds. In his hair, he wore nine sticks neatly cut and smoothed, and painted with vermilion; these designated the number of gun-shot wounds which he had received, they were secured by a strip of red cloth; two plaited tresses of his hair were allowed to hang forward; his face was tastefully painted with rermilion; in 
his hand he wore a large fan of feathers of the turkey; this he frequently used.

We have never seen a nobler face, or a more impressive character, than that of the Dacota chief, as he stood that afternoon, in this manly and characteristic dress, contemplating a dance performed by the men of his own nation. It was a study worthy of the pencil of Vandyke and of the graver of Berwick. It would require the utmost talent of the artist to convey a fair idea of this chief; to display his manly and regular features, strongly stamped, it is true, with the Indian character, but admirably blended with an expression of mildness and modesty ; and it would require no less talent to represent the graceful and unstudied folds of his mantle. However difficult the task of executing such a portrait, Mr. Seymour undertook it, and a plate, engraved from his design, has been introduced as a frontispiece to this volume; it will impart, however, but a faint idea of the features and dress of this distinguished chief.

Having requested that the warriors should favour us with a dance, Wanotan had one performed for us in the afternoon; he apologized for the imperfection of the dancers, the best being then absent from the place. The dresses which they wore, were more carefully arranged than usual, and indicated that some pains had been taken for the occasion. Among the fantastic ornaments which they had as. sumed, a paper of pins, opened and hanging from the headdress of one of the warriors, was conspicuous. In his hand he held a wand about ten feet long, to which was attached a piece of red cloth of the same length, and about six inches wide; one of the edges of this band was fastened to the staff; the other was furnished with black and white feathers, closely secured to it by their quills, and forming a sort of fringe. This was one of the two insignia or wands 
of the Association of the Nanpashene; but the most singlilar dress was that of Wanotan's son, who, for the first time in his life, wore the distinguished national garb, in which he is represented in the Frontispiece plate to this volume. The dresses were evidently made for his father, and too large for him, so that they gave to his figure a stiff and clumsy appearance, which strongly reminded us of the arvkward gait of those children who, among civilized nations, are allowed, at too early an age, to assume the dress of riper years, by which they lose their infantine grace and ease. This is one of the many features in which we delight in tracing an analogy between the propensities of man, in his natural state, and in his more refined condition. This lad wore a very large head-dress, consisting of feathers made of the war-eagle, and which in form was precisely similar to that of the King of the Friendly Islands, as represented in Cook's Voyages. His dress was made of many ermine skins, variously disposed upon a white leather cloak. The performers stood in a ring, each with the wing of a bird in his hand, with which he beat time on his gun, arrow, or some thing that would emit a sound. They commenced their singing in a low tone, gradually raising it for a few minutes, then closing it suddenly with a shrill yell; after a slight interruption, they recommenced the same air, which they sang without any variation for near three quarters of an hour. Major Long reduced it to notes, and an idea of this low and melancholy, but not unpleasant, air may be formed from the first tune in Plate 5. This was accompanied by a few unmeaning words. Occasionally one of the performers would advance into the centre of the ring, and relate his warlike adventures. Among those who did this was a slender and active warxior, not tall, but distinguished by his very thin lips and 


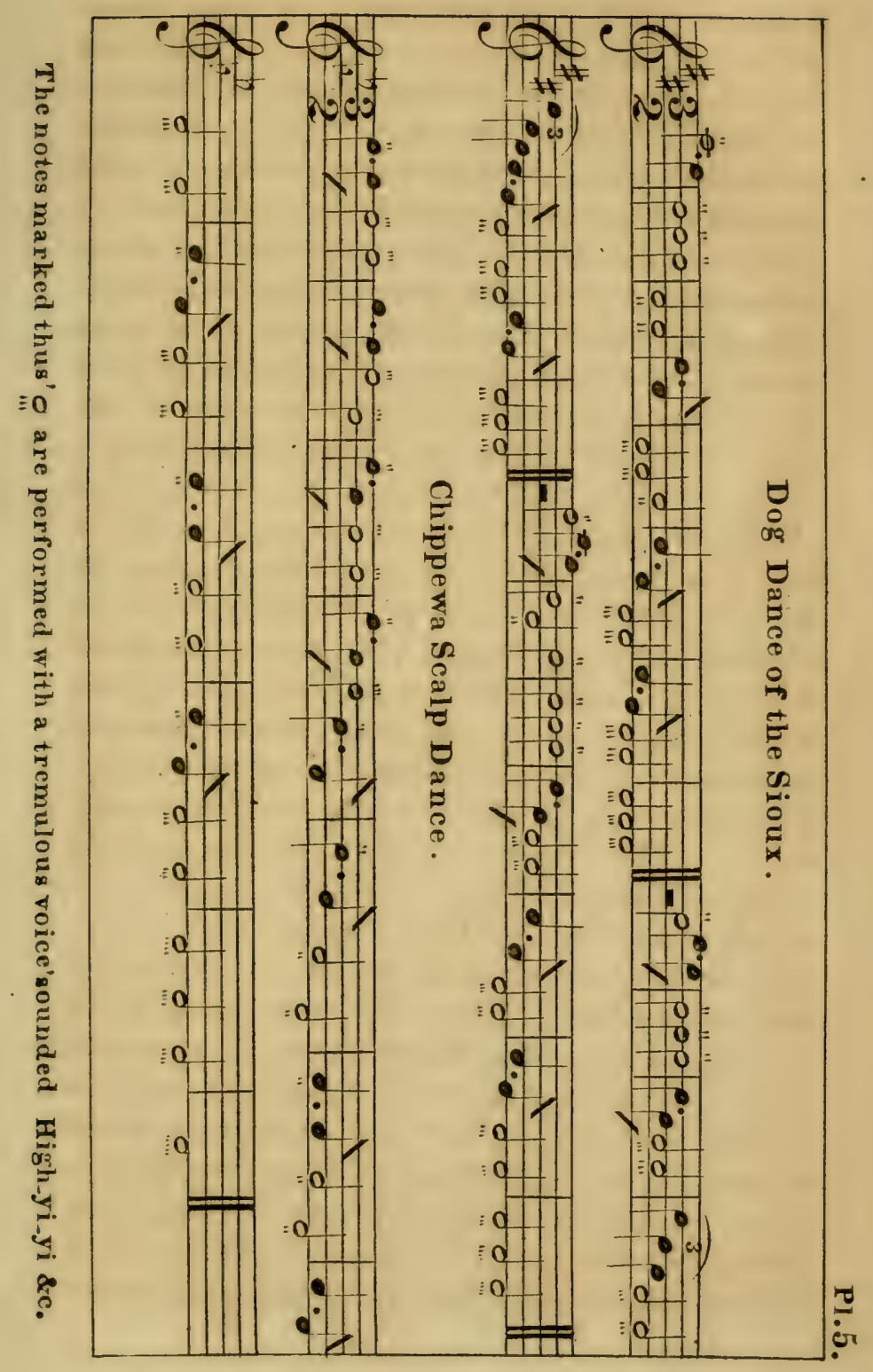


nose; he was pointed out to us as the man who had assaulted Mr. Hess' party in the manner which we have already reluted. Among the many feats which this warrior enumerated, he took care to omit his murders of white men. The dance which accompanied this had nothing particular; they frequently laughed aloud, and appeared to go through the exercise with much spirit. After the dance had continued some time, a few presents were divided among them. Upon receiving them they hastily ran away, appa. rently as much-satisfied as we were.

END OF VOL. .

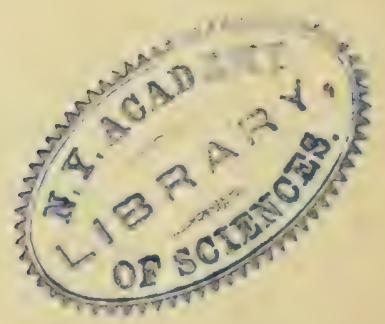



- i y $v$

(2)

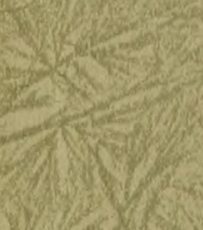

V)

and X

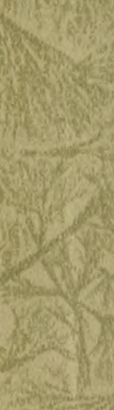

(x)

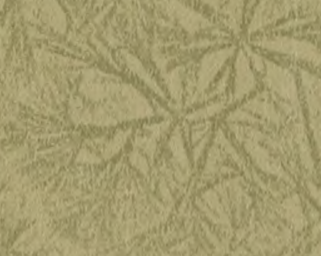

in
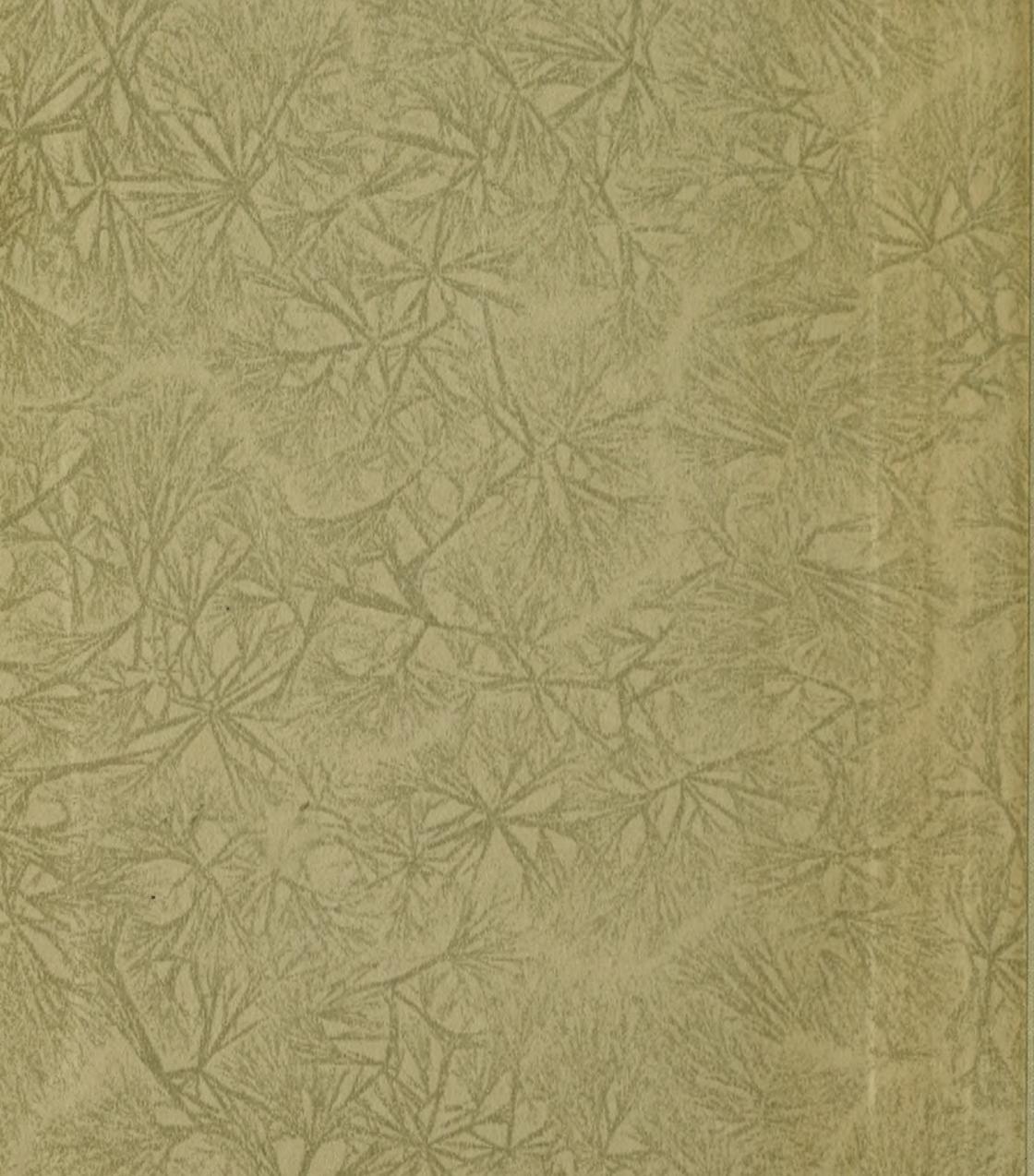


\section{F1064.W5 K4 v.1}

gen

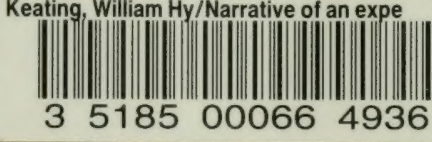

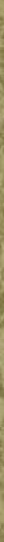


